Abordagens para aprendizado

semissupervisionado multirrótulo e hierárquico

\author{
Jean Metz
}



SERVIÇO DE PÓS-GRADUAÇÃO DO ICMC-USP

Data de Depósito: 09/12/2011.

Assinatura:

\title{
Abordagens para aprendizado semissupervisionado multirrótulo e hierárquico
}

\author{
Jean Metz \\ Orientadora: Profa. Dra. Maria Carolina Monard \\ Coorientador: Prof. Dr. Alex Alves Freitas \\ Tese apresentada ao Instituto de Ciências Matemáticas \\ e de Computação - ICMC-USP, como parte dos \\ requisitos para obtenção do título de Doutor em \\ Ciências - Ciências de Computação e Matemática \\ Computacional. VERSÃO REVISADA
}


Ficha catalográfica elaborada pela Biblioteca Prof. Achille Bassi e Seção Técnica de Informática, ICMC/USP, com os dados fornecidos pelo(a) autor(a)

Metz, Jean

M596a

Abordagens para aprendizado semissupervisionado multirrótulo e hierárquico / Jean Metz; orientador Maria Carolina Monard -- São Carlos, 2011.

$189 \mathrm{p}$.

Tese (Doutorado - Programa de Pós-Graduação em Ciências de Computação e Matemática Computacional) -Instituto de Ciências Matemáticas e de Computação, Universidade de São Paulo, 2011.

1. Classificação multirrótulo. 2. Classificação hierárquica. 3. Aprendizado semissupervisionado. 4 . Aprendizado ativo. I. Carolina Monard, Maria, orient. II. Título. 
"É um grande privilégio ter vivido uma vida difícil" Indira Ghandi 



\section{Dedicatória}

A minha amada mãe, Marlene.

A querida irmã, Jéssica.

A minha grande companheira de todos os momentos e aventuras, Thaís. 



\section{Agradecimentos}

É incrivel como a distância nos aproxima! Passados cinco anos longe de casa, neste momento é chegada a hora de voltar.

Agradeço à minha família pelo apoio incondicional em todos os momentos da minha vida. Mesmo estando tão distante fisicamente, em pensamento estou sempre ao lado de vocês. Que os doces sorrisos da minha mãe, a cada reencontro nosso, agora sejam transformados em um único sorriso contínuo. Que os abraços esporádicos vindos dos pequenos braços da minha irmãzinha, agora crescida, continuem reconfortantes, porém tão frequentes quanto o nascer do sol. Que a cada manhã eu seja recompensado pelo esforço com um beijo doce de bom dia da minha companheira. Esse trabalho é dedicado a vocês.

Agradeço em especial à professora Maria Carolina Monard, por ter seguido comigo por esse longo caminho. Obrigado por seu tempo, atenção e dedicação. Mais uma vez devo dizer que a senhora é um exemplo de postura ética e honestidade.

Muito obrigado aos meu primeiros mestres, Jorge Habib Hanna El Khouri, Juan Carlos Sotuyo, Renato Bobsin Machado e Ricardo Krauskopf Neto, por terem me mostrado e me direcionado pelo o caminho da ética.

Agradeço também ao professor Alex A. Freitas, que me recebeu em Canterbury/UK e, a partir de então, me orientou durante todo o desenvolvimento desta tese.

Aos meus "irmãos" Pablio F. Neri, Leandro W. Moreira e Maikon Bueno, que sempre acreditaram e me incentivaram. Obrigado pelos momentos de alegria, distração e companheirismo. Também pelo constante incentivo para continuar trilhando o meu caminho.

Aos amigos Everton "queridiiiiiinho" Cherman e Igor "BB gordinho" Braga. Por toda a ajuda na elaboração das ideias e execução das tarefa, mas principalmente pelos momentos de discontração e alegria.

As "meninas" da secretaria de pós-graduação do ICMC, em especial Laura e Ana Paula, sempre tão prestativas e solícitas. Muito obrigado.

Aos colegas do LABIC. Em especial ao Bruno, Cintra, Fabiano, Mel, Rafael e Ricardo, pelo incentivo e companheirismo. Também agradeço a Miguel Caro. Obrigado pela ajuda e preocupação "Miguelito".

Obrigado ao Prof. Dr. Alexandre Plastino e seu aluno Bruno C. Paes por terem fornecido alguns dos conjuntos de dados utilizados neste trabalho.

Pelo apoio financeiro para o desenvolvimento deste trabalho, agradeço à Fundação de Amparo à Pesquisa do Estado de São Paulo (FAPESP) e à Coordenação de Aperfeiçoamento de Pessoal de Nivel Superior (CAPES). 



\section{Abstract}

In machine learning, the task of classification consists on creating computational models that are able to automatically identify the class of objects belonging to a predefined domain from a set of examples whose class is known a priori. There are some classification scenarios in which each object can be associated to more than one class at the same time. Moreover, in such multilabeled scenarios, classes can be organized in a taxonomy that represents the generalization and specialization relationships among the different classes, which defines a class hierarchy, making the classification task, known as hierarchical classification, even more specific. The methods used to build such classification models are complex and highly dependent on the availability of an expressive quantity of previously classified examples. However, for a large number of applications, it is difficult to find a significant number of such examples. Moreover, when few examples are available, supervised learning algorithms are not able to build efficient classification models. In such situations it is possible to use semi-supervised learning, whose aim is to learn the classes of the domain using a few classified examples in conjunction to a considerable number of examples with no specified class. In this work, we propose methods that use the co-perspective disagreement based learning approach for both, the flat multilabel classification and the hierarchical classification tasks, among others. We also propose other methods that use active learning, aiming at improving the performance of semi-supervised learning algorithms. Additionally, two methods for the evaluation of multilabel and hierarchical learning algorithms are proposed. These methods define strategies for the identification of the "majority multilabels", which are used to estimate the baseline evaluation measures. A framework for the experimental evaluation of the hierarchical classification was developed. This framework includes the implementations of the proposed methods as well as a complete module for the experimental evaluation of the hierarchical algorithms. The proposed methods were empirically evaluated considering datasets from various domains. From the analysis of the results, it can be observed that the methods based on co-perspective disagreement are not effective for complex classification tasks, such as the multilabel and hierarchical classification. It can also be observed that the main degradation problem of the models of the semi-supervised algorithms worsens for the multilabel and hierarchical classification due to the fact that, for these cases, there is an increase in the causes of the degradation of the models built using semi-supervised learning based on co-perspective disagreement. 


\section{Resumo}

A tarefa de classificação em Aprendizado de Máquina consiste da criação de modelos computacionais capazes de identificar automaticamente a classe de objetos pertencentes a um domínio pré-definido a partir de um conjunto de exemplos cuja classe é conhecida. Existem alguns cenários de classificação nos quais cada objeto pode estar associado não somente a uma classe, mas a várias classes ao mesmo tempo. Adicionalmente, nesses cenários denominados multirrótulo, as classes podem ser organizadas em uma taxonomia que representa as relações de generalização e especialização entre as diferentes classes, definindo uma hierarquia de classes, o que torna a tarefa de classificação ainda mais específica, denominada classificação hierárquica. Os métodos utilizados para a construção desses modelos de classificação são complexos e dependem fortemente da disponibilidade de uma quantidade expressiva de exemplos previamente classificados. Entretanto, para muitas aplicações é difícil encontrar um número significativo desses exemplos. Além disso, com poucos exemplos, os algoritmos de aprendizado supervisionado não são capazes de construir modelos de classificação eficazes. Nesses casos, é possível utilizar métodos de aprendizado semissupervisionado, cujo objetivo é aprender as classes do domínio utilizando poucos exemplos conhecidos conjuntamente com um número considerável de exemplos sem a classe especificada. Neste trabalho são propostos, entre outros, métodos que fazem uso do aprendizado semissupervisionado baseado em desacordo coperspectiva, tanto para a tarefa de classificação multirrótulo plana quanto para a tarefa de classificação hierárquica. São propostos, também, outros métodos que utilizam o aprendizado ativo com intuito de melhorar a performance de algoritmos de classificação semissupervisionada. Além disso, são propostos dois métodos para avaliação de algoritmos multirrótulo e hierárquico, os quais definem estratégias para identificação dos "multirrótulos majoritários", que são utilizados para calcular os valores baseline das medidas de avaliação. Foi desenvolvido um framework para realizar a avaliação experimental da classificação hierárquica, no qual foram implementados os métodos propostos e um módulo completo para realizar a avaliação experimental de algoritmos hierárquicos. Os métodos propostos foram avaliados e comparados empiricamente, considerando conjuntos de dados de diversos domínios. A partir da análise dos resultados observa-se que os métodos baseados em desacordo não são eficazes para tarefas de classificação complexas como multirrótulo e hierárquica. Também é observado que o problema central de degradação do modelo dos algoritmos semissupervisionados agrava-se nos casos de classificação multirrótulo e hierárquica, pois, nesses casos, há um incremento nos fatores responsáveis pela degradação nos modelos construídos utilizando aprendizado semissupervisionado baseado em desacordo coperspectiva. 


\section{Sumário}

Lista de Figuras . . . . . . . . . . . . . . xix

Lista de Tabelas . . . . . . . . . . . . . . xxiii

Lista de Algoritmos . . . . . . . . . . . . . xxv

Lista de Abreviaturas . . . . . . . . . . . . . . . xxvii

Notação . . . . . . . . . . . . . . . . . . . xxix

1 Introdução 1

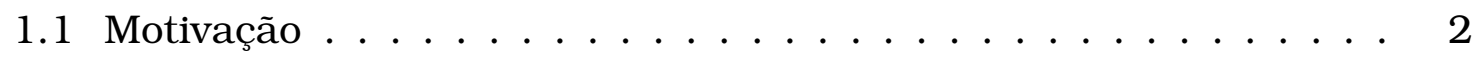

1.2 Objetivos e hipóteses $\ldots \ldots \ldots \ldots \ldots \ldots$

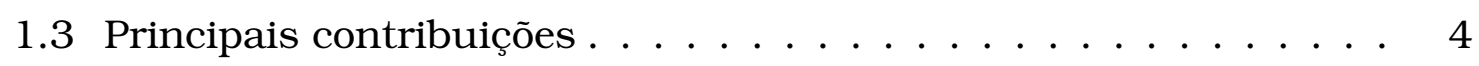

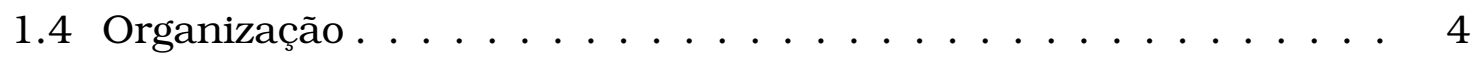

2 Classificação plana $\quad 7$

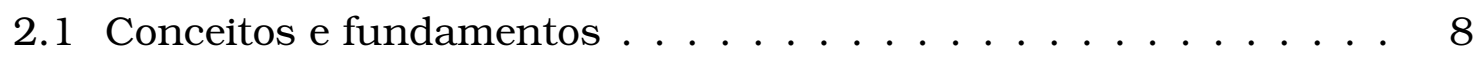

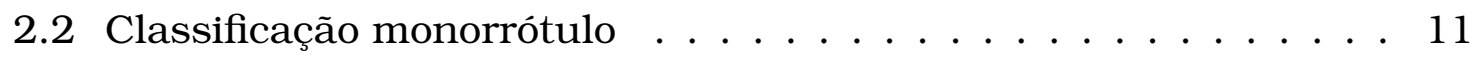

2.2.1 Representação dos dados . . . . . . . . . . . . . . 12

2.2.2 Avaliação da classificação monorrótulo . . . . . . . . . . 12

2.3 Classificação multirrótulo . . . . . . . . . . . . . . . . . . 14

2.3.1 Representação dos dados . . . . . . . . . . . . . . 15

2.3.2 Métodos de classificação multirrótulo . . . . . . . . . . 16

2.3.2.1 Adaptação de algoritmos . . . . . . . . . . 16

2.3.2.2 Transformação de problema . . . . . . . . . 17

2.3.3 Avaliação da classificação multirrótulo . . . . . . . . . 23

2.3.3.1 Medidas baseadas em exemplos . . . . . . . . . 23

2.3.3.2 Medidas baseadas em rótulos . . . . . . . . . . . 24

2.4 Considerações finais . . . . . . . . . . . . . . . . 26

3 Classificação hierárquica $\quad 27$

3.1 Classificação plana versus hierárquica . . . . . . . . . . 28

3.2 Fundamentos e definições para classificação hierárquica $\ldots . . .30$ 
3.2.1 Estrutura de representação da hierarquia de classes . . . . 31

3.2.2 Restrição no nível de classificação . . . . . . . . . . . . 33

3.2.3 Uso da estrutura de classes . . . . . . . . . . . . . . . 34

3.2.3.1 Abordagem plana . . . . . . . . . . . 34

3.2.3.2 Abordagem global ............. . . . 35

3.2.3.3 Abordagem local . . . . . . . . . . . . . 36

3.2.3.4 Estratégia de predição top-down para métodos locais . . . . . . . . . . . . . . 44 4

3.3 Medidas de avaliação . . . . . . . . . . . . . . . . . . 45

3.3.1 Medidas baseadas em distância . . . . . . . . . . . . . . 49

3.3.2 Medidas baseadas na hierarquia . . . . . . . . . . 51

3.4 Considerações finais . . . . . . . . . . . . . . . . 53

4 Aprendizado de máquina semissupervisionado 55

4.1 Motivação e justificativa para o uso do aprendizado semissuper-

visionado . . . . . . . . . . . . . . . 56

4.2 Tipos de supervisão parcial . . . . . . . . . . . . . . 57

4.3 Representação do conjunto de treinamento . . . . . . . . . . . 58

4.4 Pressupostos do aprendizado semissupervisionado . . . . . . . . 59

4.5 Utilidade da supervisão parcial . . . . . . . . . . . . . . 60

4.6 Métodos de aprendizado semissupervisionado . . . . . . . . . . 61

4.7 Aprendizado baseado em desacordo . . . . . . . . . . . . . . . 64

4.7.1 Múltiplas descrições e múltiplos classificadores . . . . . . . 64

4.7.2 Monodescrição e múltiplos classificadores . . . . . . . . . . 68

4.8 Aprendizado ativo . . . . . . . . . . . . . . . . . . . 69

4.9 Considerações finais . . . . . . . . . . . . . . 73

5 Métodos e soluções propostas para aprendizado multirrótulo e hie$\begin{array}{ll}\text { rárquico } & 75\end{array}$

5.1 Trabalhos em colaboração . . . . . . . . . . . . . 76

5.1 .1 BR+ em dados textuais de medicina . . . . . . . . . . . 77

5.1.2 BR+ em dados de diversos domínios . . . . . . . . . . . 78

5.1 .3 Upper Bound Classifier . . . . . . . . . . . . . . . . 81

5.2 Classificador base multirrótulo . . . . . . . . . . . . . . 82

5.3 Algoritmo para classificação multirrótulo supervisionado . . . . . 84

5.4 Algoritmos para classificação multirrótulo semissupervisionado . 86

5.4.1 Self-training Binary Relevance . . . . . . . . . . . . . . 87

5.4.2 Binary Relevance semissupervisionado coperspectiva . . . 88

5.4.3 Utilizando aprendizado ativo com Binary Relevance . . . . 89

5.5 Classificador base hierárquico . . . . . . . . . . . . . 90

5.6 Algoritmos para classificação hierárquica supervisionada . . . . . 94 
5.6 .1 HMR estendido . . . . . . . . . . . . . . . . 94

5.6.2 HMR estendido com estratégia de multiplicação . . . . . . . 95

5.6.3 Método híbrido de cooperação para classificação hierárquica 98

5.6.4 HBR coperspectiva supervisionado . . . . . . . . . . 102

5.7 Algoritmos para classificação hierárquica semissupervisionada . 103

5.7.1 Self-training Hierarchical Binary Relevance . . . . . . . . . . 103

5.7.2 HBR coperspectiva semissupervisionado . . . . . . . . 105

5.7.3 HBR coperspectiva semissupervisionado ativo . . . . . . . 106

5.8 HARPIA- um framework para classificação hierárquica . . . . . . . 107

5.9 Considerações finais . . . . . . . . . . . . . . 108

6 Avaliação experimental $\quad 111$

6.1 Classificação multirrótulo . . . . . . . . . . . . . 112

6.1 .1 Bases de dados . . . . . . . . . . . . . . . . 112

6.1.2 Configurações e cenários para avaliação . . . . . . . . 113

6.1.3 Resultados e discussão . . . . . . . . . . . . . . . 117

6.1.3.1 Cenário 1 - coperspectivas no contexto supervisionado . . . . . . . . . . . 117

6.1.3.2 Cenário 2 - aprendizado semissupervisionado baseado em desacordo . . . . . . . . . . . . . . 123

6.1.3.3 Cenário 3 - aprendizado semissupervisionado ativo 128

6.2 Classificação hierárquica . . . . . . . . . . . . . . . . . . . . . 134

6.2 .1 Bases de dados . . . . . . . . . . . . . . . . 134

6.2.2 Configurações e cenários para avaliação . . . . . . . . . 138

6.2.3 Resultados e discussão . . . . . . . . . . . . . . . . . . 146

6.2.3.1 Cenário 1 - bootstrapping HBR: . . . . . . . . . . 147

6.2.3.2 Cenário 2 - Avaliação das heurísticas para seleção dos conjuntos de treinamento local . . . . . . . 148

6.2.3.3 Cenário 3 - Uso de duas perspectivas no contexto supervisionado e método HBR . . . . . . . . 150

6.2.3.4 Cenário 4 - Aprendizado semissupervisionado baseado em desacordo . . . . . . . . . . . . . 155

6.2.3.5 Cenário 5 - Aprendizado semissupervisionado ativo 158

6.3 Considerações finais . . . . . . . . . . . . . . 166

7 Conclusões e direcionamentos para trabalhos futuros 169

7.1 Dificuldades e limitações . . . . . . . . . . . . . 170

7.2 Principais Contribuições . . . . . . . . . . . . 171

7.3 Trabalhos Futuros . . . . . . . . . . . . . . . 172

$\begin{array}{ll}\text { Referências } & 175\end{array}$ 


\section{Lista de Figuras}

2.1 Hierarquia do aprendizado segundo o grau de supervisão dos dados 8

2.2 Construção do classificador multirrótulo LP. . . . . . . . . . . . . . 18

2.3 Predição do classificador multirrórulo LP. . . . . . . . . . . 18

2.4 Construção do classificador multirrótulo BR. . . . . . . . . . . 20

2.5 Predição do classificador multirrórulo BR. . . . . . . . . . . . . . . 20

2.6 Método Chaining. . . . . . . . . . . . . . . . 22

3.1 Representação do conjunto de classes. . . . . . . . . . . . . . . . . 29

3.2 Estrutura de representação da hierarquia de classes. . . . . . . . 31

3.3 Tipos de predição. . . . . . . . . . . . . . . . . . 33

3.4 Abordagem plana para classificação hierárquica . . . . . . . . . . 34

3.5 Método HBR. . . . . . . . . . . . . . . . . . 38

3.6 Método HMr. . . . . . . . . . . . . . . . . . . 38

3.7 Método HMLP. . . . . . . . . . . . . . . . . . . . . . 38

3.8 Ilustração das 6 heurísticas baseadas em operações de conjuntos. 39

3.9 Heurística Best Global . . . . . . . . . . . . . . . . . . . . 41

3.10 Heurística Best $\eta$ Locals . . . . . . . . . . . . . . . . . . . . . . . . . 42

3.11 Abordagem local com o método HMR. . . . . . . . . . . . . . . . . . 42

3.12 Preparação do conjunto de treinamento para o método HMR. . . . 43

3.13 Classificação de um novo exemplo: HBR + top-down + MLN . . . . 45

3.14 Classificação de um novo exemplo: HBR + top-down + NMLN . . . . 46

3.15Erros de classificação hierárquica. . . . . . . . . . . . . . 47

3.16 Exemplo de hierarquia com pesos definidos . . . . . . . . . . 51

4.1 Ilustração do algoritmo Co-TRAINING . . . . . . . . . . . . 67

5.1 Treinamento e predição do método BR+ (SA) . . . . . . . . . . . 77

5.2 Predição do método BR+ com atualização. . . . . . . . . . . . . 80

5.3 Comparação entre BR, BR+ e UBC. . . . . . . . . . . . . . 81

5.4 Predição do método multirrótulo $\mathrm{BR}_{C o P} . \ldots \ldots$. . . . . . . . . 86 
5.5 Construção do classificador multirrótulo $\mathrm{BR}_{S T}$. . . . . . . . . . . . 87

5.6 Construção do classificador multirrótulo $\mathrm{BR}_{C o P S S}$. . . . . . . . . . 89

5.7 Distribuição de exemplos entre as classes da taxonomia. . . . . . 91

5.8 Exemplo de classificação com o método $\mathrm{HMR}_{E x t}$. . . . . . . . . . . 96

5.9 Modelo HMR com estratégia de multiplicação . . . . . . . . . . . 99

5.10 Modelo híbrido com classificadores locais. . . . . . . . . . . . 100

5.11 Exemplo de classificação por meio do método HDR. . . . . . . . . 101

5.12 Abordagem local com o método $\mathrm{HBR}_{C o P} . \quad$. . . . . . . . . . . . . . 102

5.13 Método $\mathrm{HBR}_{S T}$. . . . . . . . . . . . . . . . 105

5.14 Método $\mathrm{HBR}_{C o P S S} . \ldots \ldots \ldots$. . . . . . . . . . 106

6.1 Valores da medida $f_{1}^{\mu}$ para o Cenário $1 \ldots \ldots$. . . . . . . 119

6.2 Valores da medida $f_{1}$ para cada classificador binário independente. 122

6.3 Comparação dos métodos supervisionados e semissupervisionados (InitSize médio). . . . . . . . . . . . . . . . . . . . 124

6.4 Comparação dos métodos supervisionados e semissupervisionados (InitSize All). . . . . . . . . . . . . . . . . . . 126

6.5 Valores da medida $f_{1}^{\mu}$ para o Cenário 2. . . . . . . . . . . 127

6.6 Comparação entre métodos supervisionado e semissupervisionados para o conjunto de dados Emotions. . . . . . . . . . . . . . . 128

6.7 Comparação entre métodos supervisionado e semissupervisionados para o conjunto de dados Scene. . . . . . . . . . . . . 128

6.8 Comparação entre métodos supervisionado e semissupervisionados para o conjunto de dados Yeast. . . . . . . . . . . . . . 129

6.9 Valores da medida $f_{1}^{\mu}$ para o Cenário 3. . . . . . . . . . 131

6.10 Comparação dos métodos semissupervisionados com e sem aprendizado ativo para Emotions. . . . . . . . . . . . . . . . 133

6.11 Comparação dos métodos semissupervisionados com e sem aprendizado ativo para Scene. . . . . . . . . . . . . . . 133

6.12 Comparação dos métodos semissupervisionados com e sem aprendizado ativo para Yeast. . . . . . . . . . . . . . . . . . . . 134

6.13Hierarquia de classes Glass. . . . . . . . . . . . . . . . . . . . 135

6.14 Hierarquia de classes de Música. . . . . . . . . . . . . . . . 136

6.15Preparação dos conjuntos de treinamento locais para o cenário 1.142

6.16Preparação dos conjuntos de treinamento locais para os cenários 4 e 5. . . . . . . . . . . . . . . . . 145

6.17 Representação gráfica do post-hoc teste de Nemenyi. . . . . . . . . 150

6.18Valores da medida $f_{1}^{\mu}$ para o Cenário 3 de classificação hierárquica. 152 6.19Valores da medida $f_{1}^{\mu}$ por nível da hierarquia para o Cenário 3 de classificação hierárquica (InitSize 40). . . . . . . . . . . . . . . 154 
6.20 Comparação dos métodos supervisionados e semissupervisionados para classificação hierárquica (InitSize 40). . . . . . . . . . . 157

6.21 Comparação dos métodos supervisionados e semissupervisionados para classificação hierárquica (InitSize All). . . . . . . . . . . 157

6.22 Valores da medida $f_{1}^{\mu}$ para o Cenário 4 de classificação hierárquica. 159 6.23 Comparação por nível da taxonomia Exp - InitSize 40. . . . . . . . 159

6.24 Comparação por nível da taxonomia Marsyas - InitSize 40. . . . . 160 6.25 Comparação por nível da taxonomia G-Pfam - InitSize 40. . . . . . 160 6.26 Valores da medida $f_{1}^{\mu}$ para o Cenário 5 de classificação hierárquica. 162 6.27 Comparação dos métodos semissupervisionados hierárquicos com e sem aprendizado ativo para Exp. . . . . . . . . . . . . . . 165

6.28 Comparação dos métodos semissupervisionados hierárquicos com e sem aprendizado ativo para Marsyas. . . . . . . . . . . . . . . 166 6.29 Comparação dos métodos semissupervisionados hierárquicos com e sem aprendizado ativo para G-Pfam. . . . . . . . . . . . . 166 


\section{Lista de Tabelas}

1 Tabela de símbolos. ............... xxix

2.1 Exemplos monorrotulados no formato atributo-valor. . . . . . . . . 12

2.2 Matriz de confusão para duas classes. . . . . . . . . . . . 13

2.3 Exemplos multirrotulados no formato atributo-valor. . . . . . . . 15

2.4 Exemplo de uma base de dados multirrótulo. . . . . . . . . 17

2.5 Exemplo de predição multirrótulo. . . . . . . . . . . 25

2.6 Matrizes de confusão da predição da Tabela 2.5 . . . . . . . . . 25

3.1 Exemplos de classificação hierárquica no formato atributo-valor. . 29

3.2 Heurísticas para preparação dos conjuntos de treinamento . . . . 39

3.3 Informações utilizadas para calcular o peso das arestas. . . . . 50

4.1 Exemplos semissupervisionados monorrótulo no formato atributovalor. . . . . . . . . . . . . . . . . . . . 59

4.2 Duas descrições dos exemplos de treinamento. . . . . . . . . . . 65

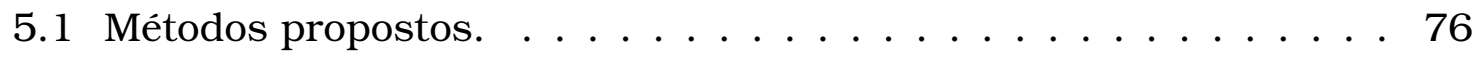

5.2 Exemplos multirrotulados. . . . . . . . . . . . . . . 83

5.3 Ranking dos monorrótulos em $L . \ldots \ldots$. . . . . . . . . . . . 83

5.4 Escores para identificação da classe majoritária hierárquica. . . . 93

5.5 Categorização dos métodos propostos . . . . . . . . . . . . . 109

6.1 Conjuntos de dados multirrótulo. . . . . . . . . . . . 113

6.2 Configuração do InitSize para cada conjunto de dados. . . . . . . 116

6.3 Valores de configuração para algoritmos de aprendizado ativo. . . 117

6.4 Métodos de classificação multirrótulo. . . . . . . . . . . . . . 117

6.5 Métodos comparados em cada cenário da avaliação experimental da classificação multirrótulo. . . . . . . . . . . . . 117

6.6 Valores de $f_{1}^{\mu}$ para o Cenário 1 da classificação multirrótulo. . . . 118

6.7 Resultados do classificador base $\mathrm{BR}_{\text {Low }}$. . . . . . . . . . . 120 
6.8 Comparação do método $\mathrm{BR}_{C o P}$ com os métodos monoperspectiva

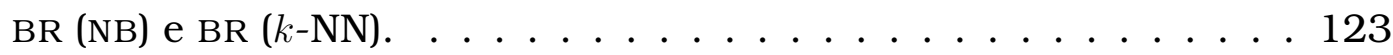

6.9 Valores de $f_{1}^{\mu}$ para o Cenário 2 da classificação multirrótulo. . . . 125

6.10Valores de $f_{1}^{\mu}$ para o Cenário 3 de classificação multirrótulo. . . . 130

6.11 Comparação dos métodos de aprendizado ativo com métodos semissupervisionados multirrótulo. . . . . . . . . . . . . . . . 132

6.12 Conjunto de dados hierárquicos. . . . . . . . . . . . . . . 139

6.13Valores de threshold para cada conjunto de dados hierárquicos. . 140

6.14 Conjunto de dados hierárquicos utilizados em cada cenário experimental. . . . . . . . . . . . . . . . 140

6.15Valores de configuração para algoritmos de aprendizado ativo. . 146

6.16 Categorização dos métodos propostos . . . . . . . . . . . . . . . . . 146

6.17 Métodos comparados em cada cenário da avaliação experimental da classificação hierárquica. . . . . . . . . . . . . . . . . . . . . 146

6.18Resultados para o Cenário 1 da avaliação experimental da classificação hierárquica. . . . . . . . . . . . . . . . . . . . . . . . . 148

6.19Heurísticas consideradas em trabalhos relacionados . . . . . . . . 150

6.20 Organização dos conjuntos de dados hierárquicos em grupos para análise dos resultados. . . . . . . . . . . . . . . 151

6.21 Valores de $f_{1}^{\mu}$ para o Cenário 3 de classificação hierárquica. . . . 151

6.22 Comparação do método $\mathrm{HBR}_{C o P}$ com os métodos monoperspectiva

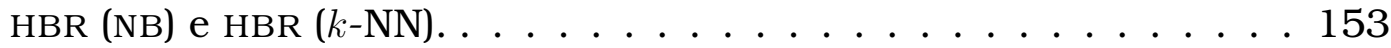

6.23Valores de $f_{1}^{\mu}$ para o Cenário 4 de classificação hierárquica. . . . 156 6.24 Valores de $f_{1}^{\mu}$ para o Cenário 5 de classificação hierárquica. . . . 161

6.25 Comparação dos métodos de aprendizado ativo com métodos semissupervisionados hierárquicos. . . . . . . . . . . . . . . 164

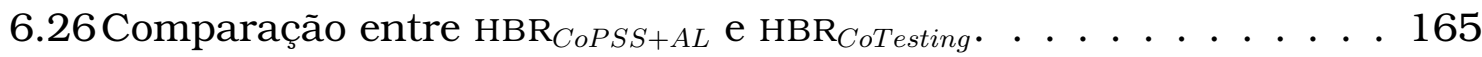

7.1 Métodos propostos . . . . . . . . . . . . 171 


\section{Lista de Algoritmos}

4.1 Algoritmo Self-TRAining . . . . . . . . . . . . . 63

4.2 Algoritmo Co-Training . . . . . . . . . . . . . 66

4.3 Função melhores Exemplos ORIGINAL . . . . . . . . . . . . . 67

4.4 Algoritmo Co-Perspective . . . . . . . . . . . . 68

4.5 Função melhoresExemplos NoContention. . . . . . . . . . . . . 70

4.6 Algoritmo Co-Testing . . . . . . . . . . . . . 71

4.7 Algoritmo CoAL . . . . . . . . . . . . . . . . . . . . . . . . . . . . . . . .

5.1 Self-training Hierarchical Binary Relevance. . . . . . . . . . . . . . . 104

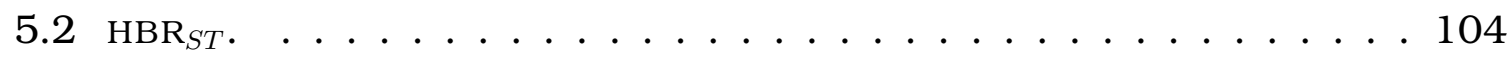




\section{Lista de Abreviaturas}

AM Aprendizado de Máquina

EM Expectation Maximization

IA Inteligência Artificial

KDD Knowledge Discovery in Databases

KNN K-Nearest Neighbor

MAP Maximum a Posteriori

MC Matriz de Confusão

MNB Multinomial Naive BAYES

MT Mineração de Texto

NB Naive Bayes

SMO Sequential Minimal Optimization

SVM Support Vector Machines

S3VM Semisupervised Support Vector Machines

TSVM Transductive Support Vector Machines 


\section{Notação}

\section{Tabela 1: Tabela de símbolos.}

\begin{tabular}{|c|c|}
\hline Símbolo & Descrição \\
\hline $\operatorname{Tr}$ & Conjunto com todos os exemplos de treinamento \\
\hline $\mathrm{Te}$ & Conjunto com todos os exemplos de teste \\
\hline $\operatorname{Tr} r^{l}$ & Conjunto de exemplos rotulados \\
\hline $\operatorname{Tr}^{u}$ & Conjunto de exemplos não rotulados \\
\hline$L$ & $\begin{array}{l}\text { Conjunto dos rótulos conhecidos para o domínio do problema. Esses são os rótulos distintos } \\
\text { dos exemplos do conjunto de treinamento }\end{array}$ \\
\hline$q$ & Número de monorrótulos em $L$, i.e., $|L|$ \\
\hline$y_{j}$ & Rótulo referente à classe $j, y_{j} \in L$ \\
\hline$Y_{i}$ & $\begin{array}{l}\text { Conjunto de rótulos verdadeiros associados ao exemplo } E_{i} \text { no formato }\left\{y_{i 1}, y_{i 2}, \ldots, y_{i q}\right\} \text {, onde } \\
q \geq 1\end{array}$ \\
\hline$\hat{Y}_{i}$ & Conjunto de rótulos preditos para o exemplo $i$ \\
\hline$\hat{y}_{j}$ & $j$-esimo rótulo predito para um determinado exemplo, $\hat{y}_{j} \in L$ \\
\hline$\Uparrow y_{j}$ & Conjunto das classes ancestrais de $y_{j}$ \\
\hline$\uparrow y_{j}$ & A classe mãe de $y_{j}$ \\
\hline$\leftrightarrow y_{j}$ & Conjunto das classes irmãs de $y_{j}$ \\
\hline$\downarrow y_{j}$ & Conjunto das classes filhas de $y_{j}$ \\
\hline$\Downarrow y_{j}$ & Conjuntos das classes descendentes de $y_{j}$ \\
\hline$\prec$ & Relação é uma, a qual representa a generalização entre classes em uma estrutura hierárquica \\
\hline$\odot\left(Y_{i}\right)$ & Classe mais específica de um conjunto de classes \\
\hline$E_{i}$ & Exemplo no formato $\left(\boldsymbol{x}_{i}, Y_{i}\right), i=1,2, \ldots|T r|$ \\
\hline$\circledast\left(E_{i}\right)$ & Classe mais específica de um exemplo \\
\hline$X_{j}$ & Rótulo dos atributos, $j=1 \ldots M$ \\
\hline$M$ & Número de atributos dos exemplos \\
\hline $\boldsymbol{x}_{i}$ & Vetor de atributos do exemplo $E_{i}$ no formato $\left(x_{i 1}, x_{i 2}, \ldots, x_{i M}\right)$ \\
\hline$x_{i j}$ & Valor do atributo $j$ do exemplo $E_{i}, j=1 \ldots M$ \\
\hline$h_{y_{j}}$ & Classificador plano associado a classe $y_{j}$ \\
\hline$\Gamma$ & Valor que representa um limiar inferior de teste (Threshold) \\
\hline$V_{P}$ & Número de exemplos verdadeiros positivos \\
\hline$V_{N}$ & Número de exemplos verdadeiros negativos \\
\hline$F_{P}$ & Número de exemplos falsos positivos \\
\hline$F_{N}$ & Número de exemplos falsos negativos \\
\hline$w_{y_{i} \rightarrow y_{j}}$ & Peso da aresta que conecta a classe $y_{i}$ à classe $y_{j}$ na taxonomia de classes \\
\hline$\zeta_{y_{j}}$ & Centróide para a classe $y_{j}$ \\
\hline$C D$ & Valor diferença crítica utilizado no post-hoc teste de Nemenyi \\
\hline$\theta_{y_{j}}$ & Grau de confiança para predição da classe $y_{j}$ \\
\hline
\end{tabular}




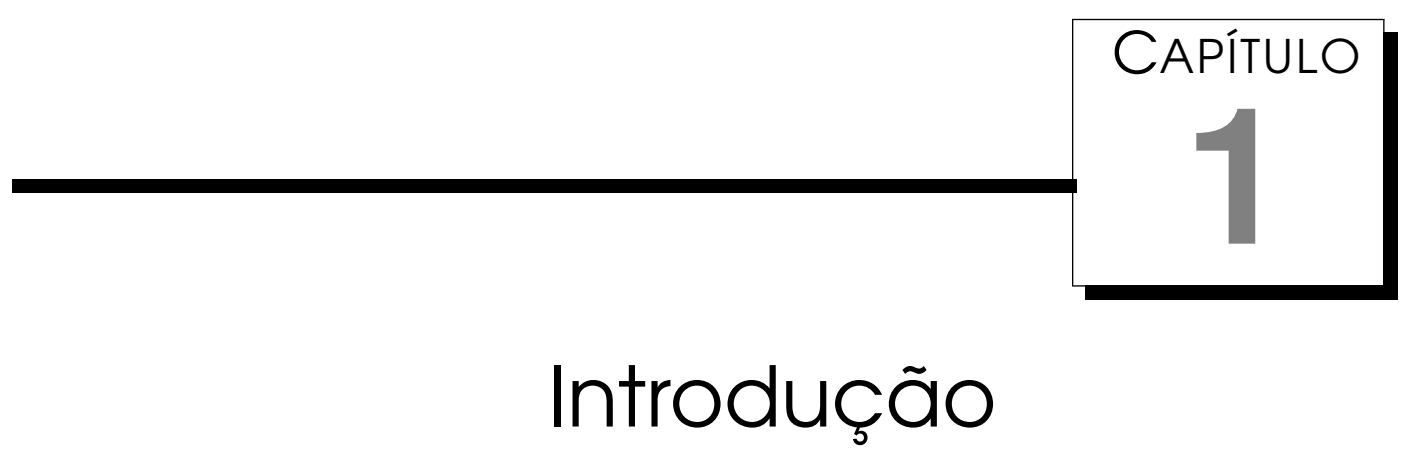

Este trabalho, cujo tema principal é a utilização de aprendizado semissupervisionado em contextos de classificação multirrótulo e hierárquica, está relacionado a quatro abordagens de aprendizado de máquina, mais especificamente a classificação multirrótulo, a classificação hierárquica, o aprendizado semissupervisionado baseado em desacordo e o aprendizado ativo.

A classificação multirrótulo é a tarefa de aprendizado na qual o objetivo é a construção de classificadores que identificam automaticamente um conjunto de classes associadas a objetos de um domínio específico. A classificação hierárquica, por sua vez, é um tipo especial de classificação multirrótulo, na qual os exemplos são também associados a múltiplas classes, mas, nesse caso, as classes do domínio descrevem uma estrutura hierárquica com diversos níveis de especificidade e regras bem definidas que governam as relações entre as diferentes classes presentes na hierarquia. Para ambas as tarefas, é necessário que exista uma quantidade expressiva de dados de treinamento previamente rotulados para a construção de bons classificadores.

Quando não existem exemplos de treinamento suficientes para o aprendizado supervisionado, o modo de aprendizado semissupervisionado pode ser utilizado. Nesse modo de aprendizado, o objetivo é aprender as classes do domínio utilizando poucos exemplos rotulados com a classe e um número considerável de exemplos para os quais a classe não é conhecida a priori. Um modelo amplamente utilizado e referenciado na literatura é o aprendizado semissupervisionado baseado em desacordo (Zhou \& Li, 2010).

Para auxiliar os métodos semissupervisionados baseados em desacordo, é possivel simular a existência de um "oráculo" capaz de predizer a classe verdadeira para um número finito e usualmente pequeno de exemplos não 
rotulados. Em um caso real, um especialista do domínio assume o papel do “oráculo" e responde a classe correta para um número pré-especificado de exemplos. Esse tipo de aprendizado é chamado de Aprendizado Ativo.

Neste trabalho é proposto o uso conjunto dessas quatro abordagens em um mesmo método de aprendizado.

A seguir são descritos a motivação, os objetivos e as hipóteses desta tese, assim como as principais contribuições originadas deste trabalho. Por fim, a organização e estrutura da tese são apresentadas.

\subsection{Motivação}

Frases como "...estamos vivendo a era da informação, na qual grandes volumes de dados são produzidos e armazenados diariamente...” expressam apenas parte da realidade atual.

Dados e informações não são somente produzidos e posteriormente armazenados em grandes bancos de dados como no passado. Atualmente, eles são compartilhados por meio da Internet por milhões de usuários espalhados pelo globo terrestre. Uma informação produzida aqui no Brasil e publicada na Internet, em poucos segundos estará disponível para usuários conectados à rede em qualquer lugar do mundo.

Existem diversas ferramentas para publicação e compartilhamento de dados, assim como para comunicação e colaboração, com as quais, usualmente categorizadas como "redes sociais", usuários podem classificar diferentes tipos de dados ou informações, rotulando artigos, web pages, conteúdo de mídias, entre outros, com suas próprias classes, o que possibilita a criação de outras ferramentas capazes de imitar o comportamento dos usuários para identificar automaticamente itens de interesse desses usuários.

Para que toda essa estrutura e ferramental sejam realmente úteis, as ferramentas disponíveis devem ser capazes não só de publicar as informações com agilidade, mas também de recuperá-las com rapidez e exatidão.

Entretanto, em um cenário tão complexo como esse, nem sempre é possivel fazer uso eficiente dos dados disponíveis para a recuperação de informações interessantes. Este fato geralmente ocorre porque a maioria dos dados não está previamente rotulado. Além disso, em diversas situações, os poucos dados rotulados são classificados de acordo com alguma taxonomia de classes pré-definida, mas nem sempre conhecida. Essas características dificultam ainda mais a tarefa de recuperação de informações.

Esse contexto motivou o desenvolvimento desta tese de doutorado, na qual são propostos alguns métodos para a classificação automática (supervisionada e semissupervisionada) e semiautomática (aprendizado ativo) de dados mul- 
tirrotulados e com classes que pertencem a uma hierarquia. Esses métodos de classificação foram propostos visando situações nas quais somente poucos dados previamente rotulados e muitos dados para os quais os rótulos não são conhecidos, estão disponíveis.

\subsection{Objetivos e hipóteses}

O objetivo geral deste trabalho é o desenvolvimento de novos métodos de aprendizado semissupervisionado para tarefas de classificação de exemplos multirrotulados, tanto para o caso no qual as classes do problema estão organizadas de maneira plana quanto hierárquica.

Uma vez que esse tema é pouco explorado, e consequentemente, informações a respeito do mesmo são praticamente inexistentes, foram elaborados alguns objetivos específicos a fim de sanar as carências da área:

1. elaborar e desenvolver métodos que possibilitem mensurar a capacidade de aprendizado de algoritmos para classificação multirrótulo e hierárquica;

2. desenvolver o ferramental que possibilite a avaliação empírica de métodos de classificação hierárquica;

3. elaborar e implementar métodos de classificação supervisionada e semissupervisionada baseado em desacordo coperspectiva, tanto para a classificação multirrótulo como para a classificação hierárquica;

4. desenvolver métodos semissupervisionados baseado em bootstrapping para classificação multirrótulo e hierárquica; e

5. desenvolver métodos de aprendizado ativo baseados em desacordo para classificação multirrótulo e classificação hierárquica.

Considerando esses objetivos, as hipóteses avaliadas neste trabalho são:

- O uso de duas ou mais perspectivas contribui para a melhora no poder de predição dos classificadores;

- Mesmo com poucos exemplos, métodos semissupervisionados são capazes de aproximar os resultados de métodos supervisionados; e

- O uso do aprendizado ativo para a construção do modelo inicial para o processo de aprendizado semissupervisionado contribui para a construção de classificadores mais precisos. 


\subsection{Principais contribuições}

Duas das principais contribuições deste trabalho estão relacionadas ao objetivo específico 1, para o qual foram elaborados dois métodos, um para a classificação multirrótulo plana e outro para a classificação hierárquica, que são utilizados nas avaliações experimentais dos algoritmos desenvolvidos para essas tarefas.

Com relação ao objetivo 2, foi desenvolvido um framework para classificação hierárquica, no qual estão implementados diversos algoritmos, inclusive os propostos neste trabalho, e um módulo completo para a avaliação dessa tarefa. Esse framework, nomeado HARPIA ${ }^{1}$ em homenagem à ave de rapina Harpia harpyja típica do continente sulamericano e muito comum no Brasil, foi implementado em linguagem Java e está disponível para a comunidade.

Ainda com relação ao desenvolvimento de ferramentas, uma segunda contribuição é a implementação dos métodos para classificação multirrótulo, os quais foram inclusos na biblioteca de classes para classificação multirrótulo Mulan $^{2}$. Entretanto, esses métodos ainda não estão disponiveis para a comunidade, uma vez que não temos controle sobre os códigos fontes dessa biblioteca. Futuramente, entraremos em contato com os responsáveis para verificar a possibilidade de incluir definitivamente esses métodos na biblioteca Mulan, e disponibilizá-los para uso público.

Com relação aos objetivos específicos 3, 4 e 5, foram elaborados algoritmos tanto para classificação multirrótulo quando para a classificação hierárquica.

Além dessas contribuições, durante a realização deste projeto de doutorado, foram desenvolvidas outras atividades correlatas, a partir das quais também foram geradas contribuições, como as propostas de métodos para classificação plana multirrótulo supervisionada, feitas em colaboração com outros pesquisadores do grupo de pesquisa. Outros métodos também foram propostos para a classificação hierárquica supervisionada.

\subsection{Organização}

Os capítulos deste trabalho estão organizados da seguinte maneira:

Capítulo 2: Classificação plana

Neste capítulo são apresentados conceitos e definições envolvidos na tarefa de classificação, assim como as diferenças entre os tipos de classificação plana.

\footnotetext{
${ }^{1}$ http: // labic.icmc.usp.br seção de Software and Application Tools.

${ }^{2}$ http://mulan.sourceforge.net/
} 
Capítulo 3: Classificação hierárquica

Neste capítulo são descritas as diferenças entre a classificação plana e a classificação hierárquica. São apresentados os conceitos relacionados aos diversos aspectos da classificação hierárquica, como a estruturas dos dados para esse tipo de tarefa e as estratégias de predição de novos exemplos. Além disso, são apresentadas medidas de avaliação utilizadas especificamente para a classificação hierárquica.

Capítulo 4: Aprendizado de máquina semissupervisionado

Neste capítulo são apresentados alguns conceitos relacionados ao aprendizado de máquina semissupervisionado e diversas abordagens propostas na literatura para essa tarefa de classificação considerando conjuntos de dados monorrotulados. Os diferentes tipos de semissupervisão, a representação do conjunto de treinamento semissupervisionado e dois pressupostos necessários para a utilização da semissupervisão, bem como a utilidade desse tipo de aprendizado são apresentados. Por fim, é descrito com mais detalhes o modelo de aprendizado baseado em desacordo e o aprendizado ativo.

Capitulo 5: Métodos e soluções propostas para aprendizado multirrótulo e hierárquico

Neste capítulo são apresentados os métodos propostos para classificação multirrótulo e para classificação hierárquica. Além disso, os métodos propostos em colaboração com outros pesquisadores também são descritos.

Capítulo 6: Avaliação experimental

Neste capítulo são descritas e analisadas as avaliações experimentais realizadas para avaliar as propostas apresentadas no Capítulo 5.

Capitulo 7: Conclusões

Neste capítulo são apresentadas as conclusões deste trabalho e os direcionamentos de trabalhos futuros. 


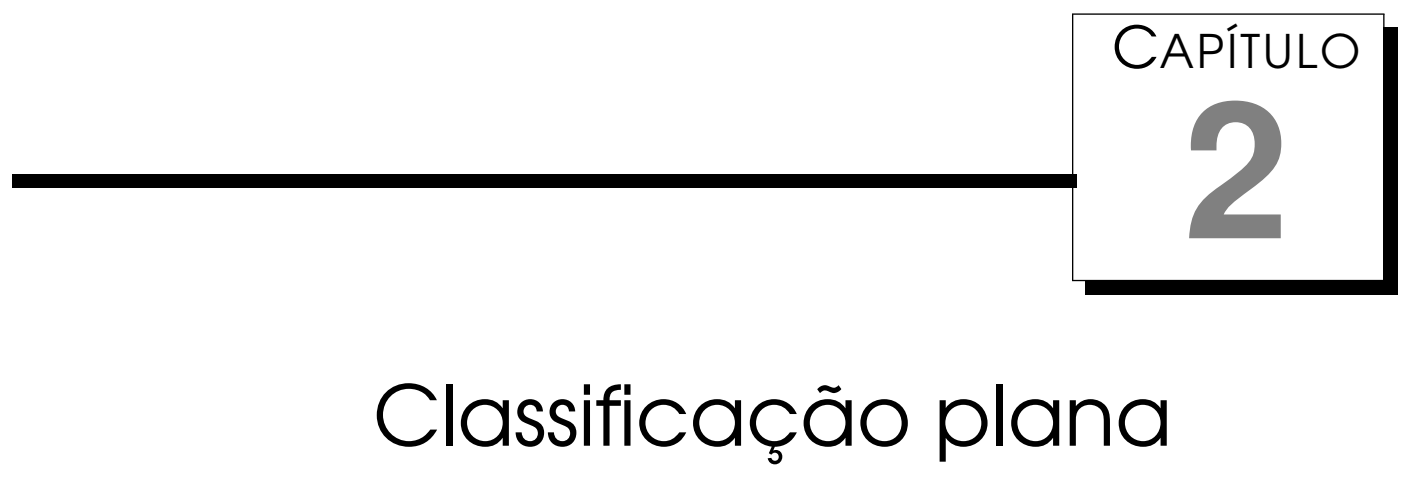

Neste capítulo são apresentados conceitos e definições envolvidos na tarefa de classificação, tema ao qual este trabalho está relacionado. A tarefa de classificação em Aprendizado de Máquina (AM) pode ser categorizada de maneiras distintas, dependendo das características dos rótulos das classes do problema. Uma possível categorização está relacionada à quantidade de classes associadas a cada exemplo. Quando as classes do problema não apresentam interrelacionamentos de generalização ou especialização e, consequentemente, não são organizadas em algum tipo de estrutura hierárquica, a tarefa é conhecida como classificação plana, que pode ser monorrótulo ou multirrótulo. Na classificação monorrótulo, apenas uma classe pode ser associada a cada exemplo; e na classificação multirrótulo, mais de uma classe pode ser associada a cada exemplo ao mesmo tempo (Tsoumakas et al., 2010).

Os conceitos relacionados ao aprendizado e a essas duas tarefas de classificação são apresentados neste capítulo. Na Seção 2.1 são apresentados os conceitos e fundamentos do processo de aprendizado de máquina. Na Seção 2.2 é apresentada a classificação monorrótulo, a maneira usual de representação dos conjuntos de dados (Seção 2.2.1) e os principais métodos de avaliação para esse tipo de tarefa em AM (Seção 2.2.2). Na Seção 2.3 são descritos os conceitos referentes à classificação multirrótulo. A representação dos dados, bem como os principais métodos de aprendizado desse tipo de classificação são apresentados, respectivamente, nas Seções 2.3.1 e 2.3.2. As principais medidas de avaliação propostas especificamente para a tarefa de classificação multirrótulo são apresentadas na Seção 2.3.3. 


\subsection{Conceitos e fundamentos}

AM é uma área de pesquisa cujos objetivos gerais são o desenvolvimento de técnicas computacionais que permitem simular o processo de aprendizado e a construção de sistemas capazes de adquirir conhecimento de maneira automática (Mitchell, 1997). Esses sistemas utilizam o conhecimento do domínio e os resultados de experiências anteriores para auxiliar o processo de tomada de decisão e melhorar o seu desempenho futuro. Desse modo, o foco principal está voltado para o desenvolvimento de algoritmos que melhorem automaticamente algum aspecto de seu desempenho por meio da experiência (Alpaydin, 2010).

Os algoritmos de aprendizado podem ser categorizados utilizando diversos critérios (Mitchell, 1997), como o grau de supervisão presente no conjunto de treinamento. Segundo esse critério, três tipos de aprendizado podem ser distinguidos, os quais são ilustrados na Figura 2.1. Guanto maior a quantidade de exemplos rotulados, maior o grau de supervisão.

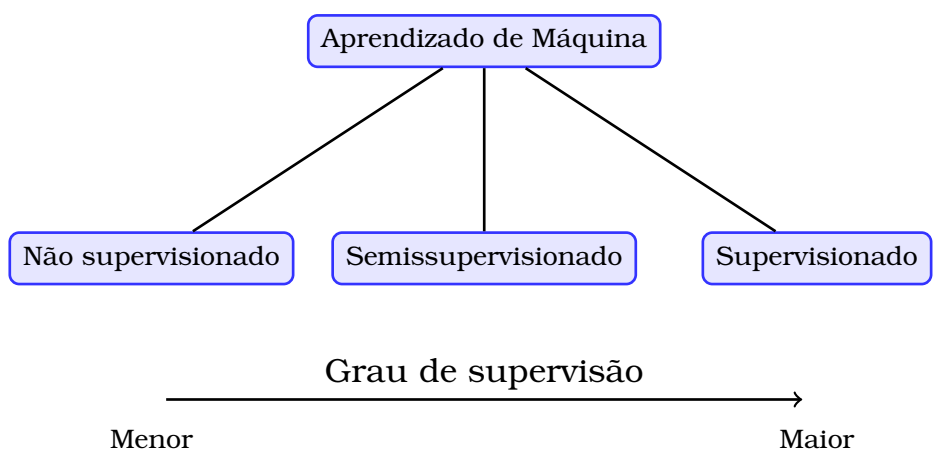

Figura 2.1: Hierarquia do aprendizado segundo o grau de supervisão dos dados.

Aprendizado supervisionado: nesse modo de aprendizado, o objetivo é induzir um classificador (ou hipótese), por meio de um conjunto expressivo de exemplos de treinamento previamente rotulados, para classificar novos exemplos ainda não rotulados. Em outras palavras, a tarefa de aprendizado, nesse caso, consiste em encontrar uma função de relacionamento, também chamada modelo ou hipótese, que mapeia um exemplo $x$ para a classe $y$ de modo que o erro de classificação de novos exemplos nunca vistos seja minimizado por essa função. Se as classes possuem valores discretos, como diferentes marcas de carro, por exemplo, o problema é conhecido como classificação. Caso as classes possuam valores contínuos, como o peso ou altura de uma pessoa, o problema é conhecido como regressão (Alpaydin, 2010). 
Existem outros contextos mais complexos de classificação, nos quais diversas classes podem estar associadas a cada exemplo. Quando não há relacionamento estrutural entre as diferentes classes associadas a cada exemplo, essa tarefa é chamada de classificação multirrórulo (Tsoumakas et al., 2010). Há ainda um terceiro cenário no qual, além de haver múltiplos rótulos associados a cada exemplo, os rótulos fazem parte de um taxonomia de classes representada por meio de algum tipo de estrutura hierárquica. Essa tarefa é chamada de classificação hierárquica (Freitas \& de Carvalho, 2007; Silla Jr \& Freitas, 2011), a qual é apresentada em maiores detalhes no Capítulo 3.

Aprendizado não supervisionado: nesse modo de aprendizado, os algoritmos recebem um conjunto de exemplos de treinamento no qual não há classificação prévia, ou seja, a classe de cada exemplo é desconhecida. Nesse caso, o objetivo é identificar alguma estrutura a partir desse conjunto de exemplos para obter uma representação concisa ou compreensão sobre o processo de geração dos dados, i.e., estimativa de um modelo de geração dos dados (Seeger, 2006). Agrupamento de dados (clustering), estimativa de densidade, detecção de novidade e regras de associação são quatro das abordagens mais comuns do aprendizado não supervisionado.

Aprendizado semissupervisionado: nesse modo de aprendizado o conjunto de exemplos utilizado para o treinamento dos algoritmos consiste de poucos exemplos rotulados e um número expressivo de exemplos não rotulados. De maneira geral, esses algoritmos tentam utilizar informação latente nos exemplos de treinamento não rotulados para rotular esses exemplos durante o processo de aprendizado. No contexto de classificação, esse modo de aprendizado permite, entre outros, contornar as limitações do modo de aprendizado supervisionado com relação ao número de exemplos rotulados necessários para o aprendizado.

Como mencionado anteriormente, na classificação, tema principal deste trabalho, o objetivo é a construção de um classificador ou modelo capaz de categorizar objetos em classes de um domínio específico do conhecimento. Esse classificador é construído por um algoritmo de aprendizado a partir de um conjunto de objetos exemplos do domínio de interesse. Após a construção do classificador, ele deve ser avaliado e, se necessário, o processo pode ser repetido para melhorar o modelo induzido.

No processo de aprendizado, é importante distinguir três conjuntos utilizados pelos algoritmos para a construção de classificadores:

Conjunto de treinamento: a partir desse conjunto de exemplos rotulados são construídos classificadores ou outros modelos e, portanto, ele deve 
ser representativo da distribuição da população dos dados do domínio. $\mathrm{Na}$ literatura esse conjunto também é conhecido como seen cases, uma vez que esses exemplos foram "vistos" pelo algoritmo de aprendizado durante a construção do modelo.

Conjunto de teste: utilizado para avaliar o modelo construído. Esse conjunto, também conhecido como unseen cases, não deve ser apresentado ao algoritmo de aprendizado durante a construção do modelo. Idealmente, o conjunto de teste não deve ter exemplos em comum com o conjunto de treinamento.

Conjunto de validação: utilizado, em alguns casos, para realizar ajustes no modelo construído pelo algoritmo de aprendizado. Dessa maneira, esses exemplos são indiretamente "vistos" durante o processo de aprendizado, o que obriga os exemplos de validação a serem distintos dos exemplos de teste.

Além de construir um bom classificador, muitas vezes, é necessário interpretar e compreender o modelo induzido por um sistema de aprendizado, os quais podem ser classificados em duas grandes categorias, considerando o grau de compreensibilidade proporcionado ao ser humano:

Sistemas tipo caixa-preta: são sistemas que desenvolvem sua própria representação do conceito e não fornecem explicações do processo de classificação, como sistemas implementados a partir de conceitos do paradigma conexionista; e

Sistemas orientados a conhecimento: são sistemas que criam estruturas simbólicas que são compreensíveis por humanos. Sistemas dessa categoria apresentam uma visão mais apurada, na qual a "caixa-preta" pode ser aberta e o conceito descrito pela hipótese induzida é facilmente compreensivel por humanos. Algoritmos nesta segunda categoria são também denominados algoritmos de aprendizado simbólico.

A seguir são descritos outros termos importantes utilizados nestes trabalho (Russell \& Norvig, 2010).

- Indutor: o indutor é um algoritmo de aprendizado que utiliza um processo indutivo para gerar uma hipótese (classificador ou modelo), a qual é posteriormente utilizada para classificar novos exemplos;

- Score: algoritmos indutores podem gerar classificadores que utilizam um valor de confiança na sua predição para determinar a classe de um exemplo, esse valor de confiança é denominado de score; 
- Ranking: a ordenação de um conjunto de exemplos em função dos scores de cada exemplo é denominada ranking;

- Overfitting: quando um classificador é induzido, é possível que ele seja muito específico para o conjunto de treinamento, i.e., apresente alta taxa de acerto para o conjunto de exemplos de treinamento e uma alta taxa de erro para o conjunto de teste. Nesse caso, pode-se dizer que o classificador "memorizou" os dados, não conseguindo generalizar o conceito. Essa situação é conhecida como overfitting; e

- Underfitting: também é possível que o conjunto de treinamento seja composto por exemplos pouco representativos, ou que o usuário defina previamente o tamanho do classificador como muito pequeno (por exemplo, um alto fator de poda ${ }^{1}$ para uma árvore de decisão) ou uma combinação de ambas as situações. Nesse caso, pode-se dizer que o classificador não conseguiu abstrair o conceito, apresentando baixa performance no conjunto de treinamento e no conjunto de teste. Essa situação é conhecida como underfitting.

Outro aspecto importante é a representação dos dados para o aprendizado. Em AM, diversos formatos podem ser utilizados para descrever os conjuntos de exemplos. Um desses formatos, chamado de atributo-valor, é amplamente utilizado pela maioria dos algoritmos de aprendizado. Nessa forma de descrição, os dados são caracterizados por um conjunto de $M$ atributos $X_{1}, X_{2}, \ldots, X_{M}$, sendo que cada exemplo pode assumir valores específicos em cada atributo. Dessa maneira, os atributos $X=X_{1} \times X_{2} \times \ldots \times X_{M}$ definem um espaço de exemplos, e um exemplo $E$ é representado como um vetor de valores desses atributos $\boldsymbol{x}=\left(x_{1}, x_{2}, \ldots, x_{M}\right)$, no qual $x_{j}$ refere-se ao valor do atributo $X_{j}$ em $x$. Os valores dos atributos podem ser contínuos ou discretos.

Os exemplos de um conjunto de dados para os quais o atributo classe é conhecido são denominados de exemplos rotulados; caso contrário, exemplos não rotulados.

\subsection{Classificação monorrótulo}

Na classificação monorrótulo, cada exemplo está associado a apenas um rótulo. Nesse caso, o formato atributo-valor dos exemplos de treinamento para o algoritmo de aprendizado têm o formato descrito na Seção 2.2.1 a seguir.

\footnotetext{
${ }^{1}$ Poda em árvores de decisão consiste na exclusão de algumas ramificações da árvore, tornando-a mais "simples".
} 


\subsubsection{Representação dos dados}

Na Tabela 2.1 é apresentado o formato atributo-valor para $N$ exemplos monorrotulados $E_{1}, \ldots, E_{N}$. Cada exemplo rotulado $E_{i}$ assume a forma $\left(\boldsymbol{x}_{i}, y_{i}\right)$, sendo que $\boldsymbol{x}_{i}=\left(x_{i 1}, x_{i 2}, \ldots, x_{i M}\right) \in X$ e $y_{i}$ é o valor do atributo classe $Y$ referente a $\boldsymbol{x}_{i}$, i.e., o valor $y$ de uma função $f$ desconhecida, $y=f(\boldsymbol{x})$.

Tabela 2.1: Exemplos monorrotulados no formato atributo-valor.

\begin{tabular}{|c|c|c|c|c|c|}
\hline Exemplo & $X_{1}$ & $X_{2}$ & $\ldots$ & $X_{M}$ & $Y$ \\
\hline$E_{1}$ & $x_{11}$ & $x_{12}$ & $\ldots$ & $x_{1 M}$ & $y_{1}$ \\
\hline$E_{2}$ & $x_{21}$ & $x_{22}$ & $\ldots$ & $x_{2 M}$ & $y_{2}$ \\
\hline$E_{3}$ & $x_{31}$ & $x_{32}$ & $\ldots$ & $x_{3 M}$ & $y_{3}$ \\
\hline : & : & : & $\ddots$ & $\vdots$ & $\vdots$ \\
\hline$E_{N}$ & $x_{N 1}$ & $x_{N 2}$ & $\ldots$ & $x_{N M}$ & $y_{N}$ \\
\hline
\end{tabular}

Em outras palavras, no problema de classificação monorrótulo, cada exemplo $E_{i}$ está associado com um único rótulo $y_{i} \in Y$, com $|Y|>1$. Quando o conjunto de exemplos contém $|Y|=2$ rótulos, o problema é denominado classificação binária, enquanto que se $|Y|>2$, o problema é denominado classificação multiclasse. O objetivo de um algoritmo de aprendizado monorrótulo é utilizar o conjunto de exemplos de treinamento para encontrar um modelo ou hipótese $h$ que aproxima bem os valores da classe de exemplos no domínio não utilizados durante o treinamento, i.e., dado um novo exemplo $\boldsymbol{x}, h(\boldsymbol{x}) \approx f(\boldsymbol{x})$.

\subsubsection{Avaliação da classificação monorrótulo}

Uma das maneiras de avaliar a predição de um classificador monorrótulo, seja ele binário ou multiclasse, é por meio da Matriz de Confusão (MC), também chamada de matriz de contingência. Essa matriz representa o número de classificações corretas e erradas obtidas pelo classificador sobre um conjunto de exemplos de teste. Os resultados são totalizados em duas dimensões: classes verdadeiras e classes preditas. Cada célula $M C\left(y_{i}, y_{j}\right)$ da matriz representa o número de exemplos que realmente pertencem a classe $y_{i}$ mas que foram classificados como pertencentes a classe $y_{j}$. Na Tabela 2.2 é mostrada a matriz de confusão de um classificador plano com duas classes, $+\mathrm{e}-$. Nessa tabela, $V_{P}$, verdadeiros positivos, e $V_{N}$, verdadeiros negativos, representam, respectivamente, a quantidade de exemplos com a classe real positiva/negativa classificados como positivos/negativos. Por outro lado, $F_{P}$, falsos positivos, e $F_{N}$, falsos negativos, representam, respectivamente, a quantidade de exemplos cuja classe real é negativa/positiva e foram classificados como positivos/negativos.

A partir dessas informações são definidas diversas medidas de performance, tais como acurácia $(A c c)$, erro $(E r r)$, precisão $(P r)$ e recall $(R e)$, definidas respectivamente pelas Equações 2.1 a 2.4. 
Tabela 2.2: Matriz de confusão para duas classes.

\begin{tabular}{|c|c|c|}
\hline Classe & Predita $C_{+}$ & Predita $C_{-}$ \\
\hline Verdadeira $C_{+}$ & $V_{P}$ & $F_{N}$ \\
\hline Verdadeira $C_{-}$ & $F_{P}$ & $V_{N}$ \\
\hline
\end{tabular}

A acurácia, também conhecida como precisão total, é uma medida simples que calcula a fração de exemplos corretamente classificados. O erro por outro lado, é o complemento da acurácia.

$$
\begin{gathered}
A c c=\frac{V_{P}+V_{N}}{V_{P}+V_{N}+F_{P}+F_{N}} \\
E r r=\frac{F_{P}+F_{N}}{V_{P}+V_{N}+F_{P}+F_{N}}=1-A c c
\end{gathered}
$$

A precisão, também chamada de positive reliability ou positive predictive value, é calculada como uma medida de fidelidade, no sentido de que seu valor representa a fração de exemplos relevantes dentre os exemplos classificados como relevantes, i.e., o número de exemplos corretamente preditos como positivos dividido pelo número total de exemplos preditos como positivos.

$$
\operatorname{Pr}=\frac{V_{P}}{V_{P}+F_{P}}
$$

$\mathrm{O}$ recall (sensitivity ou true positive rate), por outro lado, representa uma medida de perfeição no sentido de que seu valor representa a fração de exemplos corretamente classificados como relevantes dentre os exemplos verdadeiramente relevantes. Ou seja, o número de exemplos preditos como positivos pelo número total de exemplos cuja classe verdadeira é positiva.

$$
R e=\frac{V_{P}}{V_{P}+F_{N}}
$$

Outra maneira bastante usual para a avaliação de classificadores é utilizar a medida $f_{\beta}$, que considera a média harmônica entre duas medidas, por exemplo precisão e recall, apresentada na Equação 2.5, na qual o parâmetro $\beta$ indica o peso dado a uma das medidas. Quando o valor de $\beta$ é igual a 1 as duas medidas têm o mesmo peso no cálculo da média final. Com $\beta=2 \mathrm{a}$ medida de recall recebe o dobro do peso dado a precisão, ao passo que para $\beta=0,5$ ocorre a situação inversa, ou seja, a precisão recebe o dobro do peso que recall.

$$
f_{\beta}=\left(1+\beta^{2}\right) \times \frac{\operatorname{Pr} \times R e}{\beta^{2} \times \operatorname{Pr}+R e}
$$

Além dessas medidas de performance, o erro majoritário também é uma in- 
formação importante. Essa taxa de erro representa um limite inferior da taxa de erro para um problema de classificação plana, simplesmente assumindo a classe majoritária como a classe predita para todos os exemplos. A taxa de erro majoritário é definida pela Equação 2.6:

$$
\text { Error }_{\text {majority }}=1-\max _{j=1 . .|Y|} P\left(y_{j}\right)
$$

onde $P\left(y_{j}\right)$ representa a probabilidade da classe $y_{j}$, e $|Y|$ é o número de classes do problema.

As medidas apresentadas são aplicáveis apenas no contexto de classificação plana e monorrótulo.

\subsection{Classificação multirrótulo}

Grande parte dos métodos de aprendizado supervisionado considera que cada um dos exemplos do conjunto de treinamento está associado a um único rótulo. Entretanto, existem diversos domínios de aplicação nos quais os exemplos são rotulados com mais de uma classe ao mesmo tempo, os quais são chamados de exemplos multirrótulo (Tsoumakas et al., 2010).

Duas aplicações que motivaram o desenvolvimento desses métodos são a Mineração de Texto (MT) e a mineração na web (Ueda \& Saito, 2003). Entretanto, outras aplicações também tiveram papel importante, como a classificação de músicas em emoções e gêneros (Trohidis et al., 2008; Li et al., 2006; Li \& Ogihara, 2003); a anotação semântica de imagens e vídeos (Zhang \& Zhou, 2007; Gi et al., 2007; Boutell et al., 2004); e o marketing direto (Zhang, 2006).

Nos últimos anos, tem-se observado um crescimento contínuo no número de publicações relacionadas à classificação multirrótulo, indicando o grande interesse da comunidade científica nessa área de pesquisa. Corrobora com essa observação a realização de dois workshops de aprendizado multirrótulo (Learning from Multi-Label Data) em conjunto com duas das mais renomadas conferências internacionais da área de AM, respectivamente, a ECML/PKDD $2009^{2}$ e a ICML/COLT $2010^{3}$. Além disso, o Machine Learning Journal ${ }^{4}$, um dos principais periódicos científicos relacionados a AM, publicará neste ano uma edição especial dedicada exclusivamente ao aprendizado multirrótulo.

Os conceitos que envolvem o desenvolvimento de algoritmos para classificação multirrótulo e as principais abordagens propostas são apresentados a seguir.

\footnotetext{
${ }^{2}$ http://lpis.csd.auth.gr/workshops/mld09/

3 http://cse.seu.edu.cn/conf/MLD10/

${ }^{4}$ http://www.springer.com/computer/ai/journal/10994
} 


\subsection{Representação dos dados}

Como visto na classificação monorrótulo, a entrada do algoritmo de aprendizado consiste em um conjunto de $N$ exemplos no formato atributo-valor, e cada exemplo $E_{i}$ está associado a um único rótulo $y_{i}$ contido no conjunto de rótulos $L$, i.e., $y_{i} \in L$, com $|L|>1$.

Para o caso de algoritmos de classificação multirrótulo, os dados também são representados por meio do formato atributo-valor. Porém, nesse caso, o atributo classe admite mais de um rótulo associado a cada exemplo ao mesmo tempo. Assim, um exemplo $E_{i}$ é representado por $\left(\boldsymbol{x}_{i}, Y_{i}\right)$, onde $Y_{i} \subseteq L \mathrm{e}$ $L=\left\{y_{j}: j=1 . . q\right\}$ é o conjunto dos $q$ monorrótulos que constituem os multirrótulos $Y_{i}, i=1 . . N$ (Tsoumakas et al., 2010), como representado na Tabela 2.3. Observe que se todos os exemplos do conjunto de treinamento estão associados a conjuntos de rótulos unitários, i.e. $\forall \boldsymbol{x}_{i},\left|Y_{i}\right|=1$, o problema se torna monorrótulo. Nesse sentido, a representação atributo-valor dos dados monorrótulo é uma especialização do caso multirrótulo.

Tabela 2.3: Exemplos multirrotulados no formato atributo-valor.

\begin{tabular}{|c|c|c|c|c|c|}
\hline Exemplo & 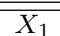 & 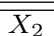 & $\overline{c \ldots}$ & 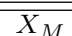 & $\overline{\bar{Y}}$ \\
\hline$E_{1}$ & $x_{11}$ & $x_{12}$ & $\ldots$ & $x_{1 M}$ & $Y_{1}=\left\{y_{1}, y_{4}\right\}$ \\
\hline$E_{2}$ & $x_{21}$ & $x_{22}$ & $\ldots$ & $x_{2 M}$ & $Y_{2}=\left\{y_{1}, y_{2}, y_{4}\right\}$ \\
\hline$E_{3}$ & $x_{31}$ & $x_{32}$ & $\ldots$ & $x_{3 M}$ & $Y_{3}=\left\{y_{1}, y_{3}\right\}$ \\
\hline$\vdots$ & : & • & $\ddots$ & : & 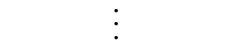 \\
\hline$E_{N}$ & $x_{N 1}$ & $x_{N 2}$ & $\ldots$ & $x_{N M}$ & $Y_{N}=\left\{y_{2}, y_{3}\right\}$ \\
\hline
\end{tabular}

Em tarefas de classificação monorrótulo, é interessante obter algumas informações sobre o conjunto de dados, dentre elas a frequência relativa das classes, a qual pode afetar a qualidade dos modelos construídos (Batista et al., 2004). No caso da classificação multirrótulo, são também importantes outras informações que podem afetar o desempenho dos classificadores, como o número de exemplos multirrotulados e a distribuição dos monorrótulos no conjunto de exemplos (Tsoumakas \& Katakis, 2007), o que possibilita compreender como cada monorrótulo participa dos multirrótulos no conjunto de treinamento. Essa informação é obtida por meio da cardinalidade e densidade de rótulos do conjunto de exemplos de treinamento $\mathrm{Tr}$, definidas pelas Equações 2.7 e 2.8, respectivamente.

$$
\begin{gathered}
\operatorname{Card}(T r)=\frac{1}{|T r|} \sum_{i=1}^{|T r|}\left|Y_{i}\right| \\
\operatorname{Dens}(T r)=\frac{\operatorname{Card}(T r)}{|L|}
\end{gathered}
$$

A cardinalidade representa o tamanho médio dos multirrótulos, enquanto que a densidade representa quanto cada monorrótulo participa dos multir- 
rótulos presentes no conjunto de treinamento. Essas informações são úteis para analisar a complexidade do problema tratado e, também, para auxiliar na escolha do algoritmo a ser utilizado para o aprendizado. A seguir são apresentados os principais métodos para a construção de classificadores multirrótulo.

\subsubsection{Métodos de classificação multirrótulo}

Os métodos de classificação multirrótulo podem ser divididos em dois grupos (Tsoumakas \& Katakis, 2007): Adaptação de algoritmos e Transformação de problema, descritos a seguir.

\subsubsection{Adaptação de algoritmos}

Métodos desse grupo são adaptações de algum algoritmo existente na literatura para a classificação monorrótulo. O resultado dessa adaptação é um novo algoritmo que possibilita tratar o problema multirrótulo diretamente, sem a necessidade de modificar ou transformar o problema de classificação multirrótulo. Assim, o algoritmo adaptado passa a predizer um conjunto de rótulos e não apenas um único rótulo para cada exemplo.

No trabalho de Clare \& King (2001), foi proposta uma modificação do algoritmo C4.5 (Quinlan, 1993) para a classificação multirrótulo de genes de acordo com suas funções. Para isso, a medida de entropia utilizada pelo algoritmo C4.5 foi adaptada de modo a considerar os multirrótulos para a seleção dos atributos que representam os nós da árvore de decisão. A medida de entropia adaptada para o problema multirrótulo é apresentada na Equação 2.9, onde $p\left(y_{j}\right)$ é a frequência relativa do monorrótulo $y_{j}$ e $q\left(y_{j}\right)=1-p\left(y_{j}\right)$.

$$
\text { entropia }=-\sum_{j=1}^{|L|}\left(p\left(y_{j}\right) \log p\left(y_{j}\right)+q\left(y_{j}\right) \log q\left(y_{j}\right)\right)
$$

Outra modificação proposta por Clare \& King (2001) altera a funcionalidade dos nós-folha da árvore de decisão, os quais passam a representar um subconjunto de rótulos e não apenas um único rótulo como no algoritmo original.

Em (Schapire \& Singer, 2000) foram propostas duas extensões do algoritmo AdaBoost (Freund \& Schapire, 1995), para tratar o problema de classificação multirrótulo. Uma dessas adaptações, denominada AdaBoost.MH, tenta minimizar a medida Hamming Loss, enquanto que a outra adaptação, denominada AdaBoost.MR, foi projetada para construir um ranking com os rótulos, no qual, para cada novo exemplo, os melhores rótulos são dispostos no topo do ranking. A partir desse ranking obtém-se o conjunto de rótulos associados ao exemplo.

Além desses, outros pesquisadores propuseram outros algoritmos basea- 
dos em diversas técnicas de AM, como Support Vector Machines (SVM) (Elisseeff \& Weston, 2001b,a), K-Nearest Neighbor (KNN) (Trohidis et al., 2008; Spyromitros et al., 2008; Brinker \& Hüllermeier, 2007; Luo \& Heywood, 2005; Zhang \& Zhou, 2005), regras de associação (Thabtah et al., 2004) e redes neurais (Zhang, 2006; Crammer et al., 2003).

\subsubsection{Transformação de problema}

Os métodos classificados nessa categoria decompõem o problema multirrótulo em um ou mais problemas monorrótulo e utilizam algoritmos de classificação monorrótulo para resolução de cada problema separadamente. É importante observar que esses métodos são independentes do algoritmo base, uma vez que qualquer algoritmo de aprendizado monorrótulo pode ser utilizado para construir os classificadores individuais.

Nessa categoria existem diversos métodos, dentre os quais destacamos: Label Powerset (Tsoumakas et al., 2010), Binary Relevance (Tsoumakas et al., 2010) e baseados em Stacking (Wolpert, 1992; Ozay \& Vural, 2008), descritos a seguir.

\section{Label Powerset - LP}

O método LP consiste em transformar o problema multirrótulo em um problema monorrótulo multiclasse, no qual todos os conjuntos únicos de rótulos presentes no conjunto de treinamento são transformados em valores unitários do atributo classe, a partir dos quais um classificador multiclasse é construído.

Como ilustração, considere o conjunto de exemplos multirrótulo apresentado na Tabela 2.4, o qual contém cinco exemplos rotulados com um ou mais rótulos do conjunto de monorrótulos $L=\left\{y_{1}, y_{2}, y_{3}\right\}$.

Tabela 2.4: Exemplo de uma base de dados multirrótulo.

\begin{tabular}{|c|c|}
\hline Exemplo & $Y_{i}$ \\
\hline$E_{1}$ & $Y_{1}=\left\{y_{1}, y_{2}, y_{3}\right\}$ \\
\hline$E_{2}$ & $Y_{2}=\left\{y_{1}, y_{3}\right\}$ \\
\hline$E_{3}$ & $Y_{3}=\left\{y_{1}\right\}$ \\
\hline$E_{4}$ & $Y_{4}=\left\{y_{2}, y_{3}\right\}$ \\
\hline$E_{5}$ & $Y_{5}=\left\{y_{3}\right\}$ \\
\hline
\end{tabular}

Com o método LP, os multirrótulos desses exemplos são transformados em monorrótulos, utilizando por exemplo a concatenação dos múltiplos rótulos para a criação de um novo monorrótulo. Outras transformações podem ser utilizadas, como a criação de um índice único para cada combinação de multirrótulos no conjunto de treinamento. Por exemplo, o multirrótulo $\left\{y_{1}, y_{3}\right\}$ poderia ser transformado em $A$. A partir desse novo monorrótulo é possível recuperar os múltiplos rótulos originais, uma vez 
que $A=\left\{y_{1}, y_{3}\right\}$. Após essa transformação, esse conjunto de exemplos é apresentado a um algoritmo de aprendizado para a construção de um classificador monorrótulo multiclasse, cuja tarefa é predizer um dos novos monorrótulos para novos exemplos. Esse processo de transformação dos dados e a construção do classificador é ilustrado na Figura 2.2, na qual a notação $y_{i-j-k}$ representa a concatenação dos rótulos $y_{i}, y_{j}$ e $y_{k}$, ou seja, o multirrótulo $\left\{y_{i}, y_{j}, y_{k}\right\}$ no conjunto original é transformado em um monorrótulo correspondente à concatenação $y_{i} \wedge y_{j} \wedge y_{k}$.

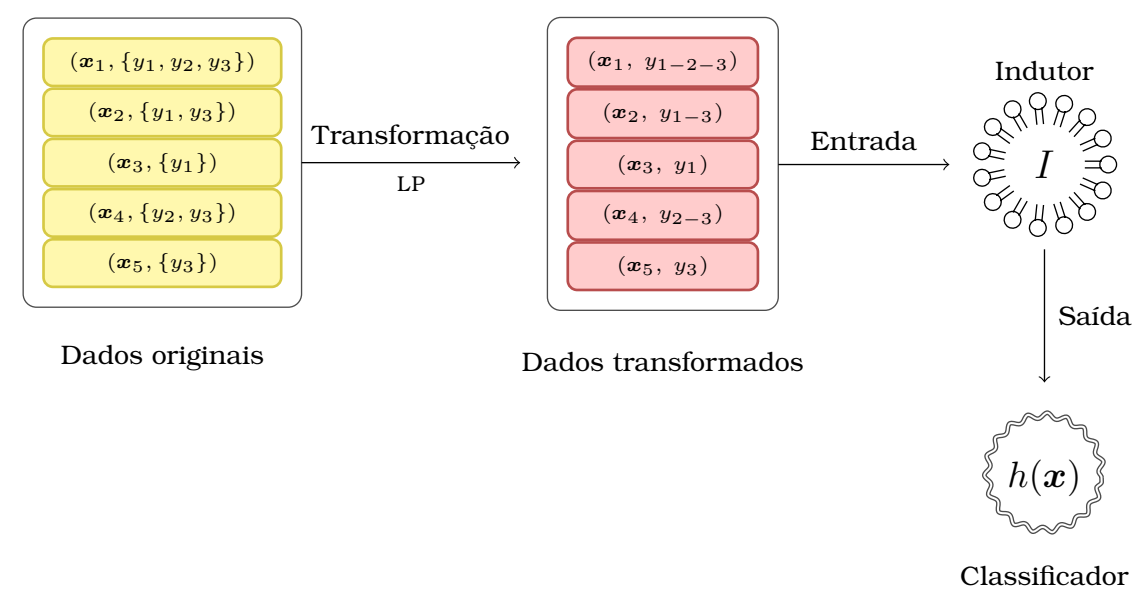

Figura 2.2: Construção do classificador multirrótulo LP.

A classificação de um novo exemplo por meio do método LP é ilustrada na Figura 2.3. Observe que, para obter a classificação multirrótulo para um novo exemplo, é necessário fazer a transformação inversa da realizada para a construção do classificador. Em outras palavras, identificar o subconjunto de rótulos que o monorrótulo predito pelo classificador representa e, então, atribuir esses múltiplos rótulos ao novo exemplo.

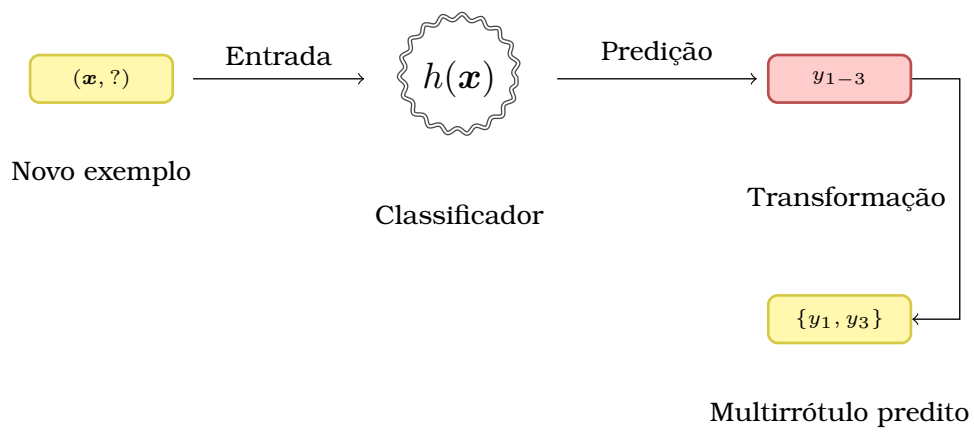

Figura 2.3: Predição do classificador multirrórulo LP.

Uma desvantagem desse método é que a transformação dos multirrótulos em monorrótulos pode resultar em um conjunto com muitas classes a serem preditas pelo classificador multiclasse, uma vez que cada 
combinação de rótulos presente no conjunto de treinamento é substituída por um novo monorrótulo. Observe que no exemplo ilustrado na Figura 2.2, apesar de existirem apenas três monorrótulos no conjunto original, o número de combinações distintas desses rótulos (multirrótulos distintos) é cinco. Consequentemente, após a transformação dos rótulos, o classificador multiclasse é construído para discriminar um número maior de classes. Nesse caso, o conjunto de rótulos passa a ser $L=\left\{y_{1-2-3}, y_{1-3}, y_{1}, y_{2-3}, y_{3}\right\}$. Na maioria das bases de dados multirrótulo, o número de monorrótulos resultantes após essa transformação é muito maior que o número inicial de monorrótulos no conjunto de treinamento.

Outro problema inerente dessa abordagem é a desbalanceamento entre as classes, umas vez que, usualmente, conjuntos de dados multirrotulados contêm muitas classes com baixa frequência e poucas classes com alta frequência. Nesses casos, se houver sobreposição entre as classes, o modelo final pode ser seriamente degradado.

Por outro lado, esse método é simples e considera informações de dependência entre rótulos diretamente na construção do classificador.

\section{Binary Relevance - BR}

O método BR consiste em dividir o problema multirrótulo em $|L|$ problemas de classificação binária, um para cada rótulo contido em $L$.

Para cada problema monorrótulo binário, o conjunto de exemplos é replicado e os rótulos desses exemplos são modificados, de modo que cada exemplo seja positivo ou negativo para esse problema. Assim, considerando o monorrótulo $y_{j}$, os exemplos do conjunto de dados original que contêm esse monorrótulo são rotulados como positivos, enquanto que os exemplos que não contêm esse monorrótulo são rotulados como negativos. Esse processo de transformação dos exemplos, considerando os dados apresentados na Tabela 2.4, é ilustrado na Figura 2.4.

A partir desses classificadores monorrótulos, a predição multirrótulo de um novo exemplo é formada pela união dos rótulos associados aos classificadores binários que classificam esse exemplo como positivo, conforme ilustrado na Figura 2.5.

A principal desvantagem desse método é não considerar a dependência de rótulos na construção do modelo de classificação multirrótulo, uma vez que cada classificador binário é construído de maneira independente dos demais. Por outro lado, esse método é simples e eficiente, apresentando complexidade linear com o número de monorrótulos no conjunto 


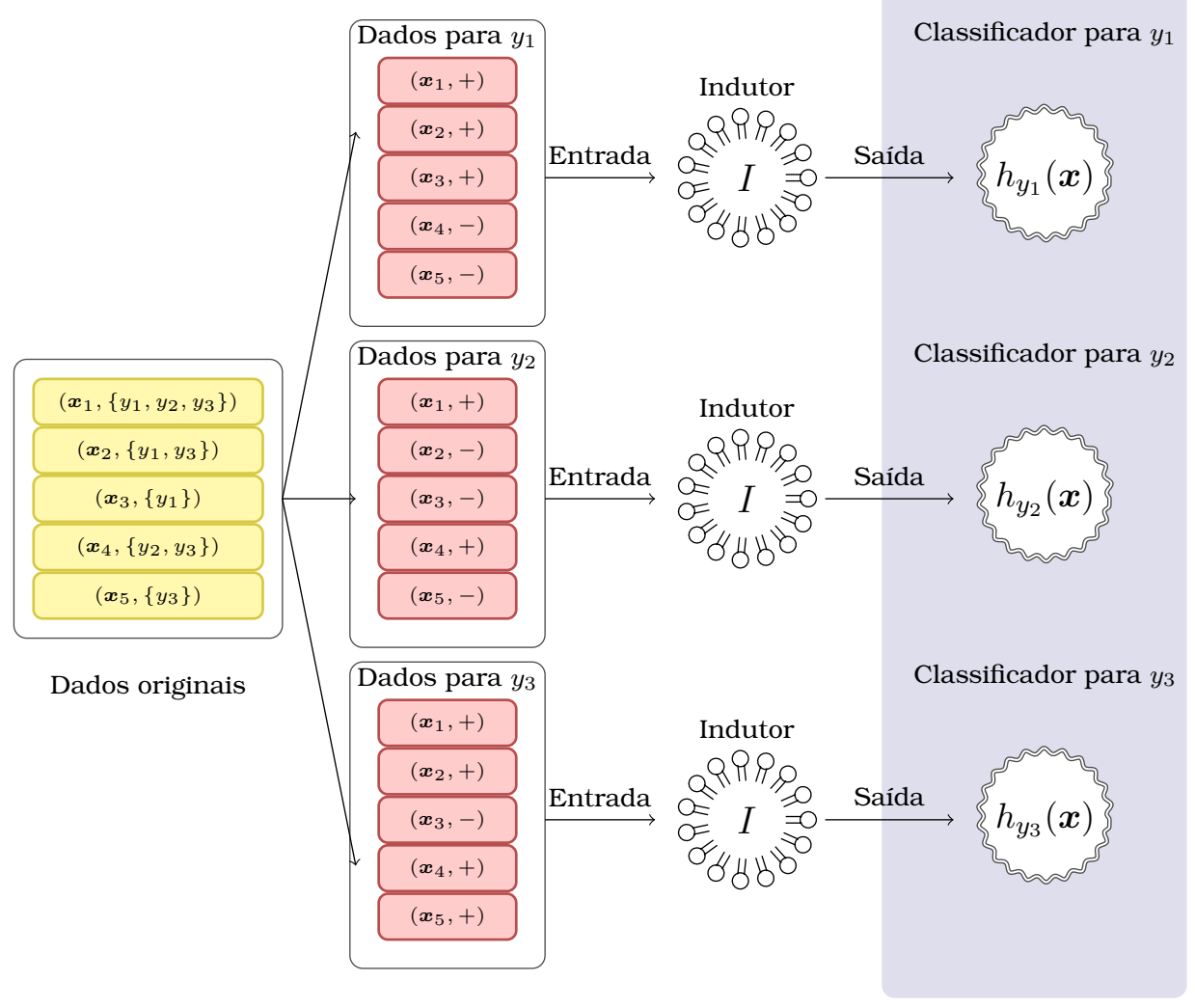

Figura 2.4: Construção do classificador multirrótulo BR.

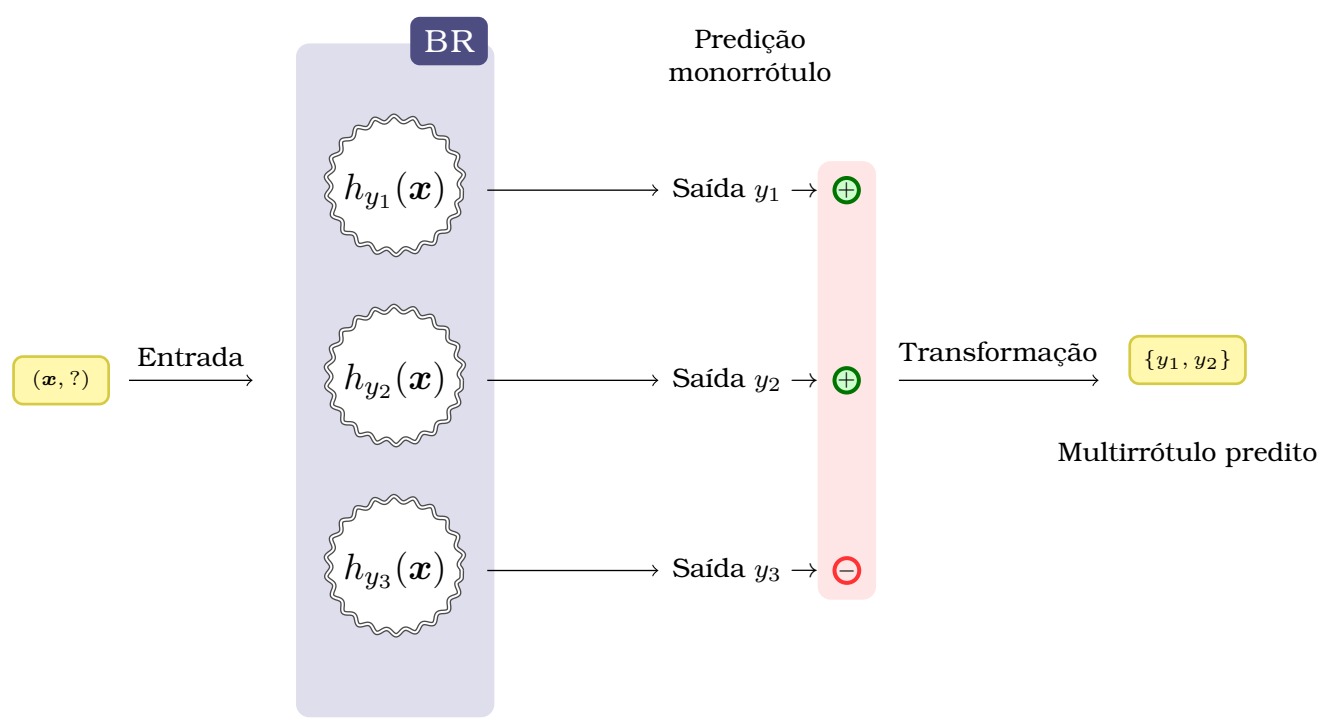

Figura 2.5: Predição do classificador multirrórulo BR. 
de dados. Além disso, a característica de independência entre os classificadores binários permite que todos os classificadores sejam construídos em paralelo, diminuindo ainda mais o tempo para a construção do modelo final.

Stacking A ideia básica dos métodos baseados em stacking é construir metaclassificadores que utilizam a saída de outros classificadores (base) como entrada para a sua predição. No contexto de classificação multirrótulo, os metaclassificadores são responsáveis por "corrigir" as predições iniciais dos classificadores base considerando as relações de dependência entre rótulos.

Em (Godbole \& Sarawagi, 2004) foi proposta uma extensão do método BR que usa o modelo de stacking para a construção de dois modelos de classificação em duas etapas, o modelo base (primeira etapa) e o metaclassificador (segunda etapa). Nessa proposta, chamada de Meta Stacking Classifier (MSC), é utilizado SVM como algoritmo de aprendizado para a construção dos classificadores binários, tanto no BR base quanto no metaclassificador BR. Na primeira etapa, os $q=|L|$ classificadores binários são construídos considerando o conjunto de exemplos de treinamento original. Na segunda etapa, um metaclassificador BR é construído, porém utilizando além dos atributos originais dos exemplos de treinamento, os monorrótulos do conjunto $L$ como atributos descritores adicionais, para os quais, os valores são obtidos por meio da predição do modelo base. Desse modo, esse algoritmo incrementa o espaço de atributos dos exemplos de treinamento para a construção do metaclassificador. Com os valores de todos os atributos, os originais e as estimativas iniciais dos monorrótulo, o metaclassificador é utilizado para a predição final, a qual é realizada de maneira análoga ao método BR tradicional.

O algoritmo proposto por Godbole \& Sarawagi (2004), apesar de incorporar a dependência de rótulos no processo de aprendizado, é restrito ao uso do SVM como algoritmo base de aprendizado. Além disso, na construção de cada classificador binário do metaclassificador, todos os atributos adicionais são utilizados. Esse fator pode levar ao overfitting do modelo, uma vez que a estimativa inicial do rótulo $y_{j}$ é utilizada como atributo descritor para a construção do classificador criado para predizer esse mesmo rótulo. Portanto, ao menos esse atributo deveria ser ignorado para a construção do classificador.

Como alternativa para minimizar essas limitações do método MSC, em (Cherman et al., 2010b) foi proposto o método BR+, no qual, de maneira análoga ao MSc, são criados dois modelos Binary Relevance, mas, nesse 


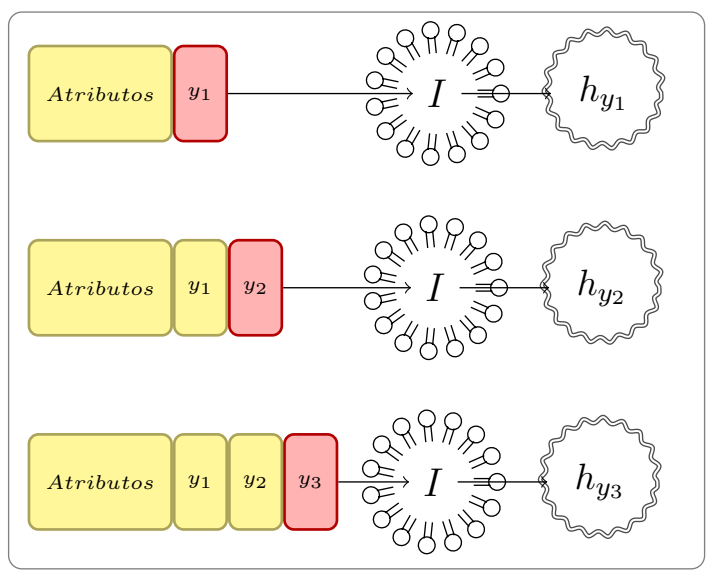

Vetores de atributos descritores Atributo classe

(a) Fase de treinamento

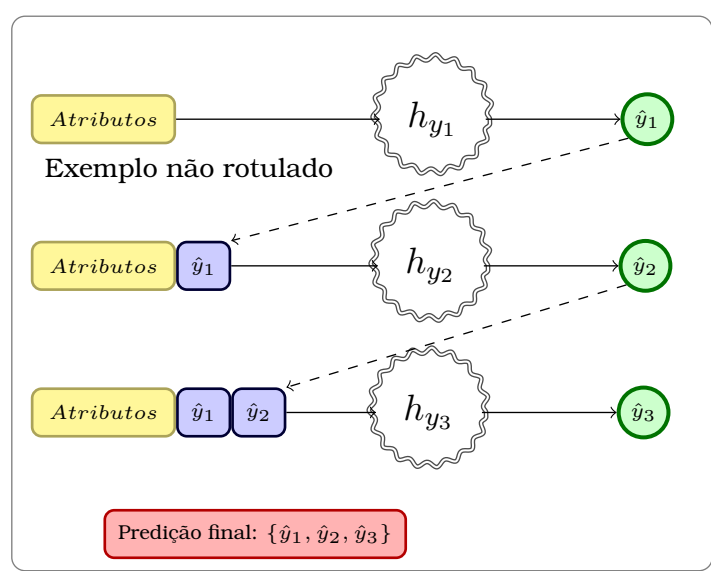

Vetor de atributos descritores originais Predição utilizada como novo atributo

(b) Fase de predição

Figura 2.6: Método Chaining.

caso, o conjunto de treinamento correspondente a cada classificador binário do metaclassificador não contém o rótulo a ser predito pelo respectivo classificador binário. Além disso, qualquer algoritmo de aprendizado pode ser utilizado para a construção dos classificadores binários.

Outro método também baseado em stacking, chamado Chaining Method, foi proposto por Read et al. (2009). Nesse método, metaclassificadores binários são construídos sequencialmente, de modo que a predição de todos os classificadores construídos anteriormente são utilizados como entrada para a construção do próximo metaclassificador. Para isso, um monorrótulo é selecionado aleatoriamente para a construção de um classificador binário, para o qual todos os outros monorrótulos em $L$ são ignorados e apenas os atributos descritores originais são utilizados como entrada. Em seguida, o primeiro metaclassificador é criado para predizer um outro monorrótulo selecionado aleatoriamente. Para a construção desse metaclassificador, o espaço de atributos dos exemplos é incrementado adicionando-se o monorrótulo correspondente ao classificador binário criado na etapa anterior. Na próxima etapa, outro metaclassificador é criado, agora considerando como atributos descritores os dois monorrótulos selecionados anteriormente para a construção dos classificadores binários. Esse processo é repetido até que tenham sido criados $q$ classificadores binários, um para cada monorrótulo em $L$. O funcionamento desse algoritmo é ilustrado na Figura 2.6. 


\subsubsection{Avaliação da classificação multirrótulo}

As medidas utilizadas para avaliação de algoritmos de classificação multirrótulo são semelhantes às medidas utilizadas para avaliar algoritmos monorrótulo. No entanto, enquanto na classificação monorrótulo existem apenas dois resultados possíveis para a avaliação da predição de um exemplo (classificado corretamente ou incorretamente), na classificação multirrótulo existem diferentes graus de erro (ou acerto) de classificação, uma vez que a avaliação é realizada comparando dois conjuntos de rótulos, dentre os quais um subconjunto pode estar correto e o restante incorreto para um mesmo exemplo. Assim, as medidas para classificação multirrótulo devem ser capazes de mensurar erros (ou acertos) parciais.

Para descrever as medidas propostas para a avaliação da classificação multirrótulo, considere um conjunto de exemplos multirrotulados $D$, composto por $N$ exemplos na forma $\left(\boldsymbol{x}_{i}, Y_{i}\right)$, com $i=1 \ldots N$ e $Y_{i} \subseteq L$ o conjunto de rótulos do $i$-ésimo exemplo. Considere $h$ um classificador multirrótulo que, dado um vetor de atributos $\boldsymbol{x}$, prediz um subconjunto de $L$, i.e., $h(\boldsymbol{x})=\hat{Y}$ e $\hat{Y} \subseteq L$ é o conjunto de classes preditas por $h$ para o exemplo $x$.

Grosso modo, existem dois tipos de medidas para essa tarefa: baseadas em exemplos e baseadas em rótulos. Essas medidas são descritas a seguir.

\subsubsection{Medidas baseadas em exemplos}

Uma vez que os multirrótulos são conjuntos de monorrótulos, é possível utilizar operações de conjuntos para avaliar a qualidade da predição. Em outras palavras, a comparação entre os multirrótulos verdadeiros e os preditos pode ser feita a partir de operações como intersecção e união entre conjuntos.

A intersecção dos multirrótulos verdadeiros e os preditos resulta nos rótulos corretamente preditos. Com base nessa informação, é possível calcular o grau de acurácia da predição do classificador $h$ em relação às predições realizadas sobre um conjunto de exemplos D, conforme a Equação 2.10.

$$
\operatorname{Acc}(h, D)=\frac{1}{N} \sum_{i=1}^{N} \frac{\left|Y_{i} \cap \hat{Y}_{i}\right|}{\left|Y_{i} \cup \hat{Y}_{i}\right|}
$$

De maneira análoga, a precisão e o recall também podem ser calculadas com base nessas operações. Essas medidas são definidas pelas Equações 2.11 e 2.12, respectivamente.

$$
\operatorname{Pr}(h, D)=\frac{1}{N} \sum_{i=1}^{N} \frac{\left|Y_{i} \cap \hat{Y}_{i}\right|}{\left|\hat{Y}_{i}\right|}
$$

A medida precisão considera apenas se os rótulos preditos realmente estão 
entre os rótulos que deveriam ser preditos. Caso todos estejam, não importando a quantidade, o valor de precisão é máximo.

$$
\operatorname{Re}(h, D)=\frac{1}{N} \sum_{i=1}^{N} \frac{\left|Y_{i} \cap \hat{Y}_{i}\right|}{\left|Y_{i}\right|}
$$

O recall, no entanto, considera a quantidade de rótulos preditos que estão contidos no conjunto de rótulos verdadeiros. Se todos os rótulos verdadeiros estiverem contidos no conjunto de rótulos preditos, não importando a existência de outros rótulos no conjunto predito, o valor de recall é máximo.

Na Equação 2.13 é definida a medida $f_{\beta} \operatorname{com}$ valor de $\beta=1$. É importante lembrar que a medida $f_{\beta}$ é uma média entre a precisão e o recall, na qual o valor de $\beta$ determina a qual das duas medidas é dado maior peso (ver Seção 2.2.2).

$$
f_{1}(h, D)=\frac{1}{N} \sum_{i=1}^{N} \frac{2\left|Y_{i} \cap \hat{Y}_{i}\right|}{\left|Y_{i}\right|+\left|\hat{Y}_{i}\right|}
$$

A medida Subset Accuracy, definida pela Equação 2.14, também é uma medida muito utilizada para a avaliação de classificadores multirrótulo. Ela é considerada uma medida bastante conservadora, pois requer que o conjunto de monorrótulos preditos seja exatamente igual ao conjunto de monorrótulos verdadeiros.

$$
\operatorname{SubsetAccuracy}(h, D)=\frac{1}{N} \sum_{i=1}^{N} I\left(\hat{Y}_{i}=Y_{i}\right)
$$

onde $I$ (verdadeiro $)=1$ e $I($ falso $)=0$.

Outra das medidas utilizadas para a avaliação de classificador multirrótulo, definida pela Equação 2.15, é chamada de Hamming Loss (Tsoumakas \& Katakis, 2007). Essa medida representa a diferença simétrica $(\Delta)$ entre dois conjuntos de rótulos, i.e., $Y_{i} \Delta \hat{Y}_{i}=\left(Y_{i} \cup \hat{Y}_{i}\right)-\left(Y_{i} \cap \hat{Y}_{i}\right)$. Como essa é uma medida de erro, cujos valores variam entre 0 e 1 (inclusive), quanto mais próxima de zero, melhor é a performance do classificador.

$$
H \operatorname{Loss}(h, D)=\frac{1}{N} \sum_{i=1}^{N} \frac{\left|Y_{i} \Delta \hat{Y}_{i}\right|}{|L|}
$$

\subsubsection{Medidas baseadas em rótulos}

Qualquer medida utilizada para avaliar classificadores binários monorrótulo, discutidas na Seção 2.2.2 na página 12, pode ser utilizada nessa abordagem. A ideia é calcular um valor médio de performance global para uma determinada medida com base nas informações de cada monorrótulo presente 
em $L$. Desse modo, considerando todas as predições realizadas para um conjunto de exemplos, constrói-se uma matriz de confusão para cada rótulo, as quais são preenchidas com valores de verdadeiros positivos, verdadeiros negativos, falsos positivos e falsos negativos. Cada predição multirrótulo afeta as diferentes matrizes de maneira distinta.

Considere como exemplo para a construção das matrizes de confusão os dados na Tabela 2.5, onde $L=\left\{y_{1}, y_{2}, y_{3}\right\}, Y_{i}$ é o conjunto de rótulos verdadeiros e $\hat{Y}_{i}$ é o conjunto de rótulos preditos.

Tabela 2.5: Exemplo de predição multirrótulo.

\begin{tabular}{|c|c|c|}
\hline Exemplo & $\overline{Y_{i}}$ & $\overline{\hat{Y}_{i}}$ \\
\hline$E_{1}$ & $Y_{1}=\left\{y_{1}, y_{2}, y_{3}\right\}$ & $\bar{Y}_{1}=\left\{y_{1}\right\}$ \\
\hline$E_{2}$ & $Y_{2}=\left\{y_{1}, y_{3}\right\}$ & $\hat{Y}_{2}=\left\{y_{1}, y_{2}\right\}$ \\
\hline$E_{3}$ & $Y_{3}=\left\{y_{1}\right\}$ & $\hat{Y}_{3}=\left\{y_{1}\right\}$ \\
\hline$E_{4}$ & $Y_{4}=\left\{y_{2}, y_{3}\right\}$ & $\hat{Y}_{4}=\left\{y_{2}, y_{3}\right\}$ \\
\hline$E_{5}$ & $Y_{5}=\left\{y_{3}\right\}$ & $\hat{Y}_{5}=\left\{y_{1}, y_{3}\right\}$ \\
\hline
\end{tabular}

Por exemplo, a matriz de confusão referente ao rótulo $y_{1}$ resulta em:

- $V_{P}=3$, pois $y_{1}$ é predito corretamente como positivo para os exemplos $E_{1}$, $E_{2}$ e $E_{3}$;

- $F_{P}=1$, pois $E_{5}$ é predito erroneamente como positivo para $y_{1}$; e

- $V_{N}=1$, pois $E_{4}$ é predito corretamente como negativo.

De maneira semelhante são calculadas as matrizes de confusão para os rótulos $y_{2}$ e $y_{3}$, apresentadas na Tabela 2.6.

Tabela 2.6: Matrizes de confusão da predição da Tabela 2.5.
(a) Rótulo $y_{1}$
(b) Rótulo $y_{2}$
(c) Rótulo $y_{3}$

\begin{tabular}{|c|c|}
\hline 3 & 0 \\
\hline$V_{P}$ & $\stackrel{F_{N}}{ }$ \\
\hline 1 & 1 \\
$F_{P}$ & $V_{N}$ \\
\hline
\end{tabular}

\begin{tabular}{|c|c|}
\hline 1 & 1 \\
$V_{P}$ & $F_{N}$ \\
\hline 1 & 2 \\
$F_{P}$ & $V_{N}$ \\
\hline
\end{tabular}

\begin{tabular}{|c|c|}
\hline 2 & 2 \\
\hline$V_{P}$ & $\stackrel{2}{F_{N}}$ \\
\hline 0 & 1 \\
\hline$F_{P}$ & $V_{N}$ \\
\hline
\end{tabular}

Para obter uma medida de performance global do classificador multirrótulo é necessário primeiramente calcular os valores de precisão e recall locais a partir de cada matriz de confusão e, com essas medidas locais, calcular médias micro e macro, as quais são definidas nas Equações 2.16 a 2.19, respectivamente.

$$
\begin{aligned}
\operatorname{Pr}^{\mu} & =\frac{\sum_{y_{j} \in L} V_{P_{y_{j}}}}{\sum_{y_{j} \in L}\left(V_{P_{y_{j}}}+F_{P_{y_{j}}}\right)} \\
R e^{\mu} & =\frac{\sum_{y_{j} \in L} V_{P_{y_{j}}}}{\sum_{y_{j} \in L}\left(V_{P_{y_{j}}}+F_{N_{y_{j}}}\right)}
\end{aligned}
$$




$$
\begin{aligned}
& \operatorname{Pr}^{M}=\frac{1}{|L|} \times \sum_{y_{j} \in L} P r_{y_{j}} \\
& R e^{M}=\frac{1}{|L|} \times \sum_{y_{j} \in L} R e_{y_{j}}
\end{aligned}
$$

A Equação 2.20 define a média micro entre as medidas $P r^{\mu}$ e $R e^{\mu}$, na qual o parâmetro $\beta$ define o peso dado a cada uma das medidas. $\operatorname{Com} \beta=1, \operatorname{Pr}^{\mu}$ e $R e^{\mu}$ recebem o mesmo peso.

$$
f_{\beta}^{\mu}=\left(1+\beta^{2}\right) \times \frac{\operatorname{Pr}^{\mu} \times R e^{\mu}}{\beta^{2} \times P r^{\mu}+R e^{\mu}}
$$

As Equações 2.21 e 2.22 definem, respectivamente, uma maneira genérica para representar o cálculo das médias micro e macro para qualquer medida de performance $B$ que possa ser calculada a partir de uma matriz de confusão (Tsoumakas et al., 2010).

$$
\begin{gathered}
B_{\text {micro }}=B\left(\sum_{i=1}^{q} V_{P_{y_{i}}}, \sum_{i=1}^{q} F_{P_{y_{i}}}, \sum_{i=1}^{q} V_{N_{y_{i}}}, \sum_{i=1}^{q} F_{N_{y_{i}}}\right) \\
B_{\text {macro }}=\frac{1}{q} \sum_{i=1}^{q} B\left(V_{P_{y_{i}}}, F_{P_{y_{i}}}, V_{N_{y_{i}}}, F_{N_{y_{i}}}\right)
\end{gathered}
$$

\subsection{Considerações finais}

Neste capítulo foram apresentados alguns conceitos sobre aprendizado de máquina relacionados à classificação plana monorrótulo e multirrótulo. Além disso, foram apresentadas a notação utilizada para descrever os exemplos e as principais medidas de avaliação comumente utilizadas em ambos os contextos. Foram também descritos três grupos de métodos propostos para a classificação multirrótulo, mais especificamente os métodos LP, BR e Stacking.

No entanto, existem tarefas de classificação ainda mais complexas, nas quais as classes associadas a cada exemplo fazem parte de uma estrutura hierárquica com diversos níveis de especificidade. Esse tipo de tarefa, apresentada no próximo capítulo, é chamada de classificação hierárquica. 


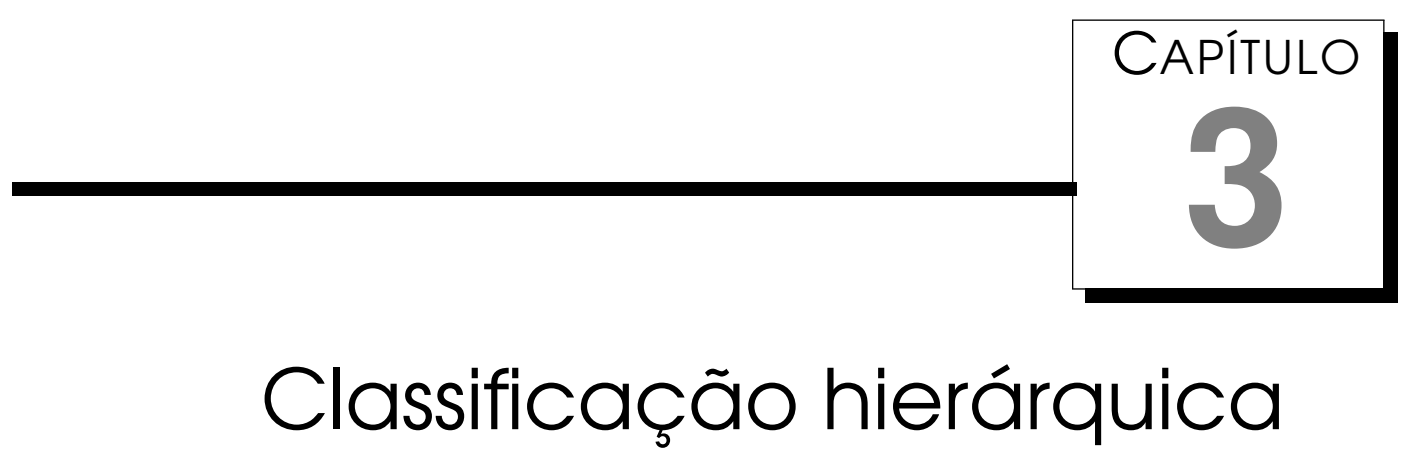

Em aprendizado de máquina e mineração de dados, a maior parte dos trabalhos relacionados ao tema de classificação envolvem problemas de classificação plana, nos quais cada exemplo pode ser classificado como monorrótulo ou multirrótulo, sem que exista qualquer relacionamento hierárquico ou estrutural entre as diferentes classes do problema. No primeiro caso, cada exemplo está associado a apenas um rótulo, ao passo que na classificação plana multirrótulo mais de um rótulo pode ser atribuído a cada exemplo.

No entanto, existem problemas de classificação mais complexos para os quais o conceito meta (classes) faz parte de uma hierarquia (Freitas \& de Carvalho, 2007), como a tarefa de sequenciamento de proteínas do MIPS (Munich Information Centre for Protein Sequences) ${ }^{1}$, cujas classes são organizadas em uma taxonomia na qual o nível mais geral consiste das classes metabolismo, energia, transcrição e síntese de proteínas. Cada uma dessas classes é subdividida em outras classes mais específicas, as quais, por sua vez, são novamente subdivididas, e assim sucessivamente até que a hierarquia complete 4 niveis (Clare \& King, 2001). Outro exemplo, chamado de catálogo funcional (FunCat - Functional Catalogue) (Ruepp et al., 2004), é um esquema de anotação da descrição funcional de proteínas de diversos organismos vivos. Suas 1362 categorias funcionais, na versão 2.1 do FunCat, são organizadas em uma estrutura de árvore com até 6 níveis de especificidade.

Conjuntos de dados hierárquicos para mineração de textos também estão disponíveis. O MeSH (Lipscomb, 2000), por exemplo, com descrições de artigos médicos e o conjunto da $\mathrm{ACM}^{2}$ com artigos relacionados a Ciências da Com-

\footnotetext{
${ }^{1}$ http://mips.gsf.de/

${ }^{2}$ http: //www.acm.org/
} 
putação. Além desses, o Dmoz Open Directory ${ }^{3}$ mantém uma hierarquia de classes conceituais para classificação de páginas web, as quais podem ser rotuladas com mais de uma classe em diferentes niveis da hierarquia.

Para esses casos, métodos de classificação plana são ineficazes, pois não são capazes de utilizar as informações de relacionamentos e dependências latentes à hierarquia de classes. Consequentemente, faz-se necessária a elaboração de outros métodos e algoritmos que sejam capazes de utilizar essa informação para a construção de modelos de classificação mais adequados e eficazes para a predição das classes de novos exemplos desse domínio. Essa abordagem de classificação tem recebido bastante atenção nos últimos anos e é um importante tema de pesquisa.

O restante deste capítulo está organizado da seguinte maneira: na Seção 3.1 são descritas as diferenças entre a classificação plana e a classificação hierárquica. Na Seção 3.2 são apresentados conceitos relacionados a diversos aspectos da classificação hierárquica, como a estrutura dos dados para esse tipo de tarefa e as estratégias de predição de novos exemplos. Na Seção 3.3 são apresentadas as medidas de avaliação utilizadas especificamente para a classificação hierárquica.

\subsection{Classificação plana versus hierárquica}

A principal diferença entre os métodos de classificação plana e de classificação hierárquica é a maneira como as classes do problema estão organizadas. No caso de classificação plana, em geral não existe um interrelacionamento direto entre as classes (monorrótulo), ou quando há algum tipo de relacionamento (multirrótulo), esse relacionamento não representa relações de super ou subclasse. Na classificação hierárquica, por outro lado, uma determinada classe pode ser a super classe de um subconjunto de classes, constituindo assim relação de generalização e especialização entre classes e uma estrutura hierárquica com diversos níveis de especificidade ou generalidade.

Na Figura 3.1 é ilustrada a diferença entre os dois tipos de classificação. Observe que na Figura 3.1(a) os rótulos são apresentados sem qualquer relacionamento, ao passo que na Figura 3.1(b) arestas que conectam pares de classes representam as relações estruturais. Os nós mais próximos da raiz da hierarquia representam classes mais gerais e os nós mais próximos das folhas representam classes mais específicas. Neste trabalho usaremos os termos raso e profundo como referência à profundidade dos nós na taxonomia de classes. Assim, quanto mais geral for a classe, mais raso será o nó, e quanto mais específica for a classe, mais profundo será o nó.

\footnotetext{
$3_{\text {http: } / / \text { www. dmoz.org/ }}$
} 


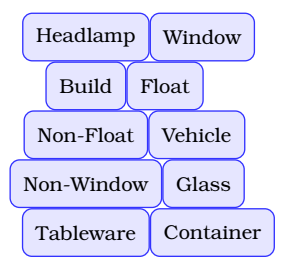

(a) Classes sem qualquer tipo de organização estrutural

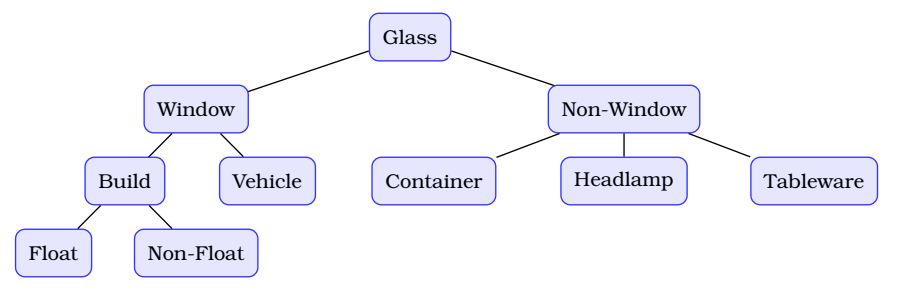

(b) Classes hierarquicamente organizadas

Figura 3.1: Representação do conjunto de classes.

Conjuntos de dados para classificação hierárquica são usualmente representados de maneira semelhante aos conjuntos de exemplos para classificação plana monorrótulo e multirrótulo, por meio da tabela atributo-valor. No entanto, na classificação hierárquica, $Y_{i}$ é o conjunto de rótulos associados ao exemplo $E_{i}$ para os quais existem relacionamentos de especialização e generalização entre os rótulos válidos de acordo com uma estrutura de classes previamente especificada (taxonomia de classes).

Considere como exemplo um conjunto de dados correspondente à classificação de exemplos em diferentes tipos de vidros, cuja hierarquia de classes corresponde à apresentada na Figura 3.1(b). Esse conjunto de dados está parcialmente representado na Tabela 3.1 e será utilizado para ilustrações apresentadas nesse trabalho.

Tabela 3.1: Exemplos de classificação hierárquica no formato atributo-valor.

\begin{tabular}{|c|c|c|c|c|c|}
\hline Exemplo & $X_{1}$ & $X_{2}$ & $\bar{c}$ & $X_{M}$ & $\overline{Y Y}$ \\
\hline$E_{1}$ & $x_{11}$ & $x_{12}$ & $\ldots$ & $x_{1 M}$ & Glass $\rightarrow$ Window $\rightarrow$ Vehicle \\
\hline$E_{2}$ & $x_{21}$ & $x_{22}$ & $\ldots$ & $x_{2 M}$ & Glass $\rightarrow$ Non-Window $\rightarrow$ Container \\
\hline$E_{3}$ & $x_{31}$ & $x_{32}$ & $\ldots$ & $x_{3 M}$ & Glass $\rightarrow$ Non-Window $\rightarrow$ Headlamp \\
\hline$E_{4}$ & $x_{41}$ & $x_{42}$ & $\cdots$ & $x_{4 M}$ & Glass $\rightarrow$ Window $\rightarrow$ Build \\
\hline$\vdots$ & : & : & $\ddots$ & : & $\vdots$ \\
\hline$E_{N}$ & $x_{N 1}$ & $x_{N 2}$ & $\ldots$ & $x_{N M}$ & Glass $\rightarrow$ Window $\rightarrow$ Build $\rightarrow$ Float \\
\hline
\end{tabular}




\subsection{Fundamentos e definições para classificação hie- rárquica}

Em alguns problemas de classificação hierárquica podem existir exemplos que tenham mais de um rótulo associado em cada nível da hierarquia de classes. Nesses casos, o termo usualmente utilizado na literatura para referenciar esse tipo de tarefa é classificação hierárquica multirrótulo. Entretanto, esse nomenclatura pode gerar confusão uma vez que a classificação hierárquica, conforme mencionado anteriormente, é um tipo especial de classificação multirrótulo. Por esse motivo, neste trabalho preferimos denominar essa tarefa como classificação hierárquica com múltiplos ramos de classificação. Por outro lado, se cada exemplo pode estar associado a apenas um ramo da taxonomia de classes, e consequentemente a apenas rótulo em cada nível da hierarquia, o problema é denominado classificação hierárquica com apenas um ramo de classificação. Os métodos descritos e propostos neste trabalho foram propostos para solucionar esse tipo de problema. Desse modo, neste trabalho utilizaremos o termo classificação hierárquica como referência à tarefa na qual apenas um ramo da taxonomia de classes pode estar associado a cada exemplo. Nos casos em que for necessária a distinção entre as duas tarefas, a nomenclatura específica será utilizada.

A organização das classes de maneira hierárquica implica que um exemplo não pode estar associado a uma classe $y_{j}$ qualquer sem que esteja também associado com às classes ancestrais de $y_{j}$. Além disso, o conjunto de rótulos associados a cada exemplo deve formar um caminho com origem no nó raiz da hierarquia terminando no nó que representa a classe mais específica associada ao exemplo.

Desse modo, dada uma hierarquia de classes pré-definida, uma maneira bastante simples para construir um classificador hierárquico é transformar a tarefa em um ou mais problemas de classificação plana, construindo um ou mais classificadores planos em cada nível da hierarquia de classes. Na rotulação de um novo exemplo, esses classificadores são acionados seguindo uma abordagem do topo para baixo, top-down, e restringindo a classificação em cada nível somente entre os classificadores filhos da classe que foi predita no nível anterior.

Outros métodos foram propostos para solucionar o problema de classificação hierárquica, alguns deles apresentados nas próximas seções, os quais podem ser categorizados considerando diversos aspectos (Silla Jr \& Freitas, 2011; Freitas \& de Carvalho, 2007; Sun \& Lim, 2001), como:

a) a estrutura de dados utilizada para representar a hierarquia de classes e suas interrelações; 
b) as restrições de nível para classificação; e

c) as estratégias para o uso da informação/estrutura hierárquica de classes.

Esses aspectos são descritos em maiores detalhes a seguir.

\subsubsection{Estrutura de representação da hierarquia de classes}

A hierarquia de classes é representada usualmente por meio de estruturas de dados de árvores ou de grafos direcionados e acíclicos (DAG - Directed Acyclic Graph), ilustradas na Figura 3.2. Em ambos os casos, os nós representam as classes a serem preditas, enquanto que as arestas representam a relação de generalização e especialização das classes.

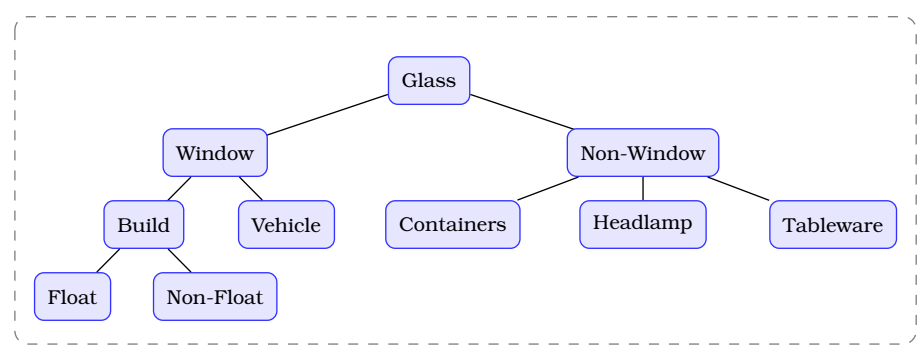

(a) Árvore

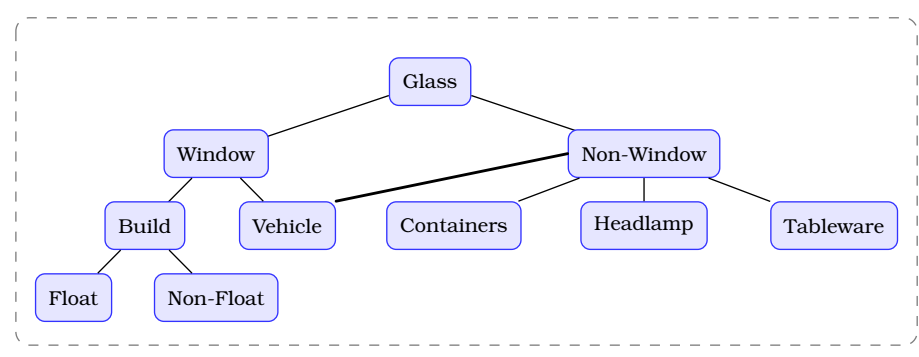

(b) Grafo

Figura 3.2: Estrutura de representação da hierarquia de classes.

Neste trabalho restringimos o uso da representação a estruturas de árvores. Desse modo, a taxonomia de classes pode ser definida como uma árvore estruturada sobre um conjunto parcialmente ordenado $(L, \prec)$, onde $L$ é um conjunto finito composto por todas as classes presentes na taxonomia e $\prec$ representa a relação é uma (is-a) assimétrica, antirreflexiva e transitiva (Silla Jr \& Freitas, 2011; Wu et al., 2005). Essas propriedades são definidas a seguir:

- existe apenas uma classe ou nó chamado raiz da árvore e todas as outras classes são descendentes desta;

- assimétrica: $\forall y_{i}, y_{j} \in L, y_{i} \prec y_{j} \rightarrow y_{j} \nprec y_{i}$; 
- antirreflexiva: $\forall y_{i} \in L, y_{i} \nprec y_{i}$; e

- transitiva: $\forall y_{i}, y_{j}, y_{k} \in L,\left(y_{i} \prec y_{j}\right) \wedge\left(y_{j} \prec y_{k}\right) \rightarrow\left(y_{i} \prec y_{k}\right)$.

Além disso, existem relações entre nós em diferentes níveis da hierarquia, que são representadas por meio dos seguintes operadores:

- $\uparrow y_{j}:$ classe mãe da classe $y_{j}$;

- $y_{j}$ : conjunto de classes ancestrais da classe $y_{j}$;

- $\leftrightarrow y_{j}$ : conjunto de classes irmãs da classe $y_{j}$;

- $\downarrow y_{j}$ : conjunto de classes filhas de $y_{j}$; e

- $\Downarrow y_{j}$ : conjunto de classes descendentes da classe $y_{j}$, ou seja, todas as classes presentes na subárvore cuja raiz é $y_{j}$, exceto $y_{j}$.

É importante, também, distinguir exemplos explicitamente e implicitamente rotulados:

- explicitamente rotulado: quando um exemplo está explicitamente rotulado com a classe $y_{j}$, significa que $y_{j}$ é a classe mais específica (mais profunda) de todas as classes associadas a esse exemplo. As outras classes associadas a esse exemplo fazem parte do conjunto $\Uparrow y_{j}$. Utilizaremos a notação $\circledast\left(E_{i}\right)=y_{j}$ sempre que for necessário dizer que o exemplo $E_{i}$ está explicitamente rotulado com a classe $y_{j}$; e

- implicitamente rotulado: caso a classe $y_{j}$ não seja a classe mais específica associada ao exemplo $E_{i}$, tal que $\circledast\left(E_{i}\right)=y_{k}$ e $y_{k} \in\left\{\Downarrow y_{j}\right\}$, considera-se que esse exemplo está implicitamente rotulado com a classe $y_{j}$. Em outras palavras, a classe mais específica do exemplo $E_{i}$ é descendente da classe $y_{j}$. Nesse caso, a notação $\odot\left(E_{i}\right)$ é utilizada como referência à classificação implícita do exemplo $E_{i}$ e, dessa maneira, representa o conjunto de classes associadas ao exemplo $E_{i}$ exceto a classe mais específica desse exemplo.

Para facilitar a visualização das imagens relacionadas ao conjunto de exemplos utilizados para apresentar os algoritmos e heurísticas tratados neste trabalho, a partir deste ponto utilizaremos apenas a primeira letra de cada rótulo (nome da classe) para identificar os nós da taxonomia referente aos diferentes tipos de vidro. Além disso, para evitar ambiguidade como nos casos de Window e Non-Window, ou Float e Non-Float, a letra N será utilizada como prefixo. Assim, a taxonomia apresentada na Figura 3.2(a) é representada pelo conjunto de rótulos $L=\{\mathrm{G}, \mathrm{W}, \mathrm{B}, \mathrm{F}, \mathrm{NF}, \mathrm{V}, \mathrm{NW}, \mathrm{C}, \mathrm{H}, \mathrm{T}\}$. 


\subsubsection{Restrição no nível de classificação}

Os métodos de classificação hierárquica diferenciam-se, também, pela maneira como a predição de um novo exemplo é obtida. São duas estratégias:

1. a classe mais específica é obrigatoriamente uma classe folha; e

2. a classe mais específica pode ser uma classe interna da taxonomia.

Muitas vezes a escolha de como é feita a classificação com relação a esse quesito (obrigatoriamente até as folhas ou não) depende das características do conjunto de dados.

Essas duas abordagens são definidas em (Sun et al., 2003a) e são nomeadas, respectivamente, árvore (ou grafo) virtual de categoria 4 e árvore (ou grafo) real de categoria ${ }^{5}$. No entanto, neste trabalho usaremos a nomenclatura proposta em (Freitas \& de Carvalho, 2007), na qual os termos utilizados são, respectivamente, predição obrigatória nos nós-folha (MLN - Mandatory Leaf Node Prediction) e predição opcional nos nós-folha (NMLN - Non-mandatory Leaf Node Prediction). Na Figura 3.3 é ilustrada a diferença entre as duas estratégias para predição.

Para o caso MLN, ilustrado na Figura 3.3(a), o exemplo foi classificado no primeiro nível como classe $\mathrm{w}$, no segundo nível como classe $\mathrm{B}$ e, finalmente, no terceiro nível como classe $\mathrm{NF}$, a qual é representada por um nó folha na hierarquia de classes. No caso NMLN, a classe predita mais específica é B, sendo que no nível anterior a classe $\mathrm{w}$ foi predita. Observe que nesse caso nenhuma das classes, F ou NF foi predita.

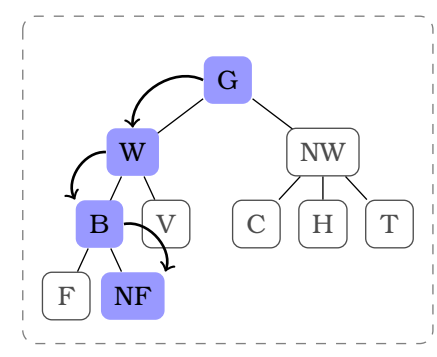

(a) MLN

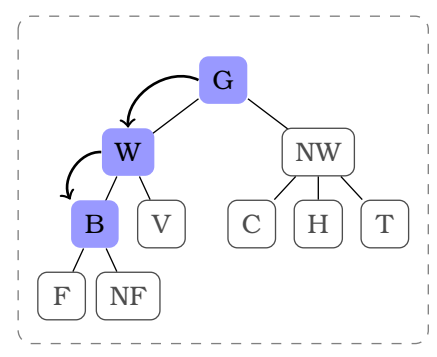

(b) NMLN

Figura 3.3: Tipos de predição.

É importante mencionar que predições feitas nos nós internos são, em geral, mais confiáveis que as predições nos nós folha. Esse comportamento é devido à maior especificidade das classes folha e, também, devido ao menor

\footnotetext{
${ }^{4}$ Virtual category tree (or DAG).

${ }^{5}$ Real category tree (or DAG).
} 
número de exemplos associados a estas classes em comparação com as classes internas na hierarquia. Por outro lado, a predição nas classes folha são em geral mais úteis para o usuário (Freitas \& de Carvalho, 2007).

\subsubsection{Uso da estrutura de classes}

O terceiro critério utilizado para diferenciar os métodos de classificação hierárquica é a maneira como a estrutura hierárquica é utilizada para a construção do classificador e para a classificação de novos exemplos:

- plana (nä̈ve);

- global; e

- local.

As três abordagens são descritas a seguir.

\subsubsection{Abordagem plana}

Uma maneira simples para resolver o problema de classificação hierárquica é transformá-lo em um problema de classificação plana monorrótulo e, então, aplicar algum dos diversos algoritmos disponíveis para essa tarefa.

Essa abordagem, referenciada como abordagem direta (Direct Approach) por Burred \& Lerch (2003) e global por Xiao et al. (2007), ignora completamente a estrutura hierárquica do problema durante o treinamento, construindo um modelo de classificação que considera apenas as classes folha da hierarquia, conforme ilustrado na Figura 3.4. Com a classe predita por meio desse modelo, obtêm-se as classes ancestrais seguindo o caminho a partir da classe predita até a raiz da estrutura hierárquica.

É importante lembrar que o termo global utilizado por Xiao et al. (2007) não deve ser confundido com o sentido de "global" em classificação verdadeiramente hierárquica, como discutido posteriormente na Seção 3.2.3.2.

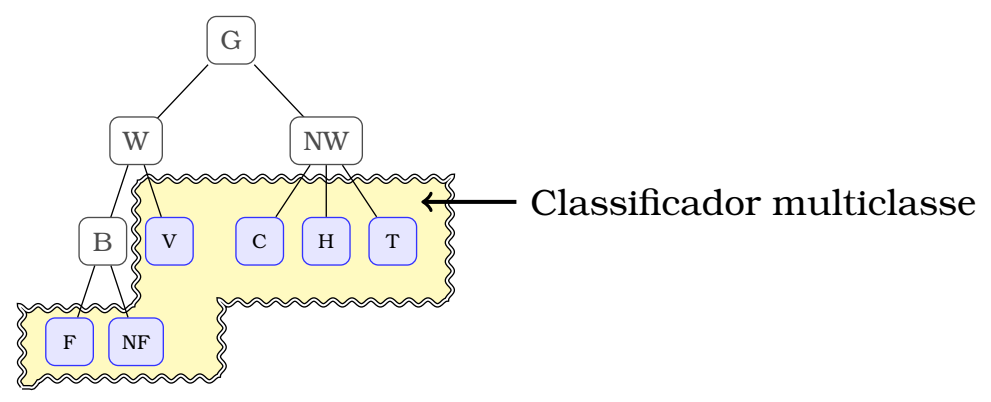

Figura 3.4: Classificação hierárquica transformada em um problema de classificação plana multiclasse. 
Observe que nessa abordagem a estrutura hierárquica é sempre virtual, i.e., a classe mais específica da predição dada a cada novo exemplo é obrigatoriamente um nó folha. Barbedo \& Lopes (2007) utilizaram o termo bottom-up para descrever essa abordagem, uma vez que um novo exemplo é classificado inicialmente de acordo com as classes folhas e as classes correspondentes aos nós internos da hierarquia são consequências dessa classificação inicial, seguindo uma abordagem de baixo para cima para a identificação das classes intermediárias (implicitamente anotadas).

Como desvantagem dessa abordagem, observa-se o fato de não considerar as informações das relações entre as classes da hierarquia e, ainda assim, ter que discriminar entre um grande número de classes (todas as classes folha).

Utilizando essa abordagem, não há distinção entre o treinamento e teste da classificação hierárquica e a classificação plana monorrótulo. A única diferença é a maneira como a predição do modelo é utilizada, uma vez que infere-se indiretamente o conjunto de classes ancestrais a partir da classe predita.

\subsubsection{Abordagem global}

Nessa abordagem, também conhecida como Big-bang, um único classificador é induzido e é capaz de rotular novos exemplos considerando toda a hierarquia de classes. O modelo construído por um algoritmo global é geralmente mais complexo que o gerado por outras abordagens. No entanto, apenas um modelo é gerado, enquanto que em outras abordagens diversos modelos são construídos (ver abordagem local na Seção 3.2.3.3 na próxima página). Além disso, as dependências entre as diferentes classes da hierarquia, como as relações de generalização/especialização, são consideradas de maneira natural no processo de construção do modelo de classificação global (Blockeel et al., 2002).

Em (Clare, 2003) foi proposto um algoritmo global de classificação hierárquica baseado no algoritmo $\mathcal{C} 4.5$, inicialmente projetado para classificação monorrótulo plana. A principal modificação realizada no algoritmo original, que resultou no algoritmo o proposto por (Clare, 2003), está na maneira como a entropia é calculada, uma vez que no caso hierárquico o cálculo deve ser feito considerando a taxonomia de classes. Desse modo, a função modificada para o cálculo da entropia é definida na Equação 3.1, onde $p\left(y_{j}\right)$ é a frequência relativa da classe $y_{j}, q\left(y_{j}\right)=1-p\left(y_{j}\right)$, treesize $\left(y_{j}\right)=1+$ número de classes descendentes e $\alpha\left(y_{j}\right)=0$ se $p\left(y_{j}\right)=0$ ou um valor constante pré-definido caso $p\left(y_{j}\right) \neq 0$.

O valor de $\alpha$ determina o peso dado para a segunda parte da equação $\left(\alpha\left(y_{j}\right) \times \log\right.$ treesize $\left.\left(y_{j}\right)\right)$, que representa o grau de especialização da classifi- 
cação. Quando $\alpha=1$, as duas partes da equação recebem o mesmo peso, ao passo que para $\alpha>1$, significa que classes mais específicas devem ser favorecidas na predição. Para casos nos quais o interesse está em classes mais gerais, valores menores que 1 devem ser especificados para $\alpha$.

$$
\text { Entropia }=-\sum_{j=1}^{|L|}\left(\left(p\left(y_{j}\right) \times \log p\left(y_{j}\right)\right)+\left(q\left(y_{j}\right) \times \log q\left(y_{j}\right)\right)-\alpha\left(y_{j}\right) \times \log \operatorname{treesize}\left(y_{j}\right)\right)
$$

No que se refere à diferenciação entre métodos globais e não globais para classificação hierárquica, existe ainda a necessidade de uma definição mais clara, uma vez que não existe um consenso da comunidade científica a esse respeito. Segundo Silla Jr \& Freitas (2011), essa distinção é feita usualmente por meio do critério de exclusão. Assim, qualquer algoritmo que não pertencer às abordagens plana ou local, é classificado como global. Além disso, os autores afirmam que embora aparentemente não existam características específicas que sejam compartilhadas por todos os algoritmos de classificação hierárquica global, em geral, esses algoritmos possuem duas características principais: (1) consideram toda a hierarquia de classes durante o treinamento do classificador; e (2) não há qualquer tipo de modularidade ou uso de informação local, como na abordagem local.

Por outro lado, é possivel considerar que a principal diferença entre a abordagem global e as outras abordagens está relacionada à fase de treinamento, pois, como mencionado anteriormente, algoritmos globais consideram todas as relações estruturais da hierarquia de classes durante a fase de treinamento. Já durante o teste de novos exemplos, mesmo algoritmos globais podem fazer uso de estratégias de predição que não sejam globais, por exemplo a estratégia de predição top-down, descrita na Seção 3.2.3.4.

Outra característica marcante dessa abordagem é a pouca quantidade de trabalhos publicados em relação à abordagem local. Um fator determinante talvez seja a complexidade para a elaboração de algoritmos globais. Ainda assim, alguns algoritmos foram propostos, como os apresentados em (Cai \& Hofmann, 2007; Vens et al., 2008; Qiu et al., 2009; Wang et al., 2009).

\subsubsection{Abordagem local}

Assim como a abordagem plana, a abordagem local também transforma o problema de classificação hierárquica em problemas mais simples e modulares para os quais já existem soluções amplamente testadas e validadas. Contudo, ao contrário da abordagem plana, nesta abordagem a estrutura hierárquica das classes não é completamente ignorada, uma vez que, além das classes folha, as outras classes também são utilizadas nas fases de treina- 
mento e teste.

Nessa abordagem, um ou mais classificadores independentes são construídos em cada nível da hierarquia de classes utilizando apenas a informação local da taxonomia e do conjunto de exemplos de treinamento, como o conjunto de exemplos associados à classe que o classificador representa. Além disso, cada classificador local "não tem conhecimento" da existência dos outros classificadores locais.

A característica modular dessa abordagem é utilizada tanto na construção dos classificadores locais como na fase de classificação de novos exemplos, na qual, aplicando-se uma estratégia de predição top-down (ver Seção 3.2.3.4), a classificação de um exemplo em um determinado nível pode guiar a predição no nivel seguinte. Em outras palavras, cada exemplo é apresentado apenas aos classificadores filhos da classe a qual foi associado em um nivel anterior.

Em termos de nomenclatura, essa abordagem tem sido amplamente referenciada na literatura como abordagem top-down (Mladenić \& Grobelnik, 1998; Sun \& Lim, 2001; Sun et al., 2003b, 2004; Tikk et al., 2004; Barutcuoglu et al., 2006; Secker et al., 2007, 2010). Contudo, alguns autores consideram o termo top-down mais apropriado para a definição da estratégia de predição que é realizada nível a nível a partir da raiz até as folhas (Freitas \& de Carvalho, 2007; Silla Jr \& Freitas, 2011; Metz \& Freitas, 2009), uma vez que o termo top-down descreve basicamente como os classificadores locais são utilizados para classificar novos exemplos. Nesse sentido, neste trabalho o termo local é utilizado como referência a essa abordagem para construção de classificadores hierárquicos.

São basicamente três os métodos utilizados para a construção dos classificadores locais:

1. construir um classificador binário para cada classe da hierarquia (exceto o nó raiz) - Figura 3.5. Neste trabalho utilizaremos o termo Hierarchical Binary Relevance (HBR) como referência a esse método, conforme proposto por Tsoumakas et al. (2010);

2. construir um classificador multiclasse para cada classe não-folha da hierarquia, chamado neste trabalho de Hierarchical Multiclass Relevance (HMR) - Figura 3.6; e

3. construir um classificador multiclasse para cada nivel da hierarquia, chamado neste trabalho de Hierarchical Multiclass Per Level (HMLP) Figura 3.7.

O modelo HMLP é mais suscetivel a inconsistências e consequentemente menos utilizado. Devido a esse fato, neste trabalho nos concentraremos nos outros dois métodos, ambos apresentados nas próximas seções. 


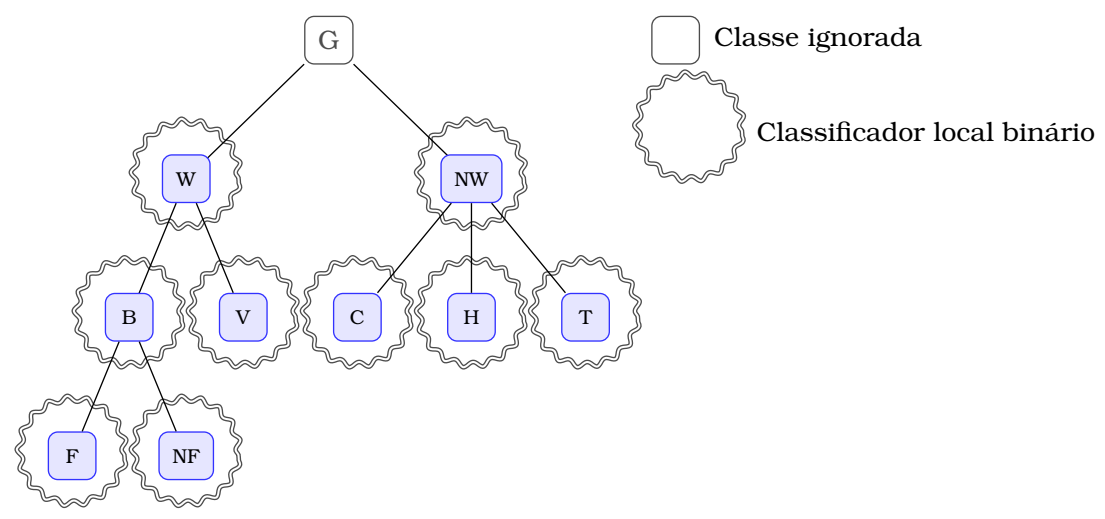

Figura 3.5: Método HBR.
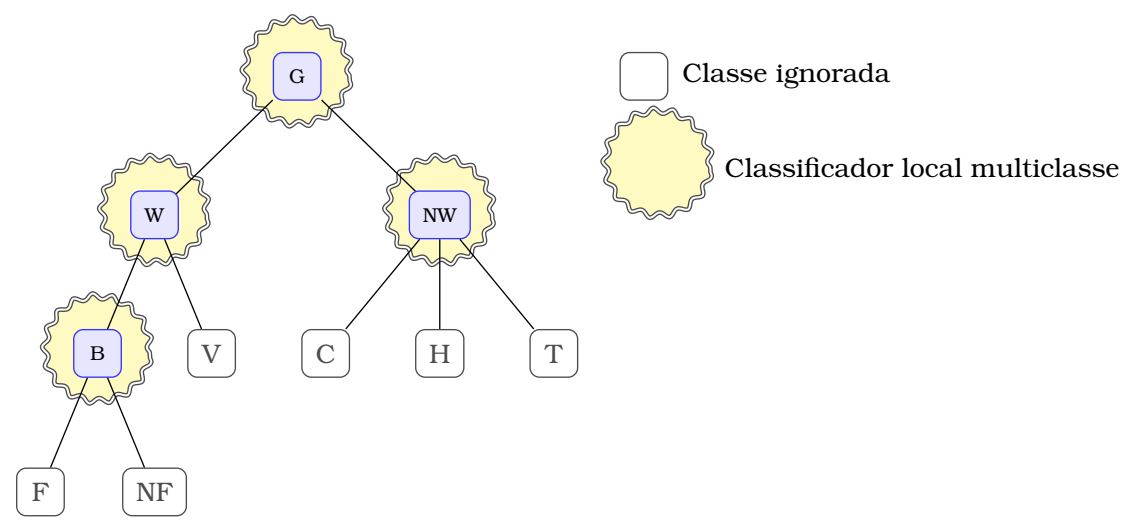

Figura 3.6: Método HMR.

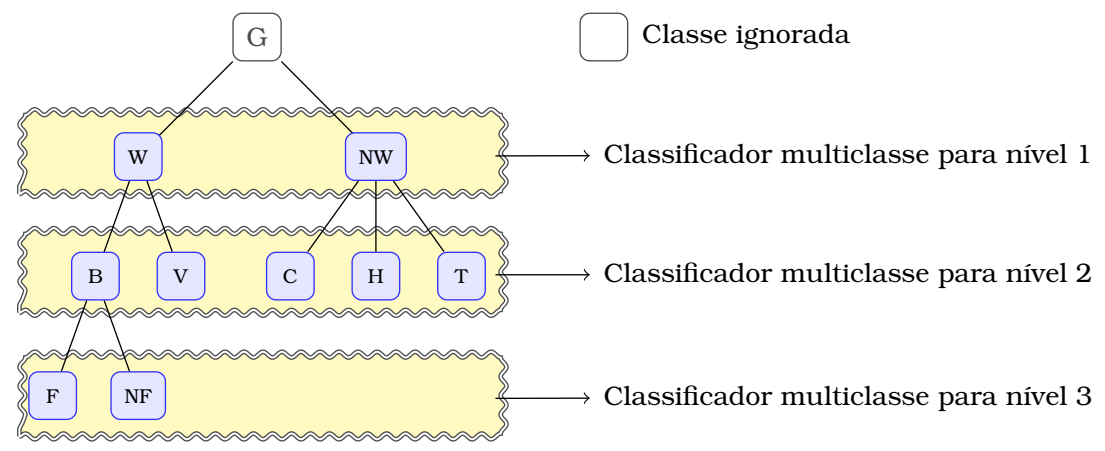

Figura 3.7: Método HMLP.

Treinamento do modelo HBR esse método, ilustrado na Figura 3.5, consiste em construir um classificador local binário $h_{y_{j}}$ para cada classe $y_{j}$ da taxonomia, com exceção do nó raiz, usando um conjunto de exemplos positivos $\left(\operatorname{Tr}_{y_{j}}^{+}\right.$, os exemplos que representam a classe $\left.y_{j}\right)$ e um conjunto de exemplos negativos $\left(T r_{y_{j}}^{-}\right.$, os exemplos que não estão associados a classe $y_{j}$ ). A união desses dois conjuntos, $T r_{y_{j}}^{+}$e $T r_{y_{j}}^{-}$, resulta no conjunto de treinamento local utilizado para a construção do classificador $h_{y_{j}}$, i.e., $\operatorname{Tr}_{y_{j}}=\operatorname{Tr}_{y_{j}}^{+} \cup \operatorname{Tr}_{y_{j}}^{-}$.

Para encontrar os conjuntos de treinamento locais relativos a cada classe 
$y_{j}$ a partir dos exemplos de treinamento global $(\mathrm{Tr})$, oito heurísticas foram propostas, as quais são detalhadas na Tabela 3.2. Dessas heurísticas, seis são baseadas em operações de conjuntos aplicadas sobre subconjuntos de exemplos considerando a taxonomia de classes e o rótulo da classe mais específica de cada exemplo presente em $\operatorname{Tr}$, i.e. $\circledast\left(E_{i}\right)$ - ver definição na Seção 3.2.1 na página 31. Além disso, essas seis heurísticas fazem uso do operador $*$ que, nesse caso, é aplicado a um conjunto de classes e resulta os exemplos em $\operatorname{Tr}$ que têm como classe mais específica uma dentre as classes especificadas como parâmetro. As outras duas heurísticas (Best Global and Best $\eta$ Locals) são baseadas em distância entre exemplos.

Tabela 3.2: Heurísticas para preparação do conjunto de treinamento dos classificadores locais binários para a seleção de $T r_{\mathrm{B}}$.

\begin{tabular}{|c|c|c|c|}
\hline Heurística & $\bar{T} T r_{y_{j}}^{+}$ & $\bar{T} \overline{T r_{y_{j}}^{-}}$ & Referência \\
\hline All (L-Inclusive) & $*\left(y_{j} \cup \Downarrow y_{j}\right)$ & $T r-T r_{y_{j}}^{+}$ & Mladenić \& Grobelnik (1998) \\
\hline Hierarchical training set (S-Inclusive ${ }^{\S}$ ) & $*\left(y_{j} \cup \Downarrow y_{j}\right)$ & $*\left(\leftrightarrow y_{j} \cup \Downarrow\left(\leftrightarrow y_{j}\right)\right)$ & Ceci \& Malerba (2003) \\
\hline Proper training set (S-Exclusive ${ }^{\S}$ ) & $*\left(y_{j}\right)$ & $*\left(\leftrightarrow y_{j}\right)$ & Ceci \& Malerba (2003) \\
\hline Inclusive & $*\left(y_{j} \cup \Downarrow y_{j}\right)$ & $\operatorname{Tr}-\left(\operatorname{Tr}_{y_{j}}^{+} \cup *\left(\Uparrow y_{j}\right)\right)$ & Eisner et al. (2005) \\
\hline Exclusive & $*\left(y_{j}\right)$ & $T r-T r_{y_{j}}^{+}$ & Eisner et al. (2005) \\
\hline L-Exclusive & $*\left(y_{j}\right)$ & $\operatorname{Tr}-*\left(y_{j} \cup \Downarrow y_{j}\right)$ & Eisner et al. (2005) \\
\hline Best Global & $*\left(y_{j} \cup \Downarrow y_{j}\right)$ & $\operatorname{Rank}^{\eta}\left(\operatorname{Tr}-\operatorname{Tr}_{y_{j}}^{+}, \operatorname{dist}\left(E_{i}, \zeta_{y_{j}}\right)\right)$ & Fagni \& Sebastiani (2007) \\
\hline Best $\eta$ Locals & $*\left(y_{j} \cup \Downarrow y_{j}\right)$ & $\operatorname{Rank}^{\eta}\left(\operatorname{Tr}-\operatorname{Tr}_{y_{j}}^{+}, \operatorname{distKnn}\left(E_{i}\right)\right) \dagger$ & Fagni \& Sebastiani (2007) \\
\hline
\end{tabular}

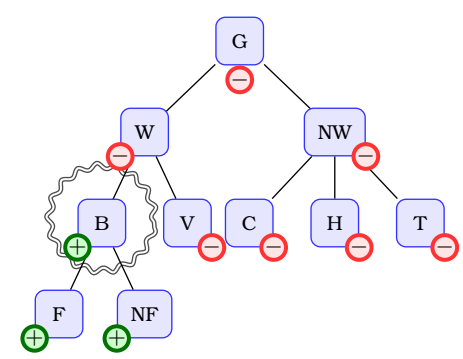

(a) L-Inclusive

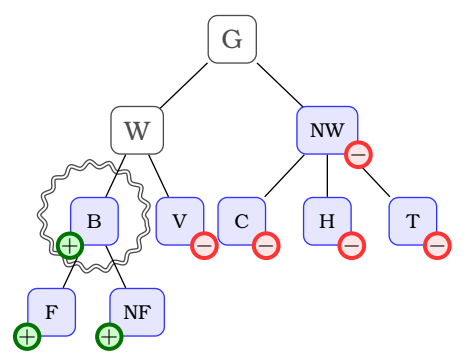

(d) Inclusive

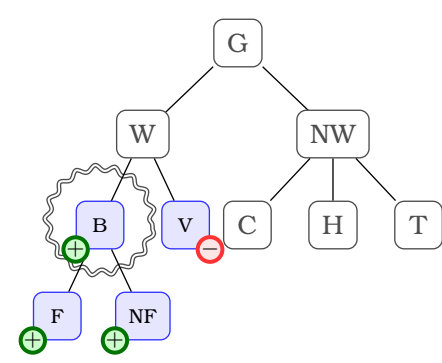

(b) S-Inclusive

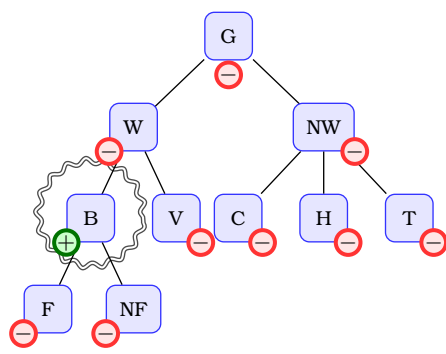

(e) Exclusive

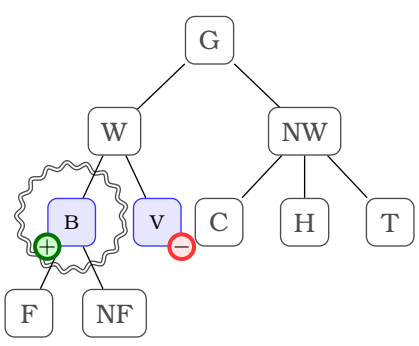

(c) S-Exclusive

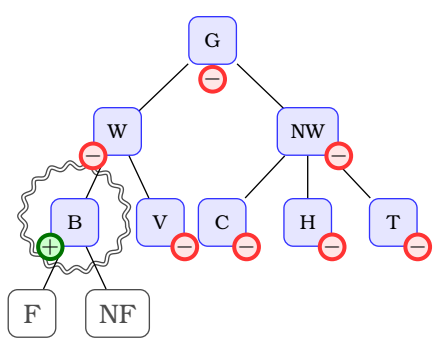

(f) L-Exclusive

Figura 3.8: Ilustração das 6 heurísticas baseadas em operações de conjuntos.

As seis heurísticas baseadas em operações de conjunto são muito similares. Primeiramente, os exemplos positivos $\left(T r_{y_{j}}^{+}\right)$do conjunto de treinamento local são selecionados, considerando a classe mais específica de cada exemplo em $\operatorname{Tr}$. Após, o conjunto $\operatorname{Tr}_{y_{j}}^{-}$é selecionado por meio 
da aplicação de operações matemáticas sobre os conjuntos $\operatorname{Tr}$ e $\operatorname{Tr} r_{y_{j}}^{+}$. A principal diferença entre essas seis heurísticas está relacionada ao tipo de operação utilizada e se essa operação é aplicada sobre todos os exemplos que não estão em $\operatorname{Tr}_{y_{j}}^{+}$ou a um subconjunto dele. Essas heurísticas são ilustradas na Figura 3.8, na qual a classe relevante para a construção dos conjuntos de treinamento locais é B, ou seja, o objetivo é selecionar o conjunto de treinamento para a construção do classificador $h_{\mathrm{B}}$.

Cada classe participa do processo assumindo diferentes papéis que dependem da heurística aplicada. Assim, uma classe pode determinar que o exemplo explicitamente associado a ela seja por vezes positivo $(\oplus$ ), negativo $(\ominus)$ ou não considerado (nós com preenchimento branco).

As heurísticas baseadas em distância (Best Global and Best $\eta$ Locals) (Fagni \& Sebastiani, 2007) fazem uso do conceito de "query-zoning" apresentado em (Singhal et al., 1997). A idéia básica é incluir em $T r_{y_{j}}^{-}$os exemplos considerados "quase positivos" para a classe $y_{j}$ (Schapire et al., 1998). Esses seriam os exemplos que estão mais próximos da região de fronteira entre os exemplos positivos e não positivos e, por isso, são os mais informativos para a construção dos classificadores locais.

A partir de uma medida de "similaridade" ou "dissimilaridade", identificase uma região de fronteira entre dois grupos de exemplos, os quais podem ser o grupo dos exemplos positivos e o grupo dos exemplos não positivos (candidatos a exemplos negativos). De acordo com o conceito de "queryzoning”, nesta região devem estar os exemplos não positivos que poderiam contribuir mais fortemente para a construção de um classificador com maior poder de predição. Assim, a partir dessa região seleciona-se alguns exemplos para compor o conjunto de exemplos negativos.

A heurística Best Global inicialmente calcula o centróide do conjunto $\operatorname{Tr}_{y_{j}}^{+}$. Após, calcula a distância de cada exemplo não positivo até o centróide. Com esses valores de distância, essa heurística inclui em $\operatorname{Tr}_{y_{j}}^{-}$os $\eta$ exemplos mais próximos do centróide.

Quando apenas um ponto de referência (nesse caso o centróide) é utilizado para selecionar os exemplos negativos, é possivel que exemplos importantes não sejam selecionados e outros menos importantes sejam inclusos no conjunto de exemplos negativos. Se a classe $y_{j}$ é linearmente separável das demais, a estratégia com o uso do centróide (Best Global) pode ser uma opção ótima. Porém, para classes não separáveis linearmente, a heurística Best Global resulta em um conjunto de exemplos negativos com exemplos que, apesar de próximos do centróide, podem estar de fato distantes da região de fronteira entre as classes. 


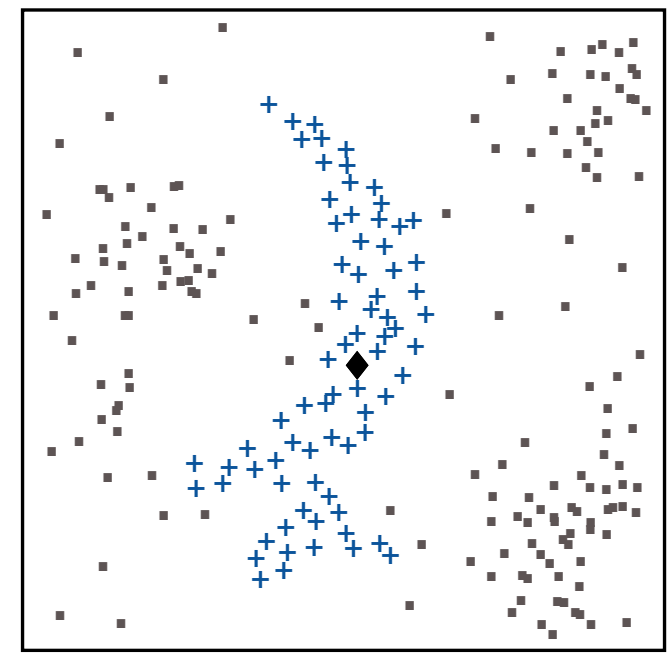

(a) Primeiro passo

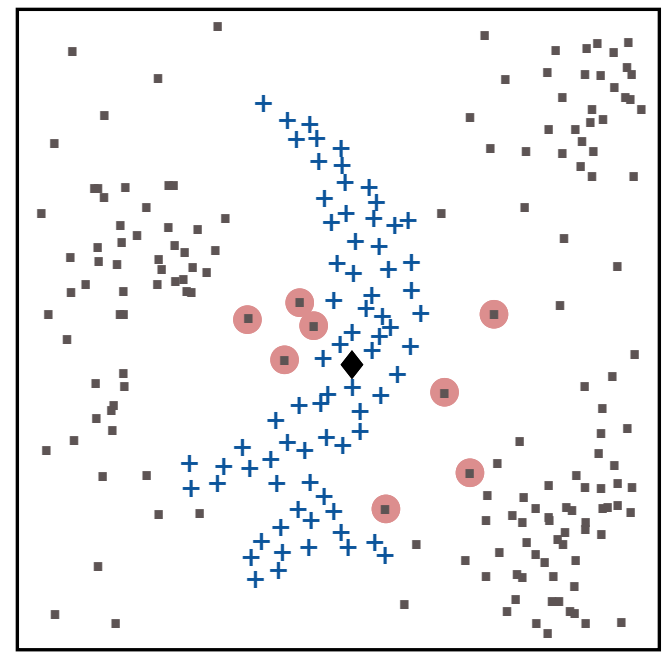

(b) Segundo passo

Figura 3.9: Ilustração da heurística Best Global. Exemplos positivos são representados pelo símbolo “+”. Os exemplos não positivos são representados pelo símbolo ๓, ao passo que o centróide dos exemplos positivos está representado pelo símbolo $\downarrow$. Os $\eta$ exemplos não positivos mais próximos do centróide são selecionados para comporem o conjunto $\operatorname{Tr}_{y_{j}}^{-}$(pontos em destaque na Figura 3.9(b)).

Desse modo, selecionar os exemplos negativos com base em um subconjunto de $k$ exemplos positivos mais próximos da região de fronteira e que representem o formato do conjunto de exemplos positivos no espaço de atributos, pode resultar em exemplos negativos que fornecem melhor informação sobre a distribuição dos dados para a construção de um classificador. Essa estratégia é utilizada pela heurística Best $\eta$ Locals, ilustrada na Figura 3.10.

Deve ser observado que a performance dos algoritmos pode ser bastante influenciada pela escolha da heurística, uma vez que há diferenças substanciais na maneira como cada heurística prepara os conjuntos de treinamento locais. Avaliações realizadas sobre o impacto que essas heurísticas causam no resultado final da classificação hierárquica, mostram que quanto mais inclusiva for a heurística, melhor será a performance do classificador em termos de qualidade da predição (Eisner et al., 2005).

Entretanto, os trabalhos publicados avaliam o impacto de subconjuntos dessas heurísticas, o que motivou a realização de um estudo que abrange a avaliação da totalidade das heurísticas propostas (Metz et al., 2011a), apresentado em maiores detalhes na Seção 6.2, cenário experimental 2. Os resultados obtidos mostram que não há diferença estatística entre as heurísticas Inclusive, S-Inclusive e L-Inclusive.

Treinamento do modelo HMR nesse modelo, também referenciado como top- 


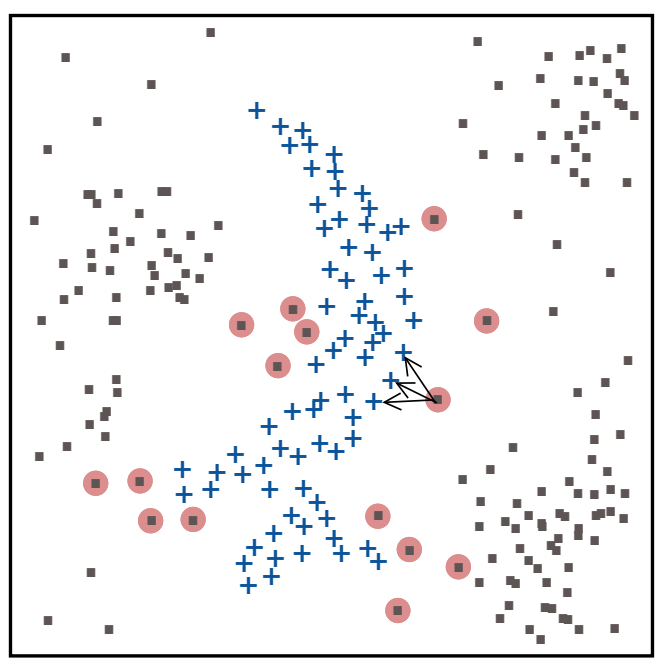

Figura 3.10: Ilustração da heurística Best $\eta$ Locals. Exemplos positivos são representados pelo símbolo “+”. Os exemplos não positivos são representados pelo símbolo $\Perp$. Os $\eta$ exemplos não positivos selecionados são mostrados em destaque. Para um desses exemplos são indicados por meio de setas $(\rightarrow)$ os seus $k$-vizinhos positivos mais próximos.

down em diversos trabalhos (Greiner et al., 1997; Sun et al., 2003a; Vens et al., 2008), para cada nó não-folha da hierarquia de classes, é construído um classificador multiclasse cuja tarefa é rotular novos exemplos de acordo com suas subclasses, i.e., discriminar apenas entre suas classes filhas. Esse modelo é ilustrado na Figura 3.11, na qual o classificador associado à classe $\mathrm{G}, h_{\mathrm{G}}$, por exemplo, é treinado para predizer as classes W ou NW. O classificador $h_{\mathrm{w}}$, por sua vez, classifica exemplos em B ou V. Os outros classificadores, $h_{\mathrm{B}}$ e $h_{\mathrm{Nw}}$, são utilizados de maneira análoga, sempre classificando novos exemplos em uma de suas respectivas classes filhas.
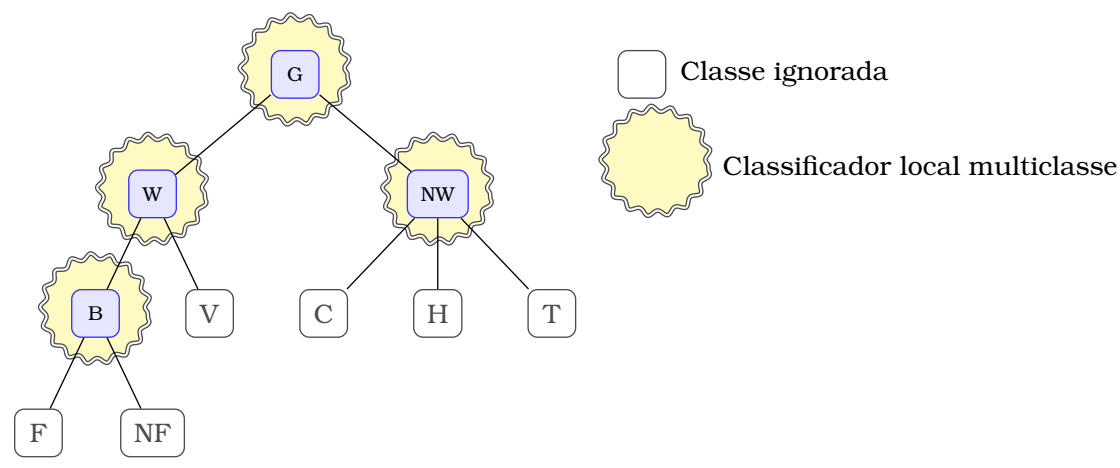

Figura 3.11: Abordagem local com o método HMR.

Assim como no modelo HBR, nesse modelo cada classificador local é construído a partir de um conjunto de exemplos de treinamento local. Uma possivel heurística para a seleção dos exemplos que compõem esses conjuntos de treinamento pode ser: $\operatorname{Tr} r_{j}=*\left(\Downarrow y_{j}\right)$. Nesse caso, os conjuntos 
de exemplos são multiclasse, uma vez que os classificadores a serem construídos são multiclasse - Figura 3.12.

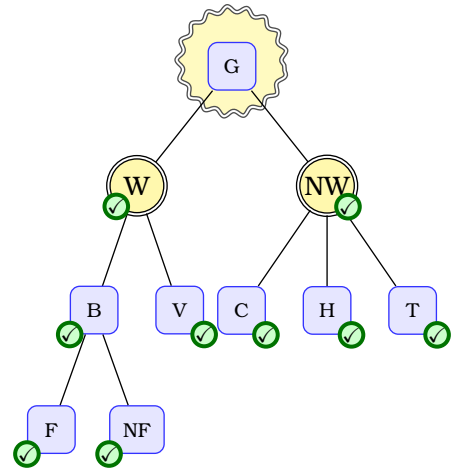

(a)

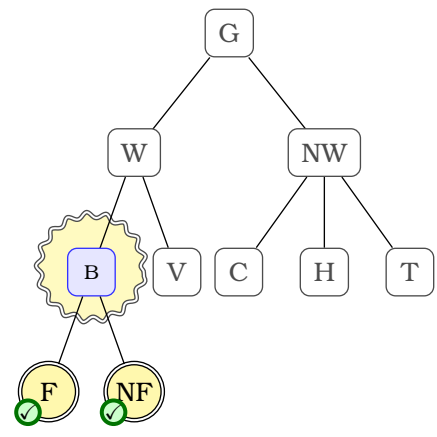

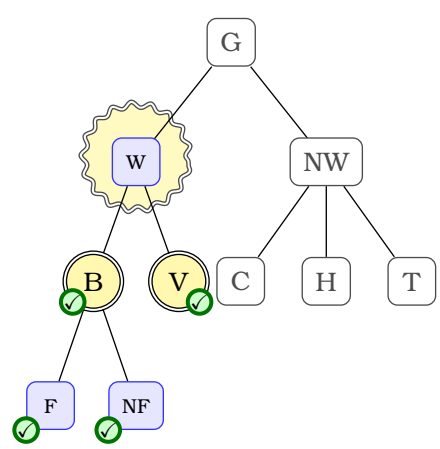

(b)

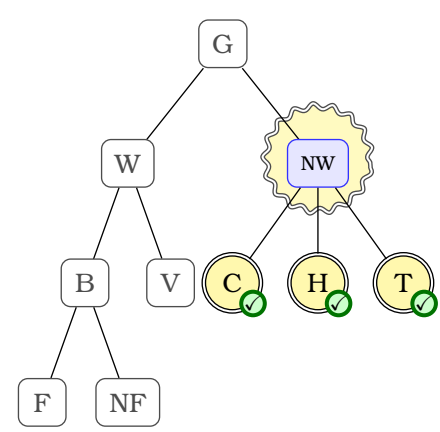

(c)

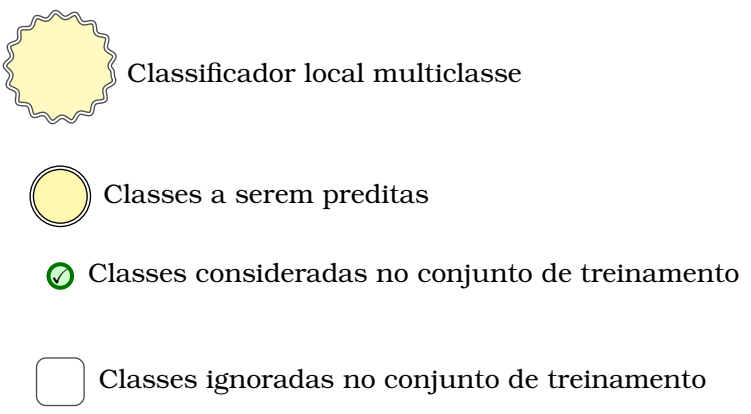

(d)

Figura 3.12: Preparação do conjunto de treinamento para o método HMR.

Cada conjunto de treinamento local deve ser preparado de modo que os exemplos nele inclusos sejam rotulados apenas com as classes que esse classificador deverá discriminar. Desse modo, é necessário que o rótulo de cada exemplo inserido no conjunto de treinamento selecionado para a construção do classificador local $h_{y_{j}}$ seja modificado de modo que apenas os rótulos referentes às classes filhas de $y_{j}$ estejam presentes. Para isso, todos os exemplos previamente selecionados, cuja classe mais específica não está no conjunto $\downarrow y_{j}$, devem ter seu rótulo generalizado segundo a relação $\prec$. Em outras palavras, todo exemplo $E_{i}$ tal que $\circledast E_{i} \in$ $\left\{\Downarrow y_{j}\right\}$ previamente selecionado, passa por um processo de generalização de classe de modo que $\circledast E_{i} \in\left\{\downarrow y_{j}\right\}$ seja verdade.

Considere como exemplo a preparação do conjunto de treinamento local para a construção do classificador $h_{\mathrm{G}}$. Todos os exemplos $\circledast E_{i} \in$ $\{\mathrm{F}, \mathrm{NF}, \mathrm{B}, \mathrm{V}\}$ serão generalizados de modo que sua classe mais específica seja $\mathrm{W}$, ou seja, dado um exemplo $E_{i}$ tal que $\circledast E_{i}=\mathrm{NF}$, o processo de generalização resulta $\mathrm{em} \circledast E_{i}=\mathrm{w}$. 


\subsubsection{Estratégia de predição top-down para métodos locais}

Durante a etapa de classificação, métodos de classificação hierárquica que seguem a abordagem local usualmente realizam a predição de um novo exemplo utilizando uma estratégia da raiz para as folhas, frequentemente referenciada como top-down e também conhecida como Pachinko Machine. Esse é um procedimento recursivo que começa com a apresentação do exemplo ao classificador (ou classificadores) no nível mais raso da hierarquia. Após, com o resultado dessa predição, o processo se repete recursivamente inspecionando apenas os classificadores referentes às classes imediatamente abaixo da(s) classe(s) predita(s) no passo anterior. Esse processo recursivo termina quando uma classe folha é encontrada. Além disso, é possivel definir outros critérios de parada, como um limiar para o grau de confiança da classificação.

É importante observar que esse método, quando aplicado com o modelo HBR, é naturalmente multirrótulo (no sentido de mais de uma classe ser predita como positiva no mesmo nível da hierarquia). Essa característica pode ser facilmente eliminada se apenas a classe predita com maior grau de confiança em cada nível for atribuída ao exemplo. Com isso, apenas as classes descendentes dessa classe poderão ser preditas nos próximos níveis.

A classificação final de um novo exemplo a partir dessa estratégia, corresponde à união de todas as classes que foram preditas como positivas para esse exemplo, desde que respeitem a taxonomia de classes.

Segundo Freitas \& de Carvalho (2007), existem dois tipos gerais de predição, ilustrados nas Figuras 3.13 e 3.14, respectivamente: predição obrigatória de classe- (Mandatory Leaf Node Prediction - MLN), quando a classe mais específica predita deve obrigatoriamente ser uma classe folha, e predição não obrigatória de classe folha (Non-mandatory Leaf Node Prediction - NMLN), quando a classe mais específica predita pode ser tanto uma classe interna quanto uma folha da taxonomia. Ambos os tipos de predição podem ser utilizados tanto com o modelo HBR quanto com o modelo HMR.

No caso da predição MLN, o algoritmo avalia inicialmente a predição dos classificadores no primeiro nível da hierarquia, e escolhe o ramo com maior confiança na predição da classe positiva para o exemplo. Nos próximos passos, o exemplo é apresentado apenas aos classificadores filhos do classificador que o classificou como positivo no nivel anterior até chegar a uma folha.

No caso da predição opcional nas folhas, NMLN, é necessário que, além de escolher o classificador com maior grau de confiança em cada nível, esse valor de confiança seja maior que um limiar pré-especificado, como ilustrado na Figura 3.14. O processo de classificação é interrompido se o grau de confiança de predição de todos os classificadores inspecionados em um determinado nivel for menor que o limiar pré-especificado. Caso contrário continua até que 


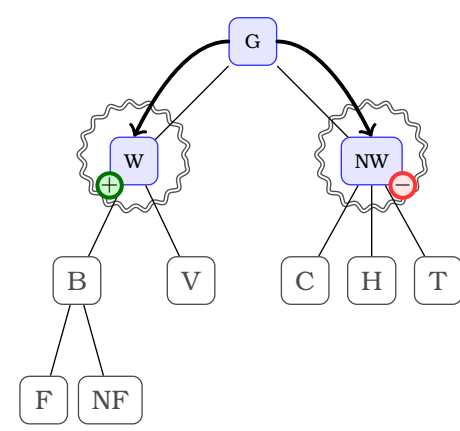

(a) Primeiro passo

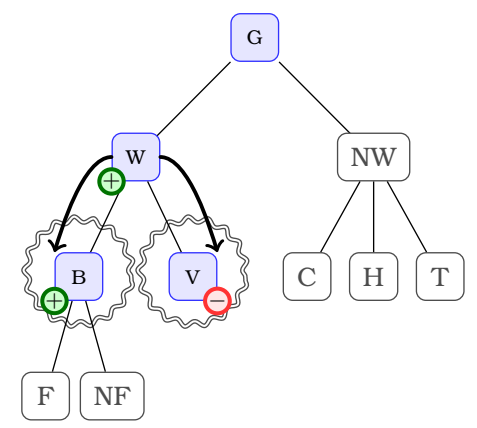

(b) Segundo passo

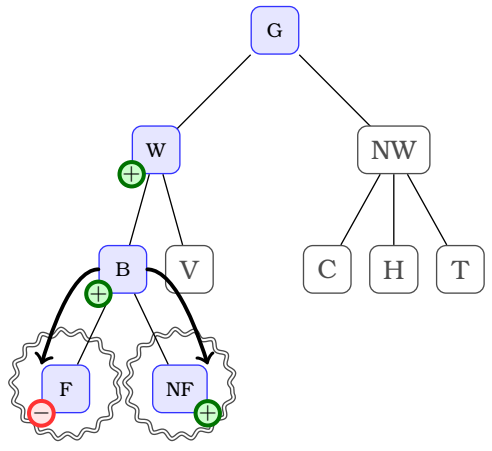

(c) Terceiro passo
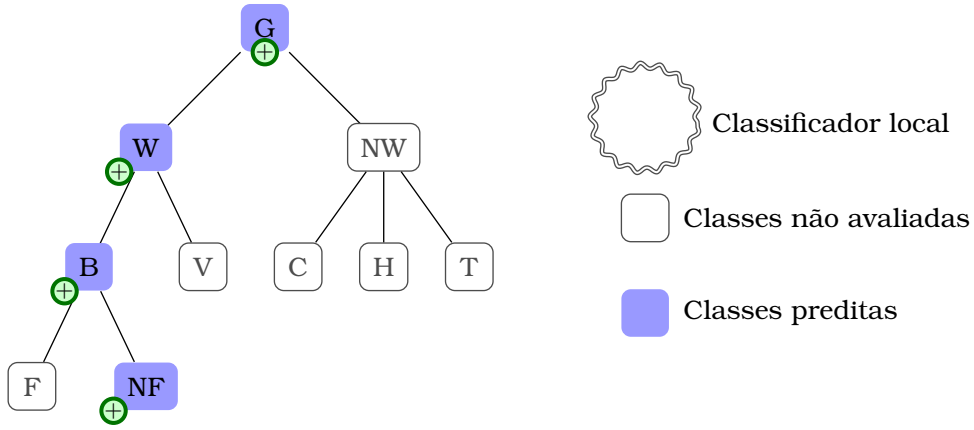

(d) Predição final

Figura 3.13: Classificação de um novo exemplo usando estratégia local com predição top-down obrigatória até as folhas.

uma classe folha seja predita.

\subsection{Medidas de avaliação}

São muitas as soluções ou algoritmos propostos para o problema de classificação. Também são abundantes as medidas propostas para avaliar o poder de predição dos algoritmos desenvolvidos para essa tarefa. No entanto, a maioria dessas medidas foram projetadas para avaliação da classificação plana e não consideram relações estruturais entre as classes, como generalização e especialização presentes em uma estrutura hierárquica de classes, e consideram que todos os erros de classificação têm a mesma importância. Portanto, são inadequadas para o problema de classificação hierárquica (Kiritchenko et al., 2005), uma vez que erros de predição cometidos nos níveis mais rasos da hierarquia (classes mais gerais) são mais importantes que os erros cometidos nos niveis mais profundos, nos quais as classes são mais específicas (Freitas \& de Carvalho, 2007). Na classificação hierárquica é importante distinguir os seguintes tipos de erros:

- erro de generalização: o percentual de exemplos classificados erroneamente em uma classe ancestral da classe correta mais específica; e 


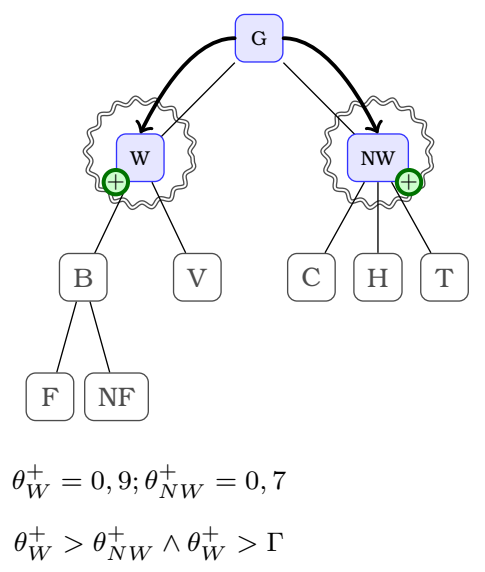

(a) Primeiro passo

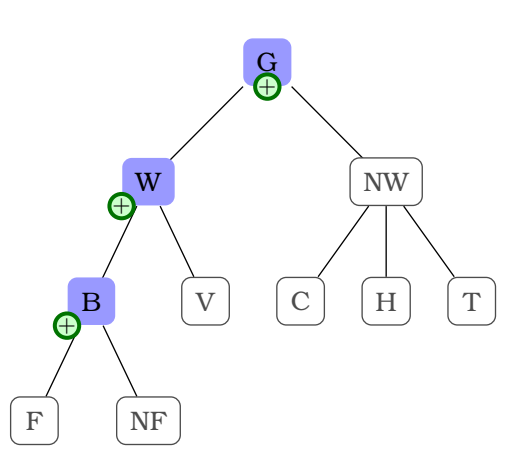

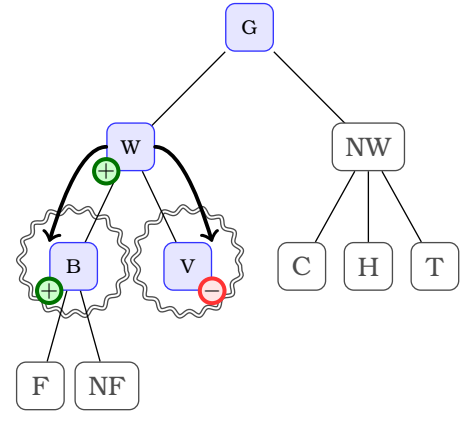

$\theta_{B}^{+}=0,75 \wedge \theta_{B}^{+}>\Gamma$

(b) Segundo passo

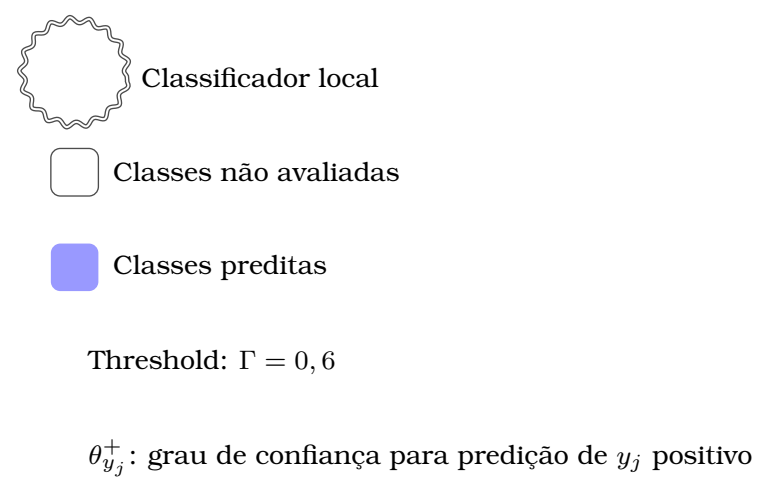

(d) Predição final

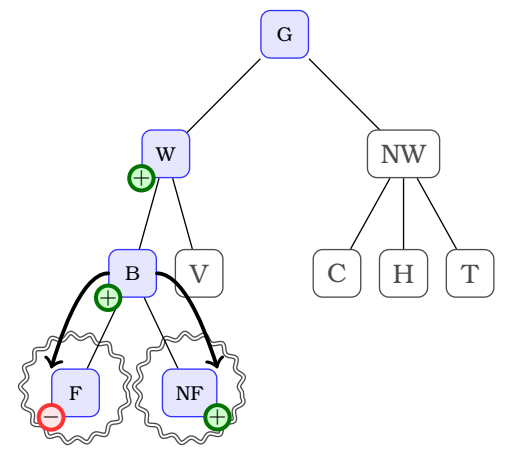

$\theta_{N F}^{+}=0,55 \wedge \theta_{N}^{+} F<\Gamma$

(c) Terceiro passo

Figura 3.14: Classificação de um novo exemplo usando estratégia top-down e predição opicional até as folhas.

- erro de especialização: o percentual de exemplos classificados erroneamente em uma das classes descendentes da classe correta mais específica.

Uma medida bastante utilizada no contexto da classificação hierárquica é baseada em conceitos de distância entre classes (número de arestas no caminho entre as duas classes na hierarquia). Mas essa medida também apresenta algumas desvantagens, como a difícil adaptação para hierarquias definidas sobre estruturas de grafos (DAG), nos quais existem múltiplos caminhos entre duas categorias. Além disso, esse tipo de medida considera que erros em diferentes níveis da hierarquia têm o mesmo peso. Por exemplo, na Figura 3.15, a predição de uma classe irmã da classe verdadeira no primeiro nível da hierarquia (predição de W ao invés de NW, acarreta distância 2, pois o caminho tem apenas duas arestas) teria o mesmo peso que a predição de uma classe irmã no nível 3 (predição de $\mathrm{F}$ ao invés de NF). Contudo, um erro no terceiro nível da hierarquia representa um erro de refinamento, em geral mais específico, e não deveria ser penalizado da mesma maneira que o erro nos níveis mais rasos da hierarquia, os quais propagam o erro para níveis mais profundos da 
hierarquia.

Mesmo sabendo que as medidas de classificação plana e as hierárquicas baseadas em distância podem não representar corretamente o poder de predição dos classificadores hierárquicos, em muitas das pesquisas publicadas os resultados são avaliados por meio dessas medidas (Clare \& King, 2001; Toutanova et al., 2001; Struyf et al., 2005). Ainda assim, os pesquisadores reconhecem que essas medidas não são apropriadas para a classificação hierárquica, pois, como mencionado, os diferentes tipos de erros recebem o mesmo grau de importância.

Outros pesquisadores reportam os resultados das suas pesquisas considerando como medida de performance apenas a contagem de exemplos corretamente (ou erroneamente) classificados considerando como acerto apenas os casos para os quais todos os rótulos foram corretamente preditos (Labrou, 1999; Sasaki \& Kita, 1998). No entanto, muitos algoritmos permitem classificação parcial. Assim, o cálculo da performance desses algoritmos considerando apenas a predição perfeita no conjunto de teste não é apropriado, pois não representa o real poder de predição dos algoritmos.

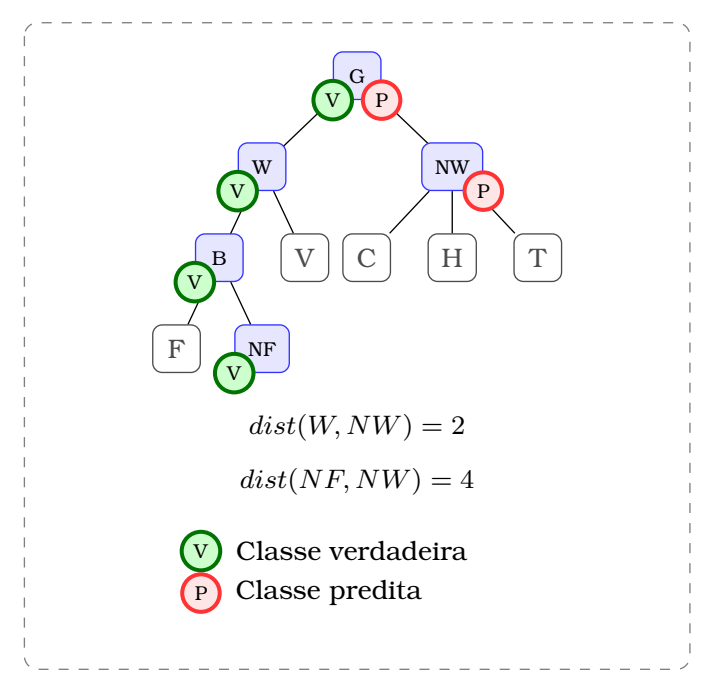

(a) Erro da predição de uma classe mais geral

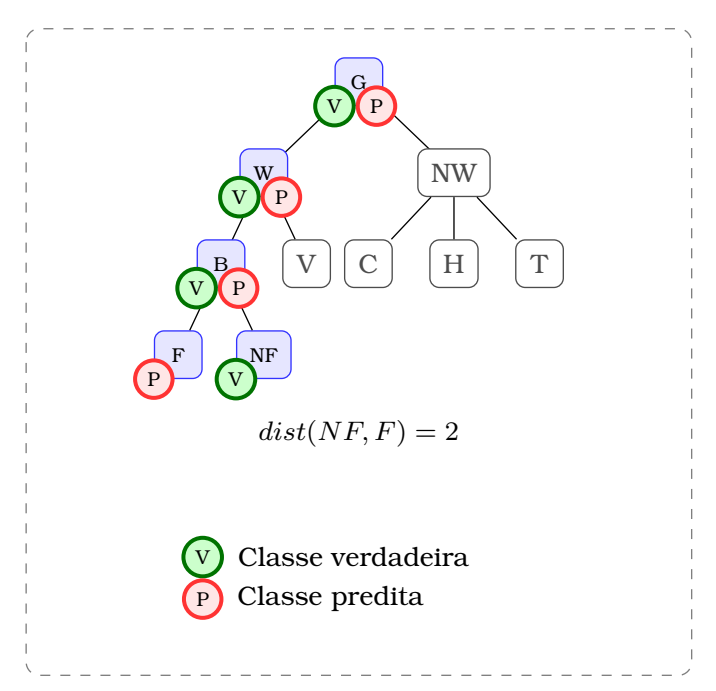

(b) Erro da predição de uma classe mais específica

Figura 3.15: Erros de classificação hierárquica.

Nesse contexto, com objetivo de definir medidas capazes de avaliar a performance dos classificadores hierárquicos de maneira fidedigna, Kiritchenko et al. (2005) formularam três pré-requisitos que devem ser satisfeitos pelas medidas propostas para esse fim:

1. A medida deve ser capaz de avaliar predições parciais: por exemplo, o erro gerado pela predição da classe B (considerando apenas a predição da classe mais específica) dado que a classe verdadeira é $\mathrm{NF}$, deve ser 
menos penalizado que a predição de NW, uma vez que B faz parte do caminho correto entre a classe verdadeira mais específica e a raiz, ao passo que NW não faz parte desse caminho;

2. A medida deve dar maior peso para erros envolvendo classes mais distantes na hierarquia de classes: dois casos devem ser considerados.

(a) a medida resulta em uma melhor avaliação para predições mais específicas corretas, mesmo que não sejam tão específicas quanto a classe verdadeira. Por exemplo, considerando a classe NF como sendo a classe verdadeira mais específica, é preferivel predizer в a W como classe mais específica, pois B está mais perto da classe verdadeira, e

(b) a medida resulta em pior avaliação para predições mais específicas erradas, comparando com predições erradas menos específicas. Por exemplo, predizer a classe $\mathrm{F}$ é pior que predizer B quando a classe correta é $\mathrm{W}$, uma vez que F está ainda mais distante que B da classe verdadeira $(\mathrm{NF})$;

3. A medida deve resultar em pior avaliação para erros de predição mais gerais: por exemplo, quando a classe mais específica verdadeira é NF, o erro dado à predição de um novo exemplo como sendo $\mathrm{F}$ sua classe mais específica é menos severo que a predição de $\mathrm{w}$ como sua classe mais especifica.

Diversas medidas para avaliar a classificação hierárquica têm sido propostas, mas nem todas respeitam os pré-requisitos apresentados por Kiritchenko et al. (2005). Essas medidas podem ser agrupadas em 4 tipos gerais (Freitas $\&$ de Carvalho, 2007; Costa et al., 2007):

1. Distância;

2. Similaridade semântica;

3. Custo de erro de classificação; e

4. Baseadas na hierarquia.

A descrição detalhada de cada um desses tipos de medidas estão disponíveis em alguns trabalhos, como (Metz et al., 2011a, 2010; Costa et al., 2007; Freitas \& de Carvalho, 2007; Kiritchenko et al., 2006; Sun \& Lim, 2001).

A seguir, são apresentados dois tipos de medidas utilizadas para avaliação da classificação hierárquica. 


\subsubsection{Medidas baseadas em distância}

Essa categoria de medidas de performance de predição consiste em atribuir para cada erro de classificação hierárquica um custo que é proporcional à distância entre a classe mais específica predita e a classe mais específica verdadeira de cada exemplo.

Uma medida baseada em distância foi proposta por Blockeel et al. (2002), na qual a distância entre duas classes é obtida por meio de uma função que considera dois fatores: (1) o número de arestas entre as classes predita e verdadeira (mais específicas) e (2) a profundidade dessas duas classes na hierarquia.

Uma maneira de definir essa função é atribuir pesos (custo) a cada aresta da hierarquia. A partir desses pesos, o erro de classificação associado à predição é dado pela soma dos pesos de todas as arestas no caminho entre as duas classes. No entanto, para implementar a ideia de que erros de predições incorretas em nós mais rasos (mais próximos ao nó raiz) tenham avaliações piores que as predições erradas em nós mais profundos, os pesos das arestas devem ser definidos considerando o nível onde ocorrem.

Para solucionar esse problema, Holden \& Freitas (2006) e Blockeel et al. (2002) propõem a definição dos pesos de modo exponencialmente decrescente de acordo com o aumento da profundidade dos nós. Porém, essa proposta também tem desvantagens. A primeira ocorre quando a árvore que representa a hierarquia de classes é fortemente desbalanceada, no sentido de que diferentes nós-folha aparecem em diferentes niveis da hierarquia. Para esse caso, um erro envolvendo duas classes folha rasas (verdadeira e predita) será menos penalizado que um erro envolvendo um par de classes folha que estão em um nível mais profundo, simplesmente porque no último caso haverá mais arestas associadas ao caminho entre as duas classes. Essa menor penalização é discutivel, uma vez que um erro na predição envolvendo classes rasas impede que os níveis mais profundos sejam avaliados.

Um outro problema identificado por Lord et al. (2003) está relacionado à variação da profundidade dos nós-folha, uma vez que o fato de uma classe folha ser mais profunda que outra não significa necessariamente que a primeira é mais informativa que a segunda. Por exemplo, uma classe no terceiro nível da árvore pode representar informação tão específica quanto uma classe no oitavo nível da estrutura hierárquica, se as duas classes estiverem em diferentes subárvores do nó raiz. Então, a atribuição de pesos considerando apenas a profundidade das arestas e não a informação associada com as classes pode ser um problema.

Para minimizar esses problemas, Holden \& Freitas (2009) propuseram usar não apenas medidas que consideram a profundidade das classes, mas tam- 
bém que resultem no mesmo peso total para cada subárvore sendo comparada. Essa estratégia, posteriormente utilizada em (Metz \& Freitas, 2009), define os pesos das arestas de modo que todo caminho partindo da raiz até um nó folha tenha peso total igual a 0,5 , ao passo que o peso de cada aresta desse caminho depende da profundidade da mesma.

Para calcular os pesos de cada aresta, respeitando a restrição de peso total igual a 0,5 para cada caminho da raiz para uma folha, propomos neste trabalho o uso da Equação 3.2, onde $\operatorname{dist}_{w}\left(y_{k}\right.$, raiz) é a soma dos pesos das arestas partido do nó $y_{k}$ até a raiz da hierarquia de classes, e $\phi$ é o valor da altura +1 da subárvore com raiz $y_{k}$, conforme Equação 3.3. Observe que para isso é preciso calcular os pesos das arestas a partir da raiz para as folhas.

$$
\begin{gathered}
w_{y_{j} \rightarrow y_{k}}=\sum_{i=1}^{\phi} \frac{0,5-\operatorname{dist}_{w}\left(y_{k}, \text { raiz }\right)}{\phi \times i} \\
\phi=\operatorname{altura}\left(y_{k}\right)+1
\end{gathered}
$$

Como exemplo, considere a hierarquia de classes Glass. As informações necessárias para calcular os pesos das arestas são apresentadas na Tabela 3.3, enquanto que dois exemplos do cálculo do peso das arestas $(\mathrm{G} \rightarrow \mathrm{W})$ e $(\mathrm{W} \rightarrow \mathrm{B})$ são apresentados nas Equações 3.4 e 3.5, respectivamente. O peso das demais arestas estão apresentados na Figura 3.16(a).

\begin{tabular}{|c|c|c|c|c|c|}
\hline Origem & Destino & $\begin{array}{c}\text { Altura da subárvore } \\
\text { destino }\end{array}$ & $\overline{\phi \phi}$ & $\overline{\text { dist }}_{w}\left(\right.$ origem $\left._{\text {,raiz }}\right)$ & $w_{\text {origem } \rightarrow \text { destino }}$ \\
\hline G & w & 2 & 3 & 0,0000 & 0,3056 \\
\hline w & B & 1 & 2 & 0,3056 & 0,1458 \\
\hline B & $\mathrm{F}$ & 0 & 1 & 0,4514 & 0,0486 \\
\hline B & $\mathrm{NF}$ & 0 & 1 & 0,4514 & 0,0486 \\
\hline w & $\mathrm{v}$ & 0 & 1 & 0,3056 & 0,1944 \\
\hline G & NW & 1 & 2 & 0,0000 & 0,3750 \\
\hline NW & C & 0 & 1 & 0,3750 & 0,1250 \\
\hline NW & $\mathrm{H}$ & 0 & 1 & 0,3750 & 0,1250 \\
\hline NW & $\mathrm{T}$ & 0 & 1 & 0,3750 & 0,1250 \\
\hline
\end{tabular}

Tabela 3.3: Informações utilizadas para calcular o peso das arestas.

$$
\begin{gathered}
w_{\mathrm{G} \rightarrow \mathrm{W}}=\sum_{i=1}^{3} \frac{0,5-0}{i \times 3}=\frac{0,5}{3}+\frac{0,5}{6}+\frac{0,5}{9}=0,3056 \\
w_{\mathrm{W} \rightarrow \mathrm{B}}=\sum_{i=1}^{2} \frac{0,5-0,3056}{i \times 2}=\frac{0,1944}{2}+\frac{0,1944}{4}=0,1458
\end{gathered}
$$

Com essa medida, a distância entre duas folhas que não fazem parte da mesma subárvore, i.e., que tenham como ancestral comum mais profundo o nó raiz da hierarquia, resultará sempre em 1, valor esse que representa o erro máximo para a classificação de um exemplo. Observe que se um erro de 


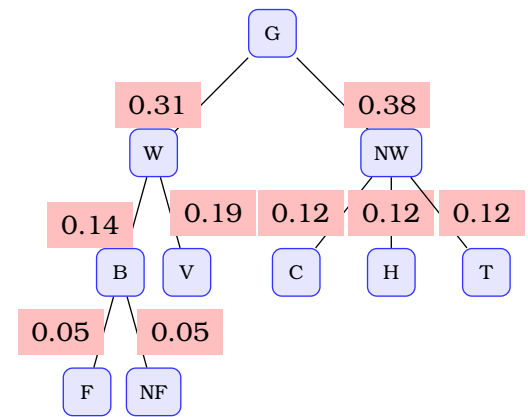

(a) Pesos definidos

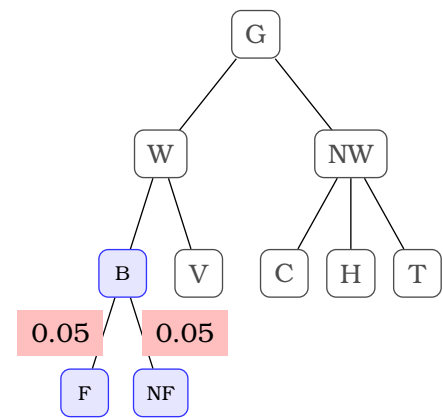

(b) Distância entre $\mathrm{F}$ e NF

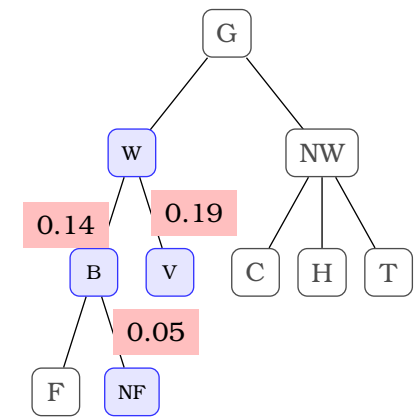

(c) Distância entre V e NF

Figura 3.16: Exemplo de hierarquia com pesos definidos para o cálculo da distâncias entre nós.

predição ocorre em um nível bastante profundo onde a classe predita é irmã da classe verdadeira, a avaliação dessa predição resulta em um valor bastante baixo se comparado com um erro que tenha sido cometido nos primeiros níveis da hierarquia.

Dados os pesos das arestas da estrutura hierárquica de classes, a acurácia baseada na distância normalizada para um exemplo de teste $E_{i}$ é definida pela Equação 3.6,

$$
A c c_{E_{i}}^{N o r m}=1-\operatorname{dist}_{w}\left(\odot\left(Y_{i}\right), \odot\left(\hat{Y}_{i}\right)\right)
$$

tal que $Y_{i}$ é o conjunto de classes verdadeiras do exemplo $E_{i}$ e $\hat{Y}_{i}$ é o conjunto de classes preditas para esse exemplo. O operador $\odot$ retorna a classe mais específica contida no conjunto de classes especificado, enquanto que $d i s t_{w}(y, \hat{y})$ é a distância entre os nós representados pelas classes $y$ e $\hat{y}$ considerando os pesos nas arestas que compõem o caminho entre essas duas classes.

É importante observar que essa medida de acurácia varia entre 0 (erro de predição em todos os níveis) e 1 (predição perfeita), e a acurácia global do classificador é simplesmente a média obtida sobre todo o conjunto de teste, conforme a Equação 3.7.

$$
A c c_{\text {global }}^{\text {Norm }}=\frac{1}{|T e|} \times \sum_{i=1}^{|T e|} A c c_{E_{i}}^{\text {Norm }}
$$

\subsubsection{Medidas baseadas na hierarquia}

Kiritchenko et al. $(2005,2006)$ propuseram uma maneira de avaliar a performance de classificadores hierárquicos com base nas medidas clássicas de classificação plana. Esse método de avaliação consiste em calcular as medidas de precisão e recall respeitando os pré-requisitos por eles propostos e a hierarquia de classes. Essas medidas, chamadas de precisão hierárquica $(h P)$ 
e recall hierárquico $(h R)$, consideram as relações de generalização e especialização da estrutura hierárquica, pois utilizam informações de nós ancestrais das classes verdadeira e predita para o cálculo.

A principal vantagem dessas medidas é que respeitam todos os pré-requisitos apresentados anteriormente. Além disso, são não paramétricas e são formuladas de modo que podem ser utilizadas também para problemas hierárquicos multirrótulo nos quais cada exemplo pode ser classificado com mais de uma classe em cada nível (com múltiplos caminhos na hierarquia) e também com estrutura de grafos. Outra vantagem de extrema importância é o fato de serem extensões de medidas muito testadas e validadas pela comunidade científica em problemas de classificação plana, o que garante maior consistência na análise da performance de classificadores hierárquicos por meio dessas medidas.

Considerando tarefas de classificação hierárquica que permitem a predição de apenas uma classe por nível (apenas um caminho), o valor de precisão da predição para cada exemplo é calculado por meio da divisão do número de classes comuns entre as classes preditas e verdadeiras pelo número de classes preditas. Utilizando a notação de conjuntos, pode-se calcular esse valor de precisão por meio da Equação 3.8 .

$$
h P\left(h, E_{i}\right)=\frac{\left|Y_{i} \cap \hat{Y}_{i}\right|}{\left|\hat{Y}_{i}\right|}
$$

De maneira análoga, o recall pode ser calculado conforme a Equação 3.9

$$
h R\left(h, E_{i}\right)=\frac{\left|Y_{i} \cap \hat{Y}_{i}\right|}{\left|Y_{i}\right|}
$$

onde $\hat{Y}_{i}$ é o conjunto de classes preditas para o exemplo de teste $i$, enquanto que $Y_{i}$ é o conjunto de classes verdadeiras desse exemplo. É importante lembrar que o nó raiz não é considerado para o cálculo dessas medidas, uma vez que, por definição, é comum a todos os exemplos.

Observe que essas medidas hierárquicas de precisão e recall para um exemplo são idênticas às apresentadas para avaliar a classificação multirrótulo plana. É importante ressaltar que a classificação hierárquica é um caso especial de classificação multirrótulo, uma vez que um conjunto de monorrótulos é predito para cada exemplo. A diferença, como mencionado anteriormente, é que na classificação hierárquica o conjunto de rótulos preditos respeita uma estrutura hierárquica de classes.

Para a avaliação global da performance do classificador é mais aconselhável calcular a média desses valores de precisão e recall. Contudo, é importante observar que o valor médio calculado com base nas Equações 3.8 e 3.9 é baseado na predição individual de cada exemplo (baseada em exemplos). 
Existem outros métodos para avaliar a performance global dos classificadores, por exemplo as médias micro e macro, chamadas de medidas baseadas em rótulos e apresentadas na Seção 2.3.3.2 na página 24.

\subsection{Considerações finais}

Neste capítulo foram apresentados diversos conceitos relacionados à tarefa de classificação hierárquica, como as principais abordagens para solucionar esse problema e várias medidas de avaliação.

No que diz respeito à avaliação dos métodos de classificação hierárquica, muitas medidas foram propostas na literatura. Porém, nenhuma delas é completamente aceita pela comunidade científica. O que se observa é que, em muitos trabalhos, os pesquisadores propõem novas medidas que apenas são utilizadas nos próprios trabalhos. Além disso, muitas dessas medidas não satisfazem os pré-requisitos básicos para a avaliação da classificação hierárquica. Mais recentemente, algumas pesquisas têm mostrado uma tendência para adoção das medidas de avaliação propostas por Kiritchenko et al. (2005) - Hierarchical Precision (hP) e Hierarchical Recall (hR), as quais são usualmente empregadas em avaliações da classificação multirrótulo plana. 


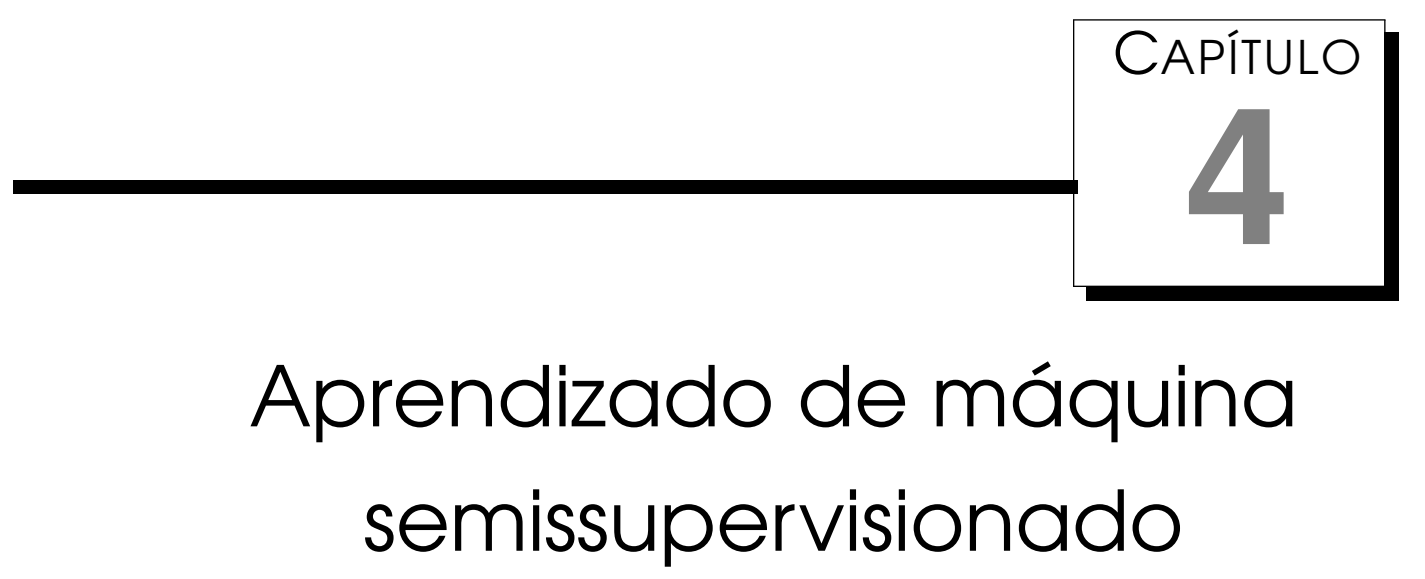

Para a construção de um modelo de classificação por meio de algoritmos de aprendizado supervisionado, é necessário que exista uma quantidade expressiva de exemplos de treinamento rotulados, i.e., casos do domínio para os quais a classe é conhecida.

Entretanto, a rotulação manual de exemplos é uma tarefa custosa, pois depende da disponibilidade e conhecimentos de um especialista do domínio. Por exemplo, para o desenvolvimento de um sistema de diagnóstico médico auxiliado por computador, cuja tarefa é obter o diagnóstico a partir de uma imagem de raio-X, é relativamente fácil e menos custoso obter um grande número de imagens de raio-X. Contudo, a tarefa de identificar manualmente as características que podem levar a um diagnóstico mais preciso é bastante complexa e demorada. Desse modo, se um classificador for construído por meio de algoritmos de aprendizado supervisionado tradicionais, apenas um pequeno número de imagens (as que tenham sido anotadas) são úteis. Consequentemente, o modelo gerado pode não ser bom o suficiente para ser usado em um sistema de predição de diagnósticos.

Devido a essa limitação do aprendizado supervisionado, diversos pesquisadores têm buscado alternativas para rotular exemplos durante o processo de aprendizado, quando o número de exemplos rotulados disponível é baixo. Essa área de pesquisa recebe o nome de Aprendizado Semissupervisionado, cujo foco principal é combinar efetivamente os poucos exemplos rotulados e os não rotulados durante o processo de aprendizado, e é um tema de central importância no contexto de aprendizado de máquina (Zhu et al., 2003; Zhou 
\& Li, 2010).

Neste capítulo são apresentados alguns conceitos relacionados ao aprendizado de máquina semissupervisionado e diversas abordagens propostas na literatura para essa tarefa de classificação considerando conjuntos de dados monorrotulados. A motivação e justificativa para a utilização desse modo de aprendizado, bem como os diferentes tipos de semissupervisão são apresentados nas Seções 4.1 e 4.2. A representação do conjunto de treinamento é descrita na Seção 4.3. Os dois pressupostos necessários para a utilização da semissupervisão, bem como a utilidade desse tipo de aprendizado, são apresentados nas Seções 4.4 e 4.5, respectivamente. Na Seção 4.6 são descritos os distintos modelos em que os algoritmos de aprendizado semissupervisinados podem ser desenvolvidos. Na Seção 4.7 é descrito com mais detalhes o modelo de aprendizado baseado em desacordo e, por fim, na Seção 4.8 são apresentados os conceitos relacionados ao aprendizado ativo.

\subsection{Motivação e justificativa para o uso do aprendi- zado semissupervisionado}

Além da representatividade, a quantidade de exemplos de treinamento é um fator importante para a qualidade do classificador construído. A necessidade de um grande número de exemplos de treinamento implica em uma restrição forte para a utilização de algoritmos de aprendizado supervisionado em aplicações e/ou problemas reais, pois nem sempre é possivel encontrar um conjunto de treinamento com número suficiente de exemplos para que seja construído um bom classificador. Por outro lado, exemplos não rotulados (para os quais a classe não é conhecida a priori) são abundantes para muitas aplicações, como o processamento de linguagem natural, a bioinformática, o reconhecimento de voz e a classificação de textos. Outro exemplo é a tarefa de classificação de funções de proteínas, na qual a rotulação manual de uma única proteína pode levar meses de estudos e análises laboratoriais, necessitando muitas vezes da utilização de equipamentos especializados e, também, do acompanhamento diário de um especialista do domínio. Consequentemente, esse processo lento, trabalhoso e caro acarreta na falta de exemplos de treinamento para utilizar algoritmos de aprendizado supervisionado.

Em geral, os exemplos não rotulados provêem informação sobre a distribuição de probabilidade dos dados, enquanto que exemplos rotulados fornecem informação sobre a distribuição condicional dos dados relativa às classes do problema (Belkin \& Niyogi, 2004). Algoritmos capazes de combinar esses dois tipos de informação durante o processo de aprendizado constituem o apren- 
dizado semissupervisionado (Chapelle et al., 2006; Zhu, 2008; Ghani, 2002), o qual foi originado a partir do trabalho de Shahshahani \& Landgrebe (1994). Outras tentativas de utilização de exemplos não rotulados precedem esse trabalho (Hosmer, 1973; McLachlan, 1975; O’Neill, 1978; McLachlana \& Ganesalingama, 1982; Lippmann, 1989). No entanto, somente após o trabalho de Blum \& Mitchell (1998) esse modo de aprendizado ganhou maior atenção da comunidade científica e, com isso, foi possivel entender melhor o valor dos exemplos não rotulados para o processo de aprendizado.

Vários autores defendem a ideia de que a maior parte do aprendizado (humano ou animal) ocorre de maneira semissupervisionada. Segundo Belkin et al. (2006):

"Estamos constantemente expostos a uma infinidade de estimulos naturais, que representam os dados não rotulados aos quais temos fácil acesso. Por exemplo, no contexto de aquisição fonológica, uma criança é exposta a muitos sons ou ruídos acústicos. Esses sons usualmente não chegam acompanhados de um marcador fonológico, em outras palavras, não contêm um rótulo que os classifica. Nesse caso, um pequeno conhecimento de fundo ou alguma forma de supervisão é suficiente para que a criança possa identificar o tipo fonético do estímulo recebido, i.e., o mapeamento entre o som e o seu significado. Como forma de supervisão para esses casos, podem ser utilizadas imagens nas quais são representados o significado do som emitido."

A habilidade dos seres humanos de aprender conceitos utilizando muitos dados não supervisionados e poucos dados supervisionados sugere que exemplos não rotulados possam ser utilizados no processo de aprendizado de máquina. Nesse contexto, a ideia básica do aprendizado semissupervisionado é explorar os poucos exemplos rotulados disponíveis para adquirir informações sobre o problema, e com essa informação guiar o processo de aprendizado sobre os exemplos não rotulados, os quais são então classificados e passam a fazer parte do conjunto de exemplos rotulados.

\subsection{Tipos de supervisão parcial}

Como visto anteriormente, um tipo de supervisão parcial ocorre quando existe apenas um pequeno número de exemplos rotulados que são utilizados para guiar o processo de aprendizado conjuntamente com um grande número de exemplos não rotulados. Este cenário é comumente encontrado em diversas aplicações reais, como a classificação automática de páginas web em categorias semânticas (Yeung et al., 2007). 
Outro tipo de supervisão parcial é comumente empregada em tarefas de aprendizado semissupervisionado baseado em distâncias ou medidas de similaridade, como no caso do clustering semissupervisionado (Basu et al., 2002; Klein et al., 2002). Nesse caso, a supervisão parcial é dada por meio de restrições de conectividade aplicadas a alguns pares de exemplos de treinamento. As restrições de conectividade frequentemente utilizadas são must-link e cannot-link, as quais indicam, respectivamente, os casos em que um par de exemplos deve obrigatoriamente ser colocado no mesmo cluster ou em clusters diferentes (Wagstaff et al., 2001). Um exemplo de aplicação na qual esse tipo de supervisão parcial pode ser utilizado é a tarefa de análise de proteínas, na qual as interações entre diferentes proteínas podem ser naturalmente representadas por meio de restrições que indicam se um determinado par de genes é similar (em termos de funcionalidade) e consequentemente é marcado como must-link, ou dissimilar, recebendo a restrição cannot-link.

Enquanto as informações de supervisão em forma de rótulos de classe podem ser transformadas em restrições de similaridade ou dissimilaridade, a transformação inversa, em geral, não é possível, exceto em casos especiais nos quais o problema considera apenas duas classes. Nesse contexto, o tipo de supervisão parcial baseado em restrições é mais fraco que o caso em que há exemplos rotulados. Os algoritmos utilizados neste trabalho de pesquisa fazem uso da supervisão parcial baseada em rótulos de classe. Desse modo, o termo supervisão parcial será utilizado sempre como referência a esse tipo supervisão, exceto quando mencionado o contrário.

\subsection{Representação do conjunto de treinamento}

De maneira análoga ao aprendizado supervisionado, no aprendizado semissupervisionado os exemplos também são usualmente representados por meio de uma tabela atributo-valor. Contudo, a coluna referente ao atributo classe não contém valores para todos os exemplos de treinamento, pois apenas alguns exemplos encontram-se rotulados. Assim, o conjunto de treinamento pode ser dividido em dois subconjuntos, os quais são ilustrados a seguir considerando conjuntos de dados monorrótulo.

1. os exemplos rotulados $\operatorname{Tr}^{l}=\left\{\left(\boldsymbol{x}_{i}^{l}, y_{i}\right) \mid i=1 \ldots p\right\}$, para os quais os rótulos $y_{j}$ estão disponíveis; e

2. os exemplos não rotulados $\operatorname{Tr}^{u}=\left\{\left(\boldsymbol{x}_{p+k}^{u}, ?\right) \mid k=1 \ldots s\right\}$, para os quais os rótulos não são conhecidos. Observe que $s \gg p$.

O conjunto de exemplos de treinamento $\operatorname{Tr}=\operatorname{Tr}^{l} \cup \operatorname{Tr}^{u}$, ilustrado na Tabela 4.1, é apresentado a um algoritmo para a construção de uma função 
$f: X \rightarrow Y$, que prediz o valor de $f(\boldsymbol{x})$ para um exemplo $\boldsymbol{x} \in \operatorname{Tr}^{u}$ a partir do seu vetor de valores dos atributos $\boldsymbol{x}=\left(x_{1}, x_{2}, \ldots, x_{M}\right)$. Assim, $X$ e $Y$ são, respectivamente, o espaço de "entrada" e o espaço de "saída" da função $f$.

Tabela 4.1: Exemplos semissupervisionados monorrótulo no formato atributovalor.

\begin{tabular}{|c|c|c|c|c|c|}
\hline Exemplo & $X_{1}$ & $X_{2}$ & $\ldots$ & $X_{M}$ & $Y$ \\
\hline$E_{1}$ & $x_{11}$ & $x_{12}$ & $\ldots$ & $x_{1 M}$ & $y_{1}$ \\
\hline$E_{2}$ & $x_{21}$ & $x_{22}$ & $\ldots$ & $x_{2 M}$ & $?$ \\
\hline$E_{3}$ & $x_{31}$ & $x_{32}$ & $\ldots$ & $x_{3 M}$ & $y_{3}$ \\
\hline$E_{4}$ & $x_{41}$ & $x_{42}$ & $\ldots$ & $x_{4 M}$ & $?$ \\
\hline$E_{5}$ & $x_{51}$ & $x_{52}$ & $\ldots$ & $x_{5 M}$ & $?$ \\
\hline : & • & : & $\ddots$ & : & : \\
\hline$E_{N}$ & $x_{N 1}$ & $x_{N 2}$ & $\ldots$ & $x_{N M}$ & $y_{N}$ \\
\hline
\end{tabular}

\subsection{Pressupostos do aprendizado semissupervisionado}

Para que o potencial do aprendizado semissupervisionado seja efetivamente aproveitado, alguns pressupostos devem ser satisfeitos, sem os quais não seria possível a generalização das classes do problema a partir de um conjunto pequeno de exemplos rotulados. Duas suposições comumente empregadas no aprendizado semissupervisionado são descritas a seguir (Chapelle, 2006):

Semi-supervised smoothness assumption: a função de rotulamento varia de maneira mais suave em regiões de alta densidade que em regiões de baixa densidade. Assim, a densidade dos dados também é importante no processo de aprendizado de um algoritmo semissupervisionado.

Suposição: se dois exemplos $\boldsymbol{x}_{1}$ e $\boldsymbol{x}_{2}$ localizados em uma região de alta densidade estão próximos, então também devem estar os respectivos resultados da função de rotulamento $f\left(\boldsymbol{x}_{1}\right) \approx f\left(\boldsymbol{x}_{2}\right)$.

Observe que, se existe uma região do espaço de exemplos contínua e densamente ocupada, dificilmente é possível distinguir duas classes diferentes de exemplos nessa região.

Cluster assumption: a partir de um expressivo número de exemplos não rotulados é possivel identificar agrupamentos de dados que representam regiões de alta densidade no espaço de atributos, separados por regiões de baixa densidade.

Suposição: se dois exemplos estão no mesmo cluster eles tem grandes chances de pertencerem a mesma classe. 
Desse modo, os algoritmos de clustering poderiam usar os exemplos rotulados para definir o rótulo da classe de cada agrupamento.

Note que a suposição de existência de clusters não implica que cada classe corresponde a um único cluster compacto, ela simplesmente significa que, usualmente, não são encontrados exemplos de classes diferentes em um mesmo cluster.

Manifold assumption: essa suposição está relacionada à dimensionalidade dos dados e à solução para um problema muito comum com diversos métodos de aprendizado de máquina, a Maldição da Dimensionalidade, a qual ocorre quando os dados são representados por um número muito grande de atributos descritores e torna a tarefa extremamente complexa em termos de tempo computacional.

Suposição: os exemplos representados em alta dimensionalidade, grosso modo, estão em manifolds de baixa dimensionalidade.

Assim, se os dados podem ser representados por manifolds de baixa dimensionalidade, os algoritmos de aprendizado podem utilizar essa representação de baixa dimensionalidade para a construção dos modelos de classificação, evitando a Maldição da Dimensionalidade.

Os pressupostos apresentados estão relacionados ao conceito de separação de baixa densidade, a qual é empregada em alguns algoritmos de aprendizado semissupervisionado. No entanto, independentemente de qual pressuposto é utilizado, o consenso é que os exemplos não rotulados fornecem informação útil a respeito da distribuição dos dados, e isso é um fator chave para o sucesso dos algoritmos semissupervisionados. Embora vários métodos não tenham sido explicitamente derivados a partir de alguma das suposições apresentadas, muitos algoritmos implementam um ou mais dos pressupostos.

\subsection{Utilidade da supervisão parcial}

Quando métodos de aprendizado semissupervisionado são utilizados, surge naturalmente uma questão entre seus praticantes:

"A supervisão parcial, seja ela em forma de exemplos rotulados, restrições de conectividade ou em outra forma de conhecimento de fundo, é útil para tarefas de aprendizado de máquina? Mais precisamente, comparado aos métodos puramente supervisionados, a utilização adicional de exemplos não rotulados melhora o desempenho dos classificadores construídos?" 
O aprendizado semissupervisionado pode melhorar desempenho dos classificadores puramente supervisionados em relação à precisão da classificação de novos exemplos. Mas para que isso ocorra, um pré-requisito deve ser satisfeito:

"A distribuição dos exemplos não rotulados deve ser relevante para o problema de classificação" (Cozman \& Cohen, 2002).

Formalmente, pode-se dizer que o conhecimento sobre a distribuição marginal dos dados não rotulados, $p(\boldsymbol{x})$, deve conter informações úteis para o processo de inferência da probabilidade condicional $p(y \mid \boldsymbol{x})$. Entretanto, se a distribuição desses exemplos não incorporar informação relevante, os algoritmos semissupervisionados não obterão melhoras em relação aos supervisionados. É possível, ainda, que os exemplos não rotulados levem à construção de modelos que degradem a precisão do classificador ao invés de melhorar, devido à pressuposições não satisfeitas.

Deve ser observado que os exemplos não rotulados não provêem tanta informação quanto os exemplos rotulados a respeito de $p(y \mid \boldsymbol{x})$, e, sozinhos, não são suficientes para que um classificador obtenha melhor resultado que métodos aleatórios (Castelli \& Cover, 1996). Além disso, Castelli \& Cover (1996) mostram que, apesar de úteis, os exemplos não rotulados são exponencialmente menos importantes que exemplos rotulados para tarefas de classificação.

Em (Cozman \& Cohen, 2006) é apresentada uma análise assimptótica para o aprendizado semissupervisionado com modelos de misturas. Nesse trabalho, foi mostrado que exemplos não rotulados sempre serão úteis ao aprendizado se o modelo paramétrico utilizado for "correto" segundo as características da distribuição geradora dos conjunto de dados.

Essas considerações levam à conclusão de que a utilização de supervisão parcial pode contribuir, mas deve ser utilizada com cautela, pois erros na modelagem do problema ou escolhas equivocadas de parâmetros podem degradar o modelo induzido.

\subsection{Métodos de aprendizado semissupervisionado}

Algoritmos de aprendizado semissupervisionado podem ser desenvolvidos segundo modelos distintos, como: modelo gerativo, transdução, baseado em grafos, bootstrapping e baseado em desacordo, descritos brevemente a seguir.

Modelo gerativo: em métodos que seguem o modelo gerativo, o processo de inferência envolve a estimativa de densidades condicionais entre o espaço de atributos e o espaço das classes, i.e., $p(\boldsymbol{x} \mid y)$. Nesse caso, considera-se 
que tanto exemplos rotulados como não rotulados são gerados a partir de um mesmo modelo paramétrico que descreve a geração de dados observados e representa explicitamente a suposição de como esses dados são gerados. Algoritmos desse modelo usualmente tratam o atributo classe como uma informação ausente e empregam o método Expectation Maximization (EM) para a estimativa da probabilidade máxima a posteriori das classes do domínio para a rotulação dos exemplos não rotulados. Esses algoritmos são diferenciados usualmente por meio do modelo gerativo empregado, como Naive Bayes (Nigam et al., 2000) ou misturas gaussianas (Shahshahani \& Landgrebe, 1994). Quando o modelo gerativo utilizado não é adequado para os dados do domínio, a performance do algoritmo semissupervisionado tende a degradar (Cohen et al., 2004; Cozman \& Cohen, 2002).

Modelo transdutivo: no contexto de aprendizado indutivo, o objetivo é induzir uma função que apresente uma baixa taxa de erro de classificação sobre toda a distribuição dos dados (qualquer exemplo do domínio em questão) de uma tarefa em particular. Entretanto, algumas tarefas são mais específicas, como inferir o valor da classe somente para alguns exemplos pré-determinados do domínio. A esse tipo de tarefa mais específica foi dado o nome de inferência transdutiva (Vapnik, 1998). Algoritmos transdutivos utilizam a informação latente nos exemplos não rotulados disponíveis no conjunto de treinamento para ajustar uma função de classificação obtida a partir dos exemplos de treinamento rotulados. Essa mesma função é utilizada para classificar os exemplos não rotulados no conjunto de treinamento minimizando a taxa de erro de classificação apenas sobre esses exemplos. Um algoritmo representante do modelo de transdução, denominado Transductive Support Vector Machines (TSVM), foi proposto por Joachims (1999).

Modelo baseado em grafos: nesse modelo, os algoritmos usualmente constroem um grafo a partir do conjunto de dados, no qual os exemplos rotulados e não rotulados são representados pelos nós e as arestas representam algum tipo de relação, como similaridade. A partir desse grafo, a tarefa de aprendizado semissupervisionado é tratada como um problema de corte mínimo no grafo, de modo que os nós em cada componente conexo resultante contenham o mesmo rótulo de classe (Blum \& Chawla, 2001).

Bootstrapping: é uma abordagem simples para o aprendizado semissupervisionado (Abney, 2007). A ideia é obter um classificador inicial $h^{0}$ usando um algoritmo base supervisionado e o conjunto de exemplos rotulados 
$\operatorname{Tr}^{l}$. Em seguida, $h^{0}$ é utilizado para classificar os exemplos não rotulados em $\operatorname{Tr}^{u}$. Então, aqueles exemplos que foram classificados com alta confiança ${ }^{1}$ são retirados do conjunto $\operatorname{Tr}^{u}$ e colocados em $\operatorname{Tr}^{l}$, com a classe dada por $h^{0}$. Logo após, um novo classificador $h^{1}$ é obtido a partir do conjunto expandido de exemplos rotulados. Esse procedimento iterativo continua até que todos os exemplos em $\operatorname{Tr}^{u}$ tenham sido rotulados ou algum outro critério não permita mais que se rotule exemplos.

O Algoritmo 4.1, denominado SELF-TRAINING (Chapelle et al., 2006), segue a abordagem bootstrapping. Note que melhoresExemplos é a função responsável por selecionar os exemplos que foram classificados com maior grau de confiança em cada iteração do algoritmo. Isso pode ser feito selecionando os exemplos cuja confiança na rotulação não esteja abaixo de um determinado limiar, ou até mesmo rotulando um determinado número de exemplos começando por aqueles que obtiveram a mais alta confiança na classificação.

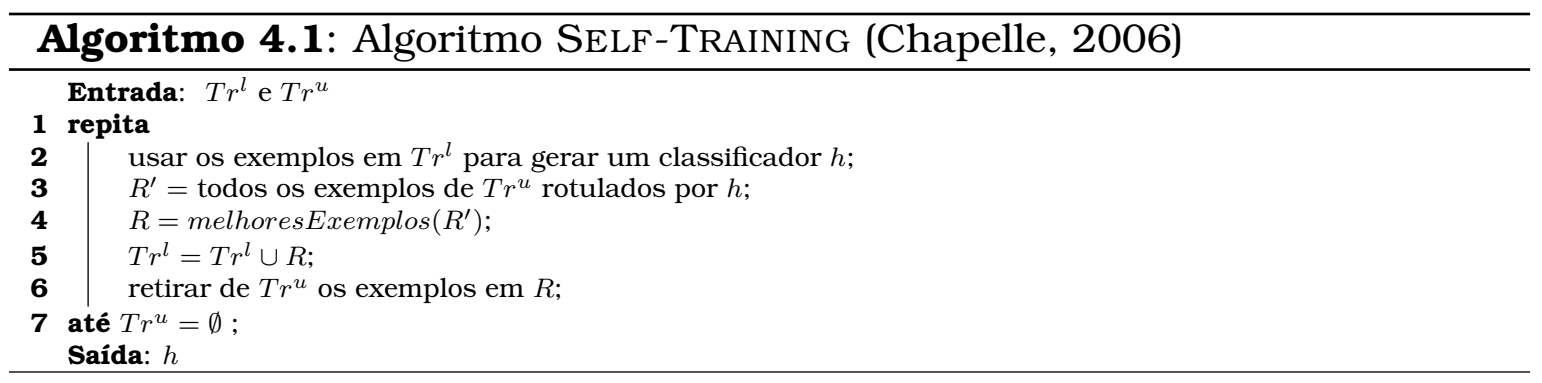

Apesar de simples, a abordagem bootstrapping tem sido bastante utilizada pela comunidade. No entanto, todo algoritmo que segue a abordagem bootstrapping está sujeito à propagação de erros de rotulação, pois quando um exemplo é rotulado erroneamente em uma iteração do algoritmo, esse erro permanecerá nas iterações subsequentes, podendo comprometer a rotulação de outros exemplos.

Como alternativa para minimizar a propagação de erros do modelo bootstrapping, é possível empregar o modelo baseado em desacordo, o qual utiliza mais de uma descrição dos dados, ou mais de um classificador, os quais são construídos utilizando a mesma ou diferentes informações do mesmo domínio, a fim de melhorar o poder de classificação dos algoritmos semissupervisionados. Esse é o modelo de aprendizado semissupervisionado de maior interesse neste trabalho e, por esse motivo, é apresentado em maiores detalhes na próxima seção.

\footnotetext{
${ }^{1} \mathrm{O}$ algoritmo base deve ser capaz de induzir um classificador escore, que é aquele que emite um valor de confiança para a classificação de um exemplo.
} 


\subsection{Aprendizado baseado em desacordo}

Esse modo de aprendizado semissupervisionado foi originado a partir do trabalho de Blum \& Mitchell (1998), no qual os autores propuseram a utilização de dois ou mais classificadores construídos para resolver o mesmo problema de classificação, porém com cada classificador considerando subconjuntos distintos de atributos descritores dos exemplos.

A ideia básica desse modelo de aprendizado é explorar a discordância entre as predições dos diferentes classificadores, de modo que um classificador com maior confiança na predição possa "ensinar" classificadores com menor confiança na predição. Em geral, existem duas abordagens para implementação de algoritmos baseados em desacordo:

1. múltiplas descrições dos dados; e

2. uma única descrição dos dados.

Desde a publicação do trabalho de Blum \& Mitchell (1998), o termo CoTRAINING tem sido utilizado para descrever esses algoritmos. Porém, em (Zhou, 2008) o termo aprendizado semissupervisionado baseado em desacordo foi proposto para descrever a família de algoritmos de aprendizado semissupervisionado que, de alguma maneira, fazem uso de mais de uma descrição do problema para o aprendizado, uma vez que Co-TRAINING é na verdade o nome do algoritmo proposto por Blum \& Mitchell (1998).

As duas abordagens desse modo de aprendizado são apresentadas a seguir.

\subsubsection{Múltiplas descrições e múltiplos classificadores}

Existem tarefas de classificação para as quais é possivel encontrar facilmente duas ou mais maneiras distintas para descrever os objetos que pertencem ao domínio do problema. Exemplos dessas tarefas incluem:

- A filtragem de spam (Kiritchenko \& Matwin, 2001; Koprinska et al., 2007), na qual é possível construir um classificador para identificar spam usando o texto contido no campo assunto das mensagens ou o texto contido no corpo das mensagens;

- Para classificar imagens em uma página web, é possível construir um classificador usando as informações dos pixels das imagens ou o texto que acompanha as imagens (Gupta et al., 2008);

- Para identificar artigos científicos de uma determinada área, é possível construir um classificador usando o texto dos artigos ou usando uma rede de citações extraída dos artigos (Laguna \& Lopes, 2009); e 
- Para identificar funções de proteínas, é possível construir um classificador utilizando como atributos diferentes tipos de informação, por exemplo a sequência primária de aminoácidos, $\alpha$-hélices (estrutura helicoidal formada pelas subsequências de aminoácidos) ou ainda a estrutura tridimensional da proteína (Vapnik \& Vashist, 2009).

Como ilustração, considere a Tabela 4.2, na qual são apresentados os exemplos de treinamento de um domínio $D$ em duas descrições, $d_{1}$ e $d_{2}$, tal que $D=d_{1} \cup d_{2}$ e $d_{1} \cap d_{2}=\emptyset^{2}$. Nesse exemplo, a tarefa consiste em classificar novos exemplos de frutas com base nos atributos descritores que compõem as duas descrições utilizadas para a construção dos classificadores. Desse modo, $d_{1}$ representa as informações visuais de cada fruta, enquanto que $d_{2}$ representa as características nutricionais de cada fruta. É importante observar que as informações em todas as descrições estão presentes para todos os exemplos de treinamento, e que há correspondência entre os índices em cada descrição, ou seja, nessa tabela, as características na linha $i$ em $d_{1}$ e $d_{2}$ se referem ao mesmo objeto $i$.

Tabela 4.2: Duas descrições dos exemplos de treinamento.

\begin{tabular}{|c|c|c|c|c|c|c|c|c|c|c|}
\hline \multicolumn{3}{|c|}{$d_{1}$} & \multicolumn{7}{|c|}{$d_{2}$} & \multirow[b]{2}{*}{ Classe } \\
\hline cor & formato & volume & carboh & vit $_{a}$ & vit $_{b}$ & vit $_{c}$ & $\min _{a}$ & $\min _{b}$ & $\min _{c}$ & \\
\hline laranja & esférico & 10 & 15 & 1340 & 567 & 100 & 40 & 2345 & 87 & cítrica \\
\hline vermelho & esférico & 9 & 2 & 1040 & 367 & 234 & 70 & 1345 & 287 & cítrica \\
\hline verde & esférico & 3 & 9 & 2340 & 395 & 86 & 39 & 1795 & 34 & cítrica \\
\hline laranja & esférico & 2 & 1 & 3540 & 129 & 834 & 89 & 1834 & 33 & cítrica \\
\hline amarelo & cilíndrico & 8 & 34 & 240 & 787 & 145 & 20 & 1845 & 345 & alcalina \\
\hline laranja & cone & 45 & 31 & 2740 & 177 & 385 & 89 & 1723 & 35 & alcalina \\
\hline vermelho & esférico & 98 & 6 & 240 & 128 & 62 & 51 & 1492 & 112 & alcalina \\
\hline
\end{tabular}

A partir das múltiplas descrições dos dados, é possível construir múltiplos classificadores (um para cada descrição), os quais são usados em um processo iterativo e cooperativo de aprendizado, no qual exemplos não rotulados são utilizados para incrementar o número de exemplos rotulados e, com isso, tentar melhorar a performance dos futuros classificadores. Nesse processo, o desacordo na predição de exemplos não rotulados é utilizado como ponto de partida para a melhora dos futuros classificadores, pois quando um exemplo não rotulado é classificado como positivo com alta confiança pelo classificador na primeira descrição e como negativo com baixa confiança pelo classificador na segunda descrição, esse exemplo torna-se um exemplo rotulado bastante informativo para o aprendizado do classificador na segunda descrição. Assim, é possivel criar métodos de aprendizado semissupervisionado nos quais os classificadores construídos nas diferentes descrições fornecem exemplos rotulados com alta confiança uns aos outros, contornando o problema da

\footnotetext{
${ }^{2}$ É importante lembrar que a intersecção vazia se refere apenas aos atributos descritores, de modo que os atributos presentes em uma descrição não fazem parte da outra descrição.
} 
escassez de exemplos rotulados. Essa ideia é explorada pelo algoritmo CoTRAINING, o qual pode ser visto como a versão multidescrição do algoritmo SELF-TRAining - Algoritmo 4.1 na página 63.

Para a elaboração do algoritmo Co-TRAINING, os autores assumiram que os dados de treinamento são apresentados em duas descrições distintas e redundantes e que, além disso, as descrições são condicionalmente independentes e suficientes para o aprendizado de um classificador "forte". Entretanto, Balcan et al. (2004) mostrou que a suposição de independência condicional não é necessária para que métodos baseados em desacordo sejam utilizados. $\mathrm{O}$ pseudo-código do Co-Training é apresentado no Algoritmo 4.2 e uma ilustração do seu funcionamento é apresentada na Figura 4.1, na qual $I_{A}$ e $I_{B}$ representam os indutores usados em cada descrição. Observe que para o algoritmo Co-Training, $I_{A}=I_{B}$, uma vez que as descrições são diferentes.

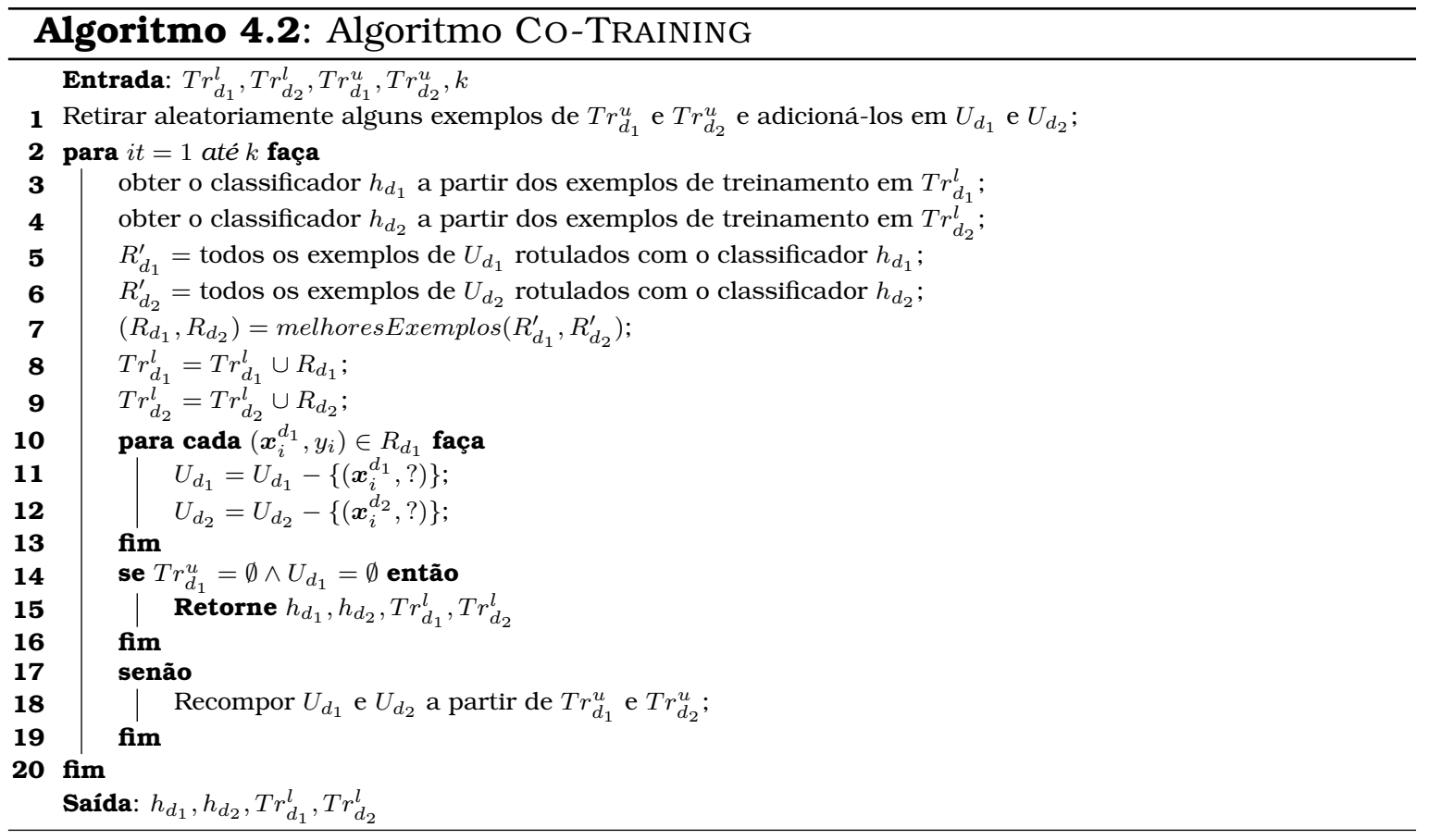

Para melhorar a eficiência desse algoritmo em termos de tempo de execução, e evitar que a cada iteração todos os exemplos não rotulados sejam classificados, é utilizado um conjunto temporário $U$ onde são armazenados apenas uma fração aleatória dos exemplos não rotulados que são retirados de $\mathrm{Tr}^{u}$. Assim, somente os exemplos nessa amostra são classificados em cada iteração. Os exemplos classificados com maior grau de confiança são inseridos no conjunto $\operatorname{Tr}^{l}$ ao final da iteração e, então, o conjunto $U$ é preenchido novamente com exemplos de $T r^{u}$.

A função melhoresExemplos (Algoritmo 4.3) é responsável por selecionar, em cada descrição dos dados, os exemplos que foram mais bem classificados, i.e., cuja predição foi obtida com alto grau de confiança. Uma descrição de- 


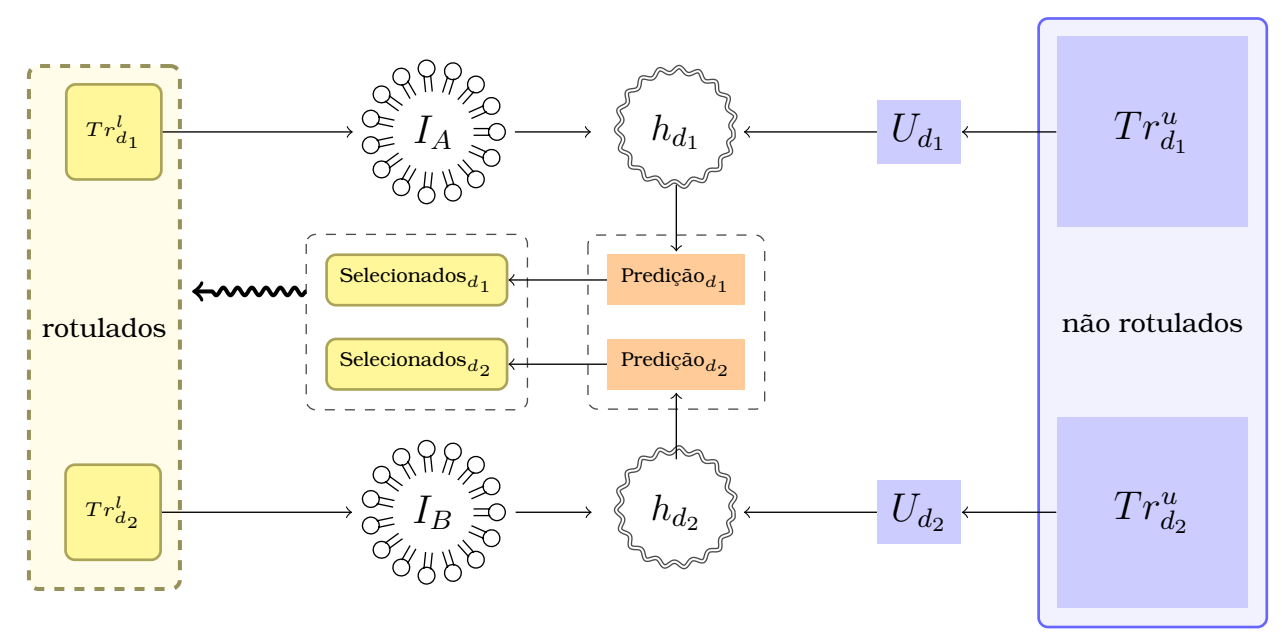

Figura 4.1: Ilustração do algoritmo CO-TRAINING.

talhada do algoritmo Co-TRAINING pode ser encontrada em (Braga \& Monard, 2010).

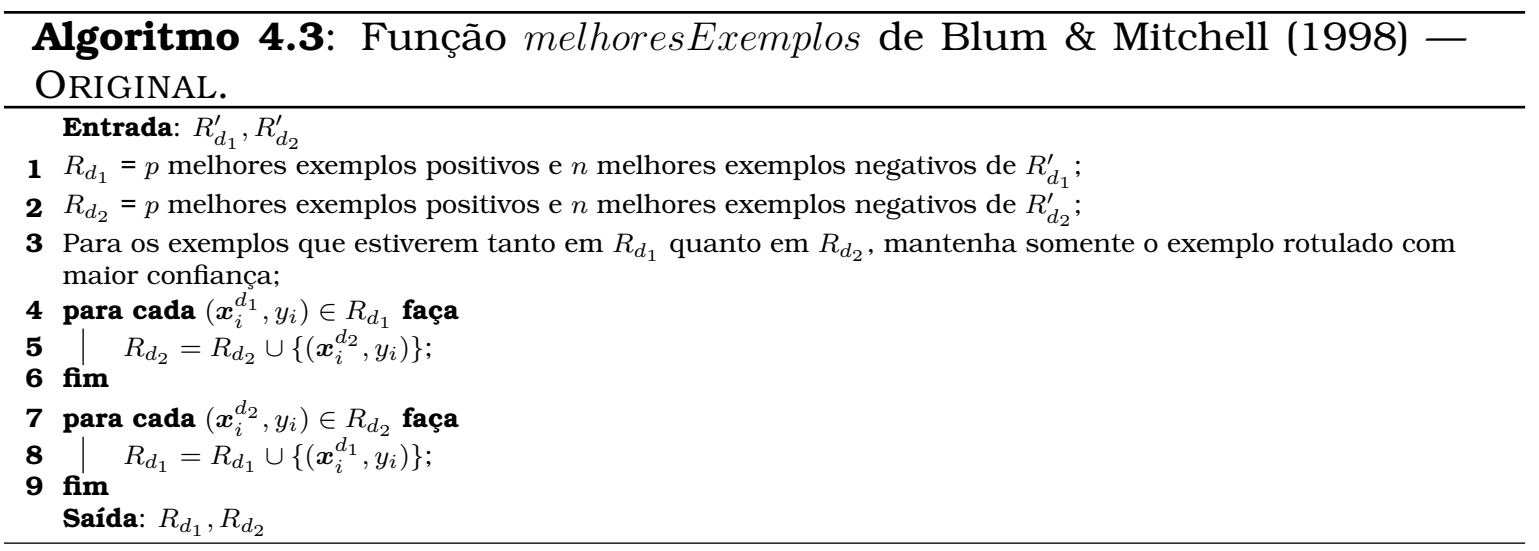

Deve ser observado que o critério de seleção dos melhores exemplos, assim como o número de exemplos de cada classe a serem rotulados em cada iteração do algoritmo, são parâmetros importantes da função melhoresExemplos. Na proposta original de Co-TrAining (Blum \& Mitchell, 1998), o conjunto de exemplos utilizado possui somente duas classes, e os autores sugerem selecionar os $p$ "melhores" exemplos positivos e os $n$ "melhores" exemplos negativos em cada descrição para incrementar o conjunto de exemplos rotulados, sendo que "melhores" exemplos se referem aos exemplos rotulados com a mais alta confiança. Porém, estimar os valores de $p$ e $n$ na presença de poucos exemplos rotulados é um problema adicional que deve ser tratado pelo Co-TRAINING. Em (Matsubara et al., 2006), foi verificado experimentalmente que uma escolha de $p$ e $n$ em uma proporção muito diferente da distribuição natural das classes tende a degradar o desempenho de Co-TRAINING. 


\subsubsection{Monodescrição e múltiplos classificadores}

Em muitas aplicações reais pode não ser possível encontrar mais de uma descrição dos dados, ou por não existirem, ou pelo custo de se obter uma segunda descrição.

Grande parte das aplicações reais é representada por apenas um conjunto de atributos. Com isso, a aplicabilidade do algoritmo Co-Training é limitada. Assim, para que algoritmos semissupervisionados possam ser projetados baseados no modelo de desacordo e cooperação entre diferentes classificadores base, é necessário que sejam desenvolvidos métodos que não necessitem de múltiplas descrições.

Uma abordagem para solucionar esse problema é construir diversos classificadores distintos sobre a mesma descrição dos dados, desde que cada classificador base tenha um bias distinto, ou seja, a maneira como os dados são utilizados pelos algoritmos base de aprendizado deve ser significativamente diferente, permitindo que cada classificador interprete a mesma descrição a partir de "perspectivas" diferentes (Zhou \& Li, 2005). Para isso, pode-se adaptar o algoritmo Co-TRAINING "replicando" a descrição dos dados para a construção dos dois classificadores, como no Algoritmo 4.4, mas, nesse caso, $I_{A} \mathrm{e}$ $I_{B}$ representam dois algoritmos de aprendizado diferentes e com bias distintos, i.e., $I_{A} \neq I_{B}$.

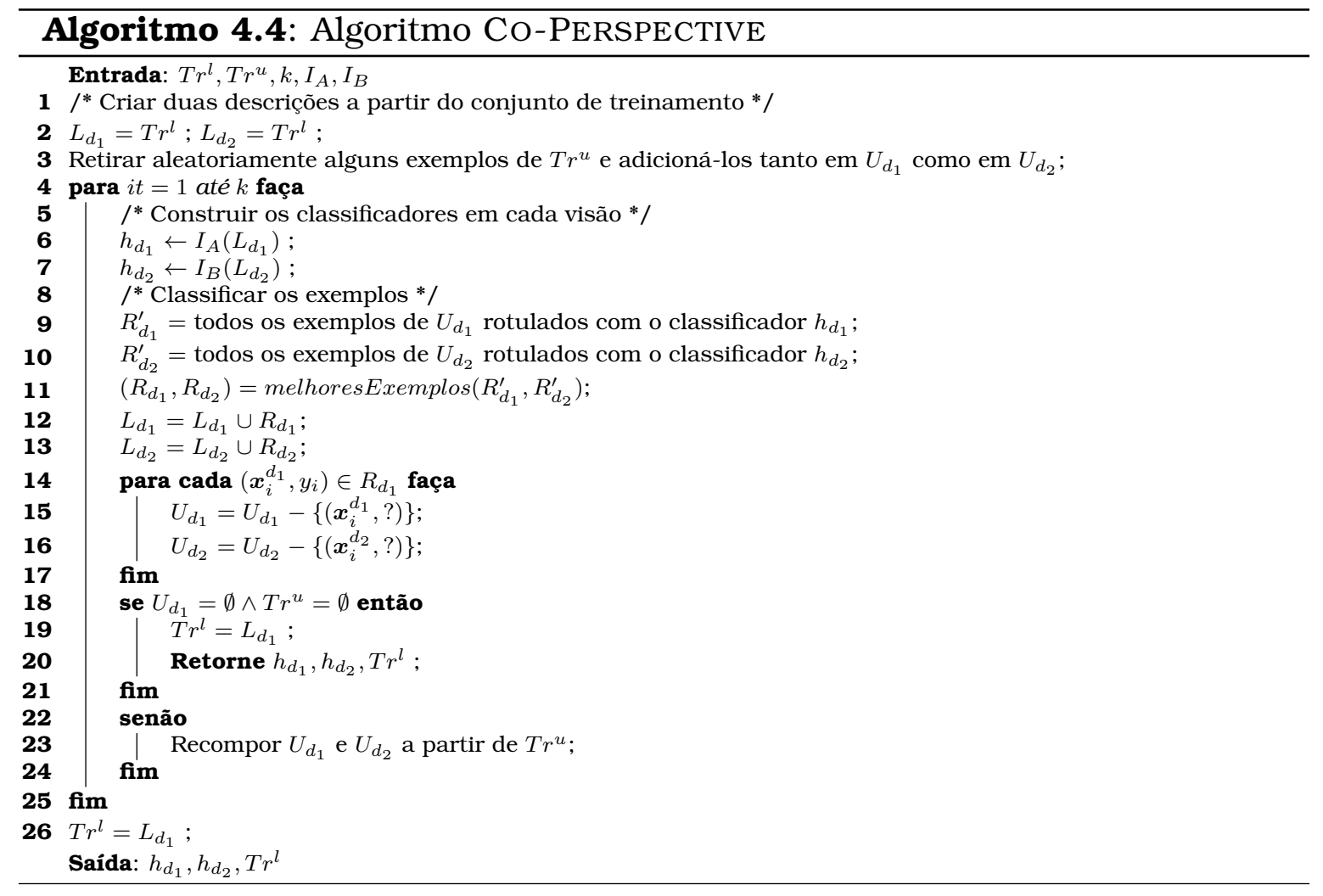




\subsection{Aprendizado ativo}

Algoritmos de aprendizado baseados em desacordo, em geral, apresentam um problema inerente a esse modelo:

"Como definir o rótulo da classe para exemplos cujas predições são conflitantes?"

Como a predição resultante de cada classificador não é necessariamente a mesma, i.e., $h_{d_{1}}\left(\boldsymbol{x}^{d_{1}}\right)=\hat{y}^{d_{1}}$ e $h_{d_{2}}\left(\boldsymbol{x}^{d_{2}}\right)=\hat{y}^{d_{2}}$, quando $\hat{y}^{d_{1}}=\hat{y}^{d_{2}}$, e a predição é obtida com alto grau de confiança, significa que os dois classificadores concordam com a classificação e se reforçam nessa predição. Por outro lado, quando ocorre um desacordo com alta confiança entre os classificadores, $\hat{y}^{d_{1}} \neq \hat{y}^{d_{2}}$, o rótulo desse exemplo, denominado ponto de contenção, deve ser determinado de outra maneira.

$\mathrm{O}$ algoritmo CO-TRAINING define os rótulos de pontos de contenção de maneira arbitrária, o que propicia a introdução de um erro de rotulação, já que somente uma das classificações é correta. Se um ponto de contenção tiver sido selecionado pela função melhoresExemplos (Algoritmo 4.3), então ele passa a integrar o conjunto de exemplos rotulados, o que não é desejável, pois não é possível decidir o rótulo correto de um ponto de contenção sem informação adicional. Deve ser observado que essa situação pode acontecer facilmente nas iterações iniciais de Co-TRAINING pois $T r^{l}$ é muito pequeno, propagando o erro para as iterações seguintes.

Para solucionar o problema dos pontos de contenção, o qual é discutido em detalhes em (Braga, 2010), e ainda explorar as informações contidas nos exemplos não rotulados considerando o desacordo entre os diferentes classificadores, pode-se utilizar algoritmos de aprendizado ativo, os quais assumem a existência de um oráculo ${ }^{3}$ a partir do qual é possivel descobrir a classificação verdadeira para um número finito (usualmente pequeno) de exemplos (Zhang \& Sun, 2010). Em outras palavras, o algoritmo tem direito de realizar algumas poucas consultas ao oráculo, cujas respostas são utilizadas para definir a classificação dos pontos de contenção. Na prática, o algoritmo de aprendizado ativo seleciona iterativamente alguns exemplos para os quais não houve consenso entre os classificadores e solicita ao usuário (especialista) que rotule esses exemplos.

O objetivo é minimizar o número de consultas ao oráculo e, ainda assim, construir um classificador forte. Para isso, um fator chave para o sucesso dessa estratégia é selecionar os pontos de contenção mais informativos para

\footnotetext{
${ }^{3} \mathrm{Um}$ oráculo pode ser um especialista do domínio, um usuário do sistema ou um outro dispositivo que informe o rótulo correto de um exemplo.
} 
a consulta, i.e., os exemplos que apresentam o maior grau de desacordo entre os classificadores construídos em cada descrição (Zhou \& Li, 2010).

Existem duas abordagens mais comumente utilizadas para essa tarefa: amostragem baseada em incerteza ${ }^{4}$ e amostragem baseada em comitê $\hat{~}^{5}$. A primeira constrói um único classificador, o qual é utilizado para classificar exemplos não rotulados; os exemplos que são classificados com menor grau de confiança são, então, selecionados para consulta ao oráculo (Lewis \& Gale, 1994). No caso da amostragem baseada em comitê, múltiplos classificadores são utilizados e, com base no maior grau de desacordo das predições desses classificadores, os exemplos são selecionados para a consulta ao oráculo (Seung et al., 1992; Abe \& Mamitsuka, 1998; Greene \& Cunningham, 2007). Neste trabalho utilizamos métodos baseados na segunda abordagem.

Algumas soluções propostas na literatura para esse problema são apresentadas brevemente a seguir.

Solução I: Não rotular pontos de contenção.

Uma solução direta de resolver o problema dos pontos de contenção é desconsiderá-los, o que pode ser realizado pela função melhores Exemplos. Em (Braga, 2010), é proposta uma função melhoresExemplos para tratar pontos de contenção, denominada NoConTEnTION ${ }^{6}$ - Algoritmo 4.5.

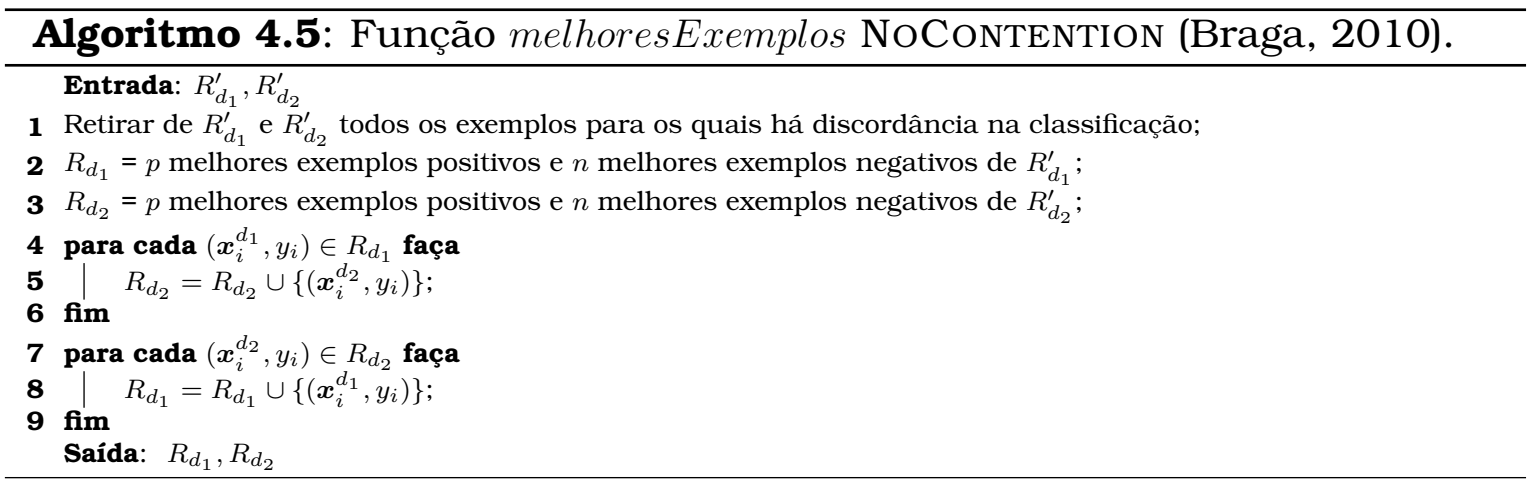

Observe que a função NoCONTENTION apresentada no Algoritmo 4.5 foi projetada para trabalhar com duas descrições dos exemplos e com duas classes. Para obter uma solução nessa mesma linha para os casos em que existam mais de duas descrições e mais de duas classes, é necessário generalizar a definição de ponto de contenção.

Solução II: Algoritmo Co-Testing.

Co-Testing (Muslea et al., 2000, 2006), descrito pelo Algoritmo 4.6, é um algoritmo multidescrição de aprendizado ativo. Esse algoritmo constrói

\footnotetext{
${ }^{4}$ Uncertainty sampling.

${ }^{5}$ Committee-based sampling.

${ }^{6}$ A função NoCONTENTION foi originalmente apresentada em (Matsubara, 2004; Braga et al., 2009) com uma ligeira diferença em relação à que é considerada em (Braga, 2010).
} 
os classificadores $h_{d_{1}}$ e $h_{d_{2}}$ utilizando os conjuntos $\operatorname{Tr}_{d_{1}}^{l}$ e $\operatorname{Tr}_{d_{2}}^{l}$ de exemplos rotulados. Em seguida, é construído o conjunto $P C$, o qual contém os exemplos que foram rotulados com classes diferentes em cada descrição, i.e., os pontos de contenção. Se esse conjunto for vazio (não existe discordância nas classificações de $h_{d_{1}}$ e $h_{d_{2}}$ ) o processo termina, caso contrário, a função selecionar escolhe um exemplo a ser submetido ao oráculo por iteração ${ }^{7}$, o qual deve fornecer o rótulo correspondente a esse exemplo. O exemplo $\left(\boldsymbol{x}_{i}^{d_{1}}, \boldsymbol{x}_{i}^{d_{2}}\right)$ rotulado pelo oráculo é retirados do conjunto de exemplos não rotulados (nas duas descrições $U_{d_{1}}$ e $U_{d_{2}}$ ) e inserido, juntamente com o rótulo informado pelo oráculo, no conjunto de exemplos rotulados, i.e., nas descrições $\operatorname{Tr}_{d_{1}}^{l}$ e $\operatorname{Tr}_{d_{2}}^{l}$ de exemplos rotulados. O processo é repetido por até $k$ iterações enquanto forem identificados pontos de contenção, ou seja, $P C \neq \emptyset$.

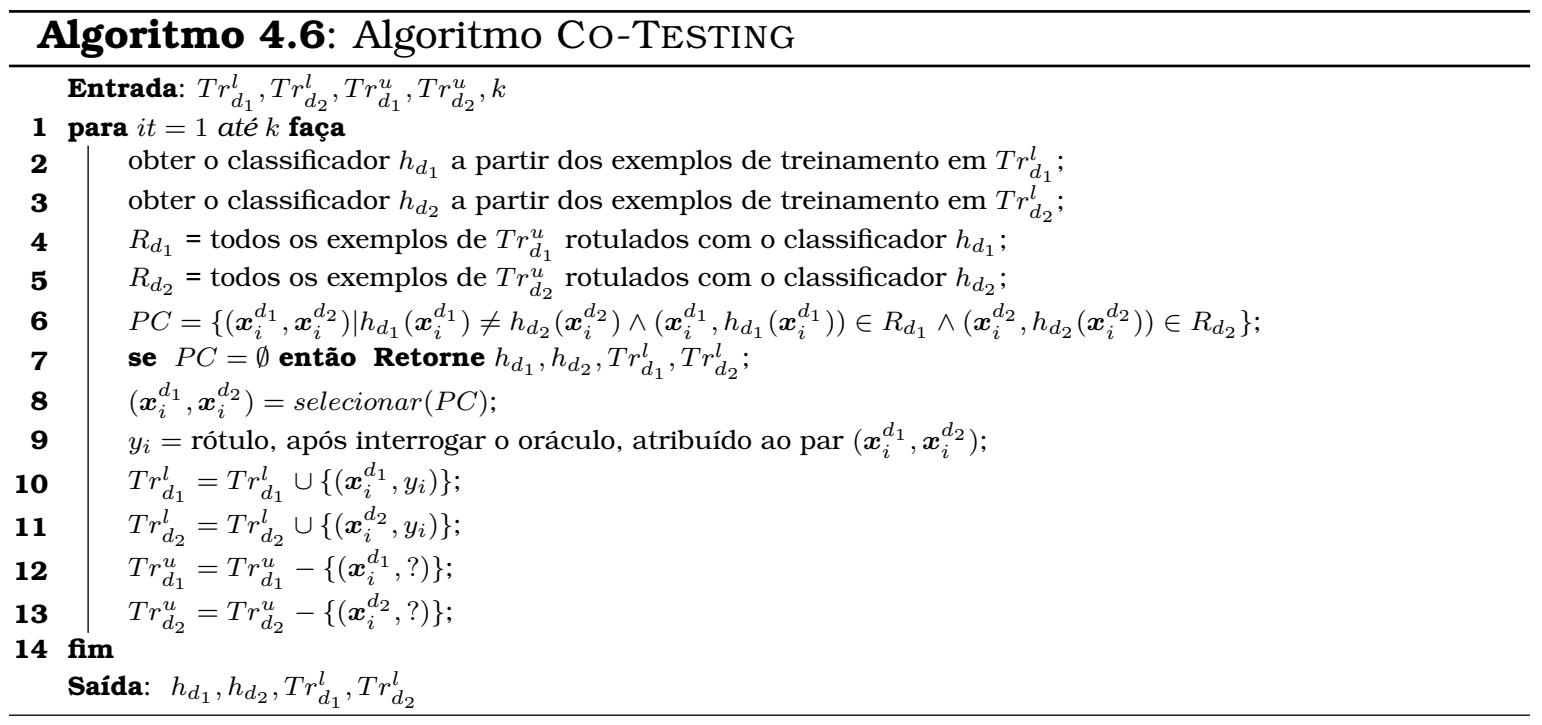

O Co-Testing foi proposto para ser usado com qualquer algoritmo-base de aprendizado, inclusive com algoritmos que não fornecem um valor de confiança para a classificação. Nesse caso, a função selecionar escolhe um exemplo aleatoriamente do conjunto $P C$. Caso seja utilizado um algoritmo-base que dá um valor de confiança (escore) para a classificação, pode-se, então, escolher o exemplo que foi classificado com máximo desacordo. De qualquer maneira, o objetivo em cada iteração é selecionar o exemplo mais informativo para o oráculo rotular.

Solução III: Algoritmo COAL.

O algoritmo COAL - CO-TRAINING with Active Learning - foi proposto por Braga (2010) como uma solução para tratar pontos de contenção no

\footnotetext{
${ }^{7}$ Caso seja necessário o algoritmo Co-TESTING pode ser facilmente adaptado para rotular mais de um ponto de contenção em cada iteração.
} 
algoritmo Co-TRAINING utilizando aprendizado ativo multidescrição nos moldes do algoritmo Co-TESTING.

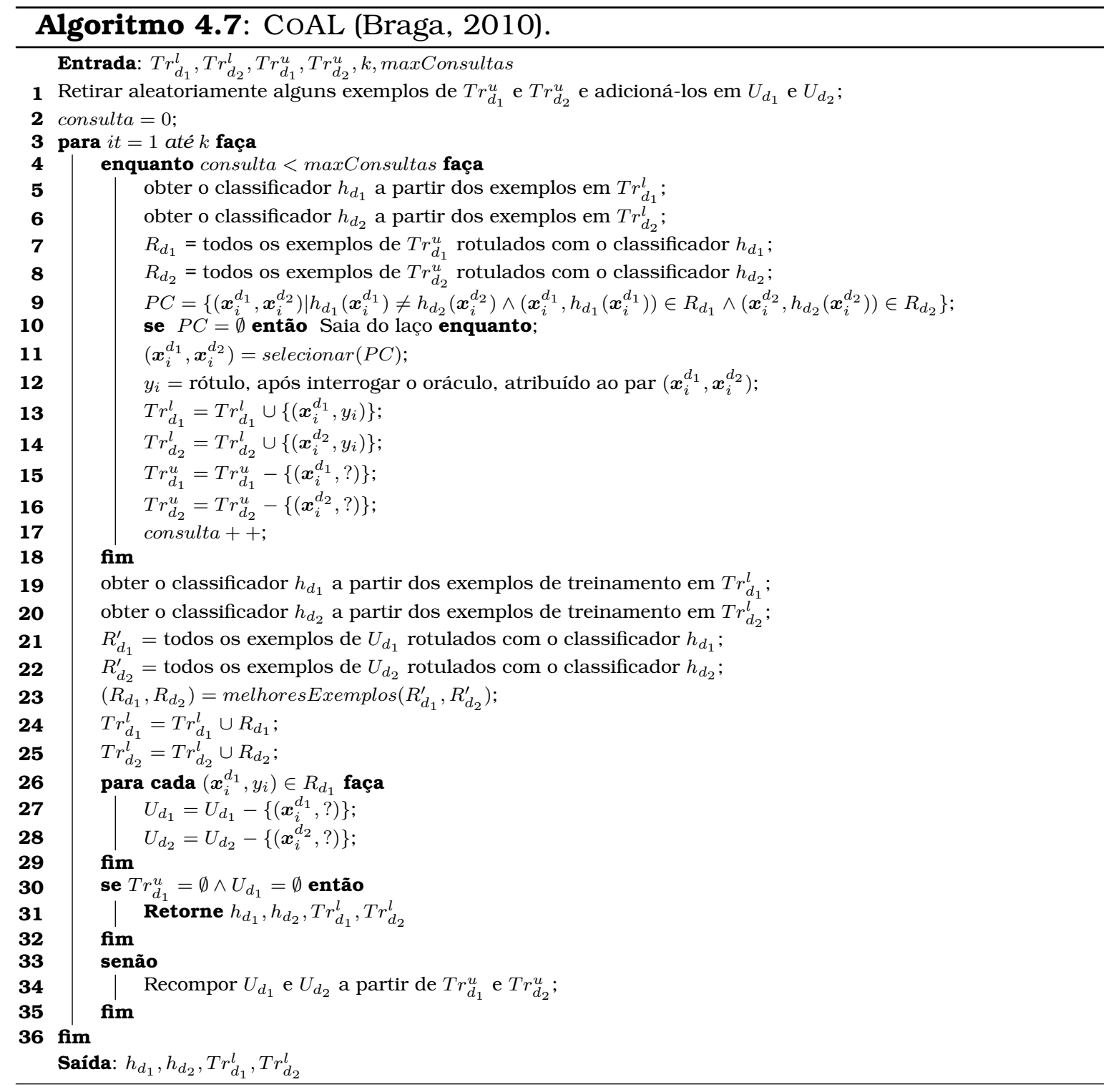

O algoritmo COAL - Algoritmo 4.7 - adiciona ao Co-TRAINING somente o bloco responsável pela identificação e rotulação dos pontos de contenção, que são inseridos no conjunto de exemplos rotulados a cada iteração dos comandos relativos ao Co-TrAINING. Em cada iteração de CoAL, os comandos dentro do bloco enquanto são executados até que não exista mais nenhum ponto de contenção ou o número máximo de consultas ao oráculo tenha sido atingido. Caso essa última condição se verifique, novas consultas não são realizadas nas iterações seguintes do algoritmo COAL.

O algoritmo COAL pode ser vantajoso no aprendizado semissupervisionado quando um usuário desempenha o papel do oráculo durante o processo de aprendizado. Quando um ponto de contenção aparece em uma 
execução de CoAL usando duas descrições e conjuntos de exemplos com duas classes, um dos classificadores está classificando erroneamente e com alta confiança o exemplo não rotulado. Assim, a rotulação do usuário contribui para que esse classificador seja corrigido em um exemplo na qual sua predição foi a pior possivel. Se os pontos de contenção aparecem logo nas primeiras iterações, o algoritmo CoAL pode ser ainda mais benéfico, pois evita que os erros de rotulação que seriam causados por esses pontos se propaguem ao longo de suas iterações.

A estratégia para identificação e classificação dos pontos de contenção usada pelo algoritmo CoAL pode ser facilmente utilizada também quando apenas uma descrição dos dados de treinamento existe, desde que mais de um classificador seja construído para resolver o mesmo problema nos moldes do aprendizado baseado em desacordo. Desse modo, essa estratégia pode ser facilmente adaptada e inserida no algoritmo Co-PERSPECTIVE, na página 68, Algoritmo 4.4.

\subsection{Considerações finais}

Em muitas aplicações de Mineração de Dados existe uma grande limitação quanto à disponibilidade de exemplos de treinamento rotulados, uma vez que a rotulação manual desses exemplos, em geral, envolve um processo altamente custoso, demorado e dependente do conhecimento de um especialista do domínio. Consequentemente, a construção de bons modelos de classificação é prejudicada devido à falta de exemplos previamente rotulados com classes do domínio. Por outro lado, exemplos não rotulados são abundantes e, geralmente, têm um custo muito baixo.

Neste capitulo foram apresentados alguns algoritmos que permitem a utilização de exemplos rotulados e não rotulados para a tarefa de classificação semissupervisionada com conjunto de dados monorrotulados. Contudo, essa tarefa pode ser realizada mais eficientemente quando há mais de uma maneira pela qual os exemplos do domínio podem ser descritos. Nos casos em que isso é possível, são necessários métodos que sejam capazes de utilizar de maneira eficaz os poucos exemplos rotulados juntamente com os muitos exemplos não rotulados, descritos por um ou mais conjuntos de atributos, a fim de construir bons classificadores semissupervisionados. Os conceitos que envolvem a construção desse tipo de algoritmo, classificados como algoritmos de aprendizado semissupervisionado baseado em desacordo, foram também apresentados neste capítulo.

A estratégia utilizada pelos algoritmos baseados em desacordo, no entanto, acarreta no problema de pontos de contenção, o qual pode ser solucionado por 
meio de algoritmos de aprendizado ativo, também apresentados neste capítulo.

Ainda que os pontos de contenção sejam resolvidos com a utilização do aprendizado ativo, não há garantias de sucesso para todos os casos semissupervisionados. Assim, é importante conhecer os fatores que influenciam no processo de aprendizado de um algoritmo semissupervisionado para tirar proveito das suas características, a fim de maximizar o uso das informações latentes nos dois tipos de exemplos, rotulados e não rotulados, na construção de classificadores. É importante lembrar, também, que esse modo de aprendizado deve ser utilizado com cautela, pois existem diversos fatores que podem levar a degradação do modelo gerado.

No próximo capítulo são descritos os métodos propostos neste trabalho para realizar o aprendizado multirrótulo e hierárquico utilizando os modos de aprendizado supervisionado e semissupervisonado. São propostos, também, dois métodos baselines para auxiliar na avaliação de algoritmos para essas tarefas. 
CAPÍTULO

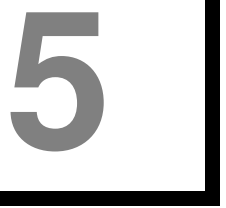

\section{Métodos e soluções propostas para aprendizado multirrótulo e hierárquico}

Como mencionado anteriormente, são diversas as aplicações de classificação multirrótulo e classificação hierárquica para as quais é difícil encontrar um número expressivo de exemplos rotulado para a construção de classificadores. Além disso, as características inerentes a essas duas tarefas tornam a classificação ainda mais complexa, pois, em geral, os exemplos do conjunto de treinamento são distribuídos de maneira desbalanceada entre as muitas classes do problema.

Com o objetivo de minimizar o problema da falta de exemplos de treinamento para a construção de classificadores para essas duas tarefas, propomos neste trabalho vários métodos capazes de aprender as classes dos problemas mesmo em cenários nos quais existem poucos exemplos de treinamento (aprendizado semissupervisionado). São também apresentadas outras propostas cujo objetivo é melhorar a capacidade de predição de algoritmos multirrótulo e hierárquico no contexto de aprendizado supervisionado. Além desses métodos, são propostos dois baselines para avaliação de algoritmos, um para cada tipo de tarefa. Todos esses métodos são listados na Tabela 5.1 e descritos nas próximas seções deste capítulo, de acordo com a seguinte organização:

- Trabalhos em colaboração: na Seção 5.1 são descritos de maneira sucinta os trabalhos realizados durante o projeto em colaboração com uma 
Tabela 5.1: Métodos propostos.

\begin{tabular}{|c|c|c|c|}
\hline Tarefa & \multicolumn{2}{|c|}{ Modo de aprendizado } & Baseline \\
\hline & Supervisionado & Semissupervisionado & \\
\hline Multirrótulo & $\mathrm{BR}_{C o P}$ & $\begin{array}{c}\mathrm{BR}_{S T}, \mathrm{BR}_{C o P S S}, \\
\mathrm{BR}_{C o T \text { esting }} \text { e } \mathrm{BR}_{C o P S S+A L}\end{array}$ & $\mathrm{BR}_{\text {Low }}$ \\
\hline Hierárquico & $\begin{array}{l}\mathrm{HBR}_{C o P}, \mathrm{HMR}_{E x t}, \\
\mathrm{HMR}_{E x t M u l t i} \text { e HDR }\end{array}$ & $\begin{array}{c}\operatorname{HBR}_{S T}, \mathrm{HBR}_{C o P S S}, \\
\mathrm{HBR}_{C o T e s t i n g} \text { e } \mathrm{HBR}_{C o P S S+A L}\end{array}$ & $\mathrm{HBR}_{\text {Low }}$ \\
\hline
\end{tabular}

linha de pesquisa relacionada ao tema desta tese, especificamente a classificação multirrótulo. A partir desses trabalhos, cujo principal objetivo é identificar e utilizar diferentes tipos de dependência de rótulos, foram aprendidos os conceitos necessários para o desenvolvimento dos métodos propostos para a tarefa de classificação multirrótulo;

- Propostas para classificação multirrótulo: na Seção 5.2 é apresentada a proposta do classificador baseline, denominado $\mathrm{BR}_{\text {Low }}$, utilizado como referência de valor mínimo para avaliar a capacidade de aprendizado dos diferentes métodos de classificação multirrótulo. Nas Seções 5.3 e 5.4 são apresentados os métodos propostos para a realização de aprendizado supervisionado e semissupervisionado multirrótulo, respectivamente; e

- Propostas para classificação hierárquica: nas Seções 5.5, 5.6 e 5.7, de maneira análoga às seções relacionadas à classificação multirrótulo, são apresentados o classificador base hierárquico $\mathrm{HBR}_{\text {Low }}$ e os métodos propostos para o aprendizado supervisionado e semissupervisionado hierárquico, respectivamente.

\subsection{Trabalhos em colaboração}

Os trabalhos realizados em colaboração estão relacionados com a linha de pesquisa de classificação multirrótulo com objetivo principal de explorar a dependência de rótulos nessas tarefas, explorando de maneira automática as informações latentes nos conjuntos de dados.

Um consenso da comunidade de aprendizado multirrótulo é que os algoritmos desenvolvidos para essa tarefa devem identificar e utilizar de maneira eficaz as informações de relacionamentos entre os diferentes monorrótulos do problema, principalmente os relacionamentos de dependência entre rótulos. Somente com o uso eficaz dessa informação, os algoritmos poderão alcançar patamares maiores de capacidade de predição.

Nesse contexto, alguns trabalhos foram propostos e publicados com o objetivo de contribuir para a compreensão e utilização mais eficaz da característica 


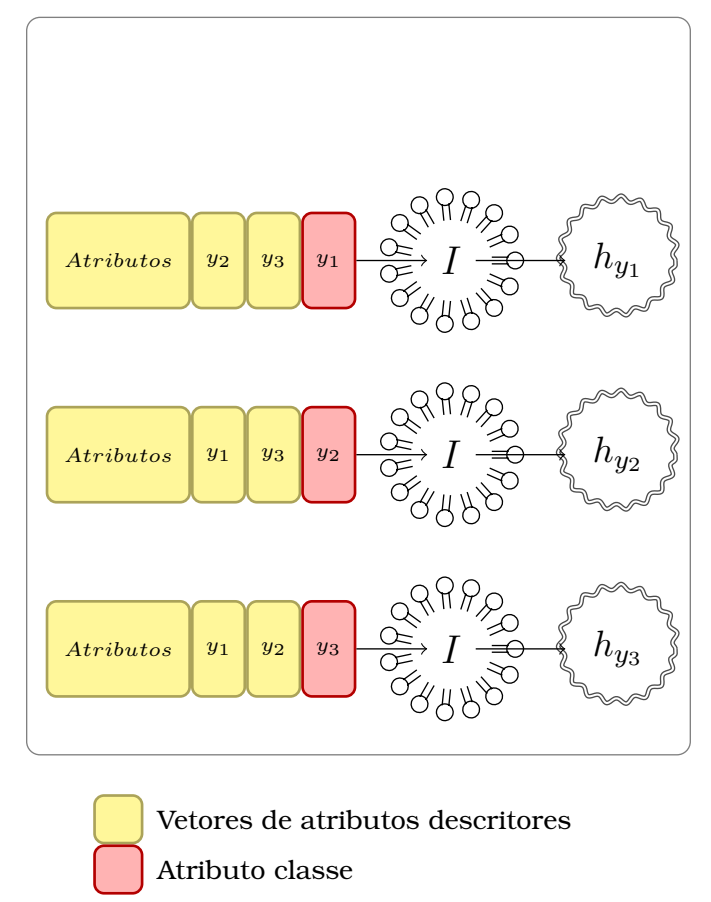

(a) Fase de treinamento

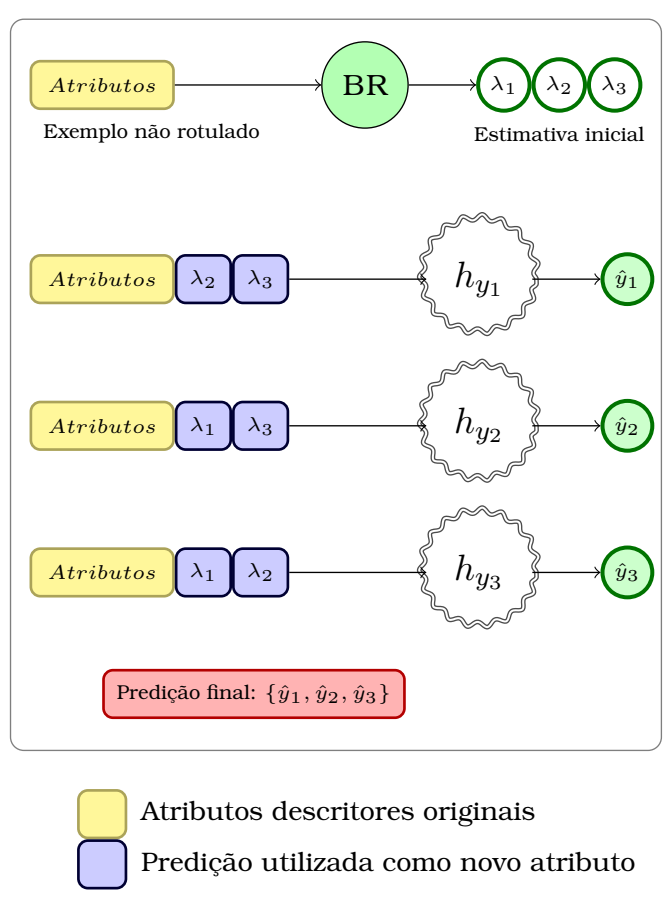

(b) Fase de predição

Figura 5.1: Treinamento e predição do método BR+ (SA).

de dependência de rótulos no processo de aprendizado. Esses trabalhos são descritos a seguir em ordem cronológica e de evolução dos conceitos e, em geral, estão baseados no método $\mathrm{BR}+$, mencionado na Seção 2.3.2.2 na página 21.

\subsection{1 $\mathrm{BR}+$ em dados textuais de medicina}

No trabalho (Cherman et al., 2010c), o classificador multirrótulo BR + foi proposto e aplicado em um estudo de caso envolvendo dados textuais de medicina. Devido à adição de rótulos aos atributos descritores realizado pelo $\mathrm{BR}+$, uma dependência cíclica é criada no momento da predição de um novo exemplo, o qual não possui os valores de rótulos conhecidos. No trabalho (Cherman et al., 2010c), foi apresentada uma proposta inicial para resolução dessa dependência, a qual consiste em realizar uma predição inicial utilizando o classificador BR para estimar os valores de rótulos não disponíveis para novos exemplos. O BR+ em conjunto com essa estratégia de predição foi chamado de $\mathrm{BR}+$ (SA) (Sem Atualização) e foi comparado com dois métodos clássicos de transformação de problemas, BR e LP, descritos na Seção 2.3.2.2. O método $\mathrm{BR}+(\mathrm{SA})$, ilustrado na Figura 5.1(a), apresentou resultados superiores para diversas medidas de avaliação, em muitos casos com diferença estatisticamente significativa.

Esse trabalho foi selecionado entre os melhores trabalhos da Conferência 
Latino-americana de Informática (CLEI'2010) e convidado para expansão e publicação no CLEI Electronic Journal. Desse modo, no trabalho estendido e aceito para publicação no periódico (Cherman et al., 2011) ${ }^{1}$, foram adicionados dois conceitos à análise comparativa dos classificadores:

- conceito de topline do BR+; e

- estratégia de predição com atualização dinâmica do BR+.

No primeiro caso, o conceito de topline, proposto nesse trabalho, consiste em uma estratégia de predição simulada na qual se conhecem os valores verdadeiros dos rótulos de cada exemplo, exceto o valor do rótulo a ser predito em cada problema binário. Essa informação pode ser utilizada pelo método $\mathrm{BR}+$ como predição inicial dos atributos adicionados, o que acarreta na melhor configuração inicial possivel para a segunda etapa do classificador BR+. Consequentemente, espera-se que a partir dessa configuração inicial otimizada o método BR+ apresente resultados melhores que se tivesse utilizado outra estimativa para esses atributos. Desse modo, é possível considerar os resultados obtidos por essa estratégia como uma aproximação do limite superior (topline) da capacidade de predição dos classificadores construídos com o método BR + , ou seja, os valores das medidas de avaliação calculados com base nos resultados obtidos por esse método aproximam o melhor resultado possivel. Por esse motivo, denominamos de Upper Bound Classifier (UBC) o método que faz uso do $\mathrm{BR}+$ com os rótulos verdadeiros como estimativa inicial para a construção dos meta-classificadores.

No segundo caso, embora o conceito de predição com atualização dinâmica tenha sido proposta em (Cherman et al., 2010a) ${ }^{2}$, a comparação do BR+ utilizando essa estratégia de predição foi utilizada na análise comparativa com o BR e LP.

Esses métodos foram comparados em (Cherman et al., 2011), onde foi observada a superioridade do método $\mathrm{BR}+$ com atualização dinâmica (descrita na Seção 5.1.2), muitas vezes com diferença estatisticamente significativa e próximos aos valores de topline.

\subsection{2 $\mathrm{BR}+$ em dados de diversos domínios}

$\mathrm{O} \mathrm{BR}+$ também foi avaliado em bases de dados benchmarks relacionadas a diversos domínios, tais como anotação de imagens e vídeos, classificação de músicas em emoções, classificação de texto da área de medicina, sugestão de tags e categorização de notícias e $e$-mails.

\footnotetext{
${ }^{1}$ http://www.clei.cl/cleiej/paper.php?id=215

${ }^{2}$ Cronologicamente, os trabalhos (Cherman et al., 2010b) e (Cherman et al., 2010a) foram submetidos para publicação antes do trabalho (Cherman et al., 2011).
} 
Em (Cherman et al., 2010b) foram propostas duas novas estratégias de predição para o $\mathrm{BR}+$, ambas consideradas estratégias de predição com atualização estática. A ideia básica consiste em utilizar as predições fornecidas pelo próprio $\mathrm{BR}+$ para atualizar a predição inicial do classificador. Para tanto, uma ordem de atualização dos valores é necessária. Nesse trabalho, dois critérios para a definição da ordem de atualização foram propostos e avaliados: $F-$ e $F+$. Ambos os critérios utilizam a informação da quantidade de exemplos de treinamento associados aos rótulos (frequência) para a definição da ordem. No primeiro caso $(F-)$, os valores de predição relacionados aos classificadores com rótulos menos frequentes são atualizados primeiro. O segundo critério $F+$ corresponde à ordem inversa ao critério $F-$. O procedimento de classificação de novos exemplos utilizando predição com atualização é ilustrado na Figura 5.2, na qual a ordem de atualização pré-definida é $y_{3}, y_{1}$ e $y_{2}$. O novo exemplo é inicialmente apresentado a um classificador BR padrão para obtenção da estimativa inicial para cada um dos monorrótulos do problema. Na segunda etapa, seguindo a ordem pré-definida, esse exemplo e a estimativa inicial para seus monorrótulos são apresentados a cada um dos classificadores binários. Conforme na Figura 5.2, o primeiro classificador a classificar esse exemplo é $h_{y_{3}}$, cujo resultado é a predição para o monorrótulo $y_{3}$, i.e., $h_{y_{3}}(\boldsymbol{x})=\hat{y}_{3}$. Em seguida, o valor da estimativa inicial para o monorrótulo $y_{3}$ é "atualizado" (substituído) considerando a predição de $h_{y_{3}}$, e o exemplo (atualizado) é então apresentado ao classificador $h_{y_{1}}$. O processo é repetido para todos os classificadores binários, respeitando a ordem pré-definida.

No trabalho (Cherman et al., 2010b), essas duas novas estratégias de predição, bem como a estratégia de predição sem atualização, foram avaliadas comparativamente com o método BR utilizando cinco conjuntos de dados de domínios distintos. $\mathrm{O} \mathrm{BR}+$ apresentou os melhores resultados para a maioria dos casos, muitas vezes com diferença estatisticamente significativa em relação ao BR. Além disso, as duas estratégias do BR+ com atualização apresentaram melhoria nos resultados do $\mathrm{BR}+$ sem atualização para alguns conjuntos de dados, em especial a estratégia $F-$.

No trabalho (Cherman et al., 2010a), como mencionado anteriormente, a estratégia de predição com atualização dinâmica (Dyn) foi proposta. O objetivo de utilizar essa estratégia é minimizar uma limitação das estratégias de atualização estática, nas quais uma mesma ordem de atualização deve ser utilizada para todos os novos exemplos a serem preditos. No caso da atualização dinâmica, a ordem de atualização é definida no momento de predição para cada novo exemplo a ser predito. O critério utilizado para a definição da ordem de atualização é o grau de confiança da predição dos valores estimados para a predição inicial. Assim, para um vetor de atributos $\boldsymbol{x}_{i}$ cuja estimativa inicial 


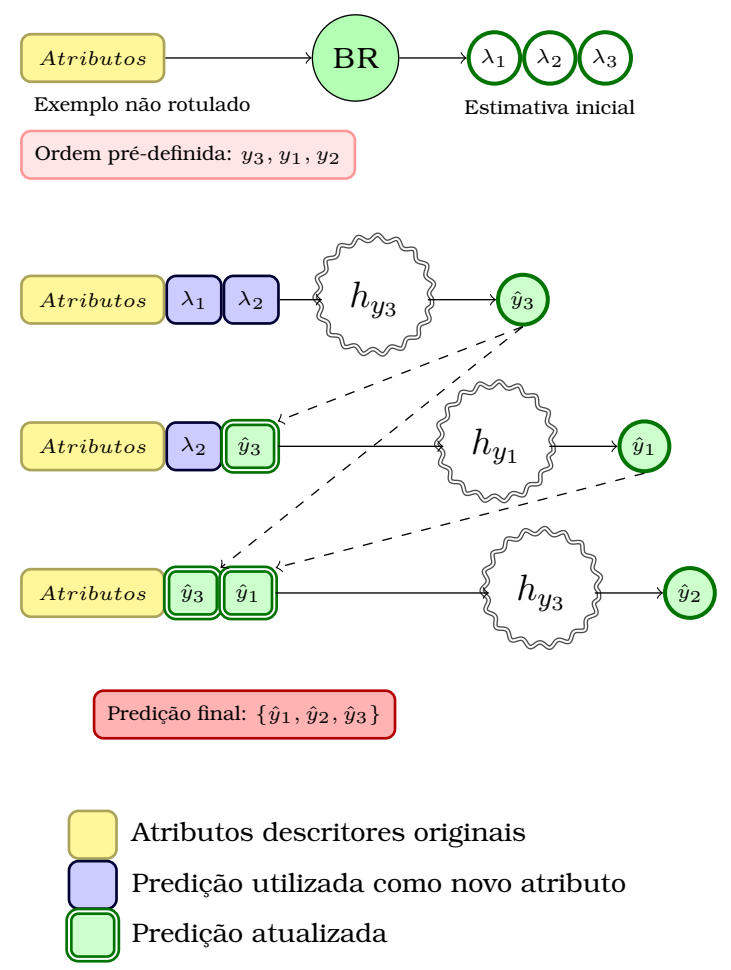

Figura 5.2: Predição do método BR+ com atualização.

para os três monorrótulos $y_{1}, y_{2}$ e $y_{3}$ tenha sido obtida com os graus de confiança 0,60, 0,85 e 0,74, respectivamente, a ordem de atualização utilizada pelo método BR+ (Dyn), considerando que a predição de menor confiança é atualizado primeiro, é $y_{1}, y_{3}$ e $y_{2}$. Para um exemplo $\boldsymbol{x}_{i+1}$, cujos graus de confiança para a predição sejam 0,80, 0,85 e 0,94, a ordem de atualização é $y_{1}, y_{2}$ e $y_{3}$.

O trabalho (Cherman et al., 2010b) foi selecionado entre os melhores trabalhos do Mexican International Conference on Artificial Intelligence (MICAI'2010) e convidado para a expansão e publicação no periódico Expert Systems With Applications International Journal, um periódico com alto fator de impacto na área. No trabalho (Cherman et al., 2012), aceito para publicação nesse periódico, foram adicionados ao trabalho (Cherman et al., 2010b), entre outros, os seguintes conceitos:

- estratégia de predição dinâmica do BR+;

- comparação do método BR+ com o método CC;

- avaliação em oitos conjuntos de dados; e

- valores de topline obtidos pelo método UBC para os oito conjuntos de dados.

Nesse trabalho, o método BR+ foi considerado competitivo ao método CC, ilustrado na Figura 2.6 na página 22, com resultados muitas vezes superi- 
ores, principalmente, quando utilizados os algoritmos de aprendizado J48 e Nä̈ve Bayes como base para a construção dos classificadores binários. Além disso, foi possivel observar que existe margem para uma melhor exploração da dependência de rótulos, constatada pela análise dos valores de topline apresentados.

\subsubsection{Upper Bound Classifier}

O método UBC foi utilizado em avaliações experimentais com o objetivo de analisar o desempenho dos métodos baseados em stacking, e para identificar informações adicionais que sejam úteis para o entendimento da influência da dependência de rótulos nos conjuntos de dados multirrótulo e, consequentemente, no processo de aprendizado multirrótulo. Dentre as informações que podem ser obtidas por meio da comparação experimental de classificadores multirrótulo baseados em stacking e do método UBC, estão o "espaço" disponivel para um algoritmo explorar a dependência de rótulos e quão efetivo um algoritmo pode ser ao tentar explorar a dependência de rótulos em um determinado conjunto de dados.

Essas informações podem ser derivadas dos valores das medidas de avaliação obtidas por meio da aplicação do UBC e do classificador BR aos conjuntos de dados. Na Figura 5.3 são apresentados alguns resultados referentes à aplicação do BR, BR+ e UBC a seis conjuntos de dados multirrótulo de distintos domínios. Os resultados referentes ao $\mathrm{BR}+$ correspondem ao melhor resultado entre as diferentes estratégias de predição (sem atualização, estática e dinâmica).

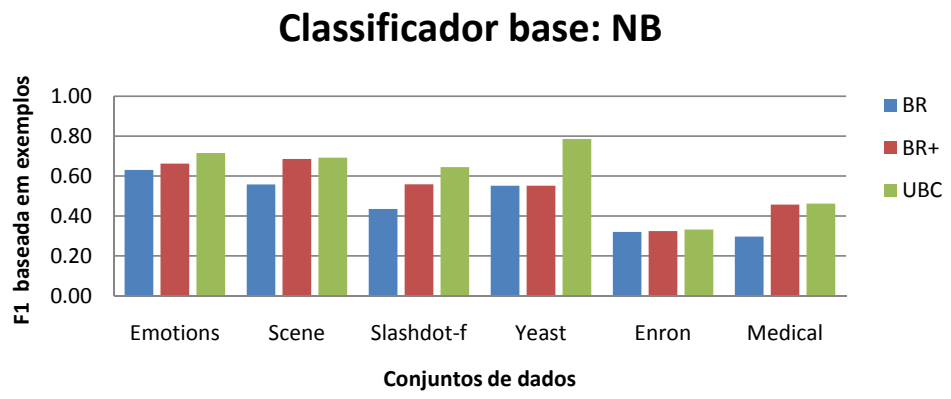

Figura 5.3: Comparação entre BR, BR+ e UBC utilizando NB como algoritmo base.

Nesse gráfico é possivel observar que existe algum tipo de dependência entre os monorrótulos do problema e que essa dependência foi "utilizada" pelos métodos de stacking $\mathrm{BR}+\mathrm{e}$ UBC no processo de aprendizado, o que influenciou na melhora da capacidade de aprendizado desses métodos. De acordo com Dembczynski et al. (2010), existem pelo menos dois tipos de dependências entre rótulos: condicionais e incondicionais. No entanto, quando "permitimos" 
que o algoritmo identifique automaticamente essas dependências por meio da estratégia proposta no método $\mathrm{BR}+$, não é possível saber qual dos dois tipos de dependência é identificada, ou mesmo se há algum outro tipo de relação que tenha sido identificada pelo método.

Analisando os resultados para o conjunto de dados Enron, apresentados na Figura 5.3, observa-se que o método UBC obteve aproximadamente o mesmo resultado do $\mathrm{BR}$ e do $\mathrm{BR}+$, o que pode indicar baixa influência da dependência de rótulo nesse conjunto de dados, uma vez que não há grande diferença de desempenho entre $\mathrm{BR}$ e $\mathrm{BR}+$, ou que o $\mathrm{BR}+$ não consegue identificar as dependências nesse conjunto de dados. No caso do conjunto Yeast, os métodos $\mathrm{BR}$ e $\mathrm{BR}+$ apresentaram resultados semelhantes, porém o UBC obteve resultados significativamente superiores, o que pode indicar que existe um tipo de dependência de rótulos que não está sendo explorado pelo $\mathrm{BR}+$, provavelmente devido à má qualidade da estimativa inicial dada pelo método $\mathrm{BR}$. Para os conjuntos de dados Scene e Medical são observados resultados com características semelhantes. Os métodos BR+ e UBC apresentaram resultados equivalentes e superiores ao BR, indicando a influência da dependência de rótulos nesses dois conjuntos e que o BR+ explorou de maneira eficaz esse tipo de dependência. Por fim, os conjuntos de dados Emotions e Slashdot-f também apresentaram comportamentos semelhantes. Para esses conjuntos, o classificador UBC apresentou os melhores resultados, seguido por BR+ em um nível intermediário e por BR, o qual apresentou resultados inferiores aos outros dois classificadores. Esse fato indica que existe influência da dependência de rótulos nesses dois conjuntos de dados e que essa dependência foi explorada parcialmente pelo $\mathrm{BR}+$.

\subsection{Classificador base multirrótulo}

Os algoritmos de classificação multirrótulo são usualmente comparados por meio das medidas de avaliação apresentadas na Seção 2.3.3 na página 23. A partir dessa comparação, identifica-se qual o algoritmo que melhor classificou um conjunto de exemplos. No entanto, essa maneira de avaliar os algoritmos não possibilita verificar se há aprendizado de fato, como é feito em tarefas de classificação monorrótulo por meio do erro majoritário.

Uma grande vantagem de utilizar essa medida de erro majoritário na classificação monorrótulo é que, para identificar a classe majoritária, basta simplesmente considerar a distribuição das classes no conjunto de treinamento, sem considerar os valores dos atributos dos exemplos. Além disso, a comparação entre o erro majoritário e o erro obtido pelo modelo de classificação induzido permite mensurar a capacidade de aprendizado do algoritmo utili- 
zado. Se o erro do classificador for maior ou igual ao erro majoritário, não houve aprendizado, caso contrário, a razão entre esses dois valores mostra o quanto o modelo induzido melhorou em relação ao erro majoritário.

Contudo, o erro majoritário utilizado em tarefas de classificação monorrótulo não é adequado para o cenário multirrótulo, pois nesse cenário não há necessariamente uma classe majoritária, mas sim um conjunto de rótulos majoritários. Não é de nosso conhecimento a existência de alguma proposta na literatura que permita identificar a "classe majoritária" no contexto de problemas multirrótulo.

Nesse contexto, propomos uma estratégia simples para identificar o "multirrótulo majoritário" em um problema de classificação multirrótulo. Para ilustrar, considere o conjunto de exemplos $D$ apresentado na Tabela 5.2, na qual são mostrados somente os multirrótulos de cada exemplo.

Tabela 5.2: Exemplos multirrotulados.

\begin{tabular}{cll}
\hline \hline Exemplo & & \multicolumn{1}{c}{$Y_{i}$} \\
\cline { 1 - 1 }$E_{1}$ & & $Y_{1}=\left\{y_{1}, y_{2}, y_{3}\right\}$ \\
$E_{2}$ & & $Y_{2}=\left\{y_{1}, y_{3}\right\}$ \\
$E_{3}$ & & $Y_{3}=\left\{y_{1}\right\}$ \\
$E_{4}$ & & $Y_{4}=\left\{y_{2}, y_{3}\right\}$ \\
$E_{5}$ & $Y_{5}=\left\{y_{3}\right\}$ \\
\hline \hline
\end{tabular}

A ideia é construir um ranking dos monorrótulos em $L$, de modo que os rótulos mais frequentes no conjunto de exemplos sejam dispostos em ordem crescente, i.e., os monorrótulos com maior frequência são mais bem colocados no ranking.

O ranking construído a partir dos dados mostrados na Tabela 5.2 é apresentado na Tabela 5.3. A partir desse ranking e um valor de corte, o conjunto de rótulos majoritário é identificado. Para respeitar a distribuição dos rótulos no conjunto de exemplos, propomos utilizar o valor de cardinalidade de rótulos para efetuar o corte no ranking, selecionando todos os monorrótulos com ranking $\leq[C D(D)]$, onde $[\# n]$ representa o inteiro mais próximo de $\# n$.

Tabela 5.3: Ranking dos monorrótulos em $L$.

\begin{tabular}{|c|c|c|}
\hline Ranking & Monorrótulo & \#Ocorrências \\
\hline 1 & $y_{3}$ & 4 \\
\hline 2 & $y_{1}$ & 3 \\
\hline 3 & $y_{2}$ & 2 \\
\hline
\end{tabular}

A cardinalidade desse conjunto de exemplos, calculada por meio da Equação 2.7, é:

$$
C D(D)=\frac{4+3+2}{5}=1,8
$$

Desse modo, os rótulos $y_{3}$ e $y_{1}$ compõem o multirrótulo majoritário $\left\{y_{1}, y_{3}\right\}$. 
A partir da identificação do multirrótulo majoritário representativo do problema, é possível simular um classificador multirrótulo, chamado de $\mathrm{BR}_{\text {Low }}$, o qual sempre prediz o mesmo multirrótulo a qualquer exemplo que lhe seja fornecido para classificação: o multirrótulo "majoritário" identificado por meio da estratégia descrita anteriormente. Desse modo, o classificador $\mathrm{BR}_{\text {Low }}$ depende apenas das informações de distribuição das classes e desconsidera completamente os atributos descritores dos exemplos, tanto para identificar o multirrótulo majoritário, quanto para predizer o mesmo. Esse fato permite que esse classificador seja utilizado como um classificador baseline para avaliação de outros classificadores multirrótulo.

Para que seja possivel utilizar esse método como um baseline forte de comparação com outros métodos, o multirrótulo majoritário deve ser identificado a partir dos exemplos do conjunto de treinamento. Em seguida, esses mesmos exemplos são apresentados a esse classificador para a classificação. Essa classificação pode ser avaliada por meio das mesmas medidas utilizadas para qualquer outro classificador multirrótulo, o que permite a comparação direta da classificação obtida com o método $\mathrm{BR}_{\text {Low }}$ com a classificação resultante de qualquer outro método de classificação multirrótulo.

Desse modo, é possível comparar os valores das medidas de avaliação para avaliar a performance de outros métodos propostos. Se os valores dessas medidas resultantes de algum algoritmo forem "melhores" que os obtidos utilizando o modelo $\mathrm{BR}_{\text {Low }}$, então esse algoritmo foi capaz de aprender conceitos relacionados às classes do problema. Caso contrário, não houve aprendizado de fato.

É importante observar que a partir desses valores calculados por meio do classificador $\mathrm{BR}_{\text {Low }}$, a avaliação da performance do classificador torna-se objetiva e de fácil interpretação, permitindo mensurar a capacidade de aprendizado do algoritmo multirrótulo. Isso se deve à facilidade de quantificar a diferença entre os erros (ou acertos) obtidos pelos classificadores de interesse e o classificador $\mathrm{BR}_{\text {Low }}$, o qual somente considera a distribuição dos multirrótulos nas classes, sem utilizar os valores dos atributos do conjunto de exemplos de treinamento.

\subsection{Algoritmo para classificação multirrótulo supervi- sionado}

A partir da análise de resultados de experimentos, observa-se que alguns dos classificadores binários do modelo BR apresentam boa performance enquanto outros apresentam um baixo desempenho, o que acarreta uma avaliação global fraca. Para tentar melhorar a performance global dos algoritmos 
baseados no modelo BR, propomos utilizar mais de um classificador para discriminar cada rótulo do domínio dentro do modelo BR. Com uma segunda opinião, os classificadores binários que apresentam baixa performance são “ajudados" a melhorar sua predição, possivelmente resultando ganho de performance global.

Nesse método, ao qual denominamos Co-Perspective Binary Relevance $\mathrm{BR}_{C o P}$ - ao invés de construir um classificador binário para cada classe, são construídos dois ou mais classificadores binários que cooperam para decidir a melhor classificação para exemplos não rotulados. É importante lembrar que nesse caso existe apenas uma descrição dos dados, a qual é "replicada" para a construção de mais de um classificador para resolver o mesmo problema binário, porém, considerando algoritmos de aprendizado com bias diferentes.

Para a classificação de um novo exemplo por meio desse modelo, o procedimento é muito parecido com o realizado no método BR. Entretanto, nesse caso, existe mais de um classificador binário para cada monorrótulo em $L$. Desse modo, a predição de cada monorrótulo no modelo $\mathrm{BR}_{C o P}$ é obtida de acordo com os valores de confiança dos classificadores em cada descrição. Considerando duas descrições $d_{1}$ e $d_{2}$, são três cenários possíveis para determinar a predição de cada monorrótulo:

1. os classificadores binários em cada descrição concordam com a predição: $h_{d_{1}, y_{j}}(\boldsymbol{x})=h_{d_{2}, y_{j}}(\boldsymbol{x})$;

2. os classificadores binários discordam na predição, porém com valores de confiança iguais: $h_{d_{1}, y_{j}}(\boldsymbol{x}) \neq h_{d_{2}, y_{j}}(\boldsymbol{x})$ e $\theta_{d_{1}, y_{j}}=\theta_{d_{2}, y_{j}}$; e

3. os classificadores binários discordam na predição, porém com valores de confiança diferentes: $h_{d_{1}, y_{j}}(\boldsymbol{x}) \neq h_{d_{2}, y_{j}}(\boldsymbol{x})$ e $\theta_{d_{1}, y_{j}} \neq \theta_{d_{2}, y_{j}}$.

Para esses três casos, a predição do monorrótulo deve ser decidida por meio de alguma estratégia pré-definida. No primeiro caso, $h_{d_{1}, y_{j}}(\boldsymbol{x})=h_{d_{2}, y_{j}}(\boldsymbol{x})$, ambos os classificadores reforçam a predição. Nos casos em que os classificadores predizem classes diferentes, é necessário avaliar o grau de confiança para a predição desses classificadores. Quando $h_{d_{1}, y_{j}}(\boldsymbol{x}) \neq h_{d_{2}, y_{j}}(\boldsymbol{x})$ e $\theta_{d_{1}, y_{j}}=\theta_{d_{2}, y_{j}}$, a predição é escolhida aleatoriamente ${ }^{3}$. Quando $h_{d_{1}, y_{j}}(\boldsymbol{x}) \neq h_{d_{2}, y_{j}}(\boldsymbol{x})$ e $\theta_{d_{1}, y_{j}} \neq$ $\theta_{d_{2}, y_{j}}$, a predição com maior grau de confiança é atribuída ao exemplo. Essa estratégia é ilustrada na Figura 5.4.

A predição do multirrótulo final para um novo exemplo é obtida como no modelo BR, considerando todos os monorrótulos preditos como positivos.

\footnotetext{
${ }^{3}$ Nesse caso, poderia também ser utilizado um outro critério, tal como a frequência do rótulo $y_{j}$ no conjunto de treinamento ser maior que um dado threshold.
} 


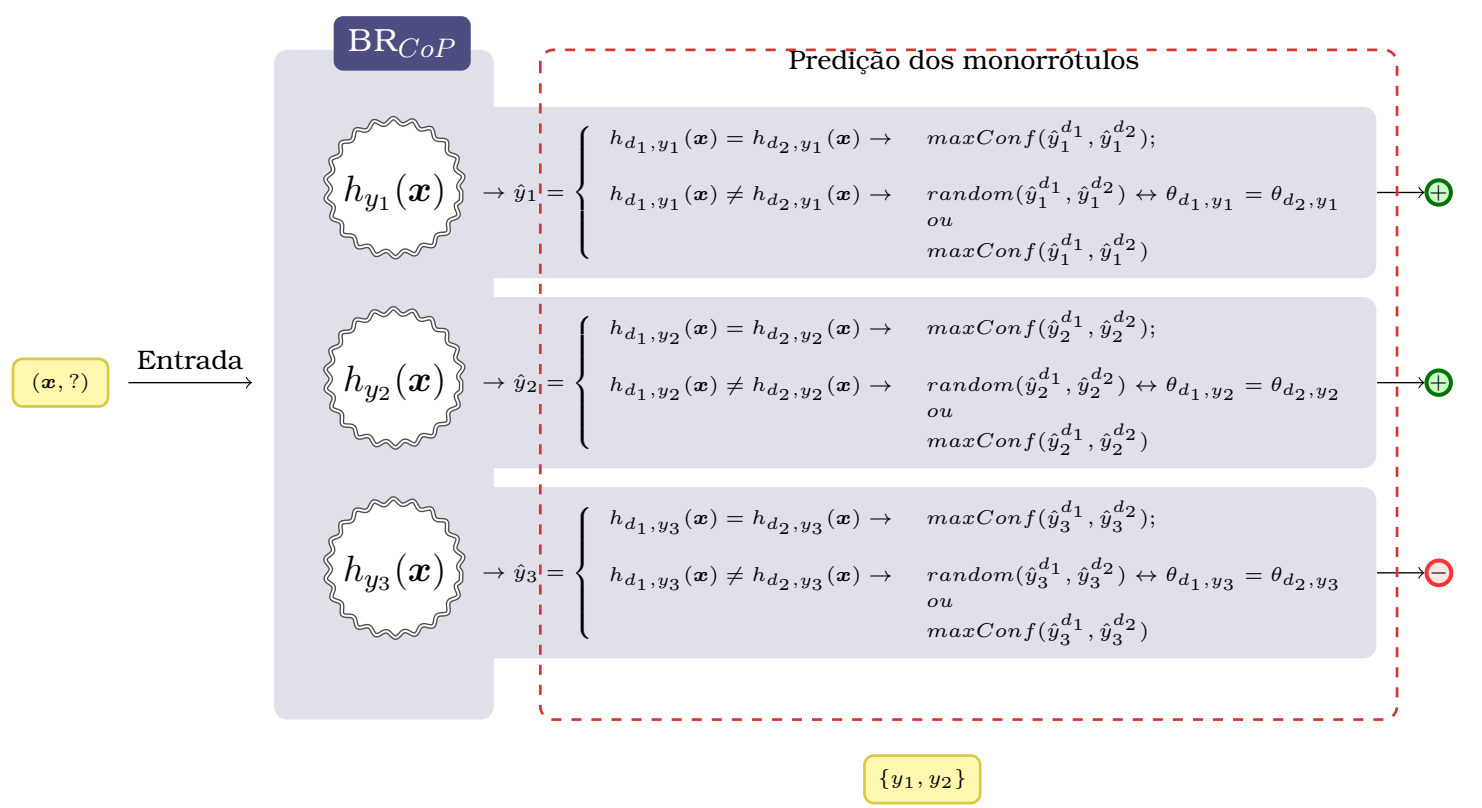

Multirrótulo predito

Figura 5.4: Predição do método multirrótulo $\mathrm{BR}_{C o P}$.

É possível que um número ímpar de classificadores sejam construídos para discriminar cada monorrótulo, eliminando o segundo cenário de predição (empate entre predição positiva e negativa). Nesses casos, um esquema simples de votação pode ser utilizado para a definição da predição referente a cada monorrótulo, associando o monorrótulo aos exemplos sempre que a maioria dos classificadores binários construídos para esse monorrótulo classificarem o exemplo como positivo. No entanto, devido à complexidade dos problemas tratados neste trabalho, a avaliação experimental apresentada no Capítulo 6 foi realizada utilizando apenas dois classificadores para cada monorrótulo.

\subsection{Algoritmos para classificação multirrótulo semissu- pervisionado}

Como mencionado anteriormente, existem muitas aplicações para as quais é difícil encontrar um número expressivo de exemplos de treinamento que sejam suficientes para o aprendizado. Nesses casos, são utilizados métodos de aprendizado semissupervisionado. No contexto de classificação multirrótulo, esse cenário pode ser ainda mais complexo, uma vez que, além de poucos exemplos, existem possivelmente muitas classes nas quais esses poucos exemplos estão distribuídos.

Uma maneira de minimizar esse problema é utilizar métodos semissupervisionados, como bootstrapping ou baseados no desacordo entre classificadores 
que são construídos para resolver um mesmo problema de classificação. Neste trabalho, propomos três métodos para essa tarefa, os quais são descritos a seguir.

\subsubsection{Self-training Binary Relevance}

Esse método, proposto neste trabalho e chamado de $\mathrm{BR}_{S T}$, é uma extensão do método tradicional $\mathrm{BR}$, no qual é construído um classificador binário semissupervisionado baseado em bootstrapping, mais especificamente o SELFTRAINING, para cada monorrótulo em $L$. Cada classificador é iterativamente refinado após a inserção de alguns exemplos não rotulados em $T r^{l}$, os quais foram classificados durante o processo de aprendizado.

Como visto na Seção 4.6 na página 61, o algoritmo SELF-TRAINING constrói um classificador inicial $h^{0}(\boldsymbol{x})$ a partir de um pequeno conjunto de exemplos rotulados e utiliza esse classificador para classificar os exemplos não rotulados. Após, os exemplos com maior grau de confiança para a classificação são removidos do conjunto de exemplos não rotulados $T r^{u}$ e inseridos no conjunto de treinamento $\operatorname{Tr}^{l}$ para a construção do classificador na próxima iteração, $h^{1}(\boldsymbol{x})$. Esse processo é ilustrado na Figura 5.5 considerando o contexto de classificação multirrótulo, e o método BR com $q$ classificadores SELF-TRAINING.

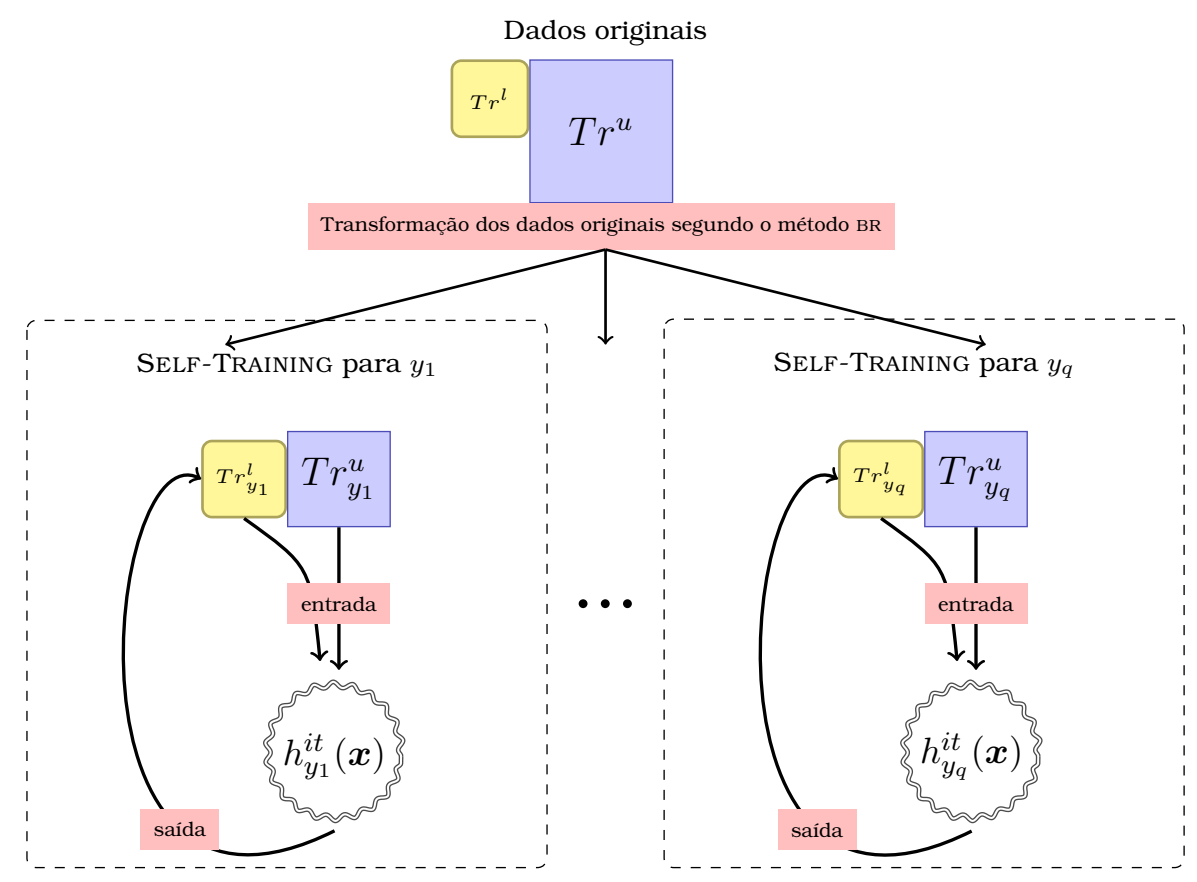

Figura 5.5: Construção do classificador multirrótulo $\mathrm{BR}_{S T}$.

Ao final do processo iterativo de refinamento dos classificadores, o resultado é um classificador binário para cada monorrótulo, o qual foi construído 
a partir de um conjunto rotulado de treinamento maior que o inicial e que foi incrementado com exemplos antes não rotulados que foram classificados pelos classificadores gerados em cada iteração do processo.

Com isso, a classificação de um novo exemplo é realizada de maneira idêntica ao método BR, mas considerando os classificadores resultantes do processo de bootstrapping.

\subsubsection{Binary Relevance semissupervisionado coperspectiva}

Esse método, chamado de $\mathrm{BR}_{C o P S S}$, além de usar um processo iterativo para refinamento dos classificadores por meio da classificação de exemplos não rotulados durante o processo de aprendizado, utiliza a estratégia de aprendizado baseado em desacordo, na qual mais de um classificador é construído para resolver um mesmo problema binário, como o método $\mathrm{BR}_{C o P}$.

A ideia básica é estender o método $\mathrm{BR}_{C o P}$ de modo que os exemplos não rotulados sejam utilizados durante o processo de aprendizado para incrementar o conjunto de exemplos rotulados. Para isso, são construídos $q$ classificadores binários Co-PERSPECTIVE, um para cada monorrótulo do problema, de acordo com o método BR. Nesse sentido, os dados originais são inicialmente transformados de modo que $q$ conjuntos de treinamento binários sejam criados, os quais são utilizados como entrada para o algoritmo responsável por criar os classificadores Co-PERspective. Para isso, o conjunto de treinamento para cada monorrótulo $y_{j}$ é "replicado" para a criação das duas descrições dos da$\operatorname{dos}^{4}$, a partir das quais dois classificadores são construídos utilizando algoritmos de aprendizado com bias diferentes, conforme descrito no Algoritmo 4.4 na página 68. A diferença entre $\mathrm{BR}_{C o P}$ e $\mathrm{BR}_{C o P S S}$ é que os classificadores CoPERSPECTIVE utilizados neste último método classificam cooperativamente os exemplos não rotulados disponíveis para incrementar o conjunto de exemplos rotulados.

Nos moldes do algoritmo Co-PERSPECTIVE, são construídos na primeira iteração os classificadores $h_{d_{1}}^{0}(\boldsymbol{x})$ e $h_{d_{2}}^{0}(\boldsymbol{x})$, os quais são utilizados para classificar uma porção dos exemplos não rotulados. Os exemplos que são classificados com maior grau de confiança (Equação 5.2) são inseridos no conjunto rotulado de treinamento. Após, uma nova iteração é executada considerando o conjunto de treinamento incrementado com os exemplos rotulados que foram inseridos na iteração anterior, para a construção dos classificadores $h_{d_{1}}^{1}(\boldsymbol{x}) \mathrm{e}$ $h_{d_{2}}^{1}(\boldsymbol{x})$.

\footnotetext{
${ }^{4}$ Nesse caso, a mesma descrição dos dados é utilizada para a construção dos diferentes classificadores, ou seja, $d_{1}=d_{2}$.
} 


$$
\hat{y}_{j}=\left\{\begin{aligned}
h_{d_{1}, y_{j}}(\boldsymbol{x})=h_{d_{2}, y_{j}}(\boldsymbol{x}) \rightarrow & \max \operatorname{Conf}\left(\hat{y}_{j}^{d_{1}}, \hat{y}_{j}^{d_{2}}\right) \\
h_{d_{1}, y_{j}}(\boldsymbol{x}) \neq h_{d_{2}, y_{j}}(\boldsymbol{x}) \rightarrow & \operatorname{random}\left(\hat{y}_{j}^{d_{1}}, \hat{y}_{j}^{d_{2}}\right) \leftrightarrow \theta_{d_{1}, y_{j}}=\theta_{d_{2}, y_{j}} \\
& \text { ou } \\
& \operatorname{maxConf}\left(\hat{y}_{j}^{d_{1}}, \hat{y}_{j}^{d_{2}}\right)
\end{aligned}\right.
$$

Esse processo, ilustrado na Figura 5.6, é repetido até que todos os exemplos não rotulados sejam classificados e inseridos em $\operatorname{Tr}^{l}$, ou algum outro critério de parada seja especificado.

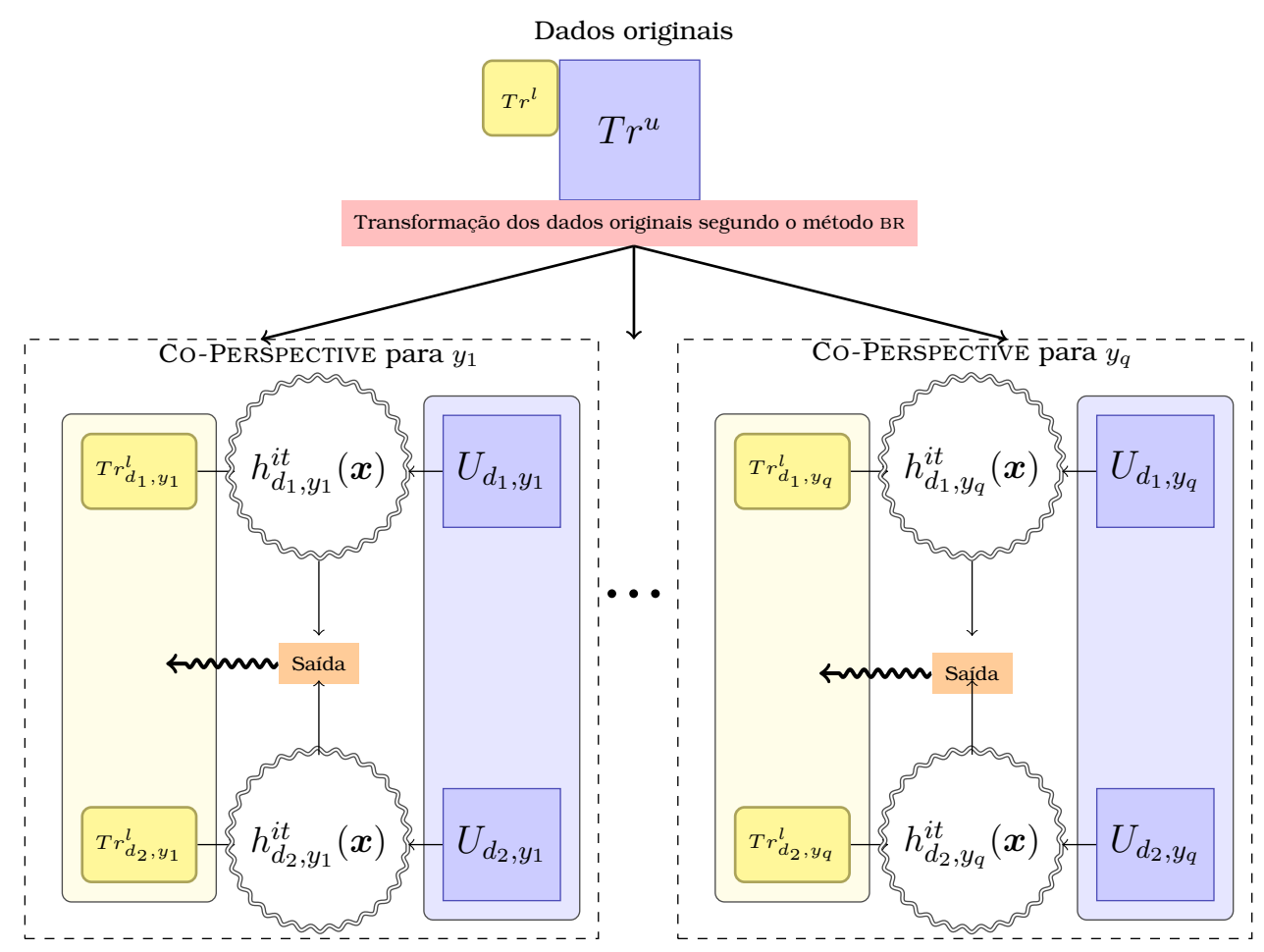

Figura 5.6: Construção do classificador multirrótulo $\mathrm{BR}_{C o P S S}$.

De maneira análoga ao método $\mathrm{BR}_{S T}$, o resultado é um conjunto de classificadores binários que foram refinados durante o processo iterativo por meio da inclusão de exemplos rotulados no conjunto de treinamento. Entretanto, nesse caso, cada classificador binário é um classificador Co-PERSPECTIVE. Consequentemente, a predição do monorrótulo $y_{j}$ para um novo exemplo depende da predição dos dois classificadores associados ao monorrótulo $y_{j}$.

\subsubsection{Utilizando aprendizado ativo com Binary Relevance}

Esse método, denominado $\mathrm{BR}_{C o P S S+A L}$, adiciona o aprendizado ativo ao $\mathrm{BR}_{\text {CoPSS }}$, de modo que dentro de cada iteração do algoritmo Co-PERSPECTIVE binário para cada monorrótulo, alguns exemplos pontos de contenção são classificados pelo "oráculo" e adicionados ao conjunto de exemplos rotulados lo- 
cal para atualização dos classificadores binários em cada descrição, os quais são então utilizados para classificar outros exemplos não rotulados restantes. Deve ser observado que apenas um pequeno número pré-especificado de consultas ao "oráculo" é permitido, o que limita o número total de pontos de contenção rotulados nesse processo. Além disso, podem ocorrer iterações nas quais não sejam identificados pontos de contenção, assim como é possível que todas as consultas sejam realizadas na primeira iteração.

Nas avaliações experimentais realizadas neste trabalho, as consultas são simuladas por meio da utilização dos rótulos verdadeiros para esse pequeno número de exemplos. Assim, cada ponto de contenção identificado pelos classificadores binários $h_{d_{1}, y_{j}}(\boldsymbol{x})$ e $h_{d_{2}, y_{j}}(\boldsymbol{x})$ no conjunto de exemplos não rotulados $\mathrm{Tr}^{u}$, considerando o limite pré-especificado, é rotulado com sua classe verdadeira para $y_{j}$. Se o número pré-especificado de consultas ao oráculo for alcançado, ou não forem identificados mais pontos de contenção, o algoritmo continua suas iterações sem considerar o aprendizado ativo, rotulando exemplos em $T r^{u}$ e os movendo para o conjunto de exemplos rotulados. O conjunto de treinamento $\operatorname{Tr}^{l}$ atualizado com os exemplos rotulados em cada iteração é utilizado para refinar os classificadores na próxima iteração.

Além da adição do aprendizado ativo, não existem outras diferenças entre este método $\mathrm{BR}_{C o P S S+A L}$ e o método $\mathrm{BR}_{C o P S S}$. Além disso, é possível que apenas a porção responsável pelo aprendizado ativo seja executada, permitindo que apenas os pontos de contenção sejam iterativamente classificados e inseridos no conjunto de exemplos rotulados. Esse método, o qual denominamos

$\mathrm{BR}_{\text {CoTesting }}$, pode ser utilizado para análise experimental com objetivo de avaliar de maneira independente a influência do aprendizado ativo no desempenho do método $\mathrm{BR}_{C o P S S+A L}$.

\subsection{Classificador base hierárquico}

Como mencionado, os resultados obtidos em pesquisas relacionadas à classificação hierárquica têm sido frequentemente comparados aos resultados obtidos com classificadores planos aplicados a problemas de classificação hierárquica (abordagem plana).

Entre outros problemas, essa estratégia limita a compreensão e a percepção da real capacidade de aprendizado dos algoritmos de classificação hierárquica, pois não é possível verificar se houve efetivamente aprendizado. Nesse contexto, seria mais interessante que fosse utilizada como baseline alguma medida semelhante ao erro majoritário, o qual é utilizado em tarefas de classificação monorrótulo (Seção 3.2.3.1) e classificação multirrótulo (Seção 5.2), e representa uma aproximação do erro obtido ao predizer, respectivamente, a 
classe majoritária ou o "multirrótulo majoritário" para todos os exemplos, ou seja, simplesmente "apostando" que a classe correta para todos os exemplos é aquela mais frequente no conjunto de dados.

Entretanto, as estratégias propostas para encontrar o erro majoritário na classificação monorrótulo e o multirrótulo majoritário na classificação multirrótulo são inadequadas para o cenário de classificação hierárquica, pois não consideram as restrições da taxonomia de classes existente nesse cenário.

No contexto de classificação hierárquica, diferentes estratégias podem ser utilizadas para identificar as "classes majoritárias". Para ilustrar três diferentes possiveis estratégias, considere as duas distribuições de exemplos apresentadas na Figura 5.7, na qual o número de exemplos associados (implicitamente ou explicitamente) a cada classe $y_{j}$ está representado pelo valor da aresta que liga o nó $y_{j}$ ao nó $\uparrow y_{j}$, enquanto que o número de exemplos explicitamente anotados com a classe $y_{j}$ está apresentado diretamente abaixo do nó da classe.

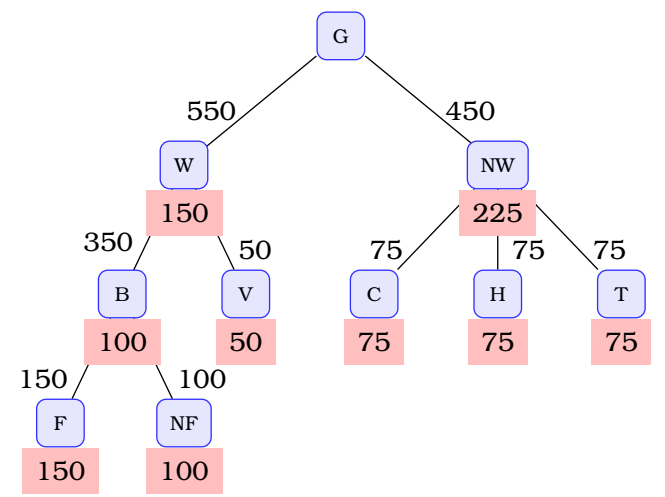

(a) Distribuição 1: exemplos explicita- (b) mente anotados com classes internas

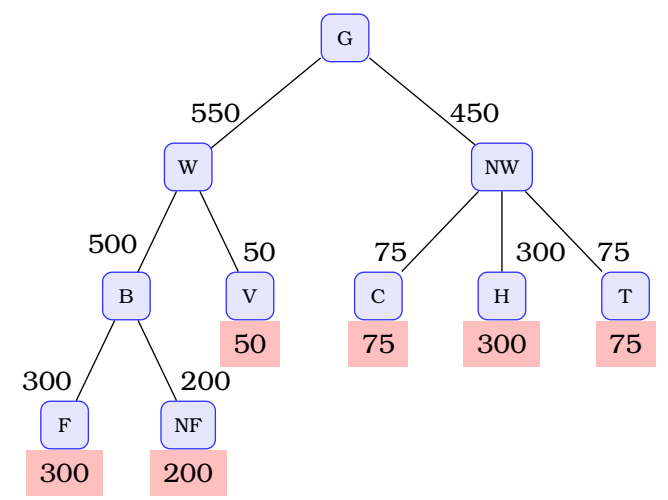

(b) Distribuição 2: exemplos explicitamente anotados somente com classes folha

Figura 5.7: Distribuição de exemplos entre as classes da taxonomia.

Por exemplo, na Figura 5.7(a), 550 exemplos estão associados à classe w, dos quais 150 apresentam essa classe como sua classe mais específica (150 exemplos explicitamente anotados com a classe w). Os demais 400 exemplos (implicitamente anotados com a classe w) têm classe mais específica dentre as classes descendentes de $\mathrm{W}$, sendo 50 exemplos explicitamente anotados com a classe V, 100 com a classe B, 150 com a classe F e os outros 100 com a classe NF. Observe que além dos 100 exemplos explicitamente anotados com B, outros 250 estão implicitamente associados a essa classe, pois $\mathrm{F} \prec \mathrm{B}$ e $\mathrm{NF} \prec \mathrm{B}$. No caso da distribuição apresentada na Figura 5.7(b), todos os exemplos estão explicitamente anotados com uma das classes folha. Consequentemente, os nós internos apresentam apenas exemplos implicitamente anotados.

As três estratégias que podem ser utilizadas para identificar a "classe ma- 
joritária” são:

1. calcular a probabilidade de cada classe da taxonomia considerando apenas os exemplos que estão explicitamente anotados com a respectiva classe. A classe com maior probabilidade é escolhida como a classe majoritária. Nesse caso, para a distribuição de exemplos apresentada na Figura 5.7(a) a classe majoritária é NW com 225 exemplos, enquanto que para a distribuição apresentada na Figura 5.7(b), ambas H e F podem ser consideradas classes majoritárias com 300 exemplos cada;

2. no segundo caso, as classes internas da taxonomia são desconsideradas e o cálculo da probabilidade das classes é efetuado apenas considerando as classes folha da taxonomia. Para esse caso, a classe majoritária para a distribuição 1 é F e para a distribuição 2, H ou F; e

3. a terceira opção é identificar recursivamente a classe majoritária em cada nível da hierarquia, considerando o número de exemplos associados implicitamente a uma das classes das subárvores até chegar a uma classe folha, a qual é eleita a classe majoritária global. Nesse caso, para as duas distribuições, F é a classe majoritária.

Porém, observe que nessas três estratégias a estrutura hierárquica de classes não é considerada para a identificação da classe majoritária. Consequentemente, essas não são estratégias adequadas para encontrar a classe majoritária de um problema hierárquico.

De maneira análoga às medidas de avaliação, qualquer informação relacionada a um problema de classificação hierárquica deve considerar a estrutura hierárquica de classes e suas interrelações. Além disso, uma medida de qualidade ou informação deve ser consistente e independente da distribuição dos exemplos nas classes. Assim, considerando as informações da taxonomia de classes, neste trabalho propomos uma função para calcular um escore para cada classe, apresentado na Equação 5.3, o qual representa a frequência da classe no conjunto de exemplos. A classe com maior valor de escore é considerada a classe (mais específica ${ }^{5}$ ) majoritária, a partir da qual qualquer medida de avaliação pode ser calculada. O critério de desempate para a definição da classe majoritária, para os casos em que mais de uma classe apresente o maior valor do escore, é o número de exemplos associados ao ramo de cada classe. Assim, a classe que estiver no ramo com maior número de exemplos é escolhida a classe majoritária. Se ainda assim persistir o empate, a classe deve ser escolhida aleatoriamente entre as que possuem maior valor de escore.

$$
\text { Escore }_{y_{j}}=P\left(y_{j}\right) \times \operatorname{level}\left(y_{j}\right)
$$

\footnotetext{
${ }^{5}$ As classes intermediárias são inferidas por meio da relação $\prec$.
} 
Na Tabela 5.4 é apresentado um exemplo do uso dessa medida de escore para as distribuições apresentadas na Figura 5.7, na qual level $\left(y_{j}\right)$ representa o nivel da taxonomia onde a class $y_{j}$ aparece, sendo que a raiz da taxonomia está no nível zero; $\left|* y_{j}\right|$ representa o número de exemplos explicitamente anotados com a classe $y_{j}$ e $P\left(y_{j}\right)$ representa a probabilidade da classe $y_{j}$ em relação ao total de exemplos rotulados, i.e., $P\left(y_{j}\right)=\frac{\left|* y_{j}\right|}{|T r|}$.

Tabela 5.4: Escores para identificação da classe majoritária.

\begin{tabular}{|c|c|c|c|c|c|c|}
\hline Classes & level $\left(y_{j}\right)$ & $\left|* y_{j}\right|$ & $P\left(y_{j}\right)$ & & Escore & Ranking \\
\hline \multicolumn{7}{|c|}{ Distribuição 1} \\
\hline G & 0 & 0 & 0,000 & & & \\
\hline $\mathrm{w}$ & 1 & 150 & 0,150 & 0,150 & & 5 \\
\hline B & 2 & 100 & 0,100 & 0,200 & & 4 \\
\hline $\mathrm{F}$ & 3 & 150 & 0,150 & 0,450 & & 1 \\
\hline $\mathrm{NF}$ & 3 & 100 & 0,100 & 0,300 & & 2 \\
\hline $\mathrm{v}$ & 2 & 50 & 0,050 & 0,100 & $\square$ & 6 \\
\hline $\mathrm{NW}$ & 1 & 225 & 0,225 & 0,225 & & 3 \\
\hline C & 2 & 75 & 0,075 & 0,150 & & 5 \\
\hline $\mathrm{T}$ & 2 & 75 & 0,075 & 0,150 & & 5 \\
\hline $\mathrm{H}$ & 2 & 75 & 0,075 & 0,150 & 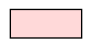 & 5 \\
\hline \multicolumn{7}{|c|}{ Distribuição 2} \\
\hline G & 0 & 0 & 0,000 & & & \\
\hline $\mathrm{w}$ & 1 & 0 & 0,000 & 0,000 & & 6 \\
\hline B & 2 & 0 & 0,000 & 0,000 & & 6 \\
\hline $\mathrm{F}$ & 3 & 300 & 0,300 & 0,300 & | & 1 \\
\hline $\mathrm{NF}$ & 3 & 200 & 0,200 & 0,200 & & 3 \\
\hline $\mathrm{V}$ & 2 & 50 & 0,050 & 0,050 & $\square$ & 5 \\
\hline NW & 1 & 0 & 0,000 & 0,0000 & & 6 \\
\hline $\mathrm{C}$ & 2 & 75 & 0,075 & 0,075 & $\square$ & 4 \\
\hline $\mathrm{T}$ & 2 & 75 & 0,075 & 0,075 & $\square$ & 4 \\
\hline $\mathrm{H}$ & 2 & 300 & 0,300 & 0,300 & & 2 \\
\hline
\end{tabular}

A partir dos escores para cada classe, identifica-se a classe majoritária mais específica, a qual juntamente com suas classes ancestrais formam o multirrótulo hierárquico majoritário.

Observe que os valores de escore para as classes $\mathrm{F}$ e $\mathrm{H}$ considerando a distribuição 2 são iguais. Entretanto, a subárvore onde a classe F está contém mais exemplos que a subárvore de $\mathrm{H}$, pois 550 exemplos estão associados à classe w enquanto apenas 450 estão associados à classe NW. Assim, por meio do critério de desempate definido anteriormente a classe $\mathrm{F}$ é escolhida como a classe mais específica majoritária. O multirrótulo hierárquico majoritário por sua vez é composto das classes $\{\mathrm{G}, \mathrm{W}, \mathrm{B}, \mathrm{F}\}$.

Utilizando esse multirrótulo hierárquico, calculam-se os valores de qualquer das medidas de avaliação hierárquica sobre o conjunto de exemplos de treinamento. Os valores dessas medidas podem ser utilizados como base para a avaliação dos algoritmos de classificação hierárquica. Esse método para cal- 
cular os valores base das medidas de avaliação, proposto neste trabalho, é chamado de $\mathrm{HBR}_{\text {Low }}$.

\subsection{Algoritmos para classificação hierárquica supervi- sionada}

Em (Sun et al., 2004) foi descrito o problema de bloqueio de exemplos na classificação hierárquica, o qual ocorre sempre que um exemplo é erroneamente rejeitado (predito como negativo) por um classificador associado à uma classe interna na hierarquia e, consequentemente, não é apresentado aos classificadores descendentes. Assim, diz-se que o classificador que rejeitou o exemplo está bloqueando sua passagem pela hierarquia de classificadores. Esse problema, na maioria das situações causado pela deficiência dos classificadores locais associados às classes mais rasas na hierarquia, acarreta na degradação da performance global dos classificadores hierárquicos.

Se os classificadores iniciais forem capazes de classificar novos exemplos com maior precisão, esses exemplos não serão bloqueados e serão apresentados aos classificadores nos níveis mais profundos na hierarquia. Para que isso ocorra, é necessário o desenvolvimento de métodos que possam assegurar a correta classificação nos níveis rasos da hierarquia.

Nesse sentido, propomos neste trabalho quatro métodos que fazem uso de diferentes técnicas com o objetivo de reforçar a predição dos classificadores locais em todos os níveis da hierarquia e, com isso, melhorar a performance global de classificadores hierárquicos baseados no modelo local com estratégia de predição top-down. Esses métodos são apresentados a seguir.

\subsection{HMR estendido}

Os algoritmos de classificação hierárquica que seguem a abordagem local são dependentes, principalmente, do bom poder de predição dos classificadores locais que estão associados aos níveis mais rasos da hierarquia de classes. Com métodos que usam a estratégia de predição top-down, em caso de falha na classificação obtida pelos classificadores associados aos nós mais rasos, todo o processo de rotulamento é comprometido, pois a predição referente aos próximos níveis depende dessa predição inicial. Desse modo, é interessante desenvolver mecanismos para reforçar a correta predição desses classificadores locais, evitando erros.

No caso do método HMR, cada classificador multiclasse local é construído para discriminar as classes filhas do nó ao qual o classificador está associado, i.e., o classificador $h_{y_{j}}$ deve sempre classificar novos exemplos em uma das 
classes $\downarrow y_{j}$.

Observe que, nesse caso, não é possível que o exemplo seja "negado" para todas essas classes. Contudo, pode ocorrer que um exemplo não pertença a nenhuma dessas classes, ou por ter sido erroneamente classificado no nível anterior, ou porque sua classe mais específica é $y_{j}$. Nesse sentido, propomos que durante a criação do classificador seja adicionada uma nova classe, denominada NULA, a qual representa os exemplos que não pertencem a qualquer das classes filhas de $y_{j}$ e, por esse motivo, não devem ser apresentados aos classificadores associados a essas classes. Em outras palavras, sempre que essa classe for predita, o processo de classificação desse exemplo deve parar, resultando a classe $y_{j}$ como a classe mais específica para o novo exemplo. Com essa estratégia, espera-se que os erros de especialização sejam minimizados ou que, ao menos, erros cometidos em níveis mais rasos não sejam propagados pela hierarquia.

Desse modo, para cada monorrótulo $y_{j} \in L$, é construído um classificador local multiclasse, tal que $h: X \rightarrow\left\{\downarrow y_{j} \cup\right.$ NULA $\}$. Para isso, os conjuntos de treinamento locais são selecionados de maneira diferente do modelo HMR, pois devem ser inseridos exemplos que representem a classe NULA, ou seja, exemplos que não estão associados às classes filhas de $y_{j}$.

Os exemplos que representam as classes $\downarrow y_{j}$ devem ser selecionados e generalizados exatamente como no modelo HMR, ou seja, todo exemplo $E_{i}$ tal que $\circledast E_{i} \in\left\{\Downarrow y_{j}\right\}$ é generalizado considerando a relação $\prec$ de modo que $\circledast E_{i} \in\left\{\downarrow y_{j}\right\}$ seja verdade. Os outros exemplos do conjunto de treinamento original devem ser inseridos no conjunto de treinamento local e rotulados com a nova classe NULA. Uma segunda alternativa para a definição dos exemplos que representam a classe NULA é adaptar as heurísticas de seleção de conjuntos de treinamento locais (apresentadas na Seção 3.2.3.3), as quais consideram a estrutura da taxonomia de classes para a seleção dos exemplos negativos e podem, também, diminuir o desbalanceamento de classes. Desse modo, o classificador local é construído com o objetivo de classificar novos exemplos considerando todas as classes em $\left\{\downarrow y_{j} \cup\right.$ NULA $\}$, conforme ilustrado na Figura 5.8(a).

A classificação de um novo exemplo, ilustrada na Figura 5.8(b), é realizada seguindo a estratégia top-down como no método HMR. Uma vez que a classe NULA tenha sido predita por qualquer classificador local $h_{y_{j}}$, o processo para e resulta como classe mais especifica a classe $y_{j}$.

\subsubsection{HMR estendido com estratégia de multiplicação}

Em (Sun et al., 2004) foi proposto o método Extended Multiplicative (EMM) com o objetivo principal de diminuir o número de exemplos "bloqueados" nos 


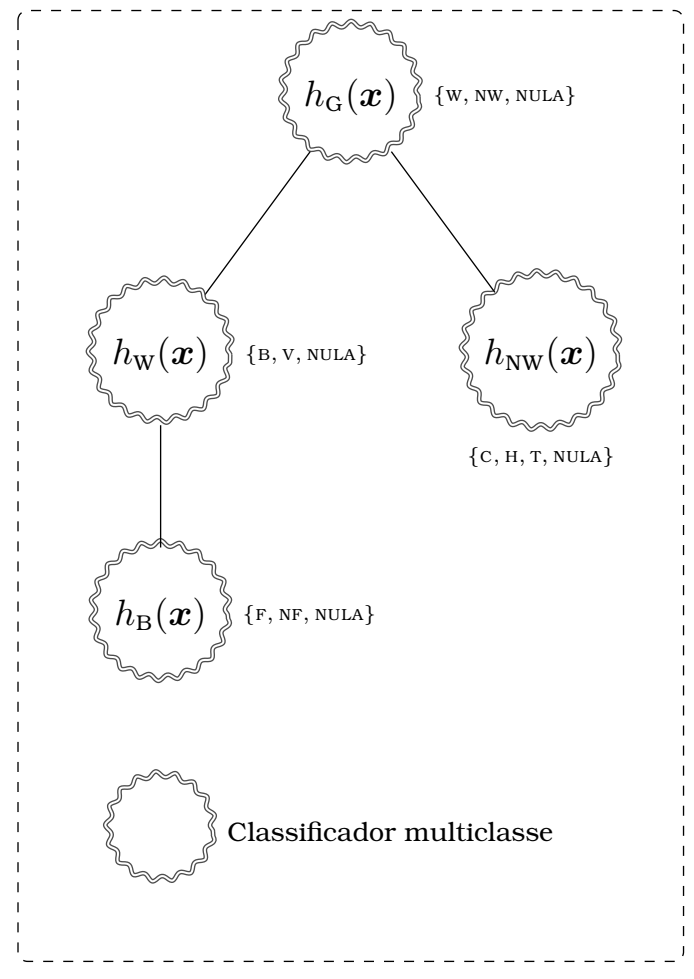

(a) Classificadores multiclasse locais do (b) Classificação de um novo exemplo $E_{i}=$ método $\mathrm{HMR}_{E x t}$

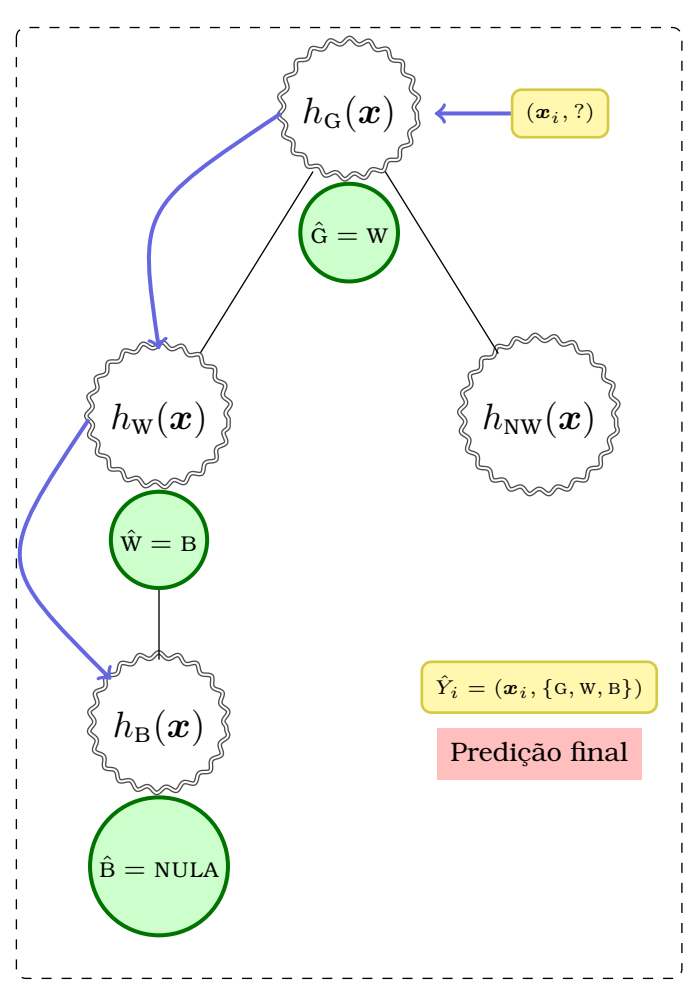

$\left(\boldsymbol{x}_{i}\right.$, ?) pelo método $\mathrm{HMR}_{E x t}$

Figura 5.8: Exemplo de classificação com o método $\mathrm{HMR}_{E x t}$.

níveis mais próximos ao nó raiz, permitindo que mais exemplos sejam apresentados aos classificadores mais profundos. Para isso, nesse método é calculada a multiplicação das probabilidades de predição obtidas por classificadores binários em diferentes níveis usando o método HBR. Os valores resultantes dessa multiplicação são comparados a um valor de threshold previamente definido para cada nível da hierarquia a fim de determinar a aceitação ou rejeição de exemplos pelos classificadores locais.

Considerando classificadores locais binários em cada nó, um novo exemplo $E$ é rotulado como $y_{j}$ se $P\left(y_{j} \mid E\right) \times P\left(\uparrow y_{j} \mid E\right) \geq \Gamma_{\left(y_{j}, \uparrow y_{j}\right)}$, onde $\Gamma_{\left(y_{j}, \uparrow y_{j}\right)}$ é o limiar (threshold) mínimo de classificação associado ao nível da classe $y_{j}$ na taxonomia.

Uma desvantagem do método EMM é a necessidade da definição de diferentes valores de threshold, sendo um para cada nivel da hierarquia. Inspirados nesse método, porém preocupados com a eficiência computacional e a diminuição de parâmetros para a execução do algoritmo, propomos uma nova heurística, mais simples, que pode ser utilizada com classificadores multiclasse em cada nó da hierarquia, i.e., HMR. Essa heurística também faz uso da predição de classificadores em diferentes níveis da hierarquia para a definição da classe mais provável de modo a reforçar a predição de cada classificador pai com auxílio dos classificadores filhos. Porém, diferentemente do método EMM, a nossa proposta considera o grau de confiança da predição dos dife- 
rentes classificadores e não valores de probabilidades, fazendo com que uma gama maior de algoritmos de aprendizado possam ser utilizados para gerar os classificadores locais. Além disso, não há a necessidade de múltiplos valores de corte para a classificação.

Para motivar o uso dessa heurística, considere que um novo exemplo deve ser classificado por meio do modelo HMR de acordo com a hierarquia de classes Glass, apresentada Figura 5.7 na página 91. Se o grau de confiança para a classificação resultante do classificador $h_{\mathrm{G}}$ for igual 0,5 para cada uma das classes filhas, por exemplo, o rótulo associado ao novo exemplo para esse nível deverá ser selecionado aleatoriamente. Consequentemente, para esse exemplo há $50 \%$ de chances de erro na classificação final, uma vez que a predição deve resultar em uma de duas classes possiveis.

No entanto, é possível desambiguar essa predição consultando "outras opiniões": os classificadores associados às classes filhas de G.

Com essa heurística, o grau de confiança do classificador primário (ou corrente) para a predição de cada classe filha é atualizado por meio da média entre o grau de confiança da predição inicial desse classificador e o máximo grau de confiança do classificador associado a cada classe filha. Assim, sendo $\Theta_{y_{j}, E}=\left\{\theta_{y_{j}, E}^{k}\right\}$ o conjunto com $k$ valores de graus de confiança obtidos pelo classificador $h_{y_{j}}$ para o exemplo $E$, e $k=1 . .\left|\downarrow y_{j}\right|$, é possível modificar cada valor $\theta_{y_{j}, E}^{k}$ considerando a predição dos classificadores filhos para melhor determinar a correta classificação para o nó corrente. A atualização é dada pela Equação 5.4, onde $\downarrow_{k} h_{y_{j}}$ representa o classificador $h_{y_{k}}$ associado à subclasse $k$ de $y_{j}$.

$$
\begin{gathered}
\hat{\theta}_{y_{j}, E}^{k}=\frac{\theta_{y_{j}, E}^{k}+f\left(\downarrow_{k} h_{y_{j}}, E\right)}{2} \\
f\left(y_{i}, E\right)=\underset{\theta^{k}}{\operatorname{argmax}} \Theta_{y_{i}, E}
\end{gathered}
$$

Como ilustração, considere que um novo exemplo é submetido a um classificador hierárquico HMR treinado exatamente com o modelo padrão descrito na Seção 3.2.3.3 na página 36, considerando a hierarquia de classes Glass. Para rotular um novo exemplo, ele é inicialmente submetido ao classificador local $h_{\mathrm{G}}$. Suponha que o grau de confiança para a classificação desse novo exemplo seja igual a 0,5 para cada uma das suas subclasses. Considere que antes de decidir a predição do classificador $h_{\mathrm{G}}$, esse mesmo exemplo é apresentado aos classificadores $h_{\mathrm{w}}$ e $h_{\mathrm{NW}}$, ambos filhos de $h_{\mathrm{G}}$, e que o grau de confiança para a classificação resultante desses classificadores seja [B : 0,9; V : 0,1] e [C: 0,33; $\mathrm{T}:$ : 34; H : 0,33], respectivamente, conforme apresentado na Figura 5.9(a). Com a informação adicional dos classificadores filhos de $h_{\mathrm{G}}$, os graus de con- 
fiança para a predição de $h_{\mathrm{G}}$ são atualizados - Equação 5.4. No caso do exemplo apresentado na Figura 5.9, o maior grau de confiança resultante do classificador $h_{\mathrm{w}}$ é 0,9 para a predição de B, enquanto que o classificador $h_{\mathrm{Nw}}$ resultou em 0,34 para a classe $\mathrm{T}$ - Figura 5.9(b).

Para esse exemplo, aplicamos a média conforme a Equação 5.4, resultando $h_{\mathrm{G}}=[\mathrm{W}:(0,5+0,9) / 2 ; \mathrm{NW}:(0,5+0,34) / 2]$ - Figura 5.9(c). Como resultado da operação $h_{\mathrm{G}}=[\mathrm{W}: 0,67 ; \mathrm{NW}: 0,41]$ - Figura 5.9(d). Consequentemente, após essa atualização e devido à influência do nível imediatamente abaixo na hierarquia, a classe mais provável escolhida pelo classificador $h_{\mathrm{G}}$ é $\mathrm{W}-$ Figura 5.9(d). Seguindo a estratégia de predição top-down, esse processo é repetido para a subárvore com raiz em $h_{\mathrm{w}}$.

É importante lembrar que a construção dos classificadores locais é realizada como no método padrão HMR, apresentando diferenças somente na fase de classificação dos novos exemplos.

Uma vantagem desse método com relação ao método HMR é que os nós filhos influenciam na classificação no nível anterior, fazendo com que cada classificador local considere um passo à frente em cada decisão. Porém, esse modelo ainda não elimina a necessidade de classificadores precisos, principalmente nos níveis mais acima da hierarquia. Quanto mais precisos forem os classificadores locais, melhor será o aproveitamento da influência dos nós filhos e, consequentemente, maiores serão as chances de acerto para a predição. Além disso, esse método por si só não trata o bloqueio de exemplos nos primeiros níveis da hierarquia. Para esse problema, é necessária a utilização de outras estratégias, como valores decrescentes de threshold para cada classificador local ou para cada nível da hierarquia.

\subsubsection{Método híbrido de cooperação para classificação hierár- quica}

Como mencionado, no método HMR cada classificador local sempre rotula novos exemplos com uma de suas classes filhas, o que, em alguns casos, pode gerar um erro que será propagado para os outros níveis da hierarquia, degradando a performance global do classificador hierárquico. Nesse contexto, propomos outro método, chamado Hierarchical Dual Relevance - HDR, para tentar evitar esse tipo de erro e sua propagação.

Para isso, propomos a utilização de um modelo híbrido que usa, além dos classificadores multiclasse nesse método chamados de classificadores primários em cada nó não-folha, classificadores locais binários associados a todos os nós, exceto ao nó raiz, os quais são tratados como classificadores secundários. Em outras palavras, estamos propondo a utilização dos métodos HMR e HBR simultaneamente para a construção do classificador hierárquico treinado 


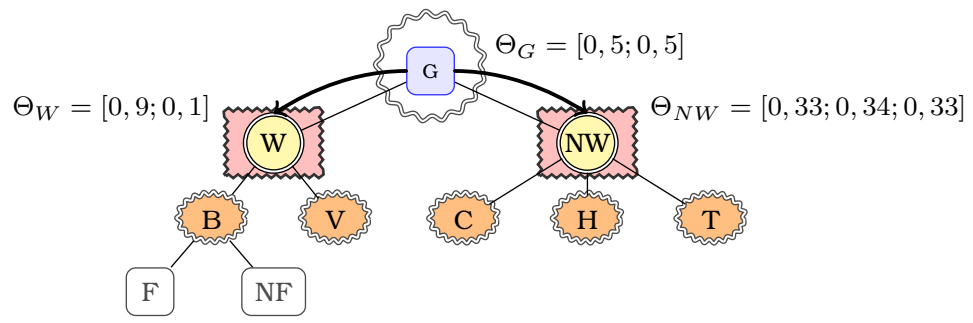

(a) Classificação do novo exemplo pelos classificadores primário e secundário

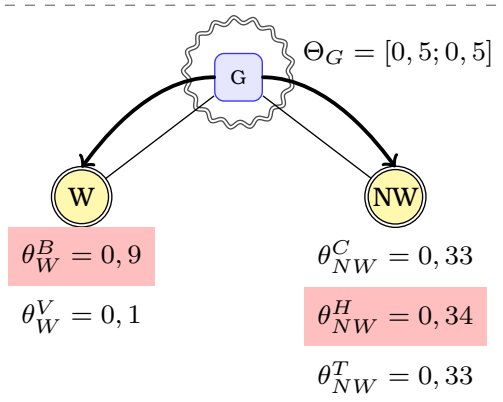

(b) Identificação das maiores confianças

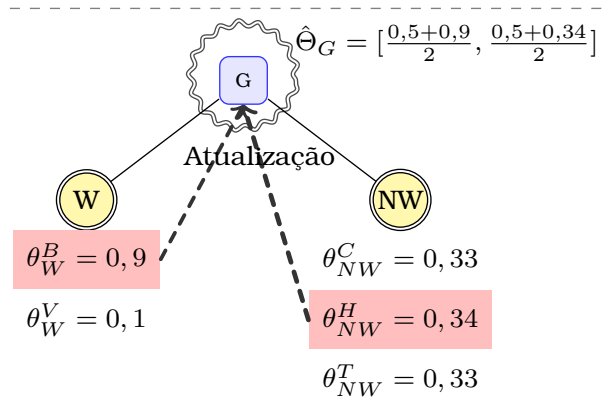

(c) Atualização dos valores de confiança do classificador primário

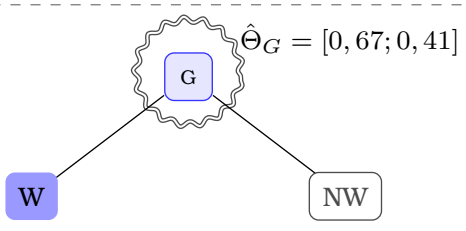

Classes consideradas pelo classificador primário

Classes consideradas pelos classificadores secundários

Classe predita $\{$ Classificador local primário

(d) Predição obtida pelo classificador primário depois da atualização

Figura 5.9: Classificação por meio do modelo HMR com estratégia de multiplicação. 
com algoritmos de aprendizado diferentes, conforme ilustrado na Figura 5.10.

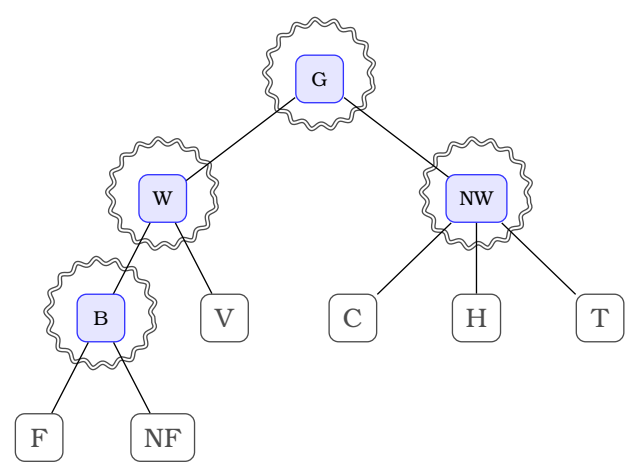

(a) Classificadores primários: método HMR

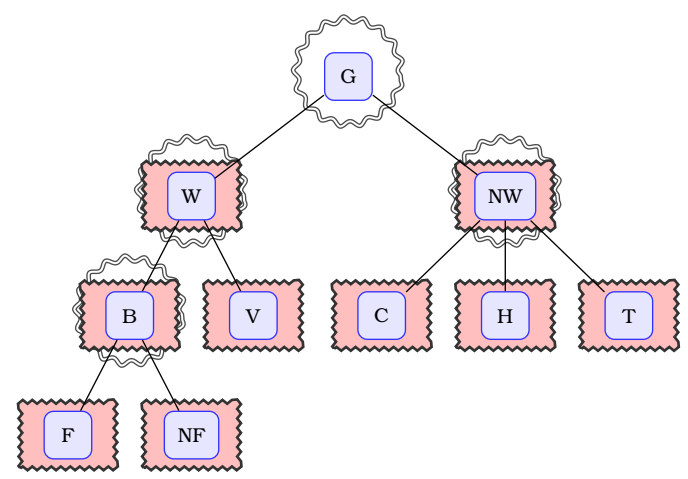

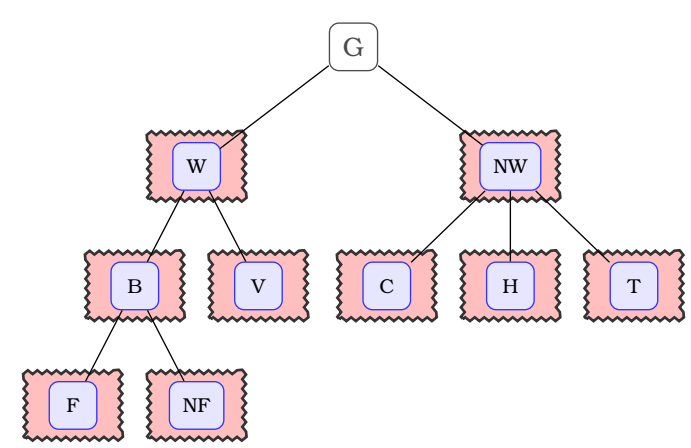

(b) Classificadores secundários: método HBR

(c) Modelo Híbrido com classificadores locais multiclasse e binários

Figura 5.10: Ilustração do modelo híbrido com classificadores locais.

A construção dos modelos HMR e HBR é feita de maneira independente. No entanto, durante a predição os classificadores secundários (binários) são utilizados para reforçar a predição dos classificadores primários (multiclasse) e evitar a propagação de erros.

Durante o rotulamento de um novo exemplo por meio da estratégia de predição top-down, o classificador primário associado ao nó raiz classifica o exemplo, resultando os valores de grau de confiança da classificação em cada uma das suas subclasses. Em seguida, os classificadores secundários associados a cada uma dessas subclasses são utilizados para classificar o novo exemplo, retornando também seus respectivos graus de confiança para predição como positivo. Então, calcula-se a média dos valores dos graus de confiança para cada uma das subclasses do classificador primário, obtidos tanto pelo classificador primário quanto pelos classificadores secundários, conforme a Equação 5.6, onde $\theta_{h_{\text {Prim }, E}}^{k}$ representa o grau de confiança para a classificação obtido pelo classificador primário referente à subclasse $k$ considerando o exemplo $E$ como entrada, e $\delta_{h_{s e c, E}^{k}}$ representa o grau de confiança na predição para o exemplo $E$ como positivo obtido por meio do classificador secundário (binário) associado a subclasse $k$ do classificador primário. 


$$
\hat{\theta}_{h_{P r i m, E}^{k}}^{k}=\frac{\left(\theta_{h_{P r i m, E}^{k}}^{k}+\delta_{h_{s e c, E}^{k}}\right)}{2}
$$

A rotulação de um novo exemplo por meio desse modelo, utilizando a estratégia de predição opcional até as classes folha, é ilustrada na Figura 5.11. Considerando que a classe verdadeira do novo exemplo é G $\rightarrow \mathrm{NW}$, o classificador $h_{\mathrm{Nw}}$ o rotularia como $\mathrm{H}$ com grau de confiança 0,7 caso não houvesse a influência dos classificadores secundários. Porém, com a avaliação das predições dadas pelos classificadores secundários $h_{\mathrm{C}}, h_{\mathrm{T}}$ e $h_{\mathrm{H}}$, os quais predizem o novo exemplo como negativo, a predição do classificador primário é modificada e, com isso, a classe correta é predita.

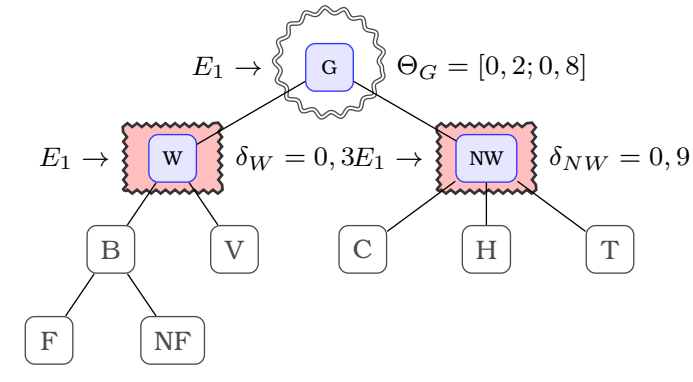

Threshold: $\Gamma=0,5 ; \quad \hat{\Theta}_{G}=[0,25 ; 0,85] ; \quad \hat{\theta}_{h_{G}}^{N W}>\Gamma$

(a) Primeiro passo

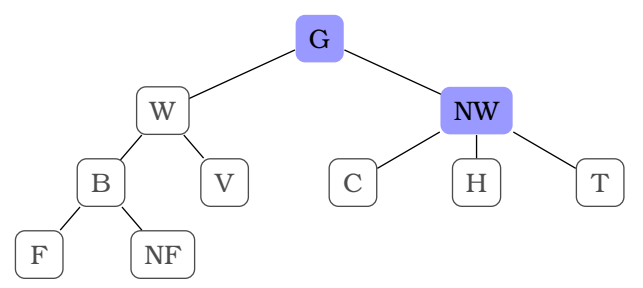

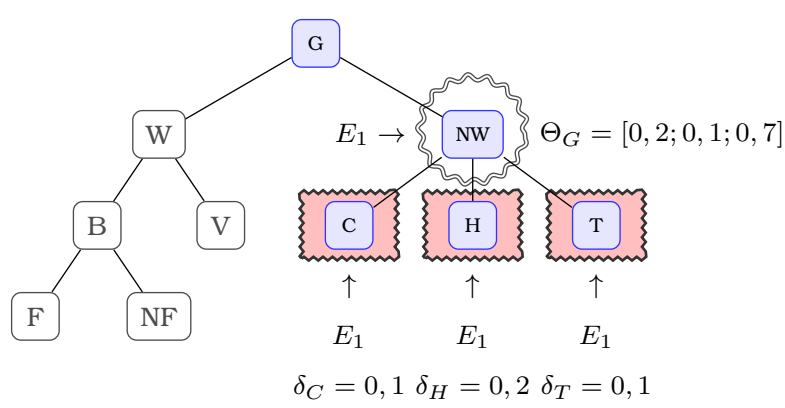

Threshold: $\Gamma=0,5 ; \quad \hat{\Theta}_{G}=[0,15 ; 0,1 ; 0,45] ; \quad \hat{\theta}_{h_{G}}^{N W}<\Gamma$

(b) Segundo passo

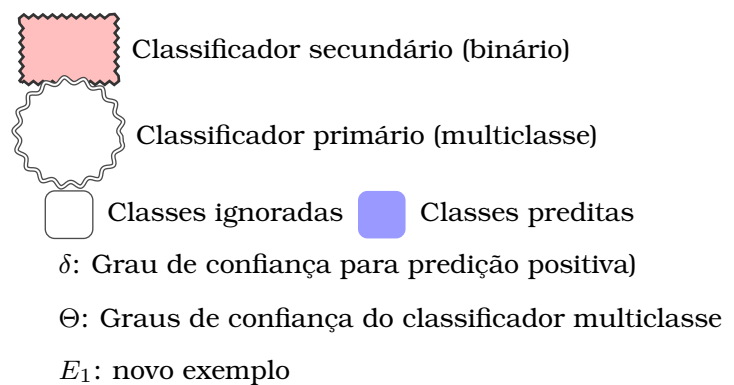

(c) Predição final

A principal desvantagem desse método com relação aos descritos anteriormente é a sua complexidade de tempo computacional, uma vez que dois modelos são treinados ao mesmo tempo. Assim, a complexidade total desse modelo é igual à soma das complexidades do modelo HMR e do modelo HBR. Se considerarmos a complexidade do modelo HBR como $(|L|-1) \times O(\operatorname{Bin})$, onde Bin representa o classificador base binário, e do modelo HMR como $(\mid L-$ folhas $\mid) \times O($ Mult $)$, onde Mult representa o classificador base multiclasse, o modelo híbrido terá complexidade total de $|L| \times(O($ Bin $)+O($ Mult $))$. 
Por outro lado, nesse método os exemplos são analisados a partir de duas perspectivas distintas (classificadores primários e secundários) que cooperam para melhorar a classificação de novos exemplos.

\subsubsection{HBR coperspectiva supervisionado}

Uma outra maneira de analisar um problema de classificação hierárquica considerando duas perspectivas é aplicando a mesma estratégia utilizada no método de classificação multirrótulo $\mathrm{BR}_{C o P}$. É importante lembrar que a classificação hierárquica é inerentemente multirrótulo, pois mais de uma classe está possivelmente associada a cada exemplo, mesmo que apenas um caminho da taxonomia seja permitido.

Nesse contexto, propomos o método $\mathrm{HBR}_{C o P}$, o qual estende o método $\mathrm{BR}_{C o P}$ incorporando as restrições da classificação hierárquica para a construção dos classificadores. De outro modo, podemos também dizer que esse método é uma extensão do método HBR com o uso de duas perspectivas, conforme ilustrado na Figura 5.12, na qual apenas o classificador $h_{\mathrm{Nw}}$ é detalhado, mas todos os classificadores locais criados apresentam a mesma estrutura.

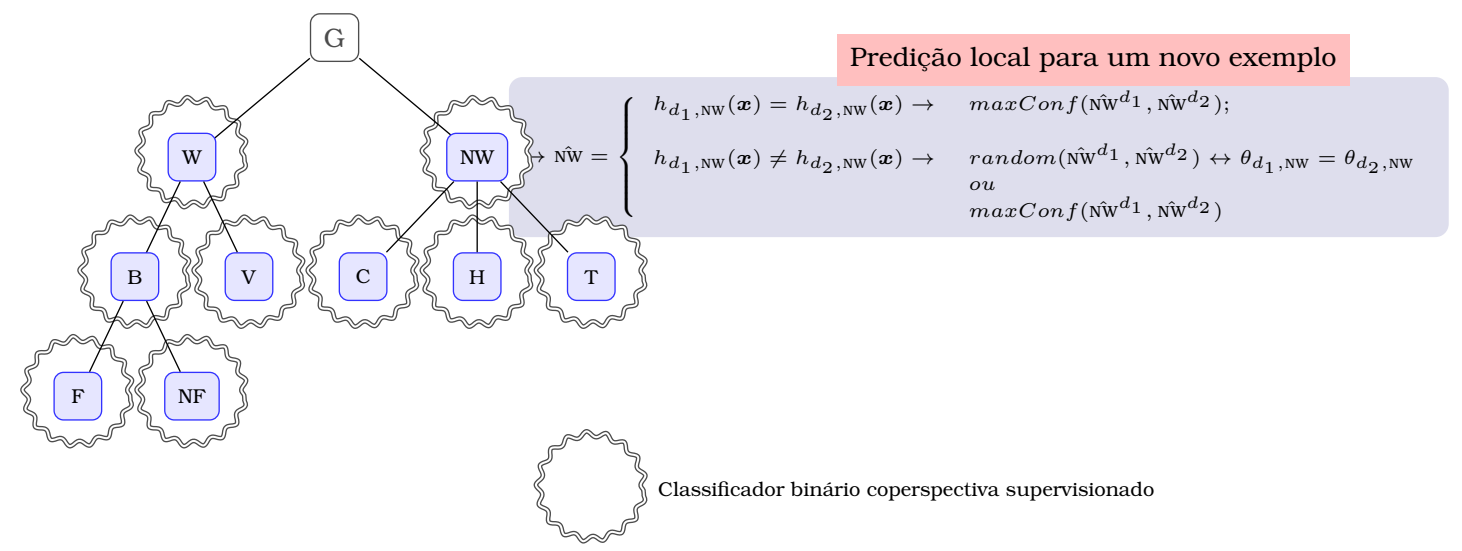

Figura 5.12: Abordagem local com o método $\operatorname{HBR}_{C o P}$.

A ideia básica é criar dois classificadores para cada monorrótulo $y_{j} \in L$, a partir de algoritmos de aprendizado diferentes. Esses classificadores locais são construídos respeitando as heurísticas de seleção de exemplos de treinamento locais para a classificação hierárquica, por meio das quais as restrições da classificação hierárquica e a estrutura da taxonomia de classes são implicitamente consideradas. Após a criação desses classificadores locais, a classificação de um novo exemplo é realizada por meio da estratégia top-down de maneira idêntica ao método HBR apresentado anteriormente. Porém, como no método $\mathrm{BR}_{C o P}$, existe a necessidade de resolver os pontos de contenção, ou seja, decidir a correta classificação para os exemplos que geram desacordo na predição dos classificadores. Essa decisão é realizada com base na estratégia 
apresentada anteriormente para o método $\mathrm{BR}_{C o P}$ e mostrada novamente na Figura 5.12 no quadro Predição local para um novo exemplo .

\subsection{Algoritmos para classificação hierárquica semis- supervisionada}

Assim como adaptamos os métodos BR e HBR para o uso de mais de uma perspectiva em cada classificador binário monorrótulo, podemos também adaptar esses métodos para o uso do aprendizado semissupervisionado, seja por meio da técnica de bootstratpping ou pelo aprendizado baseado em desacordo. Essas adaptações, considerando o método BR para a classificação multirrótulo, foram apresentadas anteriormente. Nesta seção, são apresentadas as adaptações realizadas no método HBR para a solução da classificação hierárquica, considerando o contexto de aprendizado semissupervisionado.

\subsection{Self-training Hierarchical Binary Relevance}

Uma abordagem para incluir o aprendizado semissupervisionado no contexto de classificação hierárquica é construir classificadores binários baseados na técnica de bootstrapping para cada monorrótulo $y_{j} \in L$, seguindo o método HBR.

Para simular um cenário com poucos exemplos rotulados e muitos exemplos não rotulados, o conjunto de treinamento original $\operatorname{Tr}$ pode ser dividido em dois subconjuntos de exemplos, $\operatorname{Tr}^{l}$ e $T r^{u}$. É importante mencionar que, em um cenário simulado, os rótulos dos exemplos em $\operatorname{Tr}^{u}$ são conhecidos, mas não são utilizados durante o processo de aprendizado.

A partir dos dois conjuntos de exemplos, rotulados $T r^{l}$ e não rotulados $T r^{u}$, são criados $q$ classificadores binários SELF-TRAINING, um para cada monorrótulo do problema em questão. Esse procedimento é ilustrado no Algoritmo 5.1, no qual a função heurística é responsável por preparar os conjuntos de treinamento locais binários, a função bootstrapping é responsável por classificar o máximo possível de exemplos não rotulados em $\operatorname{Tr}^{u}$, os quais são movidos para o conjunto de exemplos rotulados. Esse novo conjunto de exemplos rotulados é utilizado para a construção do classificador final pela função criarClassificador.

É importante observar que, nesse caso, tanto os conjunto de exemplos rotulados local como o conjunto de exemplos não rotulados local devem ser selecionados de acordo com alguma heurística que respeite a estrutura hierárquica, de modo que a construção dos classificadores e o processo de rotulação por meio do bootstrapping sejam consistentes com o problema de classificação 


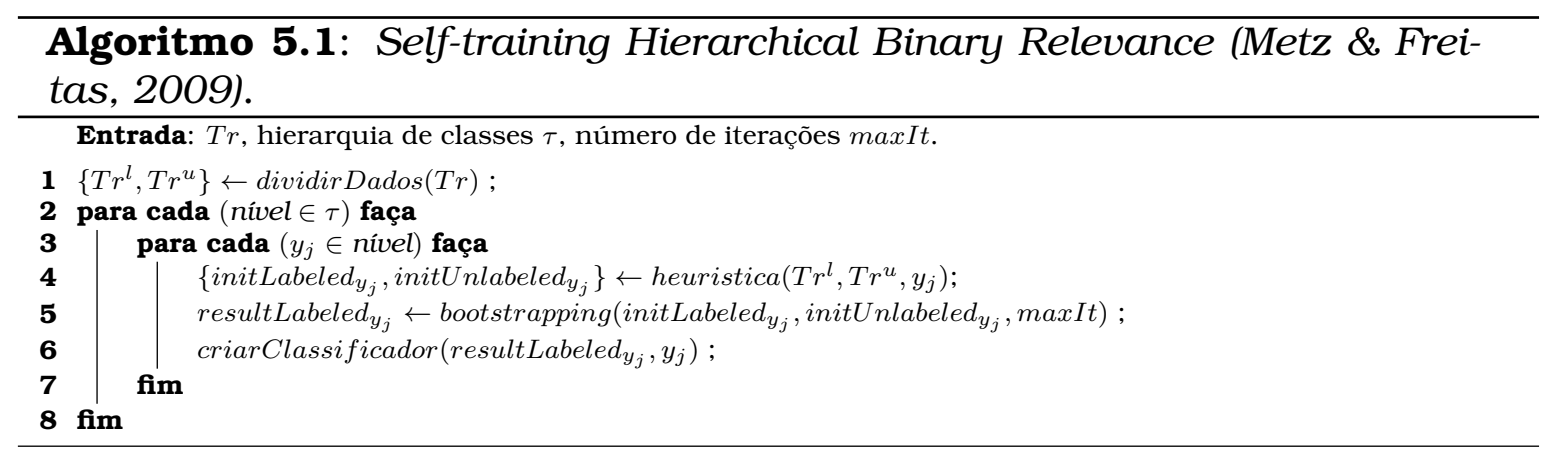

hierárquica.

Em um estudo inicial da utilização do bootstrapping no contexto de classificação hierárquica, avaliamos três diferentes maneiras para utilização dos exemplos não rotulados durante o processo de aprendizado (Metz \& Freitas, 2009). A partir desse estudo, foi observado, entre outros fatores, que a escassez de exemplos de treinamento para a construção dos classificadores relacionados às classes mais profundas da hierarquia é um problema frequente, uma vez que quanto mais profunda a classe, menor o número de exemplos associados a ela. Além disso, a aplicação das heurísticas como descrito diminui, também, o número de exemplos no conjunto local $\operatorname{Tr}^{u}$ e, com isso, diminui a quantidade de exemplos não rotulados que poderiam ser inseridos no conjunto de exemplos rotulados, dificultando ainda mais essa tarefa de classificação.

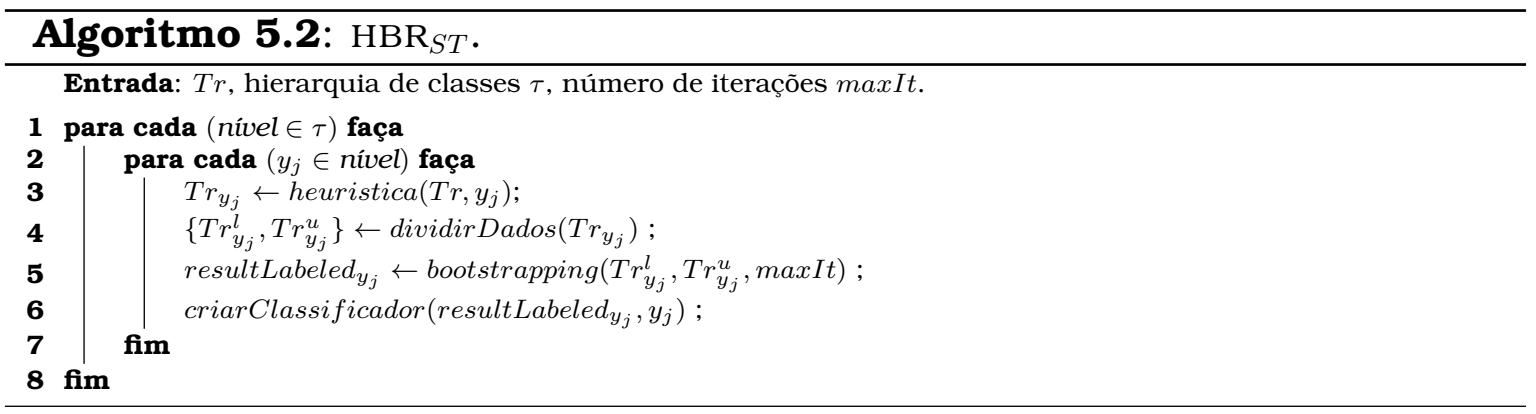

Na realidade, para qualquer algoritmo semissupervisionado, é condição necessária que as classes, tanto para classificação monorrótulo quanto multirrótulo ou hierárquica, estejam todas representadas no conjunto inicial $\operatorname{Tr}^{l} \mathrm{de}$ exemplos rotulados. Essa condição é mais difícil de ser atendida para problemas de classificação hierárquica. Neste trabalho, para minimizar a possibilidade de não ter classes representadas no conjunto inicial $\mathrm{Tr}^{l}$, na aplicação do bootstrapping em conjunto com o método HBR, propomos dividir localmente o conjunto de treinamento original $T r$, aplicando antes a heurística de seleção dos exemplos para o conjunto de treinamento local e somente após a divisão de $T r_{y_{j}}$ em $\operatorname{Tr}_{y_{j}}^{l}$ e $\operatorname{Tr}_{y_{j}}^{u}$. O pseudo-código desse método, denominado $\mathrm{HBR}_{S T}$, é apresentado no Algoritmo 5.2, e uma ilustração desse método é apresen- 
tada na Figura 5.13, na qual apenas o classificador local $h_{\mathrm{Nw}}$ é mostrado em detalhes, mas todos os outros mantêm a mesma estrutura.

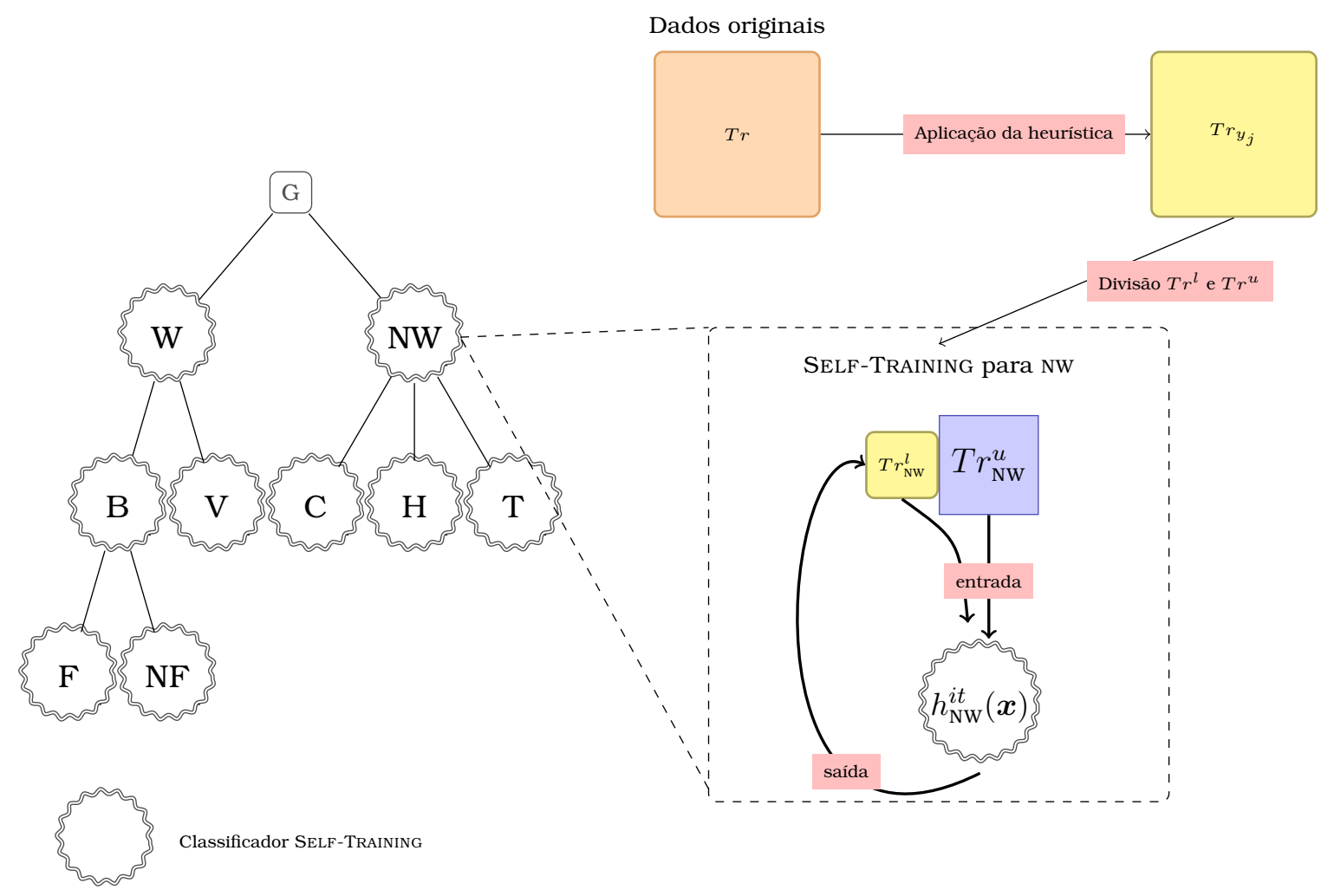

Figura 5.13: Método $\operatorname{HBR}_{S T}$.

O resultado final de cada classificador SELF-TRAINING, como já mencionado, é um classificador binário construído a partir do conjunto de exemplos rotulados, o qual é incrementado com os exemplos não rotulados que foram classificados durante o processo de aprendizado semissupervisionado. Esses classificadores "finais", referentes a cada monorrótulo, são utilizados dentro do framework HBR para a classificação de novos exemplos.

\subsubsection{HBR coperspectiva semissupervisionado}

Como no caso da classificação multirrótulo, o aprendizado semissupervisionado baseado em desacordo também pode ser utilizado no contexto de classificação hierárquica adaptando o método HBR. Nesse método, proposto neste trabalho e chamado de $\mathrm{HBR}_{C o P S S}$, o conjunto de treinamento original é utilizado de maneira similar ao método $\mathrm{HBR}_{S T}$, com a diferença de que para cada monorrótulo $y_{j} \in L$, os conjuntos locais $\operatorname{Tr}^{l}$ e $\operatorname{Tr}^{u}$ são "replicados" para formar as duas "descrições" dos dados, a partir das quais é construído um classificador Co-Perspective ao invés do SELF-Training. Esse método é ilustrado na Figura 5.14.

Tanto a etapa de treinamento como a etapa de classificação desse método, 


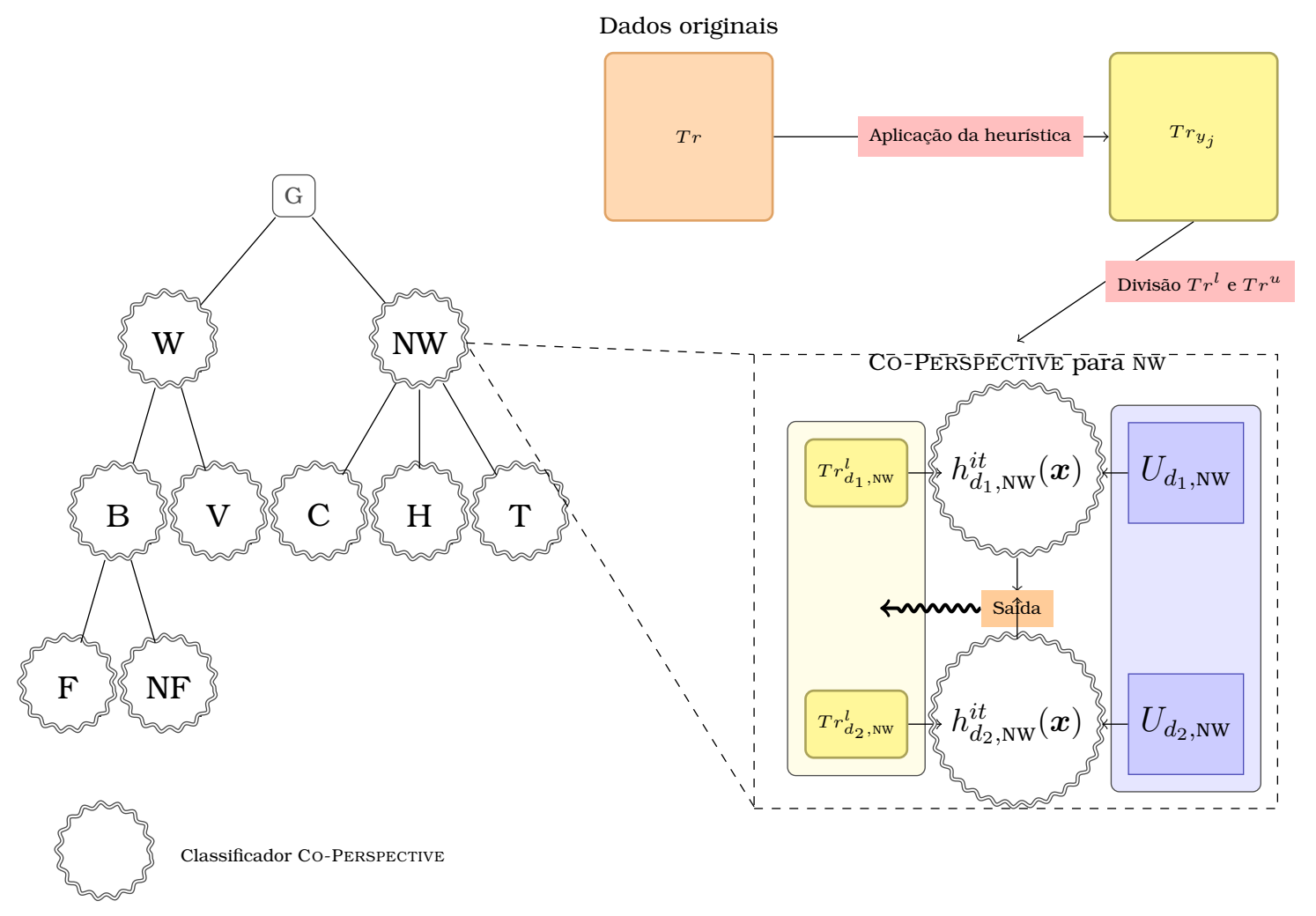

Figura 5.14: Método HBR $\mathrm{HoPSS}_{\text {. }}$

são realizadas de maneira similar ao método HBR, diferenciando-se apenas no que diz respeito à criação dos classificadores locais, os quais, neste método, são classificadores CO-PERSPECTIVE.

\subsubsection{HBR coperspectiva semissupervisionado ativo}

De maneira análoga ao método multirrótulo $\mathrm{BR}_{C o P S S+A L}$, é possível introduzir o aprendizado ativo no método $\mathrm{HBR}_{C o P S S}$. Para isso, em cada iteração do algoritmo Co-PERSPECTIVE binário para cada monorrótulo da taxonomia, alguns pontos de contenção são classificados pelo "oráculo" e adicionados ao conjunto de exemplos rotulados local para atualização dos classificadores binários em cada descrição. Após a atualização dos classificadores em cada descrição, os mesmos são utilizados para rotular os exemplos em $\operatorname{Tr}^{u}$.

Uma vez que o limite de consultas ao "oráculo" tenha sido atingido ou não houver mais pontos de contenção para serem rotulados, os demais exemplos presentes no conjunto $T r^{u}$ são iterativamente classificados por meio do processo baseado em desacordo implementado no algoritmo Co-PERSPECTIVE, até que todos tenham sido rotulados e inseridos no conjunto $\operatorname{Tr}^{l}$ para a construção dos classificadores finais.

Assim como no caso da classificação multirrótulo, com o algoritmo $\mathrm{HBR}_{\text {CoTesting }}$ também é possivel utilizar apenas o aprendizado ativo coperspectiva no con- 
texto de classificação hierárquica, o qual rotula e move para o conjunto de exemplos rotulados apenas os pontos de contenção presentes em $\operatorname{Tr}^{u}$, respeitando o limite pré-definido de consultas ao "oráculo".

A classificação de novos exemplos, mais uma vez, está sujeita ao desacordo entre os classificadores em cada descrição. Assim, a predição de cada monorrótulo $y_{j} \in L$ é definida de acordo com o procedimento apresentado anteriormente na Equação 5.2 .

\subsection{HARPIA- um framework para classificação hierár- quica}

Um dos principais resultados deste projeto de pesquisa foi o projeto e desenvolvimento da HARPIA ${ }^{6}$, um framework computacional para avaliação experimental de algoritmos de classificação hierárquica. Neste framework estão disponiveis todos os métodos de classificação hierárquica propostos neste trabalho, bem como os outros métodos utilizados como base para a comparação dos resultados.

A HARPIA, chamada assim em homenagem à ave de rapina Harpia harpyja típica do continente sulamericano e muito comum no Brasil, é um framework implementado em linguagem Java que faz uso extensivo dos recursos disponíveis na biblioteca de classes WEKA, possibilitando que esses recursos também estejam disponiveis para outros desenvolvedores que estejam interessados em contribuir com o desenvolvimento deste framework. Atualmente, este framework dispõe de métodos de classificação hierárquica baseados na abordagem local com estratégia de predição top-down, descritos anteriormente. Entretanto, uma vez que é uma biblioteca de código aberto e está disponível gratuitamente para a comunidade científica, outros métodos podem ser implementados futuramente.

O módulo de avaliação experimental da HARPIA contém diversas medidas de avaliação da classificação hierárquica, como as medidas baseadas em exemplos, medidas baseadas em rótulos e outras medidas para informações sobre os diferentes niveis da hierarquia. Com essa gama de diferentes medidas de avaliação, conjuntamente com o método baseline $\mathrm{HBR}_{\text {Low }}$, é possível realizar avaliações experimentais bastante completas para entender as capacidades de cada tipo de algoritmo desenvolvido para a tarefa de classificação hierárquica.

Uma segunda contribuição quanto à implementação de ferramentas e métodos de classificação, também importante, é a implementação dos métodos baseados em coperspectiva supervisionados e semissupervisionados, assim

\footnotetext{
${ }^{6}$ http://sites.labic.icmc.usp.br/jeanmetz/harpia.html
} 
como os métodos de aprendizado ativo para a classificação multirrótulo, os quais foram inclusos na biblioteca de classes Mulan. Porém, esses métodos ainda não estão disponíveis para a comunidade, uma vez que não temos controle sobre essa biblioteca ${ }^{7}$. O método baseline $\mathrm{BR}_{\text {Low }}$, também foi incluso na biblioteca Mulan.

\subsection{Considerações finais}

Neste capítulo foram brevemente descritas algumas propostas que são resultados de pesquisas em colaboração com colegas do mesmo grupo de pesquisa do Laboratório de Inteligência Computacional do ICMC/USP, e altamente relacionadas ao tema principal deste trabalho. São duas as principais contribuições destes trabalhos em colaboração:

- o método para classificação supervisionada multirrótulo plana, BR+; e

- o método para estimativa do limite superior de classificação para classificação supervisionada multirrótulo plana baseada na estratégia de Stacking.

Em seguida foram apresentados os métodos originados neste trabalho de pesquisa, os quais contemplam tarefas de aprendizado supervisionado e semissupervisionado, tanto para classificação multirrótulo plana quanto hierárquica. Na Tabela 5.5 são apresentados todos os métodos propostos neste trabalho e suas respectivas tarefas de aprendizado, na qual as colunas são nomeadas da seguinte maneira:

- Sup: métodos supervisionados;

- SS: métodos semissupervisionados;

- MonoP: métodos monoperspectiva;

- CoP: métodos coperspectiva; e

- AA: métodos de aprendizado ativo.

Diferentemente da classificação plana monorrótulo, os algoritmos desenvolvidos para as tarefas de classificação multirrótulo e/ou hierárquica, são usualmente avaliados por meio de comparações com outros métodos. Entretanto, esse tipo de análise comparativa não possibilita mensurar a capacidade de aprendizado dos algoritmos.

\footnotetext{
${ }^{7}$ Entraremos em contato com os responsáveis para incluir definitivamente esses métodos na biblioteca Mulan.
} 
Tabela 5.5: Categorização dos métodos propostos

\begin{tabular}{|c|c|c|c|c|c|c|c|c|c|c|}
\hline \multirow[t]{2}{*}{ Método } & \multicolumn{5}{|c|}{ Multirrótulo } & \multicolumn{5}{|c|}{ Hierárquico } \\
\hline & Sup & SS & MonoP & $\mathrm{CoP}$ & AA & Sup & SS & MonoP & $\mathrm{CoP}$ & AA \\
\hline $\mathrm{BR}_{\text {Low }}$ & $\checkmark$ & & $\checkmark$ & & & & & & & \\
\hline $\mathrm{BR}_{C o P}$ & $\checkmark$ & & & $\checkmark$ & & & & & & \\
\hline $\mathrm{BR}_{S T}$ & & $\checkmark$ & $\checkmark$ & & & & & & & \\
\hline $\mathrm{BR}_{C o P S S}$ & & $\checkmark$ & & $\checkmark$ & & & & & & \\
\hline $\mathrm{BR}_{C o P S S+A L}$ & & $\checkmark$ & & $\checkmark$ & $\checkmark$ & & & & & \\
\hline $\mathrm{BR}_{\text {CoTesting }}$ & & & & $\checkmark$ & $\checkmark$ & & & & & \\
\hline $\mathrm{HBR}_{\text {Low }}$ & & & & & & $\checkmark$ & & $\checkmark$ & & \\
\hline $\mathrm{HMR}_{E x t}$ & & & & & & $\checkmark$ & & $\checkmark$ & & \\
\hline HMR $_{E x t M u l t i}$ & & & & & & $\checkmark$ & & $\checkmark$ & & \\
\hline HDR & & & & & & $\checkmark$ & & & $\checkmark$ & \\
\hline $\mathrm{HBR}_{C o P}$ & & & & & & $\checkmark$ & & & $\checkmark$ & \\
\hline $\mathrm{HBR}_{S T}$ & & & & & & & $\checkmark$ & $\checkmark$ & & \\
\hline $\mathrm{HBR}_{C o P S S}$ & & & & & & & $\checkmark$ & & $\checkmark$ & \\
\hline $\mathrm{HBR}_{C o P S S+A L}$ & & & & & & & $\checkmark$ & & $\checkmark$ & $\checkmark$ \\
\hline HBR $_{\text {CoTesting }}$ & & & & & & & & & $\checkmark$ & $\checkmark$ \\
\hline
\end{tabular}

Para realizar esse tipo de avaliação, foram propostos neste trabalho dois métodos para estimativa de medidas de avaliação baseadas no multirrótulo majoritário, um para a tarefa de classificação multirrótulo e outro para a tarefa de classificação hierárquica, os quais podem ser utilizados como baseline para avaliações de algoritmos. É importante lembrar que esses métodos baseados no multirrótulo majoritário, $\mathrm{BR}_{\text {Low }} \mathrm{e} \mathrm{HBR}_{\text {Low }}$, analogamente à estratégia para o cálculo do erro majoritário na classificação plana monorrótulo, não fazem uso dos atributos descritores dos exemplos, pois consideram apenas a distribuição das classes associadas aos exemplos do conjunto de treinamento. Contudo, a partir desses métodos, é possivel estimar qualquer medida de avaliação "majoritária" e não apenas a medida de erro majoritário.

Durante o desenvolvimento desses métodos, foram encontrados e enfrentados diversos desafios. Dentre eles, o estudo e entendimento dos conceitos que envolvem quatro técnicas de Aprendizado de Máquina:

- Classificação Multirrótulo;

- Classificação Hierárquica;

- Aprendizado Semissupervisionado; e

- Aprendizado Ativo.

A falta de conjuntos de dados para avaliação dos métodos propostos também foi um desafio, pois em geral são poucos os conjuntos de dados disponiveis para essas tarefas, principalmente para a classificação hierárquica monorrótulo.

Outro desafio importante está relacionado à falta de informação a respeito do uso dessas diferentes técnicas de aprendizado em conjunto. Não é de nosso conhecimento a existência de trabalhos que tratam de tarefas de classificação complexas como essas em conjunto. Esse fato dificulta o desenvolvimento da 
pesquisa, uma vez que não existe a troca de informações com outros pesquisadores, seja por meio de publicações em periódicos ou comunicação pessoal em eventos científicos, a respeito do tema.

Cada técnica de aprendizado, por si, apresenta alguns fatores responsáveis pela degradação dos modelos de classificação gerados. Consequentemente, quando essas técnicas são utilizadas em conjunto esses fatores são somados, o que torna a tarefa ainda mais complexa, pois mais de um tipo de degradação do modelo deve ser considerado.

Além disso, existe a dificuldade de comparar resultados obtidos com os resultados publicados por outros pesquisadores, uma vez que, diferentemente da classificação monorrótulo, não há um método totalmente aceito pela comunidade para avaliação e comparação de resultados para classificação multirrótulo e classificação hierárquica. Assim, muitas vezes, pesquisadores publicam os resultados de suas pesquisas utilizando um subconjunto de medidas de avaliação que não são usualmente utilizados pelo restante da comunidade.

No caso da classificação plana monorrótulo e multirrótulo, existem ao menos um framework desenvolvidos para avaliação experimental, respectivamente Weka e Mulan, nos quais estão disponíveis uma grande gama de métodos de avaliação. Para a classificação hierárquica, por outro lado, não existia uma ferramenta como essa. Nesse sentido, a integração no HARPIA de diferentes bibliotecas e frameworks desenvolvidos para as tarefas de classificação, conjuntamente com a implementação dos algoritmos supervisionados e semissupervisionados hierárquicos, foram desafios enfrentados durante o desenvolvimento dos métodos propostos neste trabalho. 


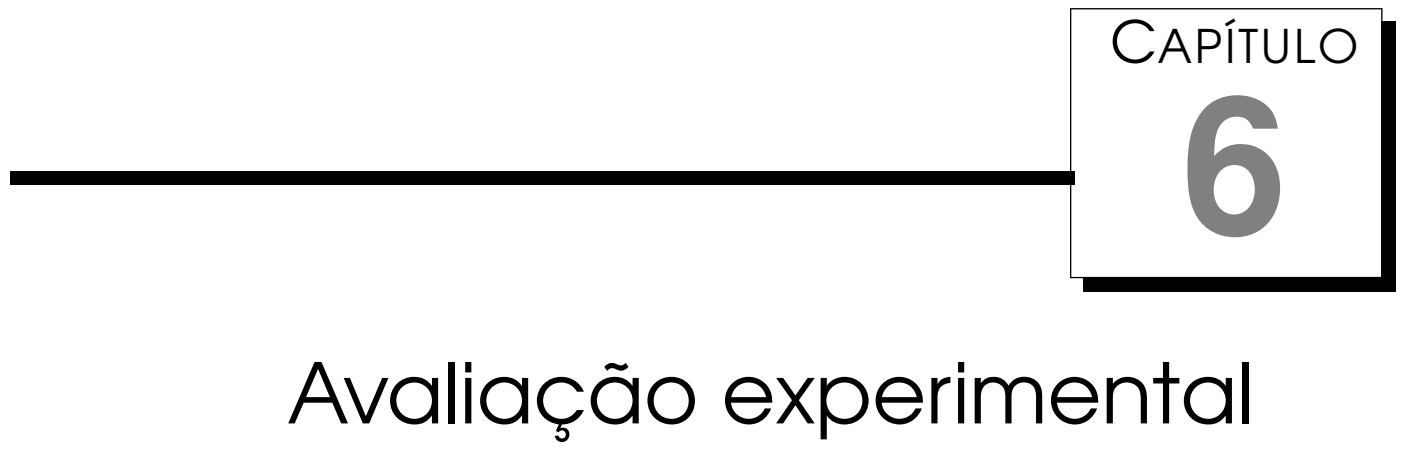

Neste capítulo, são descritas e analisadas as avaliações experimentais realizadas para avaliar as propostas apresentadas no Capítulo 5. Esses experimentos estão organizados de acordo com o tipo de tarefa de classificação ${ }^{1}$ :

1. Na Seção 6.1, são apresentados os experimentos relacionados à tarefa de classificação multirrótulo. Os conjuntos de dados bem como os cenários para avaliação e as respectivas configurações de experimentos relacionados a essa tarefa são apresentados nas Seções 6.1.1 e 6.1.2. Os resultados obtidos e a respectiva análise são apresentados na Seção 6.1.3; $\mathrm{e}$

2. Na Seção 6.2, são apresentados os experimentos relacionados à tarefa de classificação hierárquica. Os conjuntos de dados são apresentados na Seção 6.2.1 ao passo que os cenários e configurações de experimentos relacionados a essa tarefa são apresentados na Seção 6.2.2. Por fim, os resultados obtidos e a análise desses resultados são apresentados na Seção 6.2.3.

Para ambas as tarefas de classificação, os cenários experimentais elaborados contemplam tanto as propostas para aprendizado supervisionado como para aprendizado semissupervisionado.

\footnotetext{
${ }^{1}$ Todos os resultados experimentais encontram-se em http://sites.labic.icmc.usp. br/jeanmetz/harpia.html.
} 


\subsection{Classificação multirrótulo}

Foram realizados experimentos com o objetivo de avaliar os métodos propostos considerando cenários que contemplam os métodos supervisionados e semissupervisionados. Resumidamente, foram avaliados os métodos $\mathrm{BR}_{C o P}$, $\mathrm{BR}_{C o P S S}$ e $\mathrm{BR}_{C o P S S+A L}$, comparando-os a outros métodos multirrótulo, como BR, $\mathrm{BR}_{\text {Low }} \mathrm{e} \mathrm{BR}_{S T}$. Os conjuntos de dados utilizados, bem como as configurações dos experimentos e a análise dos resultados, são apresentados a seguir.

\subsubsection{Bases de dados}

Vários conjuntos de dados multirrótulo, disponíveis na internet, foram analisados. Dentre eles foram escolhidos seis conjuntos que representam diferentes áreas de conhecimento, os quais estão disponíveis nas páginas $w e b^{2}$ http: //mulan. sourceforge. net/ e http://meka. sourceforge. net/. Cada conjunto de dados é brevemente descrito a seguir:

1. Emotions: cada exemplo desse conjunto de dados representa um trecho de uma música, o qual é utilizado para detecção automática de emoções. Em outras palavras, a tarefa relacionada a esse conjunto de dados é classificar cada música em um ou mais tipo de emoções, como energética, depressiva, calma e outros (Trohidis et al., 2008).

2. Scene: com esse conjunto de dados a tarefa é rotular imagens considerando os tipos de paisagens e objetos nelas presentes, como praia, campo, montanha, automóveis, animais e outros (Boutell et al., 2004).

3. Slashdot-f: conjunto de dados composto de artigos e sinopses de livros, extraídos do diretório Slashdot.org ${ }^{3}$. A tarefa é rotular textos de acordo com as diversas classes disponíveis no diretório (Read et al., 2008).

4. Yeast: esse conjunto de dados é composto de expressões gênicas de micro-array e perfis filogenéticos. Originalmente, as classes desse conjunto de dados respeitam uma taxonomia de classes com até 6 níveis ${ }^{4}$. Porém, Elisseeff \& Weston (2001a) utilizaram apenas as classes no primeiro nível da taxonomia para a classificação multirrótulo.

5. Enron: esse é um subconjunto do conjunto de dados Enron Email, rotulado pelo UC Berkeley Enron Email Analysis Project ${ }^{5}$, e mensagens de

\footnotetext{
${ }^{2}$ Último acesso em 21 de julho de 2011.

$3_{\text {http }: \text { / / slashdot.org/. }}$

${ }^{4}$ Informações detalhadas a respeito desse conjunto de dados pode ser obtidas em http: //www.helmholtz-muenchen. de/en/mips/projects/funcat/index.html.

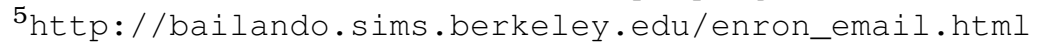


texto enviadas por correio eletrônico, as quais são organizadas em subdiretórios de caixas de mensagens. A tarefa relacionada a esse conjunto de dados é classificar automaticamente novas mensagens de texto considerando os diversos subdiretórios existentes (Read et al., 2008).

6. Medical: esse conjunto de dados é composto de relatos textuais não estruturados descrevendo resumidamente o histórico de sintomas de pacientes e os respectivos prognósticos, os quais são utilizados para predição de códigos de seguro saúde (Read et al., 2008).

Os conjuntos de dados selecionados contemplam uma variada gama de domínios de aplicação, como pode ser observado na Tabela 6.1, na qual são apresentadas as informações detalhadas para cada conjunto de dados. Nessa tabela, a coluna \#E representa o número de exemplos, \#A o número de atributos, $|L|$ o número de monorrótulos, Card a cardinalidade média de rótulos por exemplo no conjunto e Dens a densidade dos rótulos calculada como a cardinalidade normalizada pelo número total de monorrótulos. A coluna Distintos representa o número de combinações distintas de multirrótulos. Card e Dens são definidas, respectivamente, pelas Equações 2.7 e 2.8 na página 15.

Tabela 6.1: Conjuntos de dados multirrótulo.

\begin{tabular}{|c|c|c|c|c|c|c|c|}
\hline $\begin{array}{l}\text { Conjunto } \\
\text { de dados }\end{array}$ & Domínio & $\# \mathrm{E}$ & \#A & $|L|$ & Card & Dens & Distintos \\
\hline Emotions & Música & 593 & 72 & 6 & 1,87 & 0,31 & 27 \\
\hline Scene & Imagens & 2407 & 294 & 6 & 1,07 & 0,18 & 15 \\
\hline Slashdot-f & Texto & 3782 & 1079 & 22 & 1,18 & 0,04 & 156 \\
\hline Yeast & Genes/Biologia & 2417 & 103 & 14 & 4,24 & 0,30 & 198 \\
\hline Enron & Texto & 1702 & 1001 & 53 & 3,38 & 0,064 & 753 \\
\hline Medical & Texto & 978 & 1449 & 45 & 1,25 & 0,03 & 94 \\
\hline
\end{tabular}

\subsubsection{Configurações e cenários para avaliação}

Com intuito de avaliar os métodos propostos neste trabalho, foram elaborados os seguintes cenários:

1. coperspectiva no contexto supervisionado;

2. aprendizado semissupervisionado baseado em desacordo; e

3. aprendizado semissupervisionado ativo.

Para possibilitar a comparação dos resultados obtidos neste trabalho com os resultados de outros pesquisadores, os experimentos para a avaliação desses três cenários foram realizados utilizando o método de validação cruzada com 10 partições do conjunto de dados. Todos os algoritmos de aprendizado utilizados para a construção dos classificadores base são os implementados na biblioteca de classes JAVA para aprendizado de máquina WEKA (Hall et al., 
2009). A implementação do método BR utilizado neste trabalho está disponível no framework para classificação multirrótulo Mulan ${ }^{6}$, ao passo que os outros métodos para classificação multirrótulo, os quais são extensões do método BR proposto neste trabalho, foram implementados e incluídos no framework Mulan. Assim, todos os algoritmos base e as ferramentas para avaliação desses algoritmos implementados no WEKA, bem como os algoritmos multirrótulo já implementados no Mulan, além da implementação do método BR+ proposto por Cherman et al. (2011), e as ferramentas para avaliação multirrótulo do Mulan, foram aproveitados. Vale ressaltar que ambos frameworks são robustos e muito utilizados pela comunidade, o que permite compartilhar a implementação de novos algoritmos e ferramentas de apoio.

Em todos os casos foram utilizados como algoritmos base os algoritmos de aprendizado NB e $k$-NN. Devido ao fato do processo iterativo de autorrotulação nos cenários que contemplam aprendizado semissupervisionado ser custoso, utilizamos a implementação incremental dos algoritmos NB e $k$-NN, os quais apresentam um tempo de execução consideravelmente menor que a implementação padrão desses algoritmos (Braga, 2010). A implementação incremental dos algoritmos base foi executada utilizando os parâmetros com valores padrão, com exceção do algoritmo $k$-NN, para o qual o valor $k=3$ foi escolhido por apresentar melhores resultados.

No caso do algoritmo NB, foi utilizada a implementação da classe Java NaiveBayesUpdatable, disponível na biblioteca WEKA. Para lidar com atributos contínuos, essa implementação utiliza métodos estatísticos não-paramétricos de estimativa de densidade. O trabalho (John \& Langley, 1995) fornece informações detalhadas sobre esses métodos estatísticos utilizados nessa implementação. Quanto ao algoritmo de aprendizado $k$-NN, foi utilizada a implementação da classe Java IBk, também disponível na biblioteca WEKA, com valores padrão para seus parâmetros de configuração, cuja medida de distância Euclidiana atribui pesos iguais para todos os atributos. É importante observar que a eficácia do algoritmo $k$-NN poderia ser melhorada se fosse utilizada outra medida de distância ou considerados pesos maiores para os atributos mais relevantes do problema.

Os três cenários elaborados para a avaliação experimental e suas respectivas configurações são descritos em maiores detalhes a seguir.

Cenário 1 - coperspectivas no contexto supervisionado

Este cenário foi elaborado com o objetivo de avaliar o impacto do uso de mais de uma perspectiva para a classificação multirrótulo por meio do método $\mathrm{BR}_{C o P}$. Nesse sentido, utilizando dois algoritmos de aprendizado com bias diferentes, são construídos dois classificadores binários para

\footnotetext{
${ }^{6}$ http: //mulan. sourceforge.net/
} 
cada monorrótulo $y_{j} \in L$. Neste trabalho, os classificadores NB e $k$-NN são utilizados em conjunto durante a classificação de novos exemplos, como descrito no Algoritmo 5.3 na página 84.

Para avaliar a performance do método $\mathrm{BR}_{C o P}$, foram utilizados dois métodos como base de comparação: $\mathrm{BR}_{\text {Low }}$ e BR. No caso do método BR, foram construídos dois modelos, um considerando o algoritmo base NB e o segundo com o algoritmo base $k-\mathrm{NN}$.

Cenário 2 - aprendizado semissupervisionado baseado em desacordo

Neste cenário, o objetivo é avaliar o método $\mathrm{BR}_{C o P S S}$ para aprendizado multirrótulo semissupervisionado baseado em desacordo. Para isso, a performance desse método foi comparada à dos métodos $\mathrm{BR}_{L o w}, \mathrm{BR}, \mathrm{BR}_{C o P}$ e $\mathrm{BR}_{S T}$.

$\mathrm{O}$ método $\mathrm{BR}_{C o P}$ foi utilizado como base de comparação com intuito de verificar se a melhora/degradação dos resultados se deve ao aprendizado semissupervisionado ou ao número de perspectivas. Além disso, o método $\mathrm{BR}_{S T}$ também foi utilizado como base de comparação, a partir do qual é possivel avaliar a autorrotulação de exemplos.

No caso dos algoritmos de monoperspectiva, $\mathrm{BR}^{\mathrm{e}} \mathrm{BR}_{S T}$, foram construídos dois modelos, um considerando o algoritmo base NB e o segundo com o algoritmo base $k$-NN.

Para a comparação dos resultados com os diferentes métodos e a simulação do contexto semissupervisionado, o conjunto de treinamento deve ser dividido considerando um parâmetro que determina a quantidade de exemplos (initial labeled size - InitSize) para a formação dos conjuntos de exemplos rotulados, $T r^{l}$, e não rotulados, $T r^{u}$. O primeiro passo para seleção dos exemplos que serão utilizados em $T r^{l}$ é selecionar aleatoriamente um exemplo que esteja associado a cada monorrótulo $y_{j}$. Esse passo é feito para garantir que todos os monorrótulos sejam representados no conjunto de treinamento inicial. No segundo passo, são selecionados aleatoriamente os outros exemplos que serão utilizados em $\operatorname{Tr}^{l}$ de modo que, ao final desse passo, o conjunto inicial de treinamento de exemplos rotulados contenha o número de exemplos especificado por InitSize. Os exemplos que não foram selecionados para $\operatorname{Tr}^{l}$ são utilizados em $\operatorname{Tr}^{u}$.

Considerando a quantidade de monorrótulos em cada conjunto de dados e a necessidade de representar todos esses monorrótulos nos conjuntos de treinamento iniciais, foram escolhidos 10 valores diferentes para InitSize: 10, 20, 30, 40, 50, 60, 80, 100, 120 e 140. A partir desses valores e das características dos conjuntos de dados utilizados para avaliação 
experimental, como o número de exemplos e o número de classes Tabela 6.1, os conjuntos de dados foram organizados em três grupos, apresentados na Tabela 6.2:

Tabela 6.2: Configuração do InitSize para cada conjunto de dados.

\begin{tabular}{|c|c|c|c|c|c|c|c|c|c|c|c|}
\hline \multirow{2}{*}{$\begin{array}{l}\text { Conjunto } \\
\text { de dados }\end{array}$} & \multirow[t]{2}{*}{ Grupo } & \multicolumn{10}{|c|}{ InitSize } \\
\hline & & 10 & 20 & 30 & 40 & 50 & 60 & 80 & 100 & 120 & 140 \\
\hline Emotions & 1 & $\checkmark$ & $\checkmark$ & $\checkmark$ & $\checkmark$ & $\checkmark$ & & & & & \\
\hline Scene & 1 & $\checkmark$ & $\checkmark$ & $\checkmark$ & $\checkmark$ & $\checkmark$ & & & & & \\
\hline Slashdot- $f$ & 2 & & & $\checkmark$ & $\checkmark$ & $\checkmark$ & $\checkmark$ & $\checkmark$ & & & \\
\hline Yeast & 2 & & & $\checkmark$ & $\checkmark$ & $\checkmark$ & $\checkmark$ & $\checkmark$ & & & \\
\hline Enron & 3 & & & & & & $\checkmark$ & $\checkmark$ & $\checkmark$ & $\checkmark$ & $\checkmark$ \\
\hline Medical & 3 & & & & & & $\checkmark$ & $\checkmark$ & $\checkmark$ & $\checkmark$ & $\checkmark$ \\
\hline
\end{tabular}

Além das configurações de InitSize, os métodos supervisionados também são executados com todos os exemplos disponíveis no conjunto de dados original $\mathrm{Tr}$, pois esses resultados podem ser considerados um tipo de "limite superior" para a predição em relação aos resultados obtidos utilizando conjuntos de treinamento com menos exemplos.

Cenário 3 - aprendizado semissupervisionado ativo

Neste cenário, o objetivo é avaliar o uso do aprendizado ativo no contexto de classificação multirrótulo semissupervisionado baseado em desacordo. Para isso, é definido um número máximo de consultas que podem ser realizadas ao "oráculo" para a classificação dos pontos de contenção. O “oráculo”, por sua vez, é simulado por meio do acesso aos rótulos verdadeiros dos exemplos. Desse modo, para um número máximo de consultas (pontos de contenção), o "oráculo" usa esses rótulos verdadeiros para decidir a classificação com relação à cada classe $y_{j}$. Os métodos avaliados neste cenário são: $\mathrm{BR}_{L o w}, \mathrm{BR}, \mathrm{BR}_{S T}, \mathrm{BR}_{C o P S S}$, $\mathrm{BR}_{C o P S S+A L}$ e $\mathrm{BR}_{C o T e s t i n g}$.

De maneira análoga ao cenário 2, no qual o algoritmo $\mathrm{BR}_{S T}$ foi utilizado para verificar a performance do processo de autorrotulação dos exemplos não rotulados, neste cenário o método $\mathrm{BR}_{\text {CoTesting }}$ é utilizado para verificar o impacto do aprendizado ativo na construção dos classificadores. Neste caso, não ocorre a inclusão de todos os exemplos contidos em $\operatorname{Tr}^{u}$ no conjunto de exemplos rotulados $\mathrm{Tr}^{l}$, pois apenas os pontos de contenção são rotulados e adicionados ao conjunto de exemplos rotulados $\operatorname{Tr}^{l}$. Com isso, é possível avaliar a influência do aprendizado ativo de maneira isolada no método $\mathrm{BR}_{C o P S S+A L}$.

Além disso, os conjuntos de dados também são organizados como no cenário 2. Entretanto, o valor de InitSize para este cenário é diferente, pois para que a comparação entre os métodos seja possível, configura-se o valor de InitSize para os métodos de aprendizado ativo descontando-se o número de consultas ao "oráculo", conforme apresentado na Tabela 6.3. 
Tabela 6.3: Valores de configuração para algoritmos de aprendizado ativo.

\begin{tabular}{|c|c|c|c|}
\hline \multirow{2}{*}{$\begin{array}{c}\text { Aprendizado não ativo } \\
\text { InitSize }\end{array}$} & \multicolumn{2}{|c|}{ Aprendizado ativo } & \multirow[t]{2}{*}{ Bases } \\
\hline & InitSize & \#Consultas & \\
\hline 10 & - & - & Grupo 1 \\
\hline 20 & 10 & 10 & Grupo 1 \\
\hline 30 & 20 & 10 & Grupos 1 e 2 \\
\hline 40 & 20 & 20 & Grupos 1 e 2 \\
\hline 50 & 20 & 30 & Grupos 1 e 2 \\
\hline 60 & 20 & 40 & Grupos 2 e 3 \\
\hline 80 & 20 & 60 & Grupos 2 e 3 \\
\hline 100 & 20 & 80 & Grupo 3 \\
\hline 120 & 20 & 100 & Grupo 3 \\
\hline 140 & 20 & 120 & Grupo 3 \\
\hline
\end{tabular}

\subsubsection{Resultados e discussão}

Nesta seção são apresentados e discutidos os resultados obtidos para a avaliação experimental de cada cenário relacionado à classificação multirrótulo. Os métodos propostos neste trabalho para essa tarefa, categorizados na Tabela 6.4, são avaliados considerando os diferentes cenários descritos anteriormente. Na Tabela 6.5, é mostrado para cada cenário experimental, o método analisado e os métodos utilizados como base de comparação.

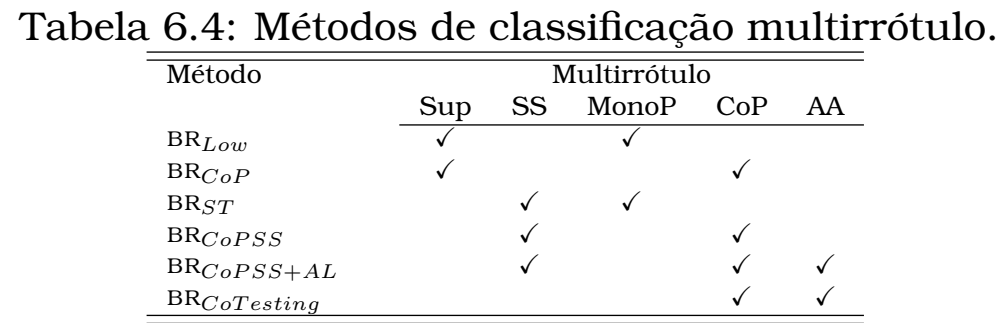

Tabela 6.5: Métodos comparados em cada cenário da avaliação experimental da classificação multirrótulo.

\begin{tabular}{|c|c|c|c|c|c|c|c|}
\hline Cenário & Método & $\mathrm{BR}_{\text {Low }}$ & $\mathrm{BR}$ & $\mathrm{BR}_{C o P}$ & $\mathrm{BR}_{S T}$ & $\mathrm{BR}_{C o P S S}$ & $\mathrm{BR}_{\text {CoTesting }}$ \\
\hline 1 - supervisionado & $\mathrm{BR}_{C o P}$ & $\checkmark$ & $\checkmark$ & & & & \\
\hline 2 - semissupervisionado & $\mathrm{BR}_{C o P S S}$ & $\checkmark$ & $\checkmark$ & $\checkmark$ & $\checkmark$ & & \\
\hline 3 - aprendizado ativo & $\mathrm{BR}_{C o P S S+A L}$ & $\checkmark$ & $\checkmark$ & & & $\checkmark$ & $\checkmark$ \\
\hline
\end{tabular}

\subsubsection{Cenário 1 - coperspectivas no contexto supervisionado}

Os resultados obtidos com os métodos avaliados neste cenário são apresentados na Tabela 6.6, na qual são mostrados, para cada conjunto de dados e métodos avaliados, as médias e desvio padrão obtidos para a medida de avaliação $f_{1}^{\mu 7}$.

Uma representação visual desses resultados é apresentada na Figura 6.1, na qual são comparados os métodos $\mathrm{BR}(\mathrm{NB})$, BR $(k-\mathrm{NN})$ e $\mathrm{BR}_{C o P}$ para os diferentes valores do parâmetro InitSize definidos na Tabela 6.3. Nessa tabela,

\footnotetext{
${ }^{7}$ Os resultados tabulados considerando as outras medidas encontram-se em http:// sites.labic.icmc.usp.br/jeanmetz/harpia.html.
} 
Tabela 6.6: Valores de $f_{1}^{\mu}$ para o Cenário 1 da classificação multirrótulo.

\begin{tabular}{|c|c|c|c|c|c|c|}
\hline InitSize & $\overline{\text { BR (NB) }}$ & $\overline{\mathrm{BR}}(k-\mathrm{NN})$ & $\overline{\mathrm{BR}_{C o P}}$ & $\overline{\text { BR (NB) }}$ & $\overline{\mathrm{BR}}(k-\mathrm{NN})$ & $\overline{\mathrm{BR}_{C o P}}$ \\
\hline & \multicolumn{3}{|c|}{ Emotions } & \multicolumn{3}{|c|}{ Scene } \\
\hline 10 & $0,40(0,07)$ & $\mathbf{0 , 4 8}(0,06)$ & $0,40(0,07)$ & $0,01(0,02)$ & $0,27(0,05)$ & $0,01(0,02)$ \\
\hline 20 & $\mathbf{0 , 5 4}(0,05)$ & $0,53(0,06)$ & $\mathbf{0 , 5 4}(0,05)$ & $0,22(0,04)$ & $\mathbf{0 , 4 0}(0,04)$ & $0,22(0,04)$ \\
\hline 30 & $\mathbf{0 , 5 9}(0,04)$ & $0,53(0,07)$ & $0,58(0,04)$ & $0,30(0,03)$ & $\mathbf{0 , 4 6}(0,05)$ & $0,30(0,02)$ \\
\hline 40 & $\mathbf{0 , 6 0}(0,03)$ & $0,52(0,06)$ & $0,59(0,04)$ & $0,37(0,02)$ & $\mathbf{0 , 4 8}(0,04)$ & $0,37(0,03)$ \\
\hline 50 & $\mathbf{0 , 6 1}(0,03)$ & $0,53(0,05)$ & $0,60(0,04)$ & $0,42(0,04)$ & $\mathbf{0 , 5 0}(0,03)$ & $0,42(0,04)$ \\
\hline All & $0,65(0,04)$ & $0,63(0,07)$ & $\mathbf{0 , 6 8}(0,06)$ & $0,55(0,02)$ & $\mathbf{0 , 6 7}(0,03)$ & $0,57(0,02)$ \\
\hline \multirow[t]{2}{*}{$\mathrm{BR}_{L o w}$} & & 0,40 & & & 0,22 & \\
\hline & \multicolumn{3}{|c|}{ Slashdot- $f$} & \multicolumn{3}{|c|}{ Yeast } \\
\hline 30 & $0,08(0,03)$ & $\mathbf{0 , 1 4}(0,07)$ & $0,09(0,05)$ & $\mathbf{0 , 5 7}(0,02)$ & $\mathbf{0 , 5 7}(0,03)$ & $\mathbf{0 , 5 7}(0,02)$ \\
\hline 40 & $0,09(0,03)$ & $\mathbf{0 , 1 4}(0,07)$ & $\mathbf{0 , 1 4}(0,08)$ & $\mathbf{0 , 5 7}(0,03)$ & $0,56(0,04)$ & $\mathbf{0 , 5 7}(0,03)$ \\
\hline 50 & $0,11(0,03)$ & $\mathbf{0 , 1 5}(0,04)$ & $\mathbf{0 , 1 5}(0,08)$ & $\mathbf{0 , 5 6}(0,03)$ & $0,55(0,03)$ & $\mathbf{0 , 5 6}(0,03)$ \\
\hline 60 & $0,13(0,03)$ & $\mathbf{0 , 1 6}(0,03)$ & $\mathbf{0 , 1 6}(0,08)$ & $\mathbf{0 , 5 7}(0,03)$ & $0,56(0,03)$ & $\mathbf{0 , 5 7}(0,03)$ \\
\hline 80 & $0,16(0,04)$ & $0,15(0,05)$ & $\mathbf{0 , 1 8}(0,08)$ & $0,57(0,02)$ & $0,57(0,03)$ & $\mathbf{0 , 5 8}(0,02)$ \\
\hline All & $\mathbf{0 , 4 6}(0,03)$ & $0,20(0,05)$ & $0,42(0,05)$ & $0,56(0,02)$ & $\mathbf{0 , 6 2}(0,03)$ & $\mathbf{0 , 6 2}(0,02)$ \\
\hline \multirow[t]{2}{*}{$\mathrm{BR}_{\text {Low }}$} & & 0,14 & & & 0,57 & \\
\hline & \multicolumn{3}{|c|}{ Enron } & \multicolumn{3}{|c|}{ Medical } \\
\hline 60 & $\mathbf{0 , 2 8}(0,05)$ & $0,22(0,04)$ & $0,27(0,05)$ & $0,00(0,00)$ & $\mathbf{0 , 3 9}(0,06)$ & $0,00(0,00)$ \\
\hline 80 & $\mathbf{0 , 3 1}(0,03)$ & $0,25(0,05)$ & $\mathbf{0 , 3 1}(0,03)$ & $0,00(0,01)$ & $\mathbf{0 , 4 5}(0,07)$ & $0,00(0,01)$ \\
\hline 100 & $\mathbf{0 , 3 1}(0,02)$ & $0,28(0,04)$ & $\mathbf{0 , 3 1}(0,03)$ & $0,01(0,01)$ & $\mathbf{0 , 4 9}(0,06)$ & $0,01(0,02)$ \\
\hline 120 & $\mathbf{0 , 3 2}(0,03)$ & $0,28(0,04)$ & $\mathbf{0 , 3 2}(0,03)$ & $0,01(0,02)$ & $\mathbf{0 , 5 1}(0,06)$ & $0,02(0,03)$ \\
\hline 140 & $\mathbf{0 , 3 2}(0,02)$ & $0,28(0,04)$ & $\mathbf{0 , 3 2}(0,03)$ & $0,04(0,03)$ & $\mathbf{0 , 5 4}(0,05)$ & $0,04(0,03)$ \\
\hline All & $0,29(0,01)$ & $\mathbf{0 , 3 9}(0,02)$ & $0,32(0,02)$ & $0,41(0,04)$ & $\mathbf{0 , 6 6}(0,05)$ & $0,48(0,04)$ \\
\hline $\mathrm{BR}_{\text {Low }}$ & \multicolumn{3}{|c|}{0,45} & \multicolumn{3}{|c|}{0,24} \\
\hline
\end{tabular}

a linha All refere-se aos resultados obtidos utilizando todos os exemplos de treinamento, e $\mathrm{BR}_{\text {Low }}$ representa o baseline da medida $f_{1}^{\mu}$ do algoritmo $\mathrm{BR}_{C o P}$ para esse caso. Além disso, para cada conjunto de dados, o valor da medida $f_{1}^{\mu}$ obtida por meio do método $\mathrm{BR}_{\text {Low }}$ é representado pela linha tracejada.

Ainda que os resultados de $\mathrm{BR}_{C o P}$ utilizando todos os exemplos de treinamento $(A l l)$ são superiores a $\mathrm{BR}_{\text {Low }}$, exceto para o conjunto de dados Enron, observa-se que nem todos os métodos apresentam valores maiores que o $\mathrm{BR}_{\text {Low }}$ para todas as configurações de InitSize. De fato, apenas os resultados obtidos com os conjuntos de dados Emotions e Scene são consideravelmente melhores que o baseline $\mathrm{BR}_{\text {Low }}$ para a maioria das configurações, ao passo que apenas a configuração que faz uso do algoritmo base $k$-NN superou o método $\mathrm{BR}_{\text {Low }}$ para o conjunto de dados Medical.

Para os conjuntos de dados Slashdot- $f$ e Yeast, as diferenças mais significativas ocorrem apenas quando todos os exemplos rotulados são utilizados para a construção dos classificadores. Observa-se, também, que os valores obtidos nas configurações com poucos exemplos, variações do InitSize de 30 a 80, são muito próximos ao baseline, não apresentando diferença significativa.

Como mencionado no caso do conjunto de dados Enron, os resultados para todas as configurações são piores que o baseline. Dois dos motivos dessa baixa performance são relacionados ao multirrótulo majoritário do conjunto de dados e à medida $f_{1}^{\mu}$. O multirrótulo majoritário para esse conjunto de dados é composto por três monorrótulos que estão associados a grande parte dos exemplos: $81,30 \%, 78,80 \%$ e $60,55 \%$ respectivamente. Uma vez que esses 


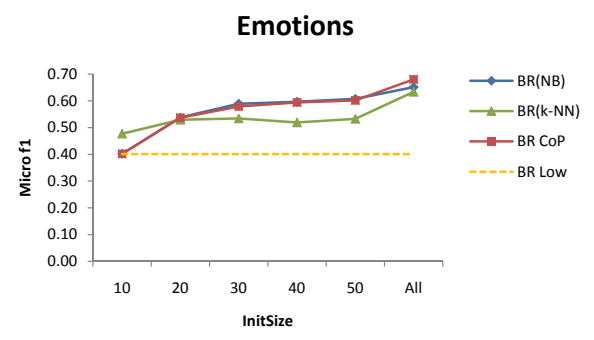

(a) Conjunto de dados Emotions

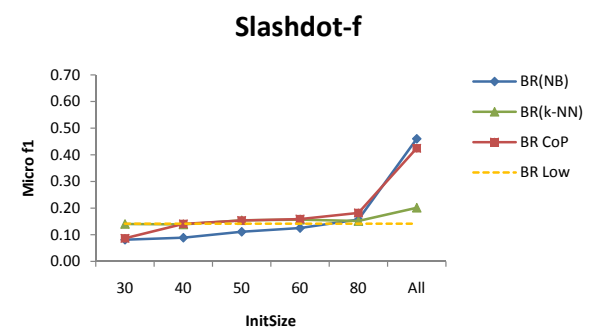

(c) Conjunto de dados Slashdot-f

Enron

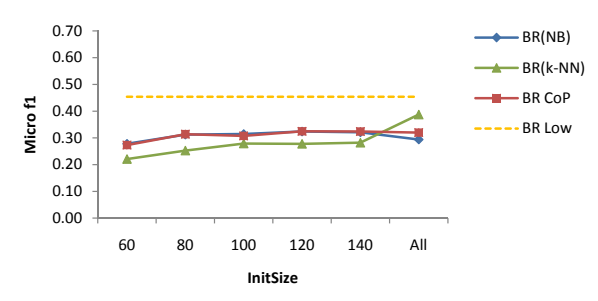

(e) Conjunto de dados Enron

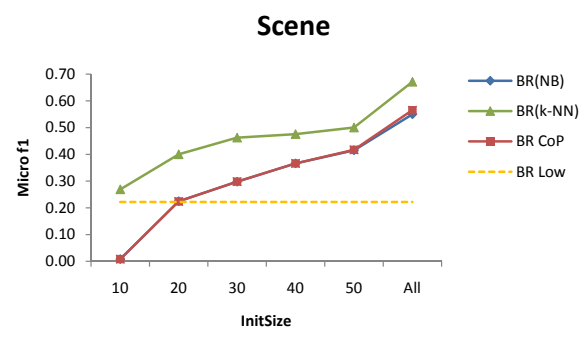

(b) Conjunto de dados Scene

Yeast

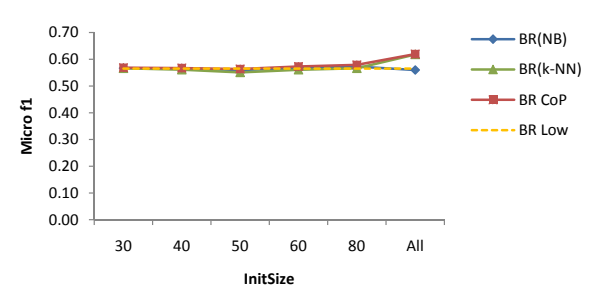

(d) Conjunto de dados Yeast

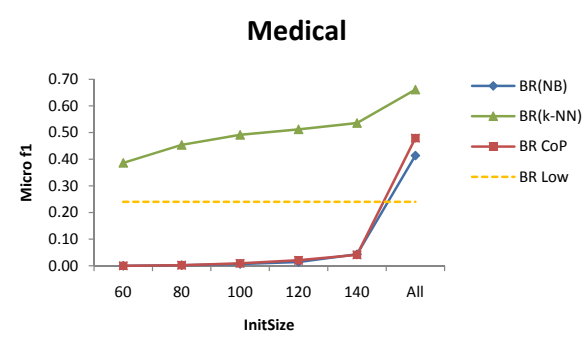

(f) Conjunto de dados Medical

Figura 6.1: Valores da medida $f_{1}^{\mu}$ para o Cenário 1. 
multirrótulos são utilizados para calcular todas as medidas de avaliação do método $\mathrm{BR}_{\text {Low }}$, é natural que a medida $f_{1}^{\mu}$ apresente valores altos, pois o recall de cada um desses monorrótulos, considerando suas respectivas probabilidades de ocorrência, é muito alto. Por outro lado, o valor da medida Subset Accuracy para o método $\mathrm{BR}_{\text {Low }}$ com esse conjunto de dados é praticamente zero - Tabela 6.7 coluna Subset Accuracy -, pois a probabilidade desse multirrótulo majoritário no conjunto de treinamento também é baixa.

É importante observar que os valores de $f_{1}^{\mu}$ para o método $\mathrm{BR}_{\text {Low }}$, considerando os conjuntos de dados Emotions, Yeast e Enron são bastante altos. Essa magnitude está relacionada à distribuição dos exemplos nos monorrótulo e à medida $f_{1}^{\mu}$, que favorece, nesses casos, os multirrótulos majoritários compostos por monorrótulos que são muito mais frequentes que os monorrótulos que não fazem parte do multirrótulo majoritário. A distribuição de cada monorrótulo que faz parte dos multirrótulos majoritários para cada conjunto de dados é apresentada na Tabela 6.7. Além disso, os valores para as medidas $f_{1}^{\mu}$, precisão micro $\left(P r^{\mu}\right)$, recall micro $\left(R e^{\mu}\right)$, Subset Accuracy (Subset Accuracy) e Hamming Loss (HLoss), obtidos pelo método $\mathrm{BR}_{\text {Low }}$, são apresentados.

Tabela 6.7: Resultados do classificador base $\mathrm{BR}_{\text {Low }}$.

\begin{tabular}{|c|c|c|c|c|c|c|}
\hline $\begin{array}{l}\text { Conjunto } \\
\text { de dados }\end{array}$ & $P\left(y_{j}\right)$ & $f_{1}^{\mu}$ & $P r^{\mu}$ & $R e^{\mu}$ & Subset Accuracy & HLoss \\
\hline Emotions & $\begin{array}{l}P\left(y_{1}\right)=0,45 \\
P\left(y_{2}\right)=0,32\end{array}$ & $0,40(0,00)$ & $0,38(0,00)$ & $0,42(0,00)$ & $0,01(0,00)$ & $0,38(0,00)$ \\
\hline Scene & $P\left(y_{1}\right)=0,22$ & $0,22(0,00)$ & $0,23(0,00)$ & $0,22(0,00)$ & $0,18(0,00)$ & $0,27(0,00)$ \\
\hline Slashdot- $f$ & $P\left(y_{1}\right)=0,31$ & $0,14(0,00)$ & $0,15(0,00)$ & $0,13(0,00)$ & $0,14(0,00)$ & $0,09(0,00)$ \\
\hline Yeast & $\begin{array}{l}P\left(y_{1}\right)=0,75 \\
P\left(y_{2}\right)=0,74 \\
P\left(y_{3}\right)=0,43 \\
P\left(y_{4}\right)=0,41\end{array}$ & $0,57(0,00)$ & $0,58(0,00)$ & $0,55(0,00)$ & $0,05(0,00)$ & $0,26(0,00)$ \\
\hline Enron & $\begin{array}{l}P\left(y_{1}\right)=0,54 \\
P\left(y_{2}\right)=0,52 \\
P\left(y_{3}\right)=0,40\end{array}$ & $0,45(0,00)$ & $0,48(0,00)$ & $0,43(0,00)$ & $0,00(0,00)$ & $0,07(0,00)$ \\
\hline Medical & $P\left(y_{1}\right)=0,27$ & $0,24(0,00)$ & $0,26(0,00)$ & $0,21(0,00)$ & $0,15(0,00)$ & $0,04(0,00)$ \\
\hline
\end{tabular}

Considerando a medida Hamming Loss, observa-se que nos casos em que o conjunto de dados contém muitos monorrótulos, como nos conjuntos de dados Enron e Medical, o valor resultante para o método $\mathrm{BR}_{L o w}$ tende a ser menor, uma vez que essa medida é favorecida pelo grande número de verdadeiros negativos. Nos casos com menor número de monorrótulos, por outro lado, como nos conjuntos de dados Emotions e Scene, ambos com $|L|=6 \mathrm{e}$ Yeast com $|L|=14$, o valor para essa medida tende a ser maior, pois nesses casos, o número de verdadeiros negativos é, invariavelmente, muito menor se comparado com os conjuntos de dados Enron e Medical, com com $|L|=53$ e 45 , respectivamente.

Essa situação não ocorre com as medidas de precisão e recall, as quais são 
favorecidas pelo número de verdadeiros positivos. Para essas medidas, caso o multirrótulo majoritário seja composto por monorrótulos muito frequentes, como no caso dos conjuntos de dados Enron e Yeast, a tendência é apresentarem valores altos para o método $\mathrm{BR}_{\text {Low }}$, mesmo decrementando Subset Accuracy.

Com relação ao uso de duas perspectivas para a construção do classificador multirrótulo, observa-se que, em geral, uma das perspectivas "domina" o processo de aprendizado, melhorando ou degradando a eficácia do classificador $\mathrm{BR}_{C o P}$, como nos experimentos utilizando os conjuntos de dados Emotions e Scene - Figuras 6.1(a) e 6.1(b), respectivamente. Esse comportamento é justificado, em partes, pela estratégia de classificação dos exemplos cuja predição em cada descrição é conflitante, uma vez que o classificador da descrição mais "confiante", mesmo que a diferença seja baixa, determina a predição. Contudo, a predição mais "confiante" não é necessariamente a correta para todos os casos.

Outro fator que degrada a performance do classificador multirrótulo, quando os classificadores em cada descrição não apresentam boa performance, é o erro na predição nos casos em que não há desacordo entre as duas descrições, ou seja, mesmo quando os dois classificadores concordam com a predição com alto grau de confiança, e consequentemente reforçam a predição, essa predição é errada. Uma solução para esse problema é utilizar algoritmos de aprendizado mais eficazes em cada descrição.

Para corroborar essa hipótese, observe na Tabela 6.6 o valor de $f_{1}^{\mu}$ obtido para os conjuntos de dados Emotions e Slashdot- $f$ utilizando todos os exemplos disponíveis $(A l l)$ e o método $\mathrm{BR}_{C o P}$. No primeiro caso, Emotions, o método $\mathrm{BR}_{C o P}$ superou o método BR para ambos classificadores base, i.e. BR (NB) e BR $\left(k\right.$-NN). Para o conjunto de dados Slashdot- $f$, o método $\mathrm{BR}_{C o P}$ superou significativamente o método $\mathrm{BR}(k-\mathrm{NN})$ e aproximou o resultado do método BR (NB). No entanto, neste último caso, o método coperspectiva foi limitado pela descrição "menos" eficaz, para a qual o algoritmo de aprendizado $k$-NN foi utilizado e, consequentemente, não foi capaz de superar os dois modelos monoperspectiva. Esse fato indica que o método coperspectiva pode ser mais eficaz que os métodos monoperspectivas, desde que os classificadores base de cada descrição sejam bons o suficiente para não degradar a performance do classificador na outra descrição. Uma segunda alternativa é utilizar um número ímpar de descrições e decidir a predição por meio de votação.

Uma segunda análise, também interessante, para avaliar a razão da degradação do modelo global de classificação multirrótulo com o método $\mathrm{BR}_{C o P}$, consiste em comparar a performance dos classificadores construídos para cada monorrótulo. Nesse sentido, os valores da medida $f_{1}$ (de classificação binária 
definidas pela Equação 2.5 na página 13) para cada monorrótulo, considerando três conjuntos de $\operatorname{dados}^{8}$ e os três métodos avaliados neste cenário, são apresentados na Figura 6.2. Os monorrótulos estão organizados em ordem decrescente pelo valor da medida obtida pelo método BR (NB).

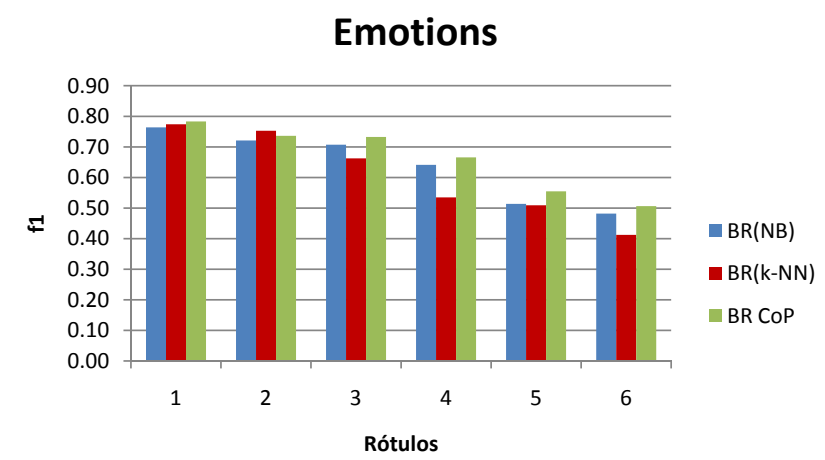

(a) Conjunto de dados Emotions

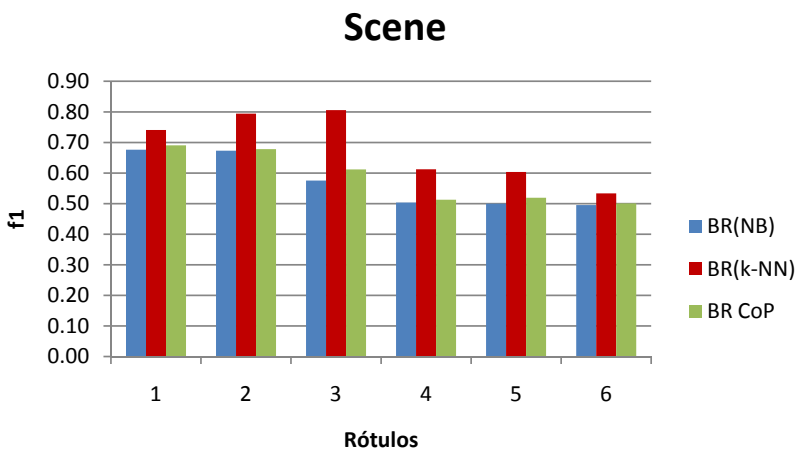

(b) Conjunto de dados Scene

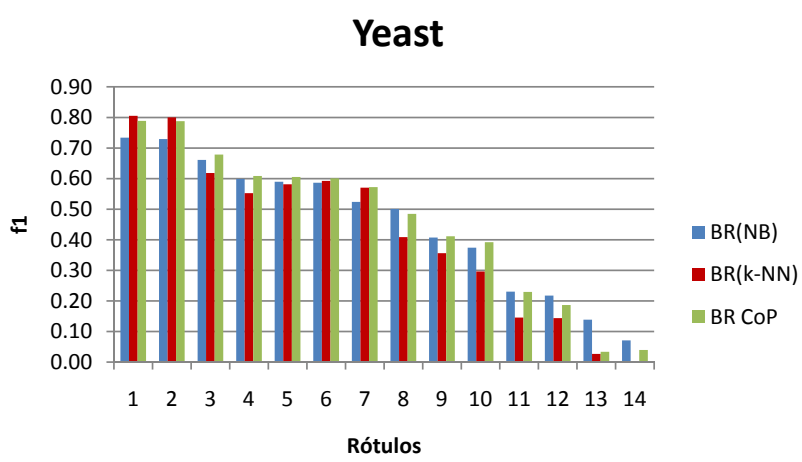

(c) Conjunto de dados Yeast

Figura 6.2: Valores da medida $f_{1}$ para cada classificador binário independente.

Observa-se que em todos os casos, para um número considerável de monorrótulos, os classificadores binários não são eficazes, uma vez que a valor da medida $f_{1}$ está muito próxima ou abaixo de 0,50 , ou seja, praticamente aleatório. Ainda assim, em alguns casos o método $\mathrm{BR}_{C o P}$ foi capaz de melhorar a eficácia para alguns monorrótulos. Para o conjunto de dados Emotions, por

\footnotetext{
${ }^{8}$ Por questões de legibilidade, somente os três conjuntos de dados com menor número de monorrótulos são apresentados.
} 
exemplo, o método $\mathrm{BR}_{C o P}$ foi melhor que os outros dois métodos em 5 dos seis monorrótulos. Com o conjunto de dados Yeast, o método $\mathrm{BR}_{C o P}$ foi melhor em 6 dos 14 monorrótulos. Entretanto, com o conjunto de dados Scene, o método $\mathrm{BR}_{C o P}$ foi inferior ao método $\mathrm{BR}(k-\mathrm{NN})$ para todos os monorrótulos.

Nesse sentido, se o método monoperspectiva BR for construído considerando o algoritmo de aprendizado mais apropriado para cada monorrótulo, a performance global desse método será melhor que a performance do mesmo método construído por meio de apenas um algoritmo de aprendizado para todos os monorrótulos.

Uma comparação entre os métodos coperspectiva e monoperspectiva é apresentada na Tabela 6.8, na qual é mostrada em termos percentuais a melhora ( $\Lambda$ ) ou a degradação ( $\nabla$ ) dos métodos monoperspectiva BR (NB) e BR $(k-\mathrm{NN})$ em relação ao método coperspectiva $\mathrm{BR}_{C o P}$, utilizando todos os exemplos rotulados disponíveis para a construção dos classificadores, i.e., InitSize All. Além disso, para facilitar a análise, na coluna $\mathrm{BR}_{C o P} f_{1}^{\mu}$ são mostrados os valores da medida $f_{1}^{\mu}$ e o respectivo desvio padrão resultantes do método $\mathrm{BR}_{C o P}$ para InitSize All.

Tabela 6.8: Comparação do método $\mathrm{BR}_{C o P}$ com os métodos monoperspectiva $\mathrm{BR}(\mathrm{NB})$ e BR $(k-\mathrm{NN})$.

\begin{tabular}{|c|c|c|c|}
\hline & $\mathrm{BR}_{C o P} f_{1}^{\mu}$ & BR (NB) & $\mathrm{BR}(k-\mathrm{NN})$ \\
\hline Emotions & $0,68(0,06)$ & $\nabla 04 \%$ & $\nabla 07 \%$ \\
\hline Scene & $0,57(0,02)$ & $\nabla 03 \%$ & $\Delta 19 \%$ \\
\hline Slashdot- $f$ & $0,42(0,05)$ & $\Delta 08 \%$ & v 53\% \\
\hline Yeast & $0,62(0,02)$ & $\nabla 10 \%$ & - \\
\hline Enron & $0,32(0,02)$ & $\nabla 08 \%$ & $\Delta 21 \%$ \\
\hline Medical & $0,48(0,04)$ & $\nabla 14 \%$ & А $38 \%$ \\
\hline
\end{tabular}

\subsubsection{Cenário 2 - aprendizado semissupervisionado baseado em desacordo}

Os valores de $f_{1}^{\mu}$ obtidos pelos métodos avaliados neste cenário são apresentados na Tabela 6.9, conjuntamente com os resultados obtidos no Cenário 1 para aprendizado supervisionado - Tabela 6.6 - para auxiliar na comparação, pois os resultados obtidos pelos respectivos métodos supervisionados são utilizados para avaliar a capacidade dos métodos semissupervisionados de aprender com poucos exemplos. Na primeira coluna da Tabela 6.9 são apresentados os tamanhos iniciais dos conjuntos de treinamento, conforme definidos na Tabela 6.2, na página 116 , na seção de descrição dos cenários experimentais. É importante lembrar que para os métodos supervisionados, $\mathrm{BR}$ e $\mathrm{BR}_{C o P}$, o valor de InitSize determina o tamanho absoluto do conjunto de treinamento, uma vez que não há incremento do conjunto de exemplos rotulados nesses métodos. Assim, o modelo de classificação é construído por esses métodos considerando apenas os exemplos fornecidos inicialmente. Os métodos semissupervisionados $\mathrm{BR}_{S T}$ e $\mathrm{BR}_{C o P S S}$, por outro lado, não são executados 
com InitSize All, uma vez que não haveria diferença com suas respectivas versões supervisionadas. Além desse fato, o objetivo de usar os métodos semissupervisionados é avaliar o aprendizado a partir de poucos exemplos de treinamento, i.e., com conjuntos de treinamento iniciais selecionados considerando os valores de InitSize de modo que $\operatorname{Tr}^{u} \gg T r^{l}$.

A hipótese avaliada nesse cenário é que, mesmo com poucos exemplos de treinamento, os métodos semissupervisionados têm capacidade de aproximar a qualidade de predição dos métodos supervisionados treinados com todo o conjunto de exemplos rotulados disponível.

Em uma primeira análise, observa-se que os métodos semissupervisionados, em geral, não alcançaram valores de $f_{1}^{\mu}$ maiores que os respectivos métodos supervisionados. Por exemplo, comparando os métodos BR (NB) e BR $(k-\mathrm{NN})$ com os respectivos SELF-TRAINING BR $\mathrm{BR}_{S T}(\mathrm{NB})$ e $\mathrm{BR}_{S T}(k-\mathrm{NN})$, os métodos semissupervisionados obtiveram melhores valores de $f_{1}^{\mu}$ apenas para os conjuntos de dados Emotions e Scene ou similares, utilizando poucos exemplos. Nos outros casos, em geral, os métodos supervisionados obtiveram melhores resultados. Além disso, o método $\mathrm{BR}_{C o P S S}$ apresenta comportamento semelhante ao $\mathrm{BR}_{C o P}$, sendo frequentemente influenciado pela perspectiva menos eficaz. Esse comportamento é apresentado na Figura 6.3, na qual são mostrados os resultados considerando o valor médio para o parâmetro InitSize, i.e., o terceiro dos 5 valores para cada conjunto de dados. No eixo X são mostrados os algoritmos base NB e $k$-NN para a construção dos classificadores, no caso dos métodos monoperspectiva, e os respectivos métodos coperspectiva, construídos com esses dois algoritmos de aprendizado.

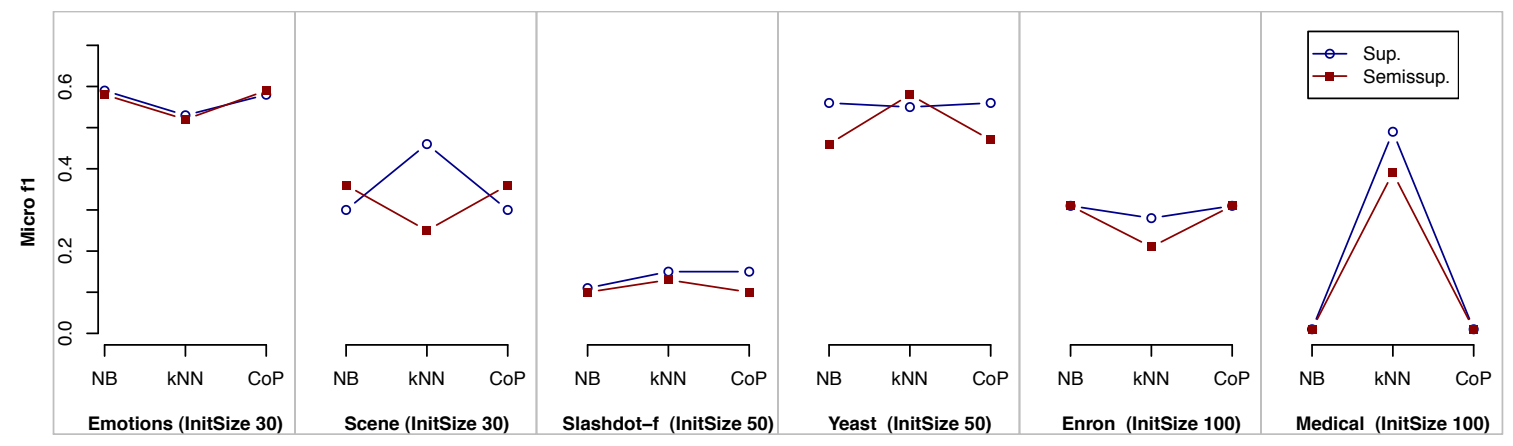

Figura 6.3: Comparação dos métodos supervisionados e semissupervisionados com valor de InitSize médio para ambos métodos.

Idealmente, os métodos semissupervisionados treinados com poucos exemplos deveriam atingir resultados semelhantes aos dos supervisionados treinados com muitos exemplos rotulados. Porém, essa é uma situação irreal, uma vez que, em geral, menos informação está disponível em conjuntos de dados com número reduzido de exemplos. Ainda assim, como pode ser observado na Figura 6.4, na qual são comparados os métodos semissupervisionados, 
Tabela 6.9: Valores de $f_{1}^{\mu}$ para o Cenário 2 da classificação multirrótulo.

\begin{tabular}{|c|c|c|c|c|c|c|}
\hline \multirow[b]{2}{*}{ InitSize } & \multicolumn{3}{|c|}{ Supervisionado } & \multicolumn{3}{|c|}{ Semissupervisionado } \\
\hline & $\mathrm{BR}(\mathrm{NB})$ & $\mathrm{BR}(k-\mathrm{NN})$ & $\mathrm{BR}_{C o P}$ & $\mathrm{BR}_{S T}(\mathrm{NB})$ & $\mathrm{BR}_{S T}(k-\mathrm{NN})$ & $\mathrm{BR}_{C o P S S}$ \\
\hline & \multicolumn{6}{|c|}{ Emotions } \\
\hline 10 & $0,40(0,07)$ & $\mathbf{0 , 4 8}(0,06)$ & $0,40(0,07)$ & $0,47(0,07)$ & $0,42(0,05)$ & $0,47(0,06)$ \\
\hline 20 & $0,54(0,05)$ & $0,53(0,06)$ & $0,54(0,05)$ & $0,56(0,04)$ & $0,52(0,05)$ & $\mathbf{0 , 5 8}(0,02)$ \\
\hline 30 & $\mathbf{0 , 5 9}(0,04)$ & $0,53(0,07)$ & $0,58(0,04)$ & $0,58(0,04)$ & $0,52(0,04)$ & $\mathbf{0 , 5 9}(0,03)$ \\
\hline 40 & $\mathbf{0 , 6 0}(0,03)$ & $0,52(0,06)$ & $0,59(0,04)$ & $0,58(0,03)$ & $0,52(0,06)$ & $\mathbf{0 , 6 0}(0,02)$ \\
\hline 50 & $\mathbf{0 , 6 1}(0,03)$ & $0,53(0,05)$ & $0,60(0,04)$ & $0,59(0,02)$ & $0,52(0,06)$ & $0,59(0,03)$ \\
\hline All & $0,65(0,04)$ & $0,63(0,07)$ & $\mathbf{0 , 6 8}(0,06)$ & & & \\
\hline \multirow{3}{*}{$\mathrm{BR}_{L o w}$} & 0,40 & & & & & \\
\hline & \multicolumn{6}{|c|}{ Scene } \\
\hline & $\mathrm{BR}(\mathrm{NB})$ & $\mathrm{BR}(k-\mathrm{NN})$ & $\mathrm{BR}_{C o P}$ & $\mathrm{BR}_{S T}(\mathrm{NB})$ & $\mathrm{BR}_{S T}(k-\mathrm{NN})$ & $\mathrm{BR}_{C o P S S}$ \\
\hline 10 & $0,01(0,02)$ & $\mathbf{0 , 2 7}(0,05)$ & $0,01(0,02)$ & $0,03(0,07)$ & $0,02(0,07)$ & $0,04(0,08)$ \\
\hline 20 & $0,22(0,04)$ & $\mathbf{0 , 4 0}(0,04)$ & $0,22(0,04)$ & $0,31(0,03)$ & $0,23(0,10)$ & $0,30(0,05)$ \\
\hline 30 & $0,30(0,03)$ & $\mathbf{0 , 4 6}(0,05)$ & $0,30(0,02)$ & $0,36(0,01)$ & $0,25(0,11)$ & $0,36(0,02)$ \\
\hline 40 & $0,37(0,02)$ & $\mathbf{0 , 4 8}(0,04)$ & $0,37(0,03)$ & $0,36(0,01)$ & $0,34(0,07)$ & $0,36(0,01)$ \\
\hline 50 & $0,42(0,04)$ & $\mathbf{0 , 5 0}(0,03)$ & $0,42(0,04)$ & $0,36(0,02)$ & $0,31(0,05)$ & $0,38(0,02)$ \\
\hline All & $0,55(0,02)$ & $\mathbf{0 , 6 7}(0,03)$ & $0,57(0,02)$ & & & \\
\hline \multirow[t]{3}{*}{$\mathrm{BR}_{\text {Low }}$} & 0,22 & & & & & \\
\hline & \multicolumn{6}{|c|}{ Slashdot-f } \\
\hline & $\mathrm{BR}(\mathrm{NB})$ & $\mathrm{BR}(k-\mathrm{NN})$ & $\mathrm{BR}_{C o P}$ & $\mathrm{BR}_{S T}(\mathrm{NB})$ & $\mathrm{BR}_{S T}(k-\mathrm{NN})$ & $\mathrm{BR}_{C o P S S}$ \\
\hline 30 & $0,08(0,03)$ & $\mathbf{0 , 1 4}(0,07)$ & $0,09(0,05)$ & $0,10(0,01)$ & $0,11(0,07)$ & $0,10(0,01)$ \\
\hline 40 & $0,09(0,03)$ & $\mathbf{0 , 1 4}(0,07)$ & $\mathbf{0 , 1 4}(0,08)$ & $0,10(0,01)$ & $0,13(0,07)$ & $0,10(0,01)$ \\
\hline 50 & $0,11(0,03)$ & $\mathbf{0 , 1 5}(0,04)$ & $\mathbf{0 , 1 5}(0,08)$ & $0,10(0,00)$ & $0,13(0,06)$ & $0,10(0,01)$ \\
\hline 60 & $0,13(0,03)$ & $\mathbf{0 , 1 6}(0,03)$ & $\mathbf{0 , 1 6}(0,08)$ & $0,10(0,01)$ & $0,14(0,04)$ & $0,10(0,01)$ \\
\hline 80 & $0,16(0,04)$ & $0,15(0,05)$ & $\mathbf{0 , 1 8}(0,08)$ & $0,10(0,00)$ & $0,15(0,05)$ & $0,10(0,01)$ \\
\hline All & $\mathbf{0 , 4 6}(0,03)$ & $0,20(0,05)$ & $0,42(0,05)$ & & & \\
\hline \multirow[t]{3}{*}{$\mathrm{BR}_{\text {Low }}$} & 0,14 & & & & & \\
\hline & \multicolumn{6}{|c|}{ Yeast } \\
\hline & $\mathrm{BR}(\mathrm{NB})$ & $\mathrm{BR}(k-\mathrm{NN})$ & $\mathrm{BR}_{C o P}$ & $\mathrm{BR}_{S T}(\mathrm{NB})$ & $\mathrm{BR}_{S T}(k-\mathrm{NN})$ & $\mathrm{BR}_{C o P S S}$ \\
\hline 30 & $\mathbf{0 , 5 7}(0,02)$ & $\mathbf{0 , 5 7}(0,03)$ & $\mathbf{0 , 5 7}(0,02)$ & $0,52(0,04)$ & $\mathbf{0 , 5 7}(0,02)$ & $0,55(0,03)$ \\
\hline 40 & $\mathbf{0 , 5 7}(0,03)$ & $0,56(0,04)$ & $\mathbf{0 , 5 7}(0,03)$ & $0,45(0,04)$ & $\mathbf{0 , 5 7}(0,03)$ & $0,50(0,03)$ \\
\hline 50 & $0,56(0,03)$ & $0,55(0,03)$ & $0,56(0,03)$ & $0,46(0,04)$ & $\mathbf{0 , 5 8}(0,02)$ & $0,47(0,03)$ \\
\hline 60 & $0,57(0,03)$ & $0,56(0,03)$ & $0,57(0,03)$ & $0,45(0,03)$ & $\mathbf{0 , 5 8}(0,01)$ & $0,47(0,03)$ \\
\hline 80 & $0,57(0,02)$ & $0,57(0,03)$ & $\mathbf{0 , 5 8}(0,02)$ & $0,47(0,03)$ & $\mathbf{0 , 5 8}(0,03)$ & $0,48(0,03)$ \\
\hline All & $0,56(0,02)$ & $\mathbf{0 , 6 2}(0,03)$ & $\mathbf{0 , 6 2}(0,02)$ & & & \\
\hline \multirow[t]{3}{*}{$\mathrm{BR}_{L o w}$} & 0,57 & & & & & \\
\hline & \multicolumn{6}{|c|}{ Enron } \\
\hline & BR (NB) & BR $(k-\mathrm{NN})$ & $\mathrm{BR}_{C o P}$ & $\mathrm{BR}_{S T}(\mathrm{NB})$ & $\mathrm{BR}_{S T}(k-\mathrm{NN})$ & $\mathrm{BR}_{C o P S S}$ \\
\hline 60 & $\mathbf{0 , 2 8}(0,05)$ & $0,22(0,04)$ & $0,27(0,05)$ & $0,26(0,07)$ & $0,15(0,05)$ & $0,26(0,07)$ \\
\hline 80 & $\mathbf{0 , 3 1}(0,03)$ & $0,25(0,05)$ & $\mathbf{0 , 3 1}(0,03)$ & $0,30(0,03)$ & $0,19(0,04)$ & $0,30(0,03)$ \\
\hline 100 & $\mathbf{0 , 3 1}(0,02)$ & $0,28(0,04)$ & $\mathbf{0 , 3 1}(0,03)$ & $\mathbf{0 , 3 1}(0,03)$ & $0,21(0,04)$ & $\mathbf{0 , 3 1}(0,03)$ \\
\hline 120 & $\mathbf{0 , 3 2}(0,03)$ & $0,28(0,04)$ & $\mathbf{0 , 3 2}(0,03)$ & $0,31(0,03)$ & $0,22(0,04)$ & $0,31(0,03)$ \\
\hline 140 & $\mathbf{0 , 3 2}(0,02)$ & $0,28(0,04)$ & $\mathbf{0 , 3 2}(0,03)$ & $0,31(0,03)$ & $0,24(0,03)$ & $0,31(0,03)$ \\
\hline All & $0,29(0,01)$ & $\mathbf{0 , 3 9}(0,02)$ & $0,32(0,02)$ & & & \\
\hline \multirow[t]{3}{*}{$\mathrm{BR}_{\text {Low }}$} & 0,45 & & & & & \\
\hline & \multicolumn{6}{|c|}{ Medical } \\
\hline & $\mathrm{BR}(\mathrm{NB})$ & $\mathrm{BR}(k-\mathrm{NN})$ & $\mathrm{BR}_{C o P}$ & $\mathrm{BR}_{S T}(\mathrm{NB})$ & $\mathrm{BR}_{S T}(k-\mathrm{NN})$ & $\mathrm{BR}_{C o P S S}$ \\
\hline 60 & $0,00(0,00)$ & $\mathbf{0 , 3 9}(0,06)$ & $0,00(0,00)$ & $0,00(0,01)$ & $0,25(0,09)$ & $0,00(0,01)$ \\
\hline 80 & $0,00(0,01)$ & $\mathbf{0 , 4 5}(0,07)$ & $0,00(0,01)$ & $0,00(0,01)$ & $0,37(0,06)$ & $0,00(0,01)$ \\
\hline 100 & $0,01(0,01)$ & $\mathbf{0 , 4 9}(0,06)$ & $0,01(0,02)$ & $0,01(0,02)$ & $0,39(0,06)$ & $0,01(0,02)$ \\
\hline 120 & $0,01(0,02)$ & $\mathbf{0 , 5 1}(0,06)$ & $0,02(0,03)$ & $0,03(0,03)$ & $0,42(0,05)$ & $0,03(0,03)$ \\
\hline 140 & $0,04(0,03)$ & $\mathbf{0 , 5 4}(0,05)$ & $0,04(0,03)$ & $0,09(0,05)$ & $0,46(0,06)$ & $0,09(0,09)$ \\
\hline All & $0,41(0,04)$ & $\mathbf{0 , 6 6}(0,05)$ & $0,48(0,04)$ & & & \\
\hline $\mathrm{BR}_{\text {Low }}$ & 0,24 & & & & & \\
\hline
\end{tabular}


considerando o valor médio para InitSize, com os métodos supervisionados construídos com todo o conjunto de exemplos rotulados disponível, em alguns casos os algoritmos semissupervisionados obtiveram resultados próximos aos dos algoritmos supervisionados, como nos casos com os conjuntos de dados Emotions, Yeast e Enron, para os quais foram utilizados InitSize igual a 30, 50 e 100 , respectivamente.

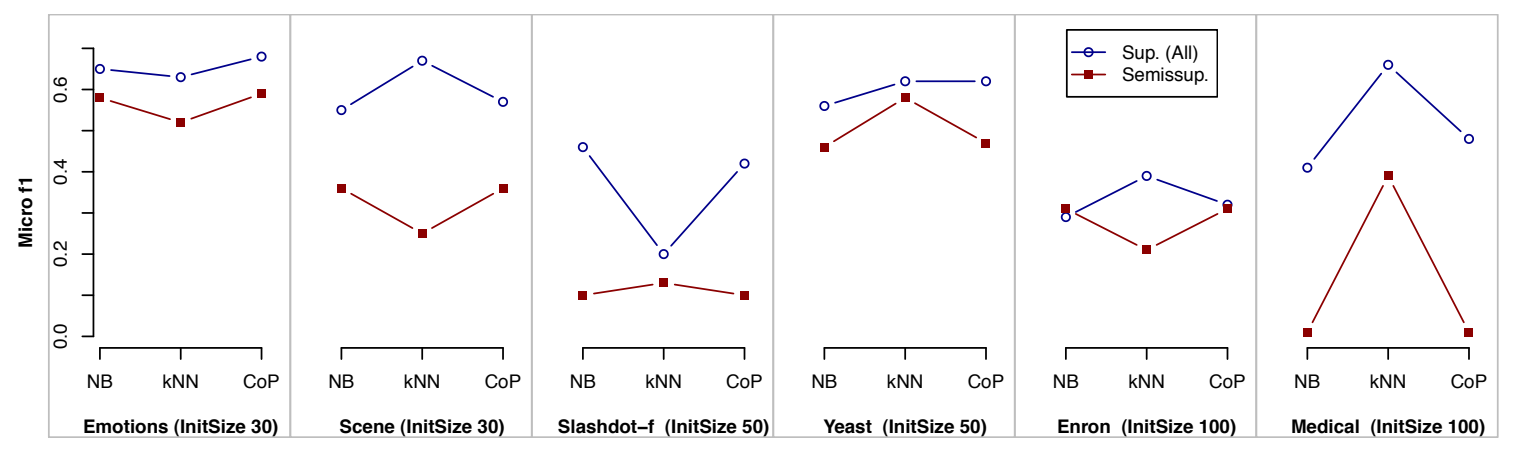

Figura 6.4: Comparação dos métodos supervisionados e semissupervisionados com valor de InitSize médio para os métodos semissupervisionados e InitSize All para os métodos supervisionados.

A representação gráfica dos resultados obtidos — Tabela 6.9 - considerando a medida $f_{1}^{\mu}$ e todos as configurações de aprendizado semissupervisionado deste cenário, é apresentada na Figura 6.5. É importante lembrar que, nestes gráficos, os valores referente a InitSize All foram obtidos pelos métodos supervisionados, pois não se justifica utilizar métodos semissupervisionados quando há um grande número de exemplos rotulados disponíveis. No entanto, esses valores são apresentados nestes gráficos para possibilitar a comparação dos métodos semissupervisionados treinados com poucos exemplos com um "limite superior" de qualidade, uma vez que o número de exemplos rotulados disponível está diretamente relacionado à qualidade do aprendizado.

A partir dos gráficos apresentados na Figura 6.5 e considerando os valores de $f_{1}^{\mu}$ obtidos pelo método baseline $\mathrm{BR}_{\text {Low }}$, é possivel observar três situações distintas:

- resultados melhores que $\mathrm{BR}_{\text {Low }}$ : com os conjuntos de dados Emotions e Scene todos os métodos semissupervisionados, apesar de não terem obtido melhores resultados que os respectivos métodos supervisionados, ao menos foram capazes de aprender o conceito meta do problema e, mais importante ainda, com poucas evidências.

- resultados piores que $\mathrm{BR}_{\text {Low }}$ : para os conjuntos de dados Slashdot-f, Yeast e Enron, por outro lado, os métodos semissupervisionados não atingiram os valores de $f_{1}^{\mu}$ do baseline em nenhuma das configurações de InitSize. No caso de Yeast, mais especificamente, à medida que o número 


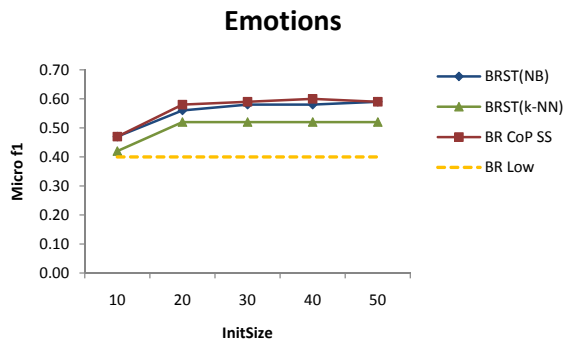

(a) Conjunto de dados Emotions

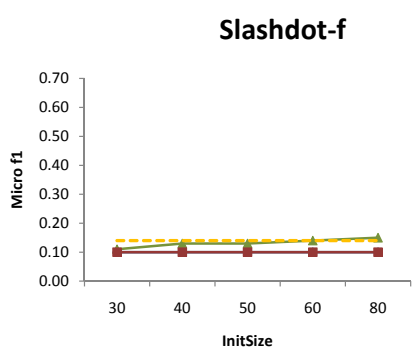

(c) Conjunto de dados Slashdot-f

Enron

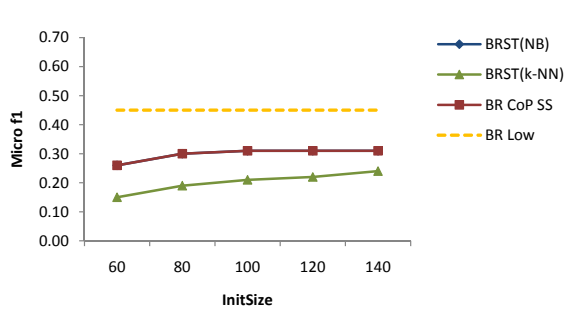

(e) Conjunto de dados Enron

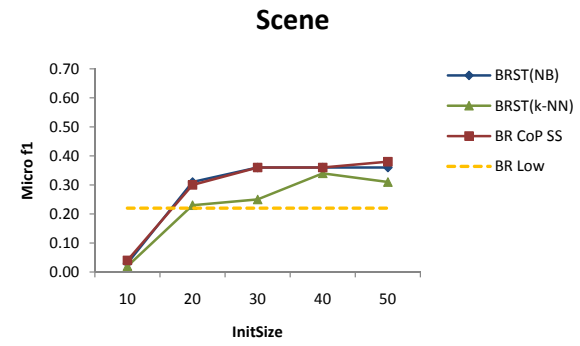

(b) Conjunto de dados Scene

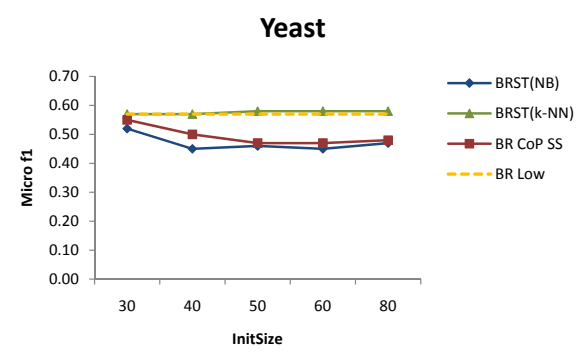

(d) Conjunto de dados Yeast

Medical

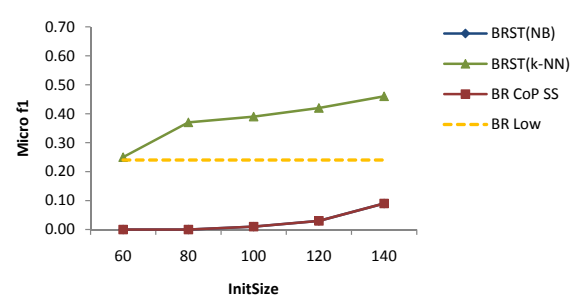

(f) Conjunto de dados Medical

Figura 6.5: Valores da medida $f_{1}^{\mu}$ para o Cenário 2.

de exemplos rotulados aumentou, a performance dos métodos $\mathrm{BR}_{S T}(\mathrm{NB})$ e $\mathrm{BR}_{C o P S S}$ degradou.

- resultados opostos para os algoritmos base de aprendizado: considerando os resultados obtidos para o conjunto de dados Medical, observase que um dos algoritmos de aprendizado é muito superior ao outro, pois o método $\mathrm{BR}(k-\mathrm{NN})$ superou o baseline, mostrando que foi capaz de aprender, mesmo que em partes, as classes do problema, ao passo que o método BR (NB) não foi capaz de aprender as classes. Consequentemente, o método $\mathrm{BR}_{C o P S S}$ foi prejudicado pela descrição treinada com o algoritmo NB.

De maneira análoga ao cenário 1 , com o objetivo de entender o comportamento do modelo de classificação semissupervisionada monoperspectiva SELFTRAINING, utilizando $\mathrm{BR}_{S T}(\mathrm{NB})$ e $\mathrm{BR}_{S T}(k-\mathrm{NN})$, e do método semissupervisionado baseado em desacordo $\mathrm{BR}_{C o P S S}$, comparamos a performance dos classificadores construídos para cada monorrótulo. Nas Figuras 6.6, 6.7 e 6.8, são apresentados os valores da medida $f_{1}$ (de classificação binária) para cada 
monorrótulo considerando três conjuntos de dados: Emotions, Scene e Yeast, respectivamente. Para facilitar a comparação entre os métodos supervisionados e semissupervisionados, os resultados obtidos para o Cenário 1 são duplicados nessas figuras e respectivos conjuntos de dados. Por meio desses gráficos, observa-se que o processo de semissupervisão monoperspectiva utilizando $k$-NN, i.e., $\mathrm{BR}_{S T}(k-\mathrm{NN})$, degradou fortemente a performance do classificador final para os três conjuntos de dados considerados, especificamente para os conjuntos Emotions, Scene e Yeast. É interessante notar que para alguns monorrótulos o valor de $f_{1}$ é próximo de zero. A degradação, ainda que menor, também acontece para o método $\mathrm{BR}_{S T}(\mathrm{NB})$. Consequentemente, o método semissupervisionado $\mathrm{BR}_{C o P S S}$ que faz uso das suas monoperspectivas também teve sua performance degradada.

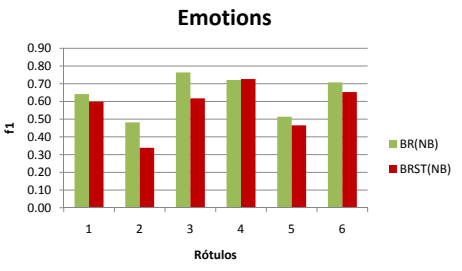

(a)

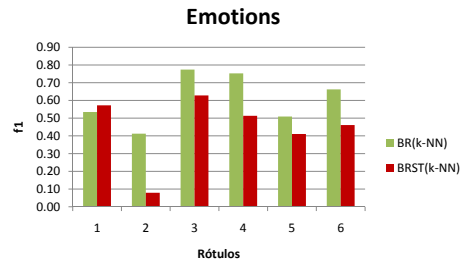

(b)

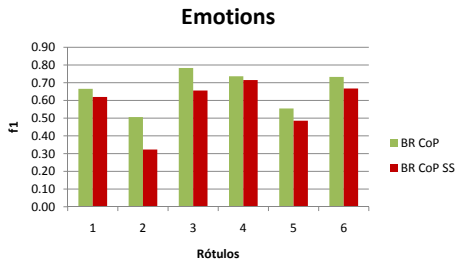

(c)

Figura 6.6: Comparação entre métodos supervisionado e semissupervisionados para o conjunto de dados Emotions. Medida $f_{1}$ para cada classificador binário independente (InitSize médio).

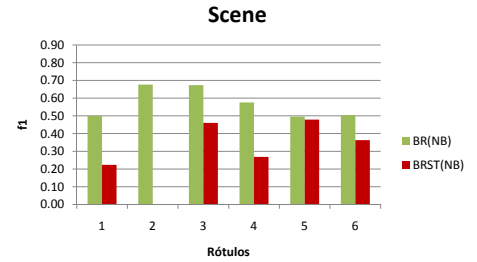

(a)

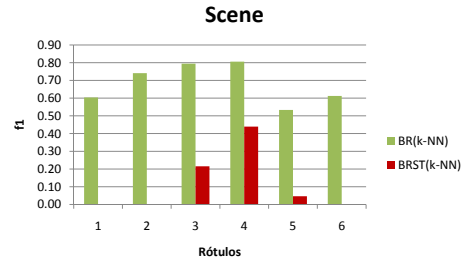

(b)

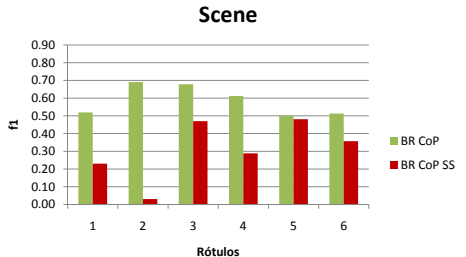

(c)

Figura 6.7: Comparação entre métodos supervisionado e semissupervisionados para o conjunto de dados Scene. Medida $f_{1}$ para cada classificador binário independente (InitSize médio).

\subsubsection{Cenário 3 - aprendizado semissupervisionado ativo}

Neste cenário os resultados obtidos por meio dos métodos semissupervisionado com uso de aprendizado ativo são avaliados e comparados com os outros métodos supervisionados e semissupervisionados. Os valores de $f_{1}^{\mu}$ obtidos pelos métodos avaliados neste cenário são apresentados na Tabela 6.10, conjuntamente com os resultados anteriores para facilitar a compreensão. 


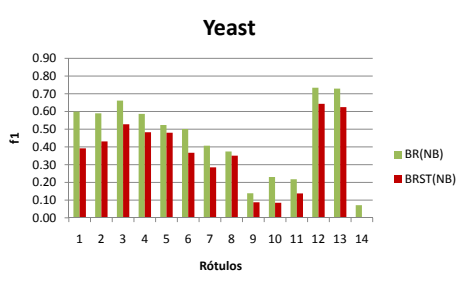

(a)

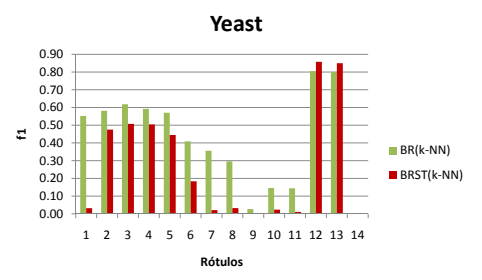

(b)

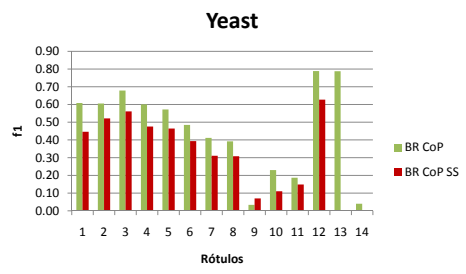

(c)

Figura 6.8: Comparação entre métodos supervisionado e semisupervisionados para o conjunto de dados Yeast. Medida $f_{1}$ para cada classificador binário independente (InitSize médio).

É importante lembrar que os métodos de aprendizado ativo não foram executados com valores de InitSize 10 (ver descrição do Cenário 3 na Tabela 6.3 na página 117). Além disso, de maneira análoga ao Cenário 2, os valores referentes ao InitSize All são os obtidos com os métodos supervisionados.

A representação gráfica dos resultados obtidos para cada uma das configurações com métodos coperspectiva semissupervisionado e coperspectiva semissupervisionado ativo, é apresentada na Figura 6.9.

Em uma primeira análise, observa-se que os métodos de aprendizado ativo $\mathrm{BR}_{C o P S S+A L} \mathrm{e} \mathrm{BR}_{C o T e s t i n g}$ obtiveram performance superior ao baseline $\mathrm{BR}_{\text {Low }}$ para os conjuntos de dados Emotions, Scene e Yeast. Como mencionado anteriormente, os resultados do baseline $\mathrm{BR}_{\text {Low }}$ são obtidos usando todos os exemplos rotulados disponíveis, ao passo que os métodos semissupervisionados e ativos utilizam apenas uma pequena fração desses exemplos, o que mostra que mesmo com poucos exemplos de treinamento rotulados os classificadores construídos com auxílio do aprendizado ativo são capazes de aprender as classes do problema. Outro fato que reforça esse resultado é a comparação dos métodos ativos com o método $\mathrm{BR}_{C o P S S}$, uma vez que para para a maioria das configurações de InitSize os métodos ativos também superaram o método $\mathrm{BR}_{C o P S S}$ com os conjuntos de dados Emotions, Yeast e Medical, mostrando que, para esses conjuntos de dados, o aprendizado ativo também contribuiu para a melhora no desempenho dos classificadores construídos. Esse comportamento se repete com relação aos métodos $\mathrm{BR}_{S T}(\mathrm{NB})$ e $\mathrm{BR}_{S T}(k-\mathrm{NN})$, como pode ser observado na Tabela 6.11, na qual são apresentados os valores percentuais de melhora/degradação do modelo comparando os métodos ativos $\mathrm{BR}_{C o P S S+A L}$ e $\mathrm{BR}_{\text {CoTesting }}$ com os métodos "inativos" $\mathrm{BR}_{S T}(\mathrm{NB}), \mathrm{BR}_{S T}(k-\mathrm{NN})$ e $\mathrm{BR}_{C o P S S}$.

Essa diferença de comportamento acontece devido aos exemplos que são utilizados para a construção do classificador inicial. No caso dos algoritmos "inativos", são selecionados aleatoriamente InitSize exemplos rotulados, os quais podem ser ou não significativos para o aprendizado. No caso dos algoritmos ativos, por outro lado, um número ainda menor de exemplos rotulados 
Tabela 6.10: Valores de $f_{1}^{\mu}$ para o Cenário 3 de classificação multirrótulo.

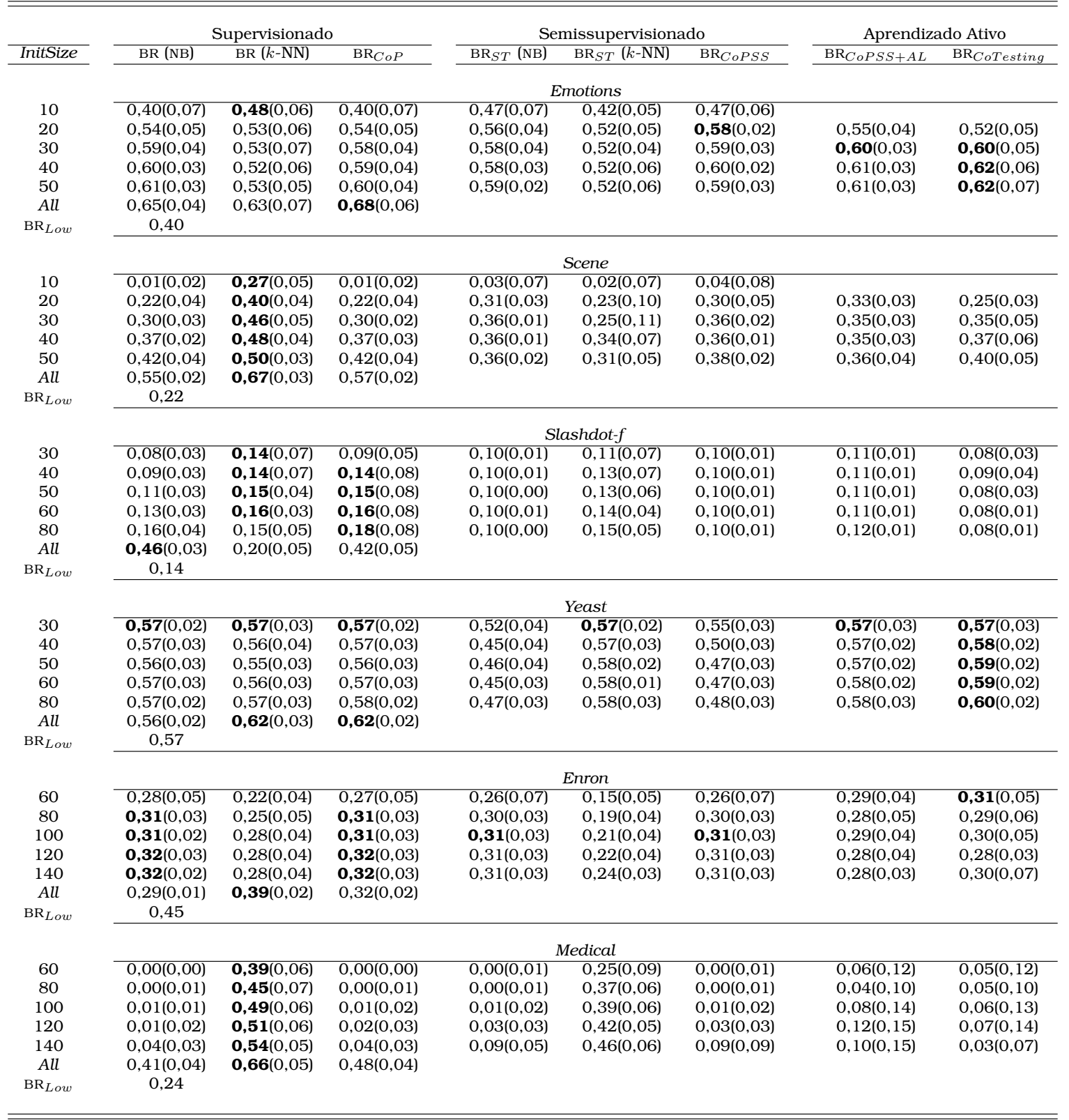

são selecionados aleatoriamente, mas os outros exemplos que são utilizados para a construção do classificador inicial, são exemplos ponto de contenção selecionados pelo processo de aprendizado ativo e rotulados pelo "oráculo". Em geral, esses exemplos são mais informativos para o classificadores que os exemplos selecionados aleatoriamente. Desse modo, quanto maior é o número de consultas permitidas ao "oráculo", maior é o número de exemplos potencialmente mais informativos para a construção dos classificadores nas iterações iniciais.

Com relação ao conjunto de dados Scene, apesar do desempenho semelhante dos diferentes métodos, observa-se que o aprendizado ativo isolado $\left(\mathrm{BR}_{\text {CoTesting }}\right)$ tende a melhorar a performance do classificador na medida que 


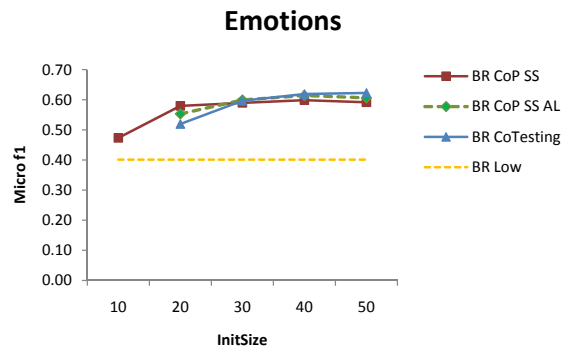

(a) Conjunto de dados Emotions

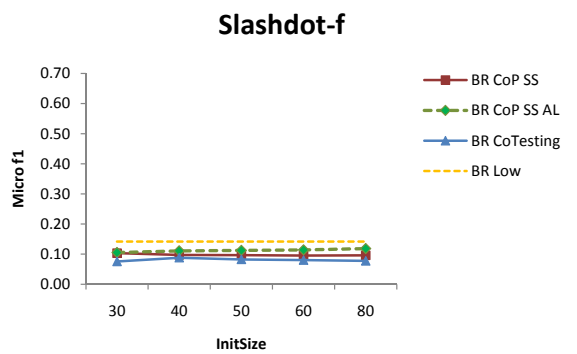

(c) Conjunto de dados Slashdot-f

Enron

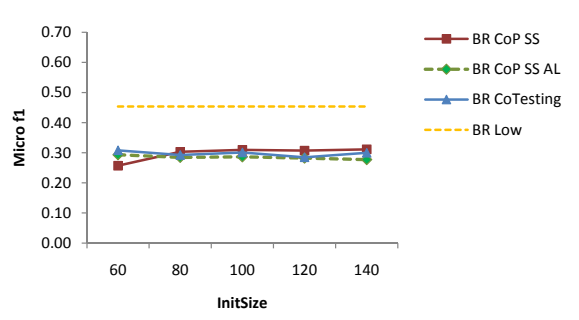

(e) Conjunto de dados Enron

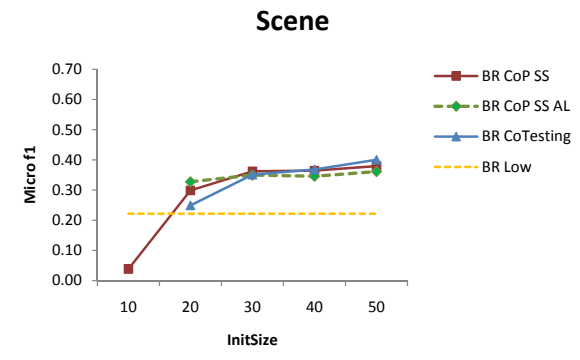

(b) Conjunto de dados Scene

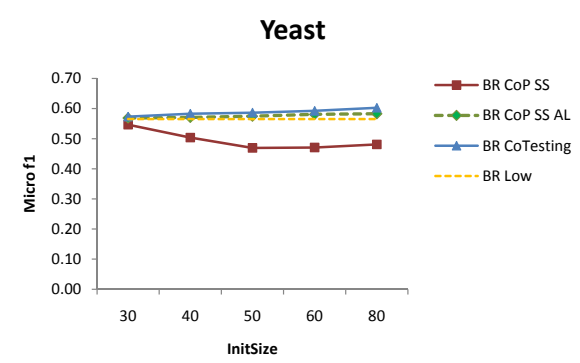

(d) Conjunto de dados Yeast

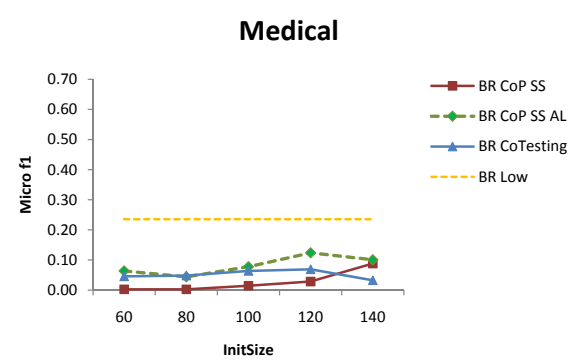

(f) Conjunto de dados Medical

Figura 6.9: Valores da medida $f_{1}^{\mu}$ para o Cenário 3.

aumenta o número de consultas ao "oráculo". Esse fato demonstra que os classificadores construídos nas iterações iniciais são fracos e que podem ser otimizados por meio da seleção de exemplos mais informativos para a rotulação com o aprendizado ativo. Guando o aprendizado ativo é executado em conjunto ao aprendizado semissupervisionado $\left(\mathrm{BR}_{C o P S S+A L}\right)$, por outro lado, observa-se que há uma pequena degradação do modelo em relação ao aprendizado semissupervisionado e ao aprendizado ativo isolados, respectivamente

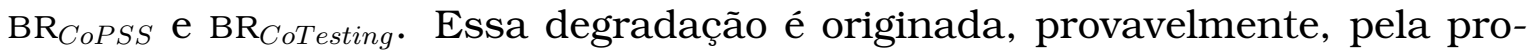
pagação de erros de classificação no processo de incremento do conjunto de treinamento rotulado.

Com relação aos conjuntos de dados Slashdot-f e Enron, apesar dos resultados abaixo do baseline, há diferenças significativas quando comparados os métodos ativos com métodos "inativos", como mostrado na Tabela 6.11.

Outra observação importante está relacionada o conjunto de dados Medical, uma vez que a partir da análise comparativa entre os métodos ativos com os demais métodos, considerando valores percentuais de melhora e/ou degra- 
Tabela 6.11: Comparação dos métodos de aprendizado ativo com métodos semissupervisionados multirrótulo. O símbolo $\Delta$ representa melhora em relação ao método ativo comparado e o símbolo $\nabla$ representa degradação.

\begin{tabular}{|c|c|c|c|c|c|c|}
\hline \multirow[t]{2}{*}{ InitSize } & \multicolumn{3}{|c|}{$\mathrm{BR}_{C o P S S+A L}$} & \multicolumn{3}{|c|}{$\overline{B R}_{\text {CoTesting }}$} \\
\hline & $\mathrm{BR}_{S T}(\mathrm{NB})$ & $\mathrm{BR}_{S T}(k-\mathrm{NN})$ & $\mathrm{BR}_{C o P S S}$ & $\mathrm{BR}_{S T}(\mathrm{NB})$ & $\mathrm{BR}_{S T}(k-\mathrm{NN})$ & $\mathrm{BR}_{C o P S S}$ \\
\hline & \multicolumn{6}{|c|}{ Emotions } \\
\hline 20 & $\Delta 02 \%$ & $\nabla 06 \%$ & $\Delta 05 \%$ & $\Delta 09 \%$ & - & $\Delta 12 \%$ \\
\hline 30 & $04 \%$ & $\nabla 13 \%$ & $02 \%$ & . $03 \%$ & $\nabla 12 \%$ & $\nabla 01 \%$ \\
\hline 40 & $\nabla 05 \%$ & $\nabla 15 \%$ & $\nabla 03 \%$ & 7 $06 \%$ & $\nabla 16 \%$ & $\nabla 03 \%$ \\
\hline \multirow[t]{2}{*}{50} & $\nabla 03 \%$ & $\nabla 14 \%$ & $\nabla 02 \%$ & $\nabla 05 \%$ & จ $17 \%$ & $\nabla 05 \%$ \\
\hline & \multicolumn{6}{|c|}{ Scene } \\
\hline 20 & $\nabla 04 \%$ & $\nabla 29 \%$ & $\nabla 09 \%$ & $\Delta 26 \%$ & $\nabla 06 \%$ & $\Delta 20 \%$ \\
\hline 30 & $\triangle 02 \%$ & จ $27 \%$ & $\triangle 03 \%$ & $\triangle 02 \%$ & จ $28 \%$ & - $03 \%$ \\
\hline 40 & $\Delta 05 \%$ & 7 3\% & $\triangle 05 \%$ & $02 \%$ & - $08 \%$ & $\nabla 01 \%$ \\
\hline \multirow[t]{2}{*}{50} & - & จ $15 \%$ & А $05 \%$ & $\nabla 10 \%$ & $\nabla 23 \%$ & $\nabla 05 \%$ \\
\hline & \multicolumn{6}{|c|}{ Slashdot-f } \\
\hline 30 & $\nabla 07 \%$ & $\Delta 07 \%$ & $\nabla 02 \%$ & $\Delta 30 \%$ & А $49 \%$ & А $37 \%$ \\
\hline 40 & $\nabla 14 \%$ & А $18 \%$ & $\nabla 12 \%$ & $\Delta 09 \%$ & А $49 \%$ & - $11 \%$ \\
\hline 50 & $\nabla 13 \%$ & $\Delta 13 \%$ & $\nabla 14 \%$ & $\Delta 19 \%$ & А $54 \%$ & - $17 \%$ \\
\hline 60 & $\nabla 13 \%$ & А $21 \%$ & $\nabla 16 \%$ & А $24 \%$ & А $72 \%$ & А $19 \%$ \\
\hline \multirow[t]{2}{*}{80} & $\nabla 19 \%$ & $\triangle 24 \%$ & $\nabla 19 \%$ & $\triangle 23 \%$ & $\triangle 89 \%$ & \ $24 \%$ \\
\hline & \multicolumn{6}{|c|}{ Yeast } \\
\hline 30 & $\nabla 09 \%$ & - & $\nabla 04 \%$ & $\nabla 10 \%$ & - & $\nabla 05 \%$ \\
\hline 40 & $\nabla 21 \%$ & - & $\nabla 12 \%$ & $\nabla 22 \%$ & $\nabla 03 \%$ & - $14 \%$ \\
\hline 50 & $\nabla 20 \%$ & - & $\nabla 18 \%$ & $\nabla 22 \%$ & $\nabla 02 \%$ & $\nabla 20 \%$ \\
\hline 60 & จ $22 \%$ & $\nabla 01 \%$ & $\nabla 19 \%$ & จ $24 \%$ & จ $03 \%$ & $\nabla 21 \%$ \\
\hline \multirow[t]{2}{*}{80} & $\nabla 20 \%$ & - & $\nabla 17 \%$ & $\nabla 23 \%$ & $\nabla 03 \%$ & $\nabla 20 \%$ \\
\hline & \multicolumn{6}{|c|}{ Enron } \\
\hline 60 & $\nabla 12 \%$ & $\nabla 48 \%$ & $\nabla 12 \%$ & $\nabla 16 \%$ & $\nabla 51 \%$ & $\nabla 17 \%$ \\
\hline 80 & $\triangle 06 \%$ & v $33 \%$ & $\triangle 06 \%$ & $\triangle 04 \%$ & จ $35 \%$ & $\triangle 04 \%$ \\
\hline 100 & А $08 \%$ & จ $27 \%$ & $\triangle 08 \%$ & $\triangle 03 \%$ & จ $30 \%$ & $\triangle 03 \%$ \\
\hline 120 & А $08 \%$ & จ $22 \%$ & А $09 \%$ & А $07 \%$ & ₹ $23 \%$ & $\Delta 08 \%$ \\
\hline \multirow[t]{2}{*}{140} & $\Delta 11 \%$ & $\nabla 14 \%$ & А $12 \%$ & $\Delta 03 \%$ & $\nabla 21 \%$ & $\Delta 04 \%$ \\
\hline & \multicolumn{6}{|c|}{ Medical } \\
\hline 60 & $\nabla 96 \%$ & А 296\% & $\nabla 96 \%$ & $\nabla 95 \%$ & $\Delta 453 \%$ & $\nabla 95 \%$ \\
\hline 80 & จ 95\% & $\Delta 746 \%$ & $\nabla 95 \%$ & จ 95\% & $\Delta 670 \%$ & $\nabla 95 \%$ \\
\hline 100 & จ $82 \%$ & А $404 \%$ & $\nabla 81 \%$ & จ 78\% & А $514 \%$ & จ 77\% \\
\hline 120 & $74 \%$ & $\triangle 241 \%$ & จ $77 \%$ & จ $52 \%$ & А $515 \%$ & จ 59\% \\
\hline 140 & $\nabla$ 09\% & А $355 \%$ & $\nabla 13 \%$ & А $183 \%$ & $\Delta 1311 \%$ & А $171 \%$ \\
\hline
\end{tabular}

dação, foram obtidos valores bastante discrepantes. Essa grande diferença no desempenho dos métodos é facilmente justificada considerando os resultados apresentados na Tabela 6.10, a partir da qual observa-se que os métodos BR (NB) e $\mathrm{BR}_{S T}(\mathrm{NB})$ apresentaram performance muito inferior os métodos BR $(k-$ $\mathrm{NN})$ e $\mathrm{BR}_{S T}(k-\mathrm{NN})$, e também influenciaram no fraco desempenho dos métodos coperspectiva.

Observe que nesse cenário, para todos os casos, o número de exemplos iniciais foi fixado e o número de consultas variado. É importante lembrar que todas as consultas ao "oráculo" podem ser realizadas na primeira iteração do algoritmo, caso a quantidade de pontos de contenção identificados seja maior ou igual ao limite especificado. Por outro lado, podem existir iterações nas quais nenhum ou poucos pontos de contenção são encontrados. Uma outra abordagem para avaliar o impacto do aprendizado ativo nesse contexto, é variar o valor de InitSize e manter o número de consultas com um valor fac- 
tível. Assim, o modelo inicial antes do aprendizado ativo pode ser construído com mais exemplos e, consequentemente, ser mais eficaz na identificação dos pontos de contenção. Com pontos de contenção ainda mais informativos, a possibilidade de melhorar a eficácia global do classificador multirrótulo aumenta.

Os gráficos para comparação da performance para cada classificador binário independente, considerando os conjuntos de dados Emotions, Scene e Yeast, são apresentados nas Figuras 6.10, 6.11 e 6.12, respectivamente.

No caso do conjunto de dados Emotions - Figura 6.10 - , observa-se que a perspectiva construída por SELF-TRAINING com o algoritmo de aprendizado $k$-NN afeta negativamente o desempenho dos métodos coperspectiva. Esse fato pode ser observado a partir do desempenho do método $\mathrm{BR}_{S T}(k-\mathrm{NN})$. Por outro lado, para dois rótulos, especificamente os rótulos 3 e 6 , os métodos de aprendizado ativo $\mathrm{BR}_{C o P S S+A L}$ e $\mathrm{BR}_{C o T e s t i n g}$ apresentam melhoras em relação aos outros métodos.

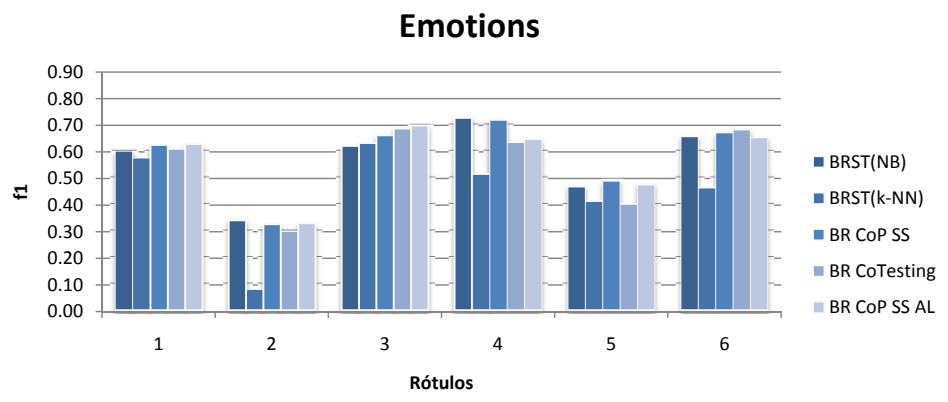

Figura 6.10: Comparação dos métodos semissupervisionados com e sem aprendizado ativo para Emotions.

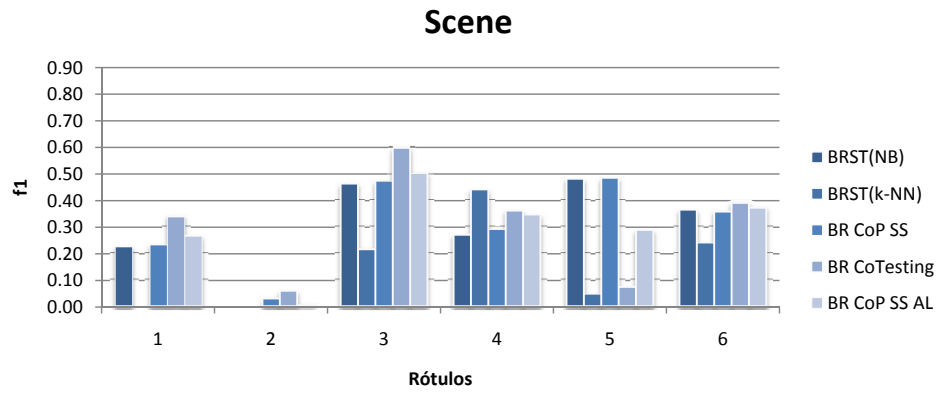

Figura 6.11: Comparação dos métodos semissupervisionados com e sem aprendizado ativo para Scene.

Para os conjuntos de dados Scene e Yeast, a perspectiva construída por SELF-TRAINING com o algoritmo de aprendizado NB e $k$-NN não é capaz de aprender algumas das classes, como pode ser observado pelos resultados obtidos pelos classificadores SELF-TRAINING BR $\mathrm{BR}_{S T}(\mathrm{NB})$ e $\mathrm{BR}_{S T}(k-\mathrm{NN})$. Além disso, para alguns rótulos, todos os métodos têm valor de $f_{1}$ bastante próximo ou 
igual a zero, fazendo com que o resultado global do classificador multirrótulo seja decrementado.

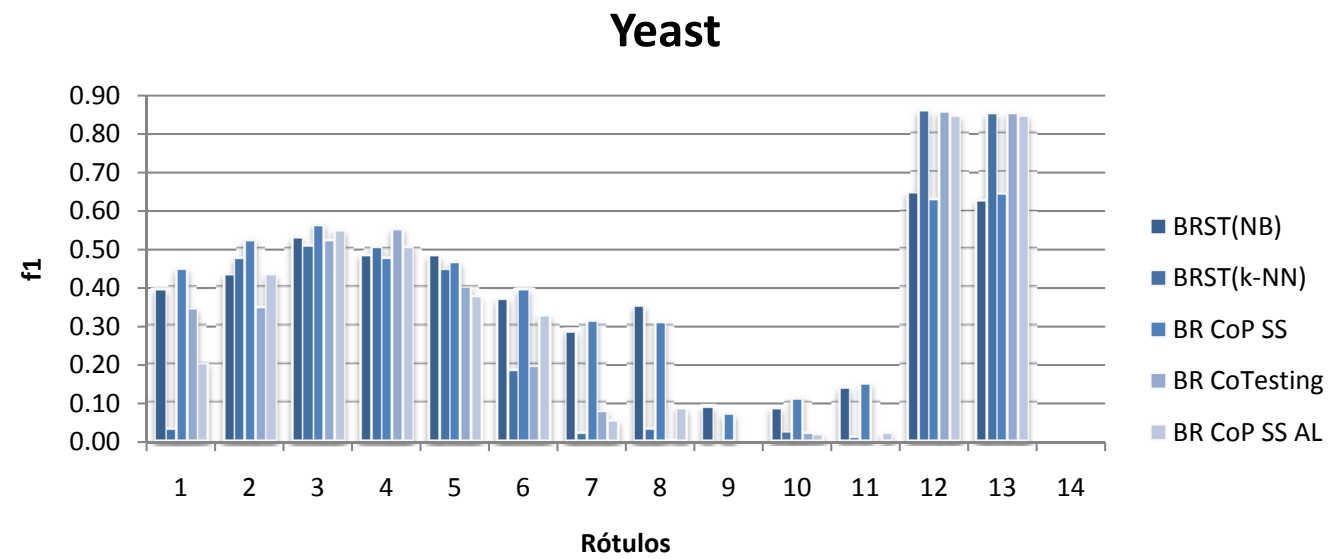

Figura 6.12: Comparação dos métodos semissupervisionados com e sem aprendizado ativo para Yeast.

\subsection{Classificação hierárquica}

Para essa tarefa, também foram realizados experimentos com objetivo de avaliar os métodos propostos considerando cenários que contemplam os métodos supervisionados e os semissupervisionados.

Como descrito no Capítulo 5, os métodos propostos para aprendizado supervisionado hierárquico são $\mathrm{HMR}_{E x t}, \mathrm{HMR}_{E x t M u l t i}, \mathrm{HDR}$ e $\mathrm{HBR}_{C o P}$. Para a tarefa semissupervisionada, os métodos são $\mathrm{HBR}_{C o P S S}, \mathrm{HBR}_{S T}, \mathrm{HBR}_{C o P S S+A L} \mathrm{e}$

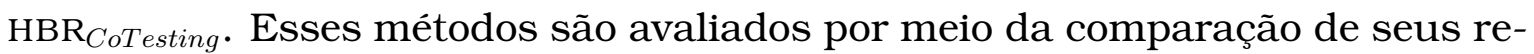
sultados com os resultados obtidos pelos métodos $\mathrm{HBR}_{\text {Low }}$, também proposto neste trabalho, e os métodos locais padrão HBR e HMR. Os conjuntos de dados utilizados, bem como as configurações dos experimentos e a análise dos resultados, são apresentados a seguir.

\subsection{Bases de dados}

Para a avaliação dos métodos hierárquicos, foram utilizados 18 conjuntos de dados de diferentes áreas de conhecimento, os quais são categorizados considerando o domínio de aplicação. O domínio desses dados é descrito brevemente a seguir:

Identificação de vidros: apenas um conjunto de dados desse domínio é utilizado, o qual é originalmente formatado para tarefas de classificação plana multiclasse motivada por investigações criminalísticas, uma vez 
que pedaços de vidros encontrados em cenas de crimes podem ser utilizados como evidências do crime, caso sejam corretamente identificados.

Entretanto, as classes desse conjunto de dados são naturalmente hierárquicas e a taxonomia que representa essa estrutura hierárquica é descrita no documento de apresentação do conjunto de dados. A partir dessa informação, esse conjunto de dados foi adaptado para que as classes atribuídas aos exemplos refletissem a taxonomia descrita no documento, a qual é apresentada na Figura 6.13(a). Observe que nessa taxonomia, as classes B e V são nós-folha em dois ramos distintos da hierarquia. Além disso, a classe $\mathrm{V}$ filha de NF, não contém exemplos a ela associados. Por esses motivos, a hierarquia foi modificada de modo que essas classes estejam presentes em apenas um ramo da taxonomia e todas as classes folhas tenham exemplos explicitamente associados a elas. A taxonomia modificada, utilizada neste trabalho, é apresentada na Figura 6.13(b).

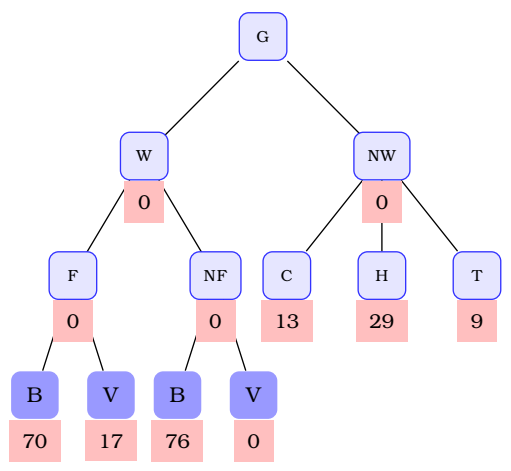

(a) Original

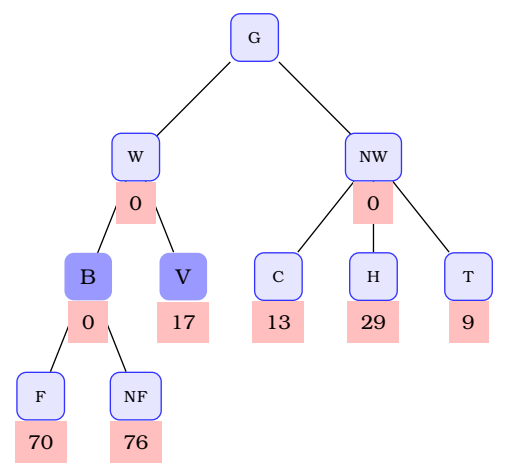

(b) Modificada

Figura 6.13: Hierarquia de classes Glass.

Música: existem diversos conjuntos de dados deste domínio para recuperação de informação, os quais contêm exemplos que representam músicas de diversas etnias e gêneros, como o Western Music Database para tarefa de classificação de gêneros musicais do ISMIR 2004 Audio Description Contest (Cano et al., 2006), e Latin Music Database - LMD (Silla et al., 2008).

Esses dois conjuntos foram utilizados para a construção e processamento dos quatro conjuntos de dados utilizados neste trabalho. Entretanto, esse processamento foi realizado anteriormente por Silla Jr \& Freitas (2009b), por meio da extração de características específicas dos exemplos presentes nos conjuntos Western e LMD. Assim, os quatro conjuntos de dados dessa categoria são construídos, na realidade, a partir do mesmo conjunto de exemplos utilizando quatro métodos diferentes de extração 
de características de arquivos de audio, descritos a seguir:

- Marsyas - este método, proposto em (Tzanetakis \& Cook, 2002), extrai três tipos de características a partir de arquivos de audio: timbre, ritmo e picos. Essas características são representadas por meio de diversos atributos.

- Rhytms histograms - RH - por meio desse método (Lidy \& Rauber, 2005), são extraídos diversos atributos que agregam a modulação de amplitude de 24 bandas de padrões de ritmos musical.

- Statistical spectrum descriptors - SSD - neste método, proposto em (Lidy \& Rauber, 2005), inicialmente é calculada a "sensação de barulho” para 24 bandas de ritmo Bark-scale. Após, para cada banda são calculadas diversas medidas estatísticas, cujos valores são utilizados como os atributos descritores dos dados.

- Inset-onset interval histogram coefficient - IOIHC - o conjunto de atributos extraídos por meio deste método é composto de propriedades de ritmo de sinais sonoros, os quais são computados a partir de função periódica específica, chamada inter-onset interval histogram (Gouyon et al., 2002). Esse método foi proposto em (Antonopoulos et al., 2007).

A taxonomia das classes resultante da união dos conjuntos Western e LMD é apresentada na Figura 6.14, na qual o número de exemplos explicitamente anotados com a classe $y_{j}$ é apresentado abaixo do respectivo nó.

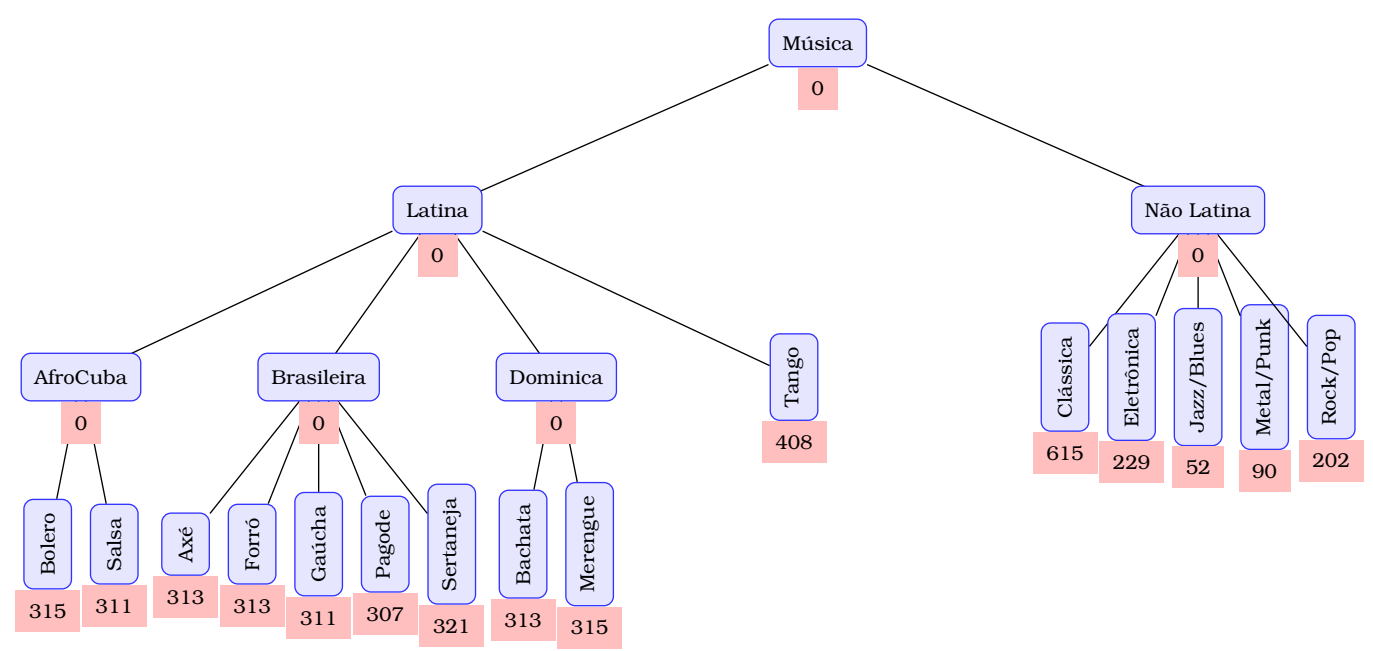

Figura 6.14: Hierarquia de classes de Música.

Funções de proteinas: proteínas são moléculas responsáveis por praticamente todas as funções celulares de organismos vivos e consistem, essencial- 
mente, de longas estruturas de aminoácidos, as quais são associadas a diferentes funções celulares (Freitas \& de Carvalho, 2007).

O número de proteínas para as quais a sequência de aminoácidos é conhecida têm crescido exponencialmente nos últimos anos. Por outro lado, para a maior parte das proteínas, sua estrutura e função ainda são desconhecidas, uma vez que identificar suas estruturas e funções é mais caro e demorado do que apenas identificar a sequência de aminoácidos que as compõem.

As proteínas podem ser organizadas em uma estrutura hierárquica com 4 níveis de especificidade: a sequência de aminoácidos, hélices- $\alpha$ e folhas$\beta$, a organização tri-dimensional da proteína e, por fim, a estrutura completa da proteína composta por duas ou mais cadeias polipeptídicas.

Neste trabalho, foram utilizados dados de funções de proteínas com descritores GPCR (G-Protein Coupled Receptors), os quais são proteínas de sinalização, e dados com funções de proteínas com descritores de Enzimas (EC). Informações mais detalhas sobre os tipos de proteínas e suas funções podem ser encontradas em (Fillmore, 2004; Freitas \& de Carvalho, 2007).

Foram utilizados quatro versões desses dados, nas quais diferentes motifs estão descritos. Os motifs utilizados neste trabalho são: Interpro, FingerPrints, Prosite e Pfam. Além disso, os dados originais foram préprocessados por Silla Jr \& Freitas (2009a), resultando em uma taxonomia com 4 níveis de especificidade, além da raiz. As modificações realizadas no pré-processamento são:

- agrupamento das classes com menos de 10 exemplos. As classes com "poucos" exemplos foram agrupadas às suas respectivas classes mãe. Essa operação foi recursivamente aplicada até que a classe resultante contivesse ao menos 10 exemplos ou fosse a classe raiz;

- exemplos rotulados com a classe raiz como sua classe específica foram removidos; e

- os atributos de peso molecular e comprimento da sequência foram discretizados.

A partir desse processamento, tantos os conjuntos de dados com funções de enzimas como GPCR resultantes contêm exemplos rotulados com até quatro níveis de especificidade.

Funções de genes: os conjuntos de dados desse grupo descrevem dados do fungo Saccharomyces cerevisiae, frequentemente utilizado em processos 
de fermentação de açúcar para a produção de etanol e na fermentação de trigo ou cevada na produção de bebidas alcóolicas.

Os 10 conjuntos de dados desse grupo podem ser categorizados de acordo com o tipo de informações neles contidas. São três categorias:

- sequência estatística;

- fenótipo; e

- expressão gênica.

Apenas um conjunto de dados foi utilizado para cada uma das duas primeiras categorias, respectivamente, o conjunto Sequence e o conjunto Phenotype. Os outros oito conjuntos de dados descrevem informações de expressão gênica por meio de microarray.

A hierarquia de classes desses conjuntos de dados, estruturada em uma árvore de acordo com o projeto FunCat, apresenta exemplos que podem ser rotulados em múltiplos caminhos da árvore. Uma vez que neste trabalho utilizamos apenas métodos que predizem somente um ramo da taxonomia, foi realizado um pré-processamento nesses conjuntos de dados para eliminar os múltiplos caminhos no conjunto de treinamento. Basicamente, para cada exemplo rotulado com dois ou mais ramos da taxonomia, apenas um desses ramos foi mantido, o qual foi selecionado aleatoriamente. Além disso, esses conjuntos de dados possuem apenas exemplos cuja classe mais específica é uma classe folha, e todas as classes folhas possuem ao menos 10 exemplos associados.

Os conjuntos de dados utilizados para a avaliação experimental dos métodos propostos neste trabalho para a tarefa de classificação hierárquica são apresentados na Tabela 6.12, na qual a coluna MLN (Mandatory Leaf Node) indica se o conjunto de dados contém todos os exemplos explicitamente anotados com classes folha, ao passo que as colunas \#E, \#A e $|L|$ representam, respectivamente, o número de exemplos, o número de atributos e o número de monorrótulos distintos no conjunto de treinamento. Na coluna $|L|$ por nível são apresentados as quantidades de monorrótulos para cada nível da taxonomia, exceto a raiz. Na última coluna é apresentada a cardinalidade média de rótulos por exemplos para cada conjunto de $\operatorname{dados}^{9}$.

\subsubsection{Configurações e cenários para avaliação}

Para avaliar os métodos de classificação hierárquica propostos neste trabalho, foram elaborados cinco cenários:

\footnotetext{
${ }^{9}$ Todos os conjuntos de dados hierárquicos utilizados encontram-se disponíveis em http: //sites.labic.icmc.usp.br/jeanmetz/datasets.html
} 
Tabela 6.12: Conjunto de dados hierárquicos.

\begin{tabular}{|c|c|c|c|c|c|c|c|}
\hline $\begin{array}{l}\text { Conjunto } \\
\text { de dados }\end{array}$ & Domínio & MLN & \#E & $\overline{\mathrm{AA}}$ & $\overline{|L|}$ & $\overline{|| L \mid \text { por nível }}$ & Card \\
\hline HGlass & Id. de vidros & $\operatorname{sim}$ & 214 & 9 & 9 & $2,5,2$ & 2,68 \\
\hline IOIHC & Gen. musicais & $\operatorname{sim}$ & 4188 & 40 & 20 & $2,9,9$ & 2,65 \\
\hline Marsyas & Gen. musicais & $\operatorname{sim}$ & 4188 & 30 & 20 & $2,9,9$ & 2,65 \\
\hline$R H$ & Gen. musicais & $\operatorname{sim}$ & 4188 & 60 & 20 & $2,9,9$ & 2,65 \\
\hline$S S D$ & Gen. musicais & $\operatorname{sim}$ & 4188 & 168 & 20 & $2,9,9$ & 2,65 \\
\hline G-Pfam & Prot./GPCR & não & 7053 & 75 & 192 & $12,52,79,49$ & 2,84 \\
\hline G-Prints & Prot./GPCR & não & 5404 & 283 & 179 & $8,46,76,49$ & 3,01 \\
\hline G-Prosite & Prot./GPCR & não & 6246 & 129 & 187 & $9,50,79,49$ & 2,95 \\
\hline G-Interpro & Prot./GPCR & não & 7444 & 450 & 198 & $12,54,82,50$ & 2,82 \\
\hline E-Pfam & Prot./Enzima & não & 13987 & 708 & 333 & $6,41,96,190$ & 3,67 \\
\hline E-Prints & Prot./Enzima & não & 14025 & 382 & 351 & $6,45,92,208$ & 3,70 \\
\hline E-Prosite & Prot./Enzima & não & 14041 & 585 & 324 & $6,42,89,187$ & 3,69 \\
\hline E-Interpro & Prot./Enzima & não & 14027 & 1216 & 330 & $6,41,96,187$ & 3,66 \\
\hline Sequence & Func. de genes & $\operatorname{sim}$ & 1680 & 437 & 180 & $4,22,70,84$ & 3,59 \\
\hline Phenotype & Func. de genes & $\operatorname{sim}$ & 621 & 64 & 168 & $4,22,66,76$ & 3,59 \\
\hline Cell-cycle & Func. de genes & $\operatorname{sim}$ & 1711 & 78 & 180 & $4,22,70,84$ & 3,58 \\
\hline Church & Func. de genes & $\operatorname{sim}$ & 1677 & 24 & 180 & $4,22,70,84$ & 3,60 \\
\hline Derisi & Func. de genes & $\operatorname{sim}$ & 1661 & 62 & 180 & $4,22,70,84$ & 3,60 \\
\hline Eisen & Func. de genes & $\operatorname{sim}$ & 1163 & 80 & 170 & $4,22,66,78$ & 3,56 \\
\hline $\operatorname{Exp}$ & Func. de genes & $\operatorname{sim}$ & 1688 & 544 & 180 & $4,22,70,84$ & 3,60 \\
\hline Gasch-1 & Func. de genes & $\operatorname{sim}$ & 1660 & 174 & 180 & $4,22,70,84$ & 3,61 \\
\hline Gasch-2 & Func. de genes & $\operatorname{sim}$ & 1678 & 53 & 180 & $4,22,70,84$ & 3,60 \\
\hline SPO & Func. de genes & $\operatorname{sim}$ & 1649 & 79 & 180 & $4,22,70,84$ & 3,59 \\
\hline
\end{tabular}

1. aplicação do método de bootstrapping no contexto de classificação hierárquica (bootstrapping $\mathrm{HBR}$ );

2. seleção de conjuntos de treinamento locais para classificadores HBR;

3. coperspectivas no contexto de classificação hierárquica supervisionada;

4. aprendizado hierárquico semissupervisionado baseado em desacordo; e

5. aprendizado hierárquico semissupervisionado ativo.

Todos os algoritmos de aprendizado utilizados para a construção dos classificadores base destes cenários, assim como nos cenários de classificação multirrótulo, são os implementados na biblioteca de classes WEKA (Hall et al., 2009). Todos os métodos de classificação hierárquica, bem como o framework de avaliação para essa tarefa, estão disponíveis na ferramenta HARPIA ${ }^{10}$, uma das principais contribuições deste trabalho.

No primeiro cenário experimental foi utilizado o algoritmo de aprendizado J48, um algoritmo para indução de árvores de decisão, como base para a construção dos classificadores locais. Nos demais cenários, devido à necessidade de classificadores mais eficientes em termos de tempo de execução, os algoritmos de aprendizado incremental NB e $k$-NN foram utilizados para este fim.

O número de vizinhos utilizados para construção dos classificadores $k$-NN, para cada conjunto de dados, foi determinado por meio de avaliação experimental utilizando os valores de $k=\{1,3,5,7,9,11\}$, dos quais o valor que

\footnotetext{
${ }^{10}$ http://sites.labic.icmc.usp.br/jeanmetz/harpia.html
} 
Tabela 6.13: Valores de threshold para cada conjunto de dados hierárquicos.

\begin{tabular}{lcc}
\hline \hline Conjunto de dados & & Valor do threshold \\
\cline { 1 - 1 } HGlass & & 0,50 \\
Marsyas & 0,60 \\
RH & & 0,50 \\
SSD & 0,75 \\
G-Pfam & 0,50 \\
G-Prints & 0,60 \\
G-Prosite & 0,50 \\
G-Interpro & 0,50 \\
E-Pfam & 0,50 \\
E-Prints & 0,50 \\
E-Prosite & 0,50 \\
E-Interpro & 0,50 \\
Sequence & 0,50 \\
Phenotype & 0,50 \\
Cell-cycle & 0,50 \\
Church & 0,50 \\
Derisi & 0,50 \\
Eisen & 0,50 \\
Exp & 0,50 \\
Gasch-1 & 0,50 \\
Gasch-2 & 0,50 \\
SPO & 0,50 \\
\hline \hline & & \\
\hline
\end{tabular}

Tabela 6.14: Conjunto de dados hierárquicos utilizados em cada cenário experimental.

\begin{tabular}{cccccc}
\hline \hline Cenário & \multicolumn{5}{c}{ Domínio dos dados } \\
\cline { 2 - 6 } 1 & Ident. de vidros & Música & Proteínas GPCR & Proteínas EC & Funções de genes \\
\cline { 2 - 6 } 2 & $\checkmark$ & $\checkmark$ & $\checkmark$ & $\checkmark$ & \\
3 & & $\checkmark$ & $\checkmark$ & $\checkmark$ \\
4 & & $\checkmark$ & $\checkmark$ & $\checkmark$ \\
5 & & $\checkmark$ & $\checkmark$ & $\checkmark$ \\
\hline \hline
\end{tabular}

resultou a melhor $f_{1}^{\mu}$ foi escolhido. Assim, para o conjunto de dados $R H$ foi utilizado o valor de $k=11$, para os demais conjuntos de dados $k=3$.

Para os métodos hierárquicos, o limiar para classificação (threshold) foi determinado também por meio de avaliação experimental para cada conjunto de dados. Os valores testados começaram em 0,45 e seguiram até 0,90 com incrementos de 0,05. O valor de threshold específico para cada conjunto de dados é apresentado na Tabela 6.13.

Em cada cenário experimental foram utilizados diferentes combinações dos conjuntos de dados apresentados anteriormente (Seção 6.2.1). A escolha dos conjuntos de dados para cada cenário foi definida considerando a disponibilidade dos dados no momento em que o cenário foi avaliado, as características dos conjuntos e dados, como quantidade de exemplos e quantidade de monorrótulos, que contribuem para a complexidade do problema, e os objetivos elaborados para cada cenário. A distribuição dos conjuntos de dados em cada cenário é apresentada na Tabela 6.14.

No Cenário 1, por ser uma avaliação piloto, apenas um conjunto de dados foi utilizado. Para a execução dos experimentos do Cenário 2, por outro lado, os conjuntos de dados do domínio Funções de Genes não estavam dis- 
poniveis. Assim, somente os conjuntos de dados dos outros domínios foram utilizados. Para os demais cenários (3, 4 e 5), nos quais os métodos avaliados são mais complexos em termos de tempo computacional, decidimos não realizar a análise com os conjuntos de dados do domínio de Funções de Proteínas com descritores EC, nos quais a taxonomia de classes contém pelo menos 324 nós distribuídos em 5 níveis. O conjunto de dados para identificação de vidros, em contra-partida, não foi utilizado devido ao baixo número de exemplos (apenas 214) e à distribuição desses exemplos na taxonomia com 9 monorrótulos, o que impossibilitaria a execução dos métodos semissupervisionados considerando os objetivos e as configurações dos cenários elaborados.

Os cenários para avaliação experimental e suas respectivas configurações são apresentados a seguir.

\section{Cenário 1 - bootstrapping HBR:}

Este cenário foi elaborado em um estudo inicial com objetivo de avaliar a aplicabilidade de métodos de aprendizado semissupervisionado no contexto de classificação hierárquica.

Neste estudo foram avaliadas três variações do método HBR com classificadores binários SELF-TRAINING para cada classe (com exceção da raiz), as quais diferem entre si devido à estratégia para seleção dos exemplos de treinamento locais, mais especificamente como é composto o conjunto de exemplos não rotulados locais. Além disso, apenas o conjunto de dados G-Interpro foi utilizado - Tabela 6.12 na página 139.

O processo de preparação dos conjuntos de treinamento locais é ilustrado na Figura 6.15. Inicialmente, o conjunto de treinamento original é particionado de acordo com o método de validação cruzada utilizado, nesse caso 10 partições estratificadas (Witten et al., 2011), considerando apenas as classes folha para a estratificação, resultando nos conjuntos de treino $(T r)$ e teste $(T e)$ para cada partição (fold). Em seguida, para cada

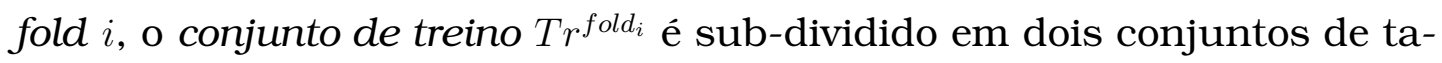
manhos distintos determinado pelo parâmetro InitSize (tamanho inicial do conjunto de exemplos rotulados). Desses dois conjuntos, um é utilizado como conjunto de exemplos rotulados $\left(T r^{l}\right)$ e o outro como conjunto de exemplos não rotulados $\left(T r^{u}\right)$. É importante lembrar que para simular o contexto semissupervisionado o número de exemplos não rotulados é muito maior que o número de exemplos rotulados para treinamento dos classificadores, ou seja, $\left|\operatorname{Tr}^{u}\right| \gg\left|\operatorname{Tr}^{l}\right|$. Após, esses dois conjuntos, $\operatorname{Tr}^{l}$ e $\operatorname{Tr}^{u}$, são utilizados para a formação dos conjuntos de treinamento locais, os quais são apresentados ao algoritmo base para a construção dos classificadores binários locais, i.e., $h_{y_{j}}$. 


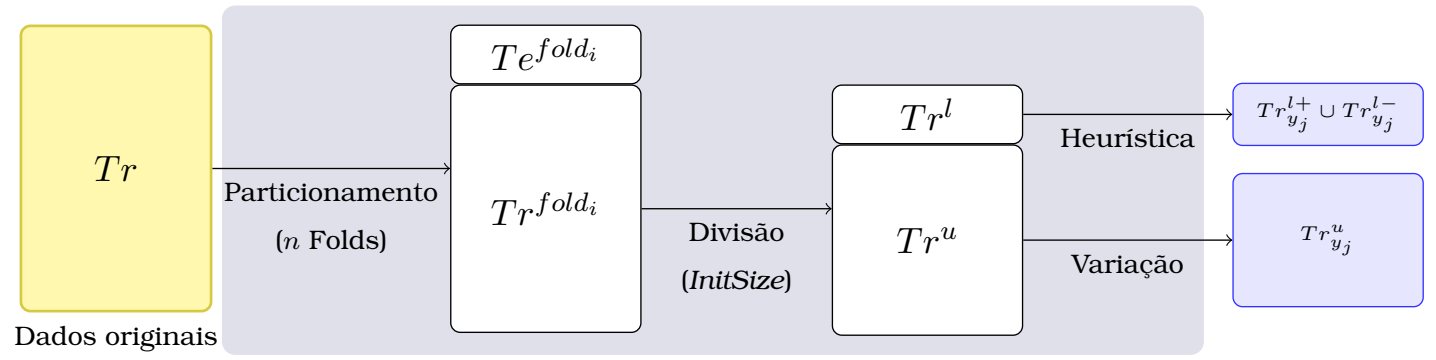

Figura 6.15: Preparação dos conjuntos de treinamento locais para o cenário 1.

Em cada uma das variações do método HBR propostas para esse estudo inicial, o conjunto de exemplos rotulados para a construção dos classificadores locais binários é determinado por meio da heurística S-Inclusive, apresentada na Seção 3.2.3.3. Os exemplos não rotulados $T r^{u}$, por outro lado, são utilizados de maneira distinta em cada uma das variações:

- variação $A$ - todos os exemplos presentes em $\operatorname{Tr}^{u}$ são utilizados como conjunto de exemplos não rotulados local, i.e., $T r_{y_{j}}^{u}=T r^{u}$;

- variação $B$ - os exemplos em $\operatorname{Tr}^{u}$ são primeiramente classificados pelos classificadores do nível anterior ao de $y_{j}$ e somente os exemplos preditos como positivos pelo classificador $h_{\uparrow y_{j}}$ são adicionados em $\operatorname{Tr}_{y_{j}}^{u}$; e

- variação $C$ - apenas os exemplos em $T r^{u}$ rotulados como positivos durante o processo de SELF-TRAINING do classificador $h_{\uparrow y_{j}}$ são inclusos em $\operatorname{Tr}_{y_{j}}^{u}$.

Essas três variações do método HBR foram comparadas a dois baselines:

- Classificador hierárquico com abordagem plana, descrito na Seção 3.2.3.1 na página 34 ; e

- Método HBR.

É importante observar que esses dois baselines são supervisionados e, portanto, são construídos considerando apenas o conjunto de exemplos de treinamento $\operatorname{Tr}^{l}$ inicial definido para cada valor de InitSize.

Cenário 2 - Avaliação das heurísticas para seleção dos conjuntos de treinamento local:

Como mencionado anteriormente, para todo método de classificação hierárquica local, é necessário que sejam selecionados os exemplos que compõem cada conjunto de treinamento local. Este cenário foi elaborado com objetivo de avaliar as diferentes heurísticas propostas na literatura 
para esse fim. Assim, as oito heurísticas descritas na Tabela 3.2 na página 39 são avaliadas com o método HBR.

Dessas oito heurísticas, as seis primeiras estão baseadas em operações de conjuntos que consideram tanto a taxonomia das classes quanto a classe mais específica de cada exemplo em $T_{r}$. As outras duas heurísticas são baseadas na distância entre exemplos. Uma descrição mais detalhada dessas oito heurísticas para determinar os exemplos positivos e negativos no conjunto de treinamento $T_{r}$ encontra-se em (Metz et al., 2011a).

Diferentemente dos experimentos realizados no contexto de classificação multirrótulo e no primeiro cenário experimental de classificação hierárquica, neste cenário e também nos Cenários 3, 4 e 5 para classificação hierárquica, o método de validação cruzada utilizado foi o de 5x2-partições, pois com esse método os conjuntos de teste resultantes após a partição dos dados é maior que os gerados pelo método de 10 partições, o que torna as estimativas de erros/acertos de classificação mais precisas (Dietterich, 1998). Os conjuntos de treinamento resultantes desse método de validação cruzada, por outro lado, contêm apenas 50\% dos exemplos, e não $90 \%$ como quando utilizadas 10 partições. Apesar da redução do número de exemplos de treinamento, os conjuntos são suficientemente grandes para a construção dos classificadores avaliados nesses cenários - ver Tabela 6.12 na página 139.

De acordo com Dietterich (1998), a validação cruzada com 10 partições apresenta maiores chances de erros to tipo $\mathrm{I}^{11}$, ao passo que a validação cruzada com 5x2 partições é menos suscetível a esse tipo de erro e, por esse motivo, mais indicada para comparação de diversos métodos em cenários complexos de classificação como os avaliados neste trabalho. Outra característica apresentada pelo autor, e que corrobora a escolha do método de 5x2 partições cruzadas, é a capacidade de mensurar a variação dos resultados devido á escolha dos conjuntos de treinamento.

Cenário 3 - Uso de duas perspectivas no contexto supervisionado e método HBR:

De maneira análoga ao cenário 1 da tarefa de classificação multirrótulo, este cenário foi elaborado com o objetivo de avaliar o impacto do uso de mais de uma perspectiva para a solução do problema de classificação hierárquica, utilizando uma extensão de um método amplamente conhecido na literatura. Este método, proposto neste trabalho, é chamado de

\footnotetext{
${ }^{11}$ Erro to tipo I representa o risco de detectar diferenças entre métodos quando elas não existem (Dietterich, 1998).
} 
$\operatorname{HBR}_{C o P}$.

Como mencionado anteriormente, o método $\mathrm{HBR}_{C o P}$ faz uso de dois algoritmos de aprendizado com bias distintos para a construção de dois classificadores binários, os quais são treinados para resolver o mesmo problema. Esses dois classificadores são utilizados em conjunto durante a classificação de novos exemplos, como descrito no Algoritmo 5.6.4 na página 102. Os algoritmos base para a construção dos classificadores binários são NB e $k$-NN.

Como base de comparação para avaliação da performance deste método, foram utilizados os métodos $\mathrm{HBR}_{\text {Low }}$ e HBR. O método HBR é utilizado para a construção de dois modelos, um considerando o algoritmo base NB e o segundo com o algoritmo base $k$-NN.

Cenário 4 - Aprendizado semissupervisionado baseado em desacordo:

Neste cenário, o objetivo é avaliar o método $\mathrm{HBR}_{C o P S S}$ para aprendizado hierárquico semissupervisionado baseado em desacordo. Para isso, a performance desse método é comparada à dos métodos $\mathrm{HBR}_{\text {Low }}$, HBR, $\operatorname{HBR}_{C o P}$ e $\mathrm{HBR}_{S T}$.

Como mencionado anteriormente, para simular um problema de aprendizado semissupervisionado é necessário dividir o conjunto de exemplos disponíveis em rotulados e não rotulados. A análise dos resultados obtidos em um estudo inicial sobre a aplicação do aprendizado semissupervisionado no contexto da classificação hierárquica (resultados do Cenário 1, página 147) possibilitou identificar algumas estratégias distintas para essa divisão do conjunto de exemplos original, assim como algumas limitações das estratégias utilizadas, como escassez de exemplos de treinamento e a falta de exemplos que representem todas as classes da taxonomia para a construção dos classificadores relacionados às classes mais profundas da hierarquia (Metz \& Freitas, 2009). Desse modo, para minimizar esses problemas e possibilitar que um maior número de exemplos associados a cada monorrótulo da taxonomia esteja presente no conjunto de treinamento local, a estratégia de preparação dos conjuntos de treinamento locais para os cenários de aprendizado semissupervisionado hierárquico (Cenários 4 e 5) foi modificada em relação à utilizada no Cenário 1. Nessa nova estratégia, a heurística S-Inclusive para seleção dos exemplos positivos e negativos para cada monorrótulo é aplicada antes da divisão em rotulados e não rotulados, a qual é realizada sobre o conjunto resultante da aplicação da heurística, conforme ilustrado na Figura 6.16.

Os valores utilizados para a configuração do parâmetro InitSize nos Ce- 


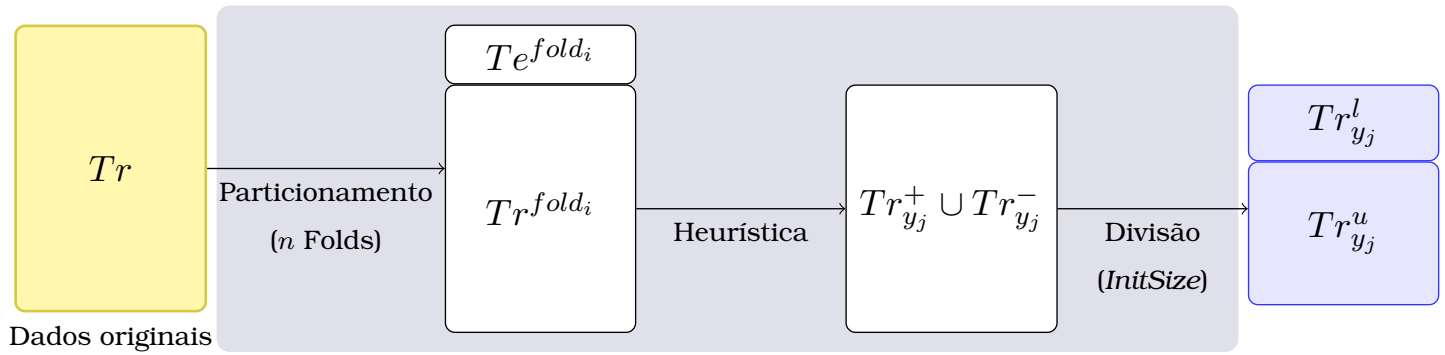

Figura 6.16: Preparação dos conjuntos de treinamento locais para os cenários 4 e 5.

nários 4 e 5 para avaliação do aprendizado semissupervisionado no contexto de classificação hierárquica são 20, 40, 80 e 120, dos quais 50\% dos exemplos são positivos e 50\% negativos.

Os métodos de aprendizado baseados em desacordo e/ou duas perspectivas são construídos a partir dos dois algoritmos base de aprendizado NB e $k$-NN. Os métodos HBR e $\mathrm{BR}_{S T}$, por outro lado, são utilizados para a construção de dois modelos de classificação, sendo um para cada algoritmo base de aprendizado. Além disso, os resultados obtidos com o método $\mathrm{HBR}_{C o P S S}$ também são confrontados com os obtidos pelos métodos supervisionados treinados com todos os dados do conjunto original $\mathrm{Tr}$, pois esses resultados podem ser considerados um limite superior para a predição em relação aos resultados obtidos utilizando conjuntos de treinamento com menos exemplos.

Cenário 5 - Aprendizado semissupervisionado ativo:

Neste cenário, o objetivo é avaliar se os métodos semissupervisionados podem melhorar a partir da inclusão do aprendizado ativo no processo de construção dos classificadores locais. Para isso, é definido um número máximo de consultas que podem ser realizadas ao "oráculo" para a classificação dos pontos de contenção. O “oráculo”, por sua vez, é simulado como no contexto multirrótulo por meio do acesso aos rótulos verdadeiros dos exemplos. Desse modo, para um número máximo de consultas (pontos de contenção), o "oráculo" usa esses rótulos verdadeiros para decidir a classificação com relação à cada classe $y_{j}$.

Os métodos avaliados neste cenário são: $\mathrm{HBR}_{L o w}$, HBR, $\mathrm{HBR}_{S T}, \mathrm{HBR}_{C o P S S}$, HBR $_{C o P S S+A L}$ e HBR CoTesting.

Como nos cenários anteriores, são construídos dois modelos para os métodos monoperspectiva $\mathrm{HBR}$ e $\mathrm{HBR}_{S T}$, um com o algoritmo de aprendizado NB e o outro com o algoritmo $k$-NN.

Para uma comparação mais conservadora entre os métodos com apren- 
dizado ativo e métodos que não utilizam essa estratégia de aprendizado, os valores do parâmetro InitSize devem ser ajustados, de modo que não haja vantagem em função das consultas ao "oráculo". Nesse sentido, o número de consultas permitidas aos métodos "ativos" deve ser somado ao valor de InitSize. O valor resultante dessa soma indica a qual configuração de InitSize para os métodos "não ativos" essa configuração deve ser comparada. A configuração desses valores para este cenário é apresentada na Tabela 6.15.

Tabela 6.15: Valores de configuração para algoritmos de aprendizado ativo.

\begin{tabular}{cccc}
\hline \hline $\begin{array}{c}\text { Aprendizado não ativo } \\
\text { InitSize }\end{array}$ & & \multicolumn{2}{c}{ Aprendizado ativo } \\
\cline { 3 - 4 } \cline { 4 - 4 } InitSize & \#Consultas \\
\hline 20 & & 10 & 10 \\
80 & & 10 & 30 \\
120 & & 10 & 70 \\
& & 10 & 110 \\
\hline \hline
\end{tabular}

\subsubsection{Resultados e discussão}

Nesta seção são apresentados e discutidos os resultados obtidos para a avaliação experimental de cada cenário relacionado à classificação hierárquica. Os métodos propostos neste trabalhos para a classificação hierárquica, categorizados na Tabela 6.16, são avaliados considerando os diferentes cenários descritos anteriormente. Na Tabela 6.17, é mostrado para cada cenário experimental, o método analisado e os métodos utilizados como base de comparação.

Tabela 6.16: Categorização dos métodos propostos

\begin{tabular}{|c|c|c|c|c|c|}
\hline \multirow[t]{2}{*}{ Método } & \multicolumn{5}{|c|}{ Hierárquico } \\
\hline & Sup & SS & MonoP & $\mathrm{CoP}$ & AA \\
\hline $\mathrm{HBR}_{\text {Low }}$ & $\checkmark$ & & $\checkmark$ & & \\
\hline $\mathrm{HMR}_{E x t}$ & $\checkmark$ & & $\checkmark$ & & \\
\hline $\mathrm{HMR}_{\text {Ext }}$ Multi & $\checkmark$ & & $\checkmark$ & & \\
\hline HDR & $\checkmark$ & & & $\checkmark$ & \\
\hline $\mathrm{HBR}_{C o P}$ & $\checkmark$ & & & $\checkmark$ & \\
\hline $\mathrm{HBR}_{S T}$ & & $\checkmark$ & $\checkmark$ & & \\
\hline $\mathrm{HBR}_{C o P S S}$ & & $\checkmark$ & & $\checkmark$ & \\
\hline HBR $_{C o P S S+A L}$ & & $\checkmark$ & & $\checkmark$ & $\checkmark$ \\
\hline HBR $_{\text {CoTesting }}$ & & & & $\checkmark$ & $\checkmark$ \\
\hline
\end{tabular}

Tabela 6.17: Métodos comparados em cada cenário da avaliação experimental da classificação hierárquica.

\begin{tabular}{llccccc}
\hline \hline Cenário & Método & $\mathrm{HBR}_{\text {Low }}$ & $\mathrm{HBR}$ & $\mathrm{HBR}_{C o P}$ & $\mathrm{HBR}_{S T}$ & $\mathrm{HBR}_{C o P S S} \mathrm{HBR}_{C o T e s t i n g}$ \\
3 - supervisionado & $\mathrm{HBR}_{C o P}$ & $\checkmark$ & $\checkmark$ & & & \\
- semissupervisionado & $\mathrm{HBR}_{C o P S S}$ & $\checkmark$ & $\checkmark$ & $\checkmark$ & $\checkmark$ & \\
5 - aprendizado ativo & $\mathrm{HBR}_{C o P S S+A L}$ & $\checkmark$ & $\checkmark$ & & & $\checkmark$ \\
\hline \hline
\end{tabular}




\subsubsection{Cenário 1 - bootstrapping HBR:}

Como mencionado anteriormente, esse cenário foi elaborado em um estudo inicial cujo objetivo foi avaliar o uso do aprendizado semissupervisionado baseado em bootstrapping no contexto de classificação hierárquica, para o qual foram propostas três variações de método HBR utilizando classificadores SELFTRAINING para cada classe da hierarquia, exceto a raiz.

Nessas três variações, os exemplos de treinamento para a construção dos classificadores iniciais são definidos por meio da heurística S-Inclusive. Entretanto, uma vez que os classificadores binários destes métodos são construídos iterativamente por meio do algoritmo SELF-TRAINING, os exemplos não rotulados também devem ser selecionados para cada classificador local. O que diferencia cada variação proposta é a estratégia utilizada para a seleção dos exemplos não rotulados:

- variação $A$ - todos os exemplos presentes em $\operatorname{Tr}^{u}$ são utilizados como conjunto de exemplos não rotulados local, i.e., $\operatorname{Tr}_{y_{j}}^{u}=\operatorname{Tr}^{u}$;

- variação $B$ - os exemplos em $\operatorname{Tr}^{u}$ são primeiramente classificados pelos classificadores do nível anterior ao de $y_{j}$ e somente os exemplos preditos como positivos pelo classificador $h_{\uparrow_{j}}$ são adicionados em $\operatorname{Tr}_{y_{j}}^{u}$; e

- variação $C$ - apenas os exemplos em $\operatorname{Tr}^{u}$ rotulados como positivos durante o processo de SELF-TRAINING do classificador $h_{\uparrow y_{j}}$ são inclusos em $\operatorname{Tr}_{y_{j}}^{u}$.

Os valores utilizados neste cenário para InitSize são 3\% e 5\% do número de exemplos contidos no conjunto de dados original, resultando em 223 e 372 exemplos, respectivamente. A medida de avaliação utilizada é $A c c_{\text {global }}^{\text {Norm }}$, apresentada anteriormente na Seção 3.3.1 na página 49. Os resultados obtidos são apresentados na Tabela 6.18, a partir da qual observa-se que os métodos hierárquicos locais são realmente mais eficazes que o método plano. Porém, não há diferenças entre o método base HBR com as suas variações semissupervisionadas $A, B$ ou $C$.

Uma possivel razão para os métodos baseados em SELF-TRAINING não terem obtido melhores resultados que o método supervisionado está relacionado à propagação dos erros de classificação cometidos nos primeiros níveis da hierarquia. Além disso, devido às características inerentes da classificação hierárquica, quanto mais profunda a classe da hierarquia, menor é o número de exemplos a ela associados. No contexto de aprendizados semissupervisionado esse fato é ainda mais grave.

Um fato importante observado a partir da análise dos resultados desse cenário está relacionado à estratégia de divisão dos conjuntos de dados para 


\begin{tabular}{|c|c|c|}
\hline InitSize & Método & $A c c_{\text {global }}^{\text {Norm }}$ \\
\hline \multirow{5}{*}{223} & plana & $0.73(0.01)$ \\
\hline & HBR & $0.83(0.00)$ \\
\hline & variação A & $0.83(0.01)$ \\
\hline & variação $B$ & $0.83(0.01)$ \\
\hline & variação C & $0.83(0.01)$ \\
\hline \multirow{5}{*}{372} & plana & $0.73(0.01)$ \\
\hline & HBR & $0.84(0.00)$ \\
\hline & variação A & $0.84(0.00)$ \\
\hline & variação $B$ & $0.84(0.00)$ \\
\hline & variação C & $0.84(0.00)$ \\
\hline
\end{tabular}

Tabela 6.18: Resultados para o Cenário 1 da avaliação experimental da classificação hierárquica.

simulação do contexto semissupervisionado. Com a divisão dos dados em rotulados e não rotulados antes da aplicação da heurística de seleção dos conjuntos de treinamento locais, menos exemplos rotulados foram disponibilizados para seleção por meio da heurística, o que acarretou a escassez de exemplos de treinamento positivos para algumas classes da taxonomia, em especial para as classes mais profundas e, consequentemente, a degradação mais acentuada de alguns dos classificadores locais. Esses resultados motivaram a redefinição da estratégia utilizada para simular o contexto semissupervisionado para a avaliação experimental dos outros métodos propostos e a avaliação de diferentes heurísticas para a seleção dos conjuntos de treinamento locais. Além disso, os resultados deste cenário serviram como base para a continuidade do projeto e elaboração de outros métodos para classificação hierárquica semissupervisionada.

\subsubsection{Cenário 2 - Avaliação das heurísticas para seleção dos conjuntos de treinamento local}

Todos os resultados apresentados para este cenário foram obtidos utilizando validação cruzada com 5x2 partições pareadas, i.e., as mesmas partições de treino e teste foram utilizadas para avaliar a eficácia das diferentes configuração do método HBR. Para analisar a existência de diferença entre o impacto das heurísticas de seleção de conjuntos de treinamento locais na performance dos classificadores hierárquicos, o teste de Friedman, com a hipótese nula de que os resultados do método HBR utilizando qualquer heurística são equivalentes, foi utilizado. Quando a hipótese nula é rejeitada pelo teste de Friedman (Demsar, 2006), com confiança de 95\%, o pós-teste de Nemenyi (Demsar, 2006) é utilizado para detectar quais diferenças entre os métodos são significativas. De acordo com esse teste, a eficácia de dois métodos é significativamente diferente sempre que seus correspondentes rankings médios diferirem por pelo menos um determinado valor de diferença crítica (CD). 
Para possibilitar a comparação justa das heurísticas baseadas em operações de conjunto e das heurísticas baseadas em distância, o número de exemplos selecionados para o conjunto de exemplos negativos pelas heurísticas baseadas em distância, $\eta$, foi mantido igual ao número de exemplos positivos. Além disso, para a heurística Best $\eta$ Locals foram utilizados cinco valores diferentes para o parâmetro $k$, são eles: 1, 3, 5, 7 e 9 .

O método HBR, implementado no framework HARPIA com estratégia de predição top-down, foi utilizado para avaliar o impacto das oito diferentes heurísticas de seleção do conjunto de treinamento local descritas na Tabela 3.2 na página 39. HBR foi executado utilizando dois diferentes algoritmos de classificação plana para construir os classificadores binários locais: o algoritmo de árvore de decisão J48 e NB, ambos implementados na biblioteca WEKA (Witten et al., 2011).

Os experimentos foram realizados com 13 dos 23 conjuntos de dados descritos na Tabela 6.12, com dados de três domínios distintos:

- Identificação de vidros;

- Gêneros musicais; e

- Funções de proteínas GPCR e Enzimas.

Os resultados obtidos na avaliação experimental desse cenário mostram que não há diferença estatística entre as heurísticas Inclusive, S-Inclusive e L-Inclusive, como pode ser observado pelos diagramas de ranqueamento apresentados na Figura 6.17. Nessa figura é mostrado graficamente o resultado dos post-hoc teste de Nemenyi (Demsar, 2006), nos quais a linha principal no eixo $X$ representa o ranking médio obtido para cada heurística com base em experimentos realizados com os 13 conjuntos de dados.

Observe que valores menores do ranking médio são melhores. As linhas abaixo do eixo $X$ conectam grupos que não apresentam diferença estatística. A diferença crítica (CD) é mostrada acima do eixo $X$. Na Figura 6.17 é possível observar também que as heurísticas baseadas em distância são significativamente piores que as heurísticas baseadas em operações de conjuntos. $\mathrm{O}$ estudo completo a respeito do uso das diferentes heurísticas pode ser encontrado em (Metz et al., 2010, 2011a), no qual também é avaliada a influência do grau de inclusão na eficácia geral do algoritmo quando utilizadas heurísticas baseadas em operação de conjuntos, bem como a influência do parâmetro $k$ para a heurística B-Local.

Na Tabela 6.19 estão sumarizados os resultados de alguns trabalhos relacionados que mostram a avaliação de um subconjunto das oito heurísticas, conjuntamente com os resultados de nosso trabalho, no qual todas heurísticas são avaliadas. 


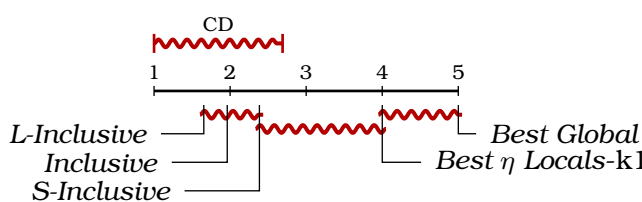

(a) Algoritmo de aprendizado base $\mathrm{J} 48$

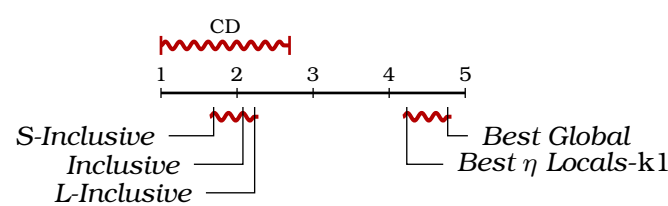

(b) Algoritmo de aprendizado base NB

Figura 6.17: Representação gráfica do post-hoc teste de Nemenyi. Métodos conectados não apresentam diferença estatísticas (para $p<0,05$ ).

Tabela 6.19: Heurísticas consideradas em trabalhos relacionados ( $\Delta$ melhor desempenho, e $\mathbf{\nabla}$ pior desempenho).

\begin{tabular}{|c|c|c|c|c|c|c|c|c|}
\hline \multirow{2}{*}{ Referência } & \multicolumn{8}{|c|}{ Heurística } \\
\hline & Exclusive & L-Exclusive & L-Inclusive & Inclusive & S-Inclusive & S-Exclusive & Best Global & Best $\eta$ Locals \\
\hline Ceci \& Malerba (2003) & & & & & $\Delta$ & $\nabla$ & & \\
\hline Eisner et al. (2005) & $\boldsymbol{\nabla}$ & $\boldsymbol{\nabla}$ & $\Delta$ & $\Delta$ & & & & \\
\hline Fagni \& Sebastiani (2007) & & & $\Delta$ & & $\Delta$ & & $\boldsymbol{\nabla}$ & $\boldsymbol{\nabla}$ \\
\hline Metz et al. (2011a) & $\boldsymbol{\nabla}$ & $\boldsymbol{\nabla}$ & $\Delta$ & $\Delta$ & $\Delta$ & $\mathbf{\nabla}$ & $\mathbf{\nabla}$ & $\mathbf{\nabla}$ \\
\hline
\end{tabular}

\subsubsection{Cenário 3 - Uso de duas perspectivas no contexto supervisionado e método HBR}

Para avaliação deste cenário experimental foram utilizados 18 conjuntos de dados dos 23 apresentados na Tabela 6.12, correspondentes aos seguintes domínios:

- Gêneros musicais;

- Funções de proteínas GPCR; e

- Funções gênicas.

Em uma análise inicial foi observado que para alguns conjuntos de dados os resultados são muito semelhantes. Assim, para facilitar o entendimento da análise deste e dos demais cenários para avaliação da classificação hierárquica, esses conjuntos de dados foram organizados em grupos, a partir dos quais foi escolhido um conjunto de dados para representar cada grupo nas seções de análise dos resultados de cada cenário. Entretanto, os resultados completos para todos os conjuntos de dados encontram-se disponíveis em http://sites.labic.icmc.usp.br/jeanmetz/harpia.html.

Os grupos resultantes são apresentados na Tabela 6.20.

Os valores de média $f_{1}^{\mu}$ e seus respectivos desvio padrão obtidos para esses conjuntos de dados, utilizando os métodos avaliados neste cenário, são apresentados na Tabela 6.21. Além disso, nessa tabela são apresentados, para cada conjunto de dados, os valores de $f_{1}^{\mu}$ obtidos com o método baseline $\mathrm{HBR}_{\text {Low }}$.

A representação visual dos resultados é apresentada na Figura 6.18, na qual é possível analisar o comportamento de cada método à medida que o número de exemplos de treinamento aumenta. 
Tabela 6.20: Organização dos conjuntos de dados hierárquicos em grupos para análise dos resultados.

\begin{tabular}{|c|c|c|}
\hline Grupo & Conjuntos de dados & Representante \\
\hline 1 & Cell-cycle e Eisen & Cell-cycle \\
\hline 2 & Church, Derisi e SPO & Church \\
\hline 3 & Exp, Gasch-1, Gasch-2 e Sequence & $\operatorname{Exp}$ \\
\hline 4 & Phenotype & Phenotype \\
\hline 5 & $R H$ & $R H$ \\
\hline 6 & Marsyas, SSD e IOIHC & Marsyas \\
\hline 7 & G-Pfam & G-Pfam \\
\hline 8 & G-Prints, G-Prosite e G-Interpro & G-Prints \\
\hline
\end{tabular}

Tabela 6.21: Valores de $f_{1}^{\mu}$ para o Cenário 3 de classificação hierárquica.

\begin{tabular}{|c|c|c|c|c|c|c|}
\hline InitSize & HBR (NB) & HBR $(k-\mathrm{NN})$ & $\mathrm{HBR}_{C o P}$ & HBR (NB) & HBR $(k-\mathrm{NN})$ & $\mathrm{HBR}_{C o P}$ \\
\hline & \multicolumn{3}{|c|}{ Cell-cycle } & \multicolumn{3}{|c|}{ Church } \\
\hline 20 & $\mathbf{0 , 1 8}(0,01)$ & $\mathbf{0 , 1 8}(0,03)$ & $0,17(0,01)$ & $\mathbf{0 , 1 6}(0,02)$ & $0,14(0,02)$ & $\mathbf{0 , 1 6}(0,02)$ \\
\hline 40 & $0,20(0,01)$ & $0,20(0,02)$ & $0,21(0,01)$ & $\mathbf{0 , 1 6}(0,01)$ & $0,15(0,02)$ & $\mathbf{0 , 1 6}(0,01)$ \\
\hline 80 & $0,23(0,01)$ & $0,22(0,02)$ & $\mathbf{0 , 2 4}(0,01)$ & $\mathbf{0 , 1 6}(0,02)$ & $\mathbf{0 , 1 6}(0,02)$ & $\mathbf{0 , 1 6}(0,02)$ \\
\hline 120 & $\mathbf{0 , 2 5}(0,01)$ & $0,23(0,01)$ & $\mathbf{0 , 2 5}(0,02)$ & $0,15(0,01)$ & $\mathbf{0 , 1 7}(0,01)$ & $0,16(0,01)$ \\
\hline All & $0,28(0,01)$ & $0,23(0,21)$ & $\mathbf{0 , 2 9}(0,01)$ & $0,15(0,01)$ & $0,12(0,01)$ & $\mathbf{0 , 1 6}(0,01)$ \\
\hline \multirow[t]{2}{*}{$\mathrm{HBR}_{\text {Low }}$} & \multicolumn{3}{|c|}{0,25} & \multicolumn{3}{|c|}{0,25} \\
\hline & \multicolumn{3}{|c|}{ Exp } & \multicolumn{3}{|c|}{ Phenotype } \\
\hline 20 & $0,16(0,02)$ & $\mathbf{0 , 1 7}(0,02)$ & $0,16(0,02)$ & $\mathbf{0 , 1 3}(0,02)$ & $\mathbf{0 , 1 3}(0,03)$ & $\mathbf{0 , 1 3}(0,02)$ \\
\hline 40 & $\mathbf{0 , 1 9}(0,02)$ & $\mathbf{0 , 1 9}(0,02)$ & $\mathbf{0 , 1 9}(0,02)$ & $0,13(0,04)$ & $\mathbf{0 , 1 4}(0,03)$ & $0,13(0,04)$ \\
\hline 80 & $\mathbf{0 , 2 3}(0,03)$ & $0,22(0,01)$ & $\mathbf{0 , 2 3}(0,03)$ & $0,16(0,03)$ & $\mathbf{0 , 1 7}(0,02)$ & $\mathbf{0 , 1 7}(0,02)$ \\
\hline 120 & $0,24(0,03)$ & $0,22(0,01)$ & $\mathbf{0 , 2 4}(0,03)$ & $0,17(0,02)$ & $0,17(0,02)$ & $\mathbf{0 , 1 8}(0,02)$ \\
\hline All & $\mathbf{0 , 2 4}(0,02)$ & $\mathbf{0 , 2 4}(0,01)$ & $\mathbf{0 , 2 4}(0,03)$ & $0,12(0,02)$ & $\mathbf{0 , 1 3}(0,02)$ & $0,12(0,02)$ \\
\hline \multirow[t]{2}{*}{$\mathrm{HBR}_{\text {Low }}$} & & 0,25 & & & 0,27 & \\
\hline & \multicolumn{3}{|c|}{$R H$} & \multicolumn{3}{|c|}{ Marsyas } \\
\hline 20 & $\mathbf{0 , 4 5}(0,05)$ & $0,24(0,08)$ & $\mathbf{0 , 4 5}(0,04)$ & $0,52(0,04)$ & $0,49(0,04)$ & $\mathbf{0 , 5 3}(0,04)$ \\
\hline 40 & $\mathbf{0 , 4 7}(0,03)$ & $0,27(0,07)$ & $\mathbf{0 , 4 7}(0,03)$ & $\mathbf{0 , 5 9}(0,02)$ & $0,51(0,02)$ & $\mathbf{0 , 5 9}(0,02)$ \\
\hline 80 & $0,48(0,01)$ & $0,30(0,07)$ & $\mathbf{0 , 4 9}(0,01)$ & $0,61(0,01)$ & $0,54(0,01)$ & $\mathbf{0 , 6 2}(0,01)$ \\
\hline 120 & $0,49(0,01)$ & $0,32(0,07)$ & $\mathbf{0 , 5 0}(0,01)$ & $0,62(0,02)$ & $0,56(0,02)$ & $\mathbf{0 , 6 3}(0,02)$ \\
\hline All & $0,51(0,00)$ & $\mathbf{0 , 5 9}(0,01)$ & $0,52(0,00)$ & $0,66(0,00)$ & $0,63(0,00)$ & $\mathbf{0 , 6 8}(0,00)$ \\
\hline \multirow[t]{2}{*}{$\mathrm{HBR}_{\text {Low }}$} & & 0,19 & & & 0,19 & \\
\hline & \multicolumn{3}{|c|}{ G-Pfam } & \multicolumn{3}{|c|}{ G-Prints } \\
\hline 20 & $\mathbf{0 , 5 1}(0,02)$ & $0,49(0,01)$ & $\mathbf{0 , 5 1}(0,02)$ & $\mathbf{0 , 5 0}(0,04)$ & $0,34(0,07)$ & $0,45(0,05)$ \\
\hline 40 & $\mathbf{0 , 5 2}(0,01)$ & $0,51(0,02)$ & $\mathbf{0 , 5 2}(0,02)$ & $\mathbf{0 , 5 5}(0,02)$ & $0,39(0,04)$ & $0,52(0,04)$ \\
\hline 80 & $\mathbf{0 , 5 4}(0,02)$ & $0,53(0,02)$ & $\mathbf{0 , 5 4}(0,02)$ & $\mathbf{0 , 5 7}(0,02)$ & $0,43(0,05)$ & $0,54(0,04)$ \\
\hline 120 & $0,54(0,01)$ & $0,54(0,03)$ & $\mathbf{0 , 5 5}(0,02)$ & $\mathbf{0 , 5 9}(0,02)$ & $0,49(0,04)$ & $0,57(0,02)$ \\
\hline All & $0,64(0,00)$ & $\mathbf{0 , 6 6}(0,01)$ & $0,65(0,01)$ & $0,72(0,01)$ & $\mathbf{0 , 7 9}(0,01)$ & $0,73(0,01)$ \\
\hline $\mathrm{HBR}_{\text {Low }}$ & \multicolumn{3}{|c|}{0,34} & \multicolumn{3}{|c|}{0,07} \\
\hline
\end{tabular}

Os conjuntos de dados representados por Cell-cycle somente superam o classificador baseline quando são construídos utilizando um grande número de exemplos de treinamento ( $\mathrm{All}$ ). Para outros valores de InitSize e métodos, o valor de $f_{1}^{\mu}$ obtido é sempre abaixo do baseline. Esses resultados são muito similares aos obtidos com o conjunto de dados Exp, com exceção da configuração com InitSize All, para a qual nenhum método superou o baseline $\mathrm{HBR}_{\text {Low }}$.

Considerando o conjunto de dados Church e todas as configurações de InitSize, todos os métodos apresentaram performance significativamente piores que o baseline. Um fato interessante desse conjunto de dados é que, mesmo utilizando todos os exemplos rotulados disponíveis para a construção dos classificadores, o método HBR $(k-\mathrm{NN})$ apresentou a pior performance. Esse comportamento se repete para o conjunto de dados Phenotype, mas nesse caso com todos os métodos. 


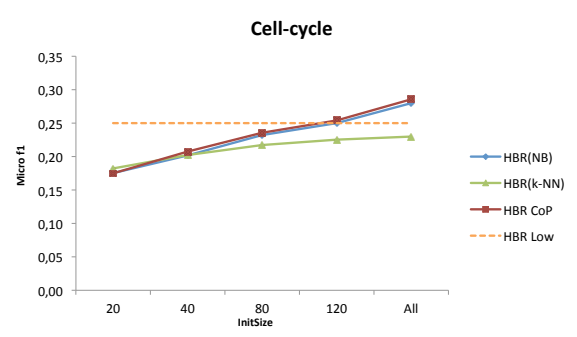

(a) Conjunto de dados Cell-cycle

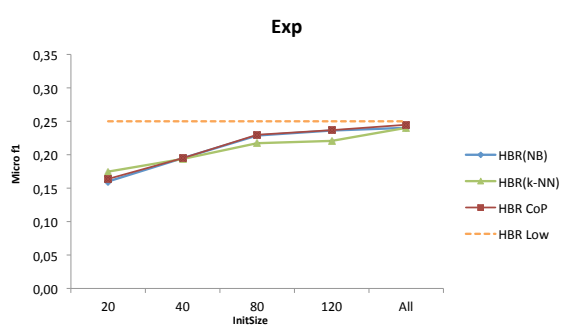

(c) Conjunto de dados Exp

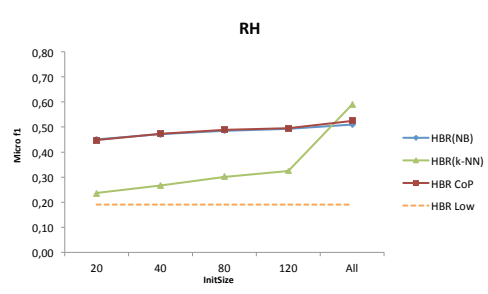

(e) Conjunto de dados $R H$

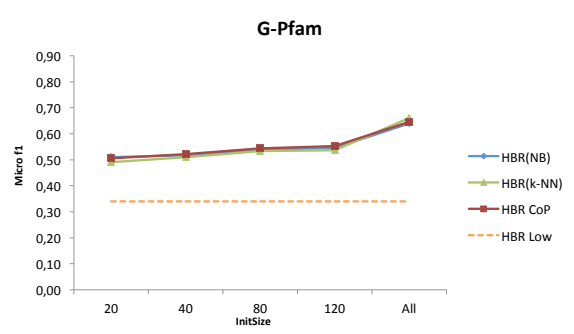

(g) Conjunto de dados G-Pfam

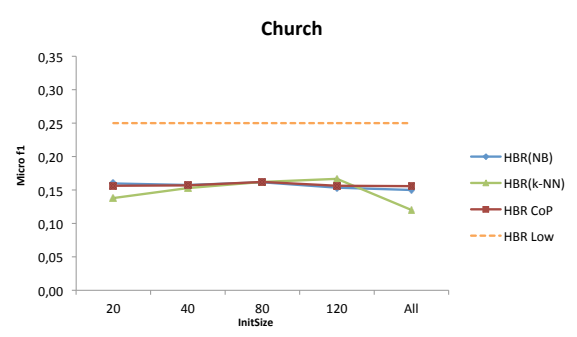

(b) Conjunto de dados Church

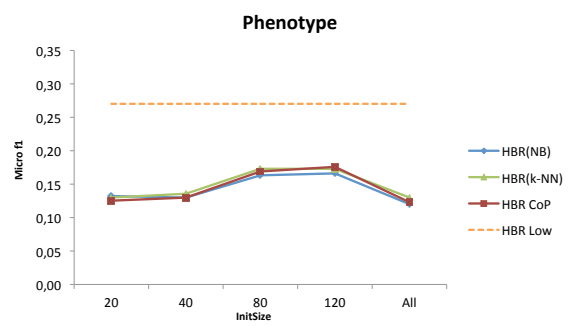

(d) Conjunto de dados Phenotype

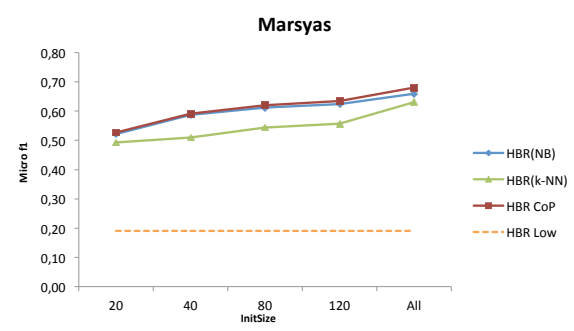

(f) Conjunto de dados Marsyas

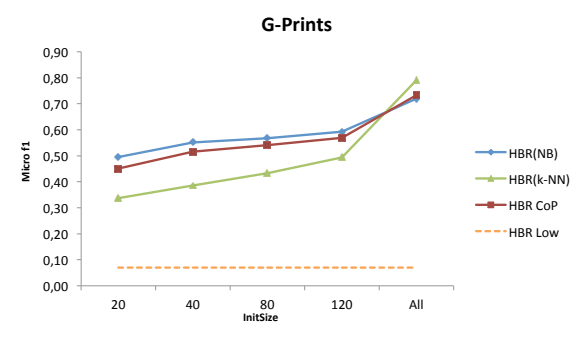

(h) Conjunto de dados G-Prints

Figura 6.18: Valores da medida $f_{1}^{\mu}$ para o Cenário 3 de classificação hierárquica.

Com relação aos conjuntos de dados dos outros grupos, a performance global do classificador hierárquico foi melhor que o baseline $\mathrm{HBR}_{\text {Low }}$, o que indica que houve de fato o aprendizado das classes do problema. Para os conjuntos de dados RH, G-Prints e os demais nos grupos representados por esses dois conjuntos de dados, o método HBR $(k-\mathrm{NN})$ somente superou os outros métodos quando todos os exemplos foram apresentados para a construção do modelo. Para outros valores de InitSize, esse método foi sempre significativamente pior que os demais. 
Para os conjuntos de dados representados por Marsyas houve pouca diferença de performance entre os métodos, pois somente o método HBR $(k-\mathrm{NN})$ apresentou valor de $f_{1}^{\mu}$ ligeiramente menor que os outros métodos para todos os valores de InitSize, mas em todos os casos os resultados sempre foram significativamente melhores que $\mathrm{HBR}_{\text {Low }}$. Para o conjunto G-Pfam, por outro lado, não houve diferenças significativas entre os três métodos avaliados, todos eles significativamente melhores que $\mathrm{HBR}_{\text {Low }}$.

Uma comparação do desempenho dos métodos HBR (NB) e HBR ( $k$-NN) em relação ao método $\mathrm{HBR}_{C o P}$ é apresentada na Tabela 6.22, na qual são mostrados em termos percentuais os casos de melhora ( $\boldsymbol{\Delta}$ ) ou degradação ( $\nabla$ ), utilizando todos os exemplos rotulados disponíveis (InitSize All). Para facilitar a análise dessa comparação, na coluna $\mathrm{HBR}_{C o P} f_{1}^{\mu}$ são mostrados os valores da medida $f_{1}^{\mu}$ resultantes do método $\mathrm{HBR}_{C o P}$ para InitSize All. A partir dessa análise observa-se que o método coperspectiva $\mathrm{HBR}_{C o P}$ apresentou melhora para a maioria dos casos, principalmente em relação ao método monoperspectiva treinado com o algoritmo base NB.

Tabela 6.22: Comparação do método $\mathrm{HBR}_{C o P}$ com os métodos monoperspectiva HBR (NB) e HBR ( $k$-NN).

\begin{tabular}{|c|c|c|c|}
\hline & $\mathrm{HBR}_{C o P} f_{1}^{\mu}$ & HBR (NB) & HBR $(k-\mathrm{NN})$ \\
\hline Cell-cycle & $0,29(0,01)$ & $\nabla 01 \%$ & $\nabla 20 \%$ \\
\hline Church & $0,16(0,01)$ & $\nabla 01 \%$ & $\nabla 20 \%$ \\
\hline $\operatorname{Exp}$ & $0,24(0,03)$ & - & $\nabla 01 \%$ \\
\hline Phenotype & $0,12(0,02)$ & $\nabla 01 \%$ & $\Delta 04 \%$ \\
\hline$R H$ & $0,52(0,00)$ & $\nabla 02 \%$ & $13 \%$ \\
\hline Marsyas & $0,68(0,00)$ & $\nabla 04 \%$ & . $07 \%$ \\
\hline G-Pfam & $0,65(0,01)$ & $\nabla 01 \%$ & $\Delta 02 \%$ \\
\hline G-Prints & $0,73(0,01)$ & $\nabla 02 \%$ & $\Delta 07 \%$ \\
\hline
\end{tabular}

Outra informação interessante latente nos gráficos apresentados na Figura 6.18 está relacionada à baixa qualidade dos classificadores construídos com os conjuntos de dados de funções gênicas. Um dos prováveis motivos para essa baixa performance pode ser o pré-processamento realizado nesses conjuntos, uma vez que parte dos exemplos desses conjuntos de dados é hierárquico e multirrótulo, i.e., podem estar associados a mais de uma classe em cada nível da hierarquia. Desse modo, a escolha aleatória de apenas um desses ramos de classes associadas aos exemplos pode ter resultado em um conjunto de exemplos com muita sobreposição de classes e ruídos, o que justifica, em parte, a baixa qualidade dos classificadores.

Com relação ao uso das duas perspectivas para classificação por meio de cooperação, as conclusões são muito semelhantes às obtidas para o contexto multirrótulo plano, uma vez que neste caso, o método $\mathrm{HBR}_{C o P}$ também é "dominado" por uma das perspectivas. No entanto, neste cenário hierárquico, a tendência é acompanhar o resultado da perspectiva que utilizou o algoritmo base NB, como pode ser observado pelos gráficos apresentados na Figura 6.18. 
Para entender melhor esse comportamento, faz-se necessária uma análise mais detalhada do processo de aprendizado dos classificadores nas diferentes perspectivas em cada iteração, considerando, por exemplo, o percentual de exemplos classificados de maneira diferente pelos dois classificadores, assim como o grau de confiança dessas predições.

No contexto de hierarquias, é possível realizar uma análise mais detalhada, considerando os diferentes niveis da taxonomia, para tentar entender os fatores que influenciam na qualidade de predição dos classificadores hierárquicos. Para isso, considere os gráficos apresentados na Figura 6.19, na qual são mostrados os valores de $f_{1}^{\mu}$ por nível da hierarquia para três conjuntos de dados representante de grupos, especificamente os conjuntos Exp, Marsyas e G-Pfam. Os valores de $f_{1}^{\mu}$ apresentados nesses gráficos foram obtidos considerando InitSize 40 e InitSize All.

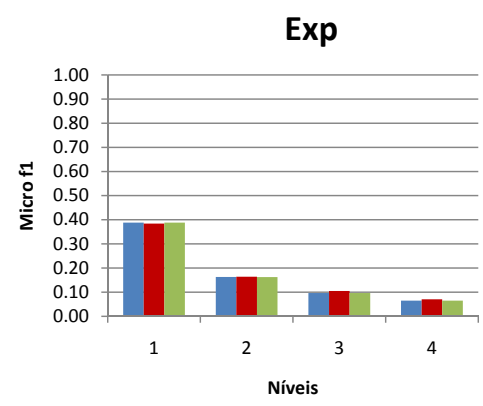

(a) Exp - InitSize 40

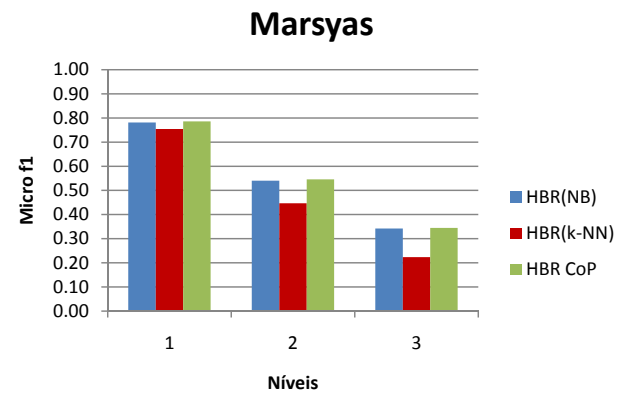

(c) Marsyas - InitSize 40

G-Pfam

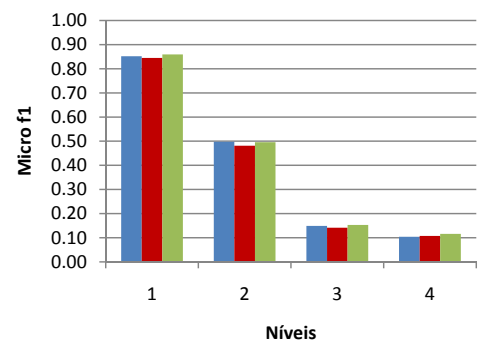

(e) G-Pfam - InitSize 40

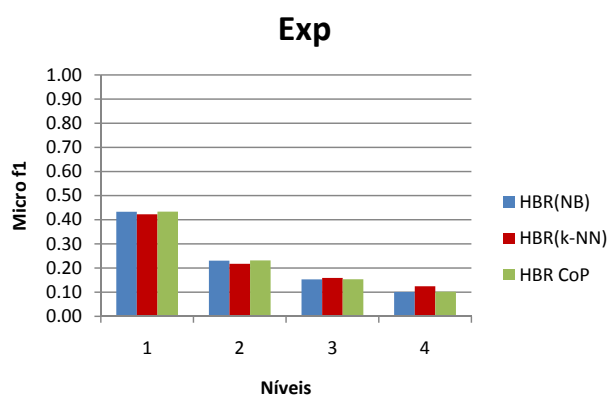

(b) Exp - InitSize All

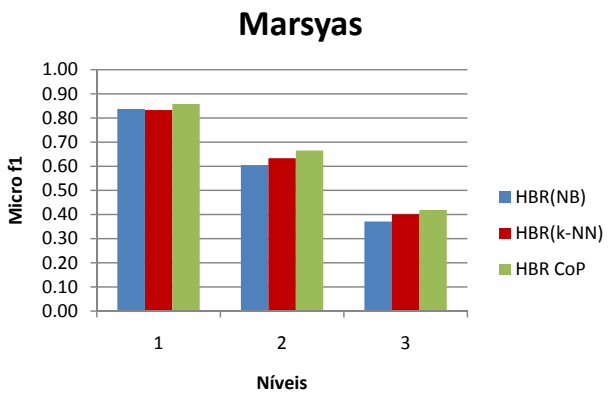

(d) Marsyas - InitSize All

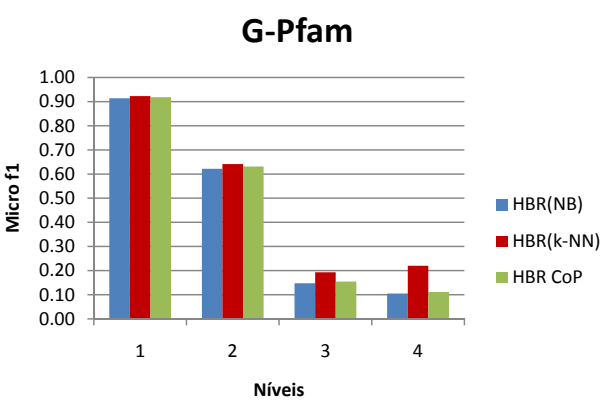

(f) G-Pfam - InitSize All

Figura 6.19: Valores da medida $f_{1}^{\mu}$ por nível da hierarquia para o Cenário 3 de classificação hierárquica (InitSize 40). 
Como pode ser observado, para todos os casos ocorre uma forte degradação do modelo nos níveis mais profundos da hierarquia, mesmo quando todo o conjunto de exemplos é fornecido ao algoritmo de aprendizado para a construção dos classificadores locais. Esse comportamento é esperado, uma vez que os exemplos de treinamento tornam-se mais escassos à medida que se aprofunda na hierarquia.

A qualidade dos classificadores locais nos niveis mais rasos da taxonomia determinam a qualidade global do classificador HBR, seja ele mono ou coperspectiva. Dessa maneira, conjuntos de dados que apresentam grande desbalanceamento de classes no primeiro nível, caso haja sobreposição de classes, tendem a degradar mais o modelo gerado. Esse é o caso dos conjuntos de dados do domínio de gêneros musicais representado pelo conjunto Marsyas, nos quais uma das classes do primeiro nível está associada a aproximadamente 73\% dos exemplos de treinamento. Para os conjuntos de dados de funções gênicas, representados pelo conjunto Exp, como mencionado, apesar de terem poucas classes no primeiro nível da taxonomia, apenas 4 , pode existir sobreposição entre elas, dificultando ainda mais a tarefa de predizer uma delas.

Outro fator a ser analisado é o número de classes no primeiro nível da taxonomia, pois quando maior é o número de classes, mais difícil é discriminar uma delas. Esse é o caso do conjunto de dados G-Pfam, no qual existem 12 classes no primeiro nível, e apresenta uma forte degradação nos outros níveis.

Em resumo, são diversos os fatores que influenciam o processo de aprendizado no contexto de classificação hierárquica. Assim, para minimizar o efeito de alguns desses fatores, é interessante usar algoritmos de aprendizado mais eficazes, mesmo que menos eficientes em termos de tempo computacional, de modo que os classificadores locais mais rasos não degradem a performance global do classificador hierárquico.

\subsubsection{Cenário 4 - Aprendizado semissupervisionado baseado em desacordo}

De maneira análoga ao Cenário 2 para classificação multirrótulo, a hipótese avaliada neste cenário é que, mesmo com poucos exemplos de treinamento, os métodos semissupervisionados hierárquicos baseados na abordagem local têm capacidade de aproximar a qualidade de predição dos métodos supervisionados treinados com todo o conjunto de exemplos rotulados disponível.

Os valores de $f_{1}^{\mu}$ obtidos pelos métodos avaliados neste cenário são apresentados na Tabela 6.23, conjuntamente com os resultados obtidos no Cenário 3 para aprendizado supervisionado - Tabela 6.21 - para auxiliar na comparação, pois os resultados obtidos pelos respectivos métodos supervisionados são utilizados para avaliar a capacidade dos métodos semissupervisionados de aprender com poucos exemplos. Além disso, lembre que os conjun- 
tos de dados apresentados neste cenário são os mesmos, e estão organizados nos mesmos grupos, que no Cenário 3.

Tabela 6.23: Valores de $f_{1}^{\mu}$ para o Cenário 4 de classificação hierárquica.

\begin{tabular}{|c|c|c|c|c|c|c|}
\hline \multirow[b]{2}{*}{ InitSize } & \multicolumn{3}{|c|}{ Supervisionado } & \multicolumn{3}{|c|}{ Semissupervisionado } \\
\hline & HBR (NB) & HBR (k-NN) & $\mathrm{HBR}_{C o P}$ & $\mathrm{HBR}_{S T}(\mathrm{NB})$ & $\mathrm{HBR}_{S T}(k-\mathrm{NN})$ & $\mathrm{HBR}_{C o P S S}$ \\
\hline & \multicolumn{6}{|c|}{ Cell-cycle } \\
\hline 20 & $\mathbf{0 , 1 8}(0,01)$ & $\mathbf{0 , 1 8}(0,03)$ & $0,17(0,01)$ & $0,14(0,04)$ & $0,17(0,06)$ & $0,17(0,04)$ \\
\hline 40 & $0,20(0,01)$ & $0,20(0,02)$ & $0,21(0,01)$ & $0,16(0,02)$ & $0,21(0,04)$ & $0,20(0,02)$ \\
\hline 80 & $0,23(0,01)$ & $0,22(0,02)$ & $\mathbf{0 , 2 4}(0,01)$ & $0,19(0,01)$ & $0,23(0,02)$ & $0,20(0,02)$ \\
\hline 120 & $\mathbf{0 , 2 5}(0,01)$ & $0,23(0,01)$ & $\mathbf{0 , 2 5}(0,02)$ & $0,19(0,01)$ & $0,24(0,02)$ & $0,21(0,02)$ \\
\hline All & $0,28(0,01)$ & $0,23(0,21)$ & $\mathbf{0 , 2 9}(0,01)$ & & & \\
\hline \multirow{2}{*}{$\mathrm{HBR}_{\text {Low }}$} & 0,25 & & & & & \\
\hline & \multicolumn{6}{|c|}{ Church } \\
\hline 20 & $\mathbf{0 , 1 6}(0,02)$ & $0,14(0,02)$ & $\mathbf{0 , 1 6}(0,02)$ & $0,15(0,03)$ & $0,14(0,03)$ & $0,14(0,02)$ \\
\hline 40 & $\mathbf{0 , 1 6}(0,01)$ & $0,15(0,02)$ & $\mathbf{0 , 1 6}(0,01)$ & $\mathbf{0 , 1 6}(0,01)$ & $0,15(0,02)$ & $\mathbf{0 , 1 6}(0,01)$ \\
\hline 80 & $\mathbf{0 , 1 6}(0,02)$ & $\mathbf{0 , 1 6}(0,02)$ & $\mathbf{0 , 1 6}(0,02)$ & $\mathbf{0 , 1 6}(0,01)$ & $0,16(0,02)$ & $\mathbf{0 , 1 6}(0,02)$ \\
\hline 120 & $0,15(0,01)$ & $\mathbf{0 , 1 7}(0,01)$ & $0,16(0,01)$ & $0,16(0,01)$ & $0,16(0,02)$ & $0,15(0,03)$ \\
\hline All & $0,15(0,01)$ & $0,12(0,01)$ & $\mathbf{0 , 1 6}(0,01)$ & & & \\
\hline \multirow[t]{2}{*}{$\mathrm{HBR}_{\text {Low }}$} & 0,25 & & & & & \\
\hline & \multicolumn{6}{|c|}{$\operatorname{Exp}$} \\
\hline 20 & $0,16(0,02)$ & $\mathbf{0 , 1 7}(0,02)$ & $0,16(0,02)$ & $0,12(0,03)$ & $0,13(0,02)$ & $0,14(0,02)$ \\
\hline 40 & $\mathbf{0 , 1 9}(0,02)$ & $\mathbf{0 , 1 9}(0,02)$ & $\mathbf{0 , 1 9}(0,02)$ & $0,16(0,03)$ & $0,16(0,04)$ & $0,16(0,03)$ \\
\hline 80 & $0,23(0,03)$ & $0,22(0,01)$ & $0,23(0,03)$ & $0,17(0,03)$ & $0,18(0,04)$ & $0,17(0,02)$ \\
\hline 120 & $0,24(0,03)$ & $0,22(0,01)$ & $0,24(0,03)$ & $0,17(0,02)$ & $0,21(0,02)$ & $0,18(0,02)$ \\
\hline All & $\mathbf{0 , 2 4}(0,02)$ & $\mathbf{0 , 2 4}(0,01)$ & $\mathbf{0 , 2 4}(0,03)$ & & & \\
\hline \multirow[t]{2}{*}{$\mathrm{HBR}_{\text {Low }}$} & 0,25 & & & & & \\
\hline & \multicolumn{6}{|c|}{ Phenotype } \\
\hline 20 & $0,13(0,02)$ & $0,13(0,03)$ & $0,13(0,02)$ & $\mathbf{0 , 1 4}(0,02)$ & $0,13(0,03)$ & $0,13(0,03)$ \\
\hline 40 & $0,13(0,04)$ & $\mathbf{0 , 1 4}(0,03)$ & $0,13(0,04)$ & $0,13(0,04)$ & $0,13(0,04)$ & $\mathbf{0 , 1 4}(0,05)$ \\
\hline 80 & $0,16(0,03)$ & $0,17(0,02)$ & $\mathbf{0 , 1 7}(0,02)$ & $0,13(0,05)$ & $0,17(0,02)$ & $0,14(0,04)$ \\
\hline 120 & $0,17(0,02)$ & $0,17(0,02)$ & $\mathbf{0 , 1 8}(0,02)$ & $0,10(0,05)$ & $0,17(0,03)$ & $0,14(0,04)$ \\
\hline All & $0,12(0,02)$ & $\mathbf{0 , 1 3}(0,02)$ & $0,12(0,02)$ & & & \\
\hline \multirow[t]{2}{*}{$\operatorname{HBR}_{\text {Low }}$} & 0,27 & & & & & \\
\hline & \multicolumn{6}{|c|}{$R H$} \\
\hline 20 & $\mathbf{0 , 4 5}(0,05)$ & $0,24(0,08)$ & $\mathbf{0 , 4 5}(0,04)$ & $0,42(0,08)$ & $0,41(0,04)$ & $0,43(0,04)$ \\
\hline 40 & $\mathbf{0 , 4 7}(0,03)$ & $0,27(0,07)$ & $\mathbf{0 , 4 7}(0,03)$ & $0,42(0,09)$ & $0,42(0,04)$ & $0,44(0,02)$ \\
\hline 80 & $0,48(0,01)$ & $0,30(0,07)$ & $\mathbf{0 , 4 9}(0,01)$ & $0,45(0,02)$ & $0,43(0,04)$ & $0,46(0,02)$ \\
\hline 120 & $0,49(0,01)$ & $0,32(0,07)$ & $\mathbf{0 , 5 0}(0,01)$ & $0,46(0,02)$ & $0,43(0,06)$ & $0,47(0,01)$ \\
\hline All & $0,51(0,00)$ & $\mathbf{0 , 5 9}(0,01)$ & $0,52(0,00)$ & & & \\
\hline \multirow[t]{2}{*}{$\mathrm{HBR}_{\text {Low }}$} & 0,19 & & & & & \\
\hline & \multicolumn{6}{|c|}{ Marsyas } \\
\hline 20 & $0,52(0,04)$ & $0,49(0,04)$ & $\mathbf{0 , 5 3}(0,04)$ & $0,51(0,02)$ & $0,48(0,02)$ & $0,51(0,03)$ \\
\hline 40 & $\mathbf{0 , 5 9}(0,02)$ & $0,51(0,02)$ & $\mathbf{0 , 5 9}(0,02)$ & $0,51(0,04)$ & $0,49(0,03)$ & $0,54(0,02)$ \\
\hline 80 & $0,61(0,01)$ & $0,54(0,01)$ & $\mathbf{0 , 6 2}(0,01)$ & $0,53(0,02)$ & $0,53(0,01)$ & $0,55(0,02)$ \\
\hline 120 & $0,62(0,02)$ & $0,56(0,02)$ & $\mathbf{0 , 6 3}(0,02)$ & $0,54(0,01)$ & $0,55(0,03)$ & $0,57(0,01)$ \\
\hline All & $0,66(0,00)$ & $0,630,00)$ & $\mathbf{0 , 6 8}(0,00)$ & & & \\
\hline \multirow[t]{2}{*}{$\operatorname{HBR}_{\text {Low }}$} & 0,19 & & & & & \\
\hline & \multicolumn{6}{|c|}{ G-Pfam } \\
\hline 20 & $\mathbf{0 , 5 1}(0,02)$ & $0,49(0,01)$ & $\mathbf{0 , 5 1}(0,02)$ & $0,2 \mathrm{~S}$ & $0,49(0,02)$ & $0,39(0,06)$ \\
\hline 40 & $\mathbf{0 , 5 2}(0,01)$ & $0,51(0,02)$ & $\mathbf{0 , 5 2}(0,02)$ & $0,35(0,03)$ & $0,50(0,01)$ & $0,41(0,05)$ \\
\hline 80 & $\mathbf{0 , 5 4}(0,02)$ & $0,53(0,02)$ & $\mathbf{0 , 5 4}(0,02)$ & $0,41(0,05)$ & $0,52(0,03)$ & $0,45(0,03)$ \\
\hline 120 & $0,54(0,01)$ & $0,54(0,03)$ & $\mathbf{0 , 5 5}(0,02)$ & $0,45(0,03)$ & $0,53(0,02)$ & $0,47(0,05)$ \\
\hline All & $0,64(0,00)$ & $\mathbf{0 , 6 6}(0,01)$ & $0,65(0,01)$ & & & \\
\hline \multirow[t]{2}{*}{$\mathrm{HBR}_{\text {Low }}$} & 0,34 & & & & & \\
\hline & & & & rints & & \\
\hline 20 & $\mathbf{0 , 5 0}(0,04)$ & $0,34(0,07)$ & $0,45(0,05)$ & $0,31(0,04)$ & $0,34(0,10)$ & $0,33(0,04)$ \\
\hline 40 & $\mathbf{0 , 5 5}(0,02)$ & $0,39(0,04)$ & $0,52(0,04)$ & $0,35(0,04)$ & $0,39(0,04)$ & $0,35(0,02)$ \\
\hline 80 & $\mathbf{0 , 5 7}(0,02)$ & $0,43(0,05)$ & $0,54(0,04)$ & $0,41(0,04)$ & $0,43(0,05)$ & $0,40(0,04)$ \\
\hline 120 & $\mathbf{0 , 5 9}(0,02)$ & $0,49(0,04)$ & $0,57(0,02)$ & $0,45(0,02)$ & $0,49(0,05)$ & $0,44(0,05)$ \\
\hline All & $0,72(0,01)$ & $0,79(0,01)$ & $0,73(0,01)$ & & & \\
\hline $\mathrm{HBR}_{\text {Low }}$ & 0,07 & & & & & \\
\hline
\end{tabular}


Fixando o algoritmo de aprendizado e comparando os métodos semissupervisionados com supervisionados, percebe-se que na maioria dos casos os métodos supervisionados, mesmo utilizando poucos exemplos de treinamento, apresentam melhores resultados. Essa observação é válida tanto para os métodos monoperspectiva HBR (NB) e HBR $(k-\mathrm{NN})$ como para o método $\mathrm{HBR}_{C o P}$, com algumas exceções como no caso do conjunto de dados $R H$, para o qual o método $\mathrm{HBR}_{S T}(k-\mathrm{NN})$ apresentou resultados significativamente melhores que seu equivalente supervisionado HBR ( $k$-NN) para InitSize 20, 40, 80 e 120. Para facilitar a comparação desses resultados, observe os gráficos apresentados na Figura 6.20, na qual todos os valores de $f_{1}^{\mu}$ foram obtidos com InitSize 40.

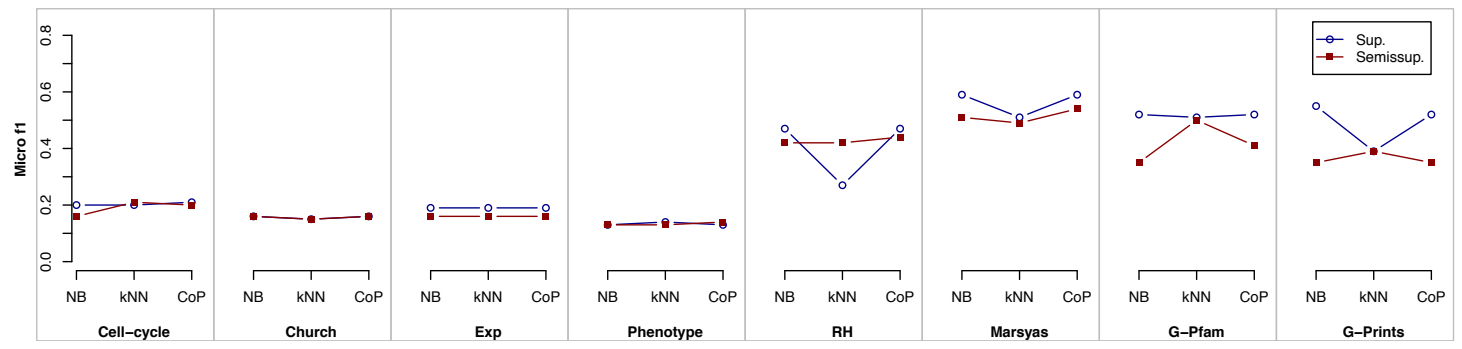

Figura 6.20: Comparação dos métodos supervisionados e semissupervisionados para classificação hierárquica. Todos os métodos treinados com InitSize 40 .

Na Figura 6.21, são apresentados gráficos semelhantes, porém, nesse caso, os métodos supervisionados foram treinados com InitSize All, enquanto que os resultados para os métodos semissupervisionados foram obtidos com InitSize 40 .

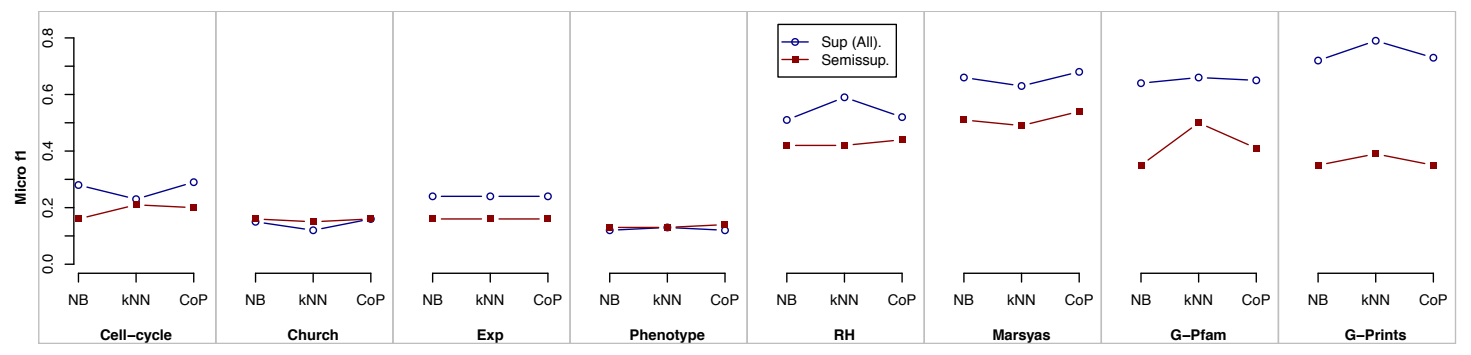

Figura 6.21: Comparação dos métodos supervisionados e semissupervisionados para classificação hierárquica. InitSize All para os métodos supervisionados e InitSize 40 para métodos semissupervisionados.

Como mencionado anteriormente, em um cenário ideal, os métodos semissupervisionados treinados com poucos exemplos deveriam ser tão eficazes quanto os métodos supervisionados treinados com muitos exemplos rotulados. Entretanto, isso não acontece em todos os casos, mas como pode ser observado pelos resultados apresentados na Figura 6.21, assim como nos casos de classificação multirrótulo descritos anteriormente, os experimentos para a classificação hierárquica semissupervisionada utilizando um conjunto 
reduzido de exemplos apresenta, em alguns casos, resultados próximos aos obtidos por métodos supervisionados treinados com muitos exemplos.

Os resultados relacionados aos métodos semissupervisionados apresentados na Tabela 6.23 são mostrados graficamente na Figura 6.22, a partir da qual observa-se que, para alguns conjuntos de dados, não houve aprendizado para nenhuma configuração de InitSize (valor de $f_{1}^{\mu}$ inferior ao de $\mathrm{HBR}_{\text {Low }}$ ). Esse é o caso dos conjuntos de dados Cell-cycle, Church, Exp e Phenotype. É importante lembrar que cada um desses conjuntos de dados representa um grupo de conjuntos de dados, para os quais os resultados obtidos são similares.

Considerando os demais conjuntos de dados, todos os métodos obtiveram $f_{1}^{\mu}$ maiores que o método $\mathrm{HBR}_{\text {Low }}$, mostrando que houve aprendizado. Contudo, a variação do tamanho do conjunto de treinamento inicial teve pouco impacto nos resultados.

Para analisar a performance dos classificadores semissupervisionados, tanto monoperspectiva como coperspectiva, são apresentados graficamente os valores da medida $f_{1}^{\mu}$ para cada nível da taxonomia dos seguintes conjuntos de dados: Exp, Marsyas e G-Pfam. Para facilitar a comparação entre os métodos supervisionados e semissupervisionados, os resultados obtidos para o Cenário 3 são também apresentados nessas figuras.

A partir desses gráficos percebe-se claramente que os métodos semissupervisionados são mais fortemente afetados pelos fatores de degradação do modelo, o qual é ainda mais crítico no contexto hierárquico semissupervisionado, pois existem ao menos dois processos que podem degradar a performance dos classificadores: os poucos exemplos nos níveis mais profundos da hierarquia e a propagação de erro causada pelo processo de autorrotulação de exemplos dos algoritmos semissupervisionados. Além desses fatores, também podem naturalmente ocorrer outros, como o desbalanceamento de classes.

\subsubsection{Cenário 5 - Aprendizado semissupervisionado ativo}

Neste cenário, os resultados obtidos por meio dos métodos semissupervisionado com uso de aprendizado ativo são avaliados e comparados com os outros métodos supervisionados e semissupervisionados não ativos. Na Tabela 6.10 são apresentados os valores de $f_{1}^{\mu}$, e seus respectivos desvio padrão entre parênteses, obtidos por esses métodos para os oito conjuntos de dados representantes dos grupos definidos na Tabela 6.20 na página 151. Observe que os valores referentes ao InitSize All, obtidos com os métodos supervisionados, representam um top-line para os métodos semissupervisionados.

Nem mesmo a utilização do aprendizado ativo em conjunto com o aprendizado semissupervisionado melhorou a performance dos classificadores para 


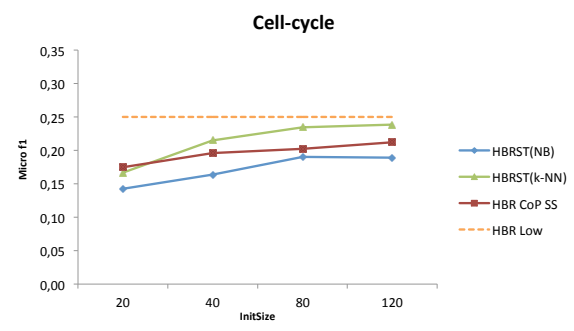

(a) Conjunto de dados Cell-cycle

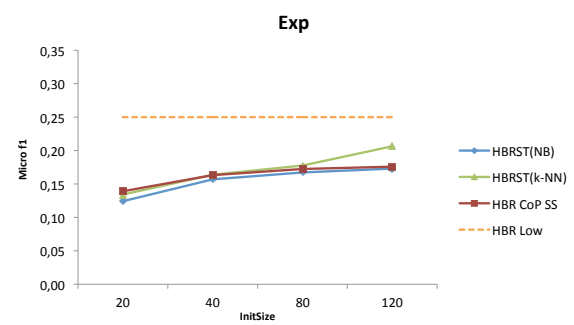

(c) Conjunto de dados Exp

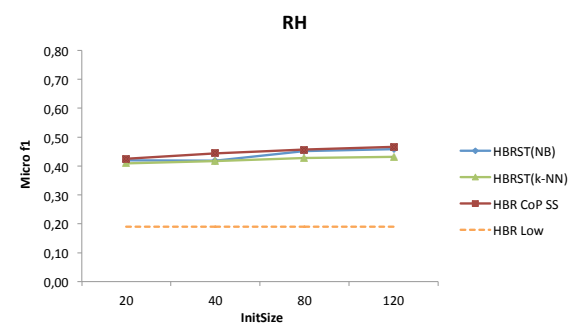

(e) Conjunto de dados $R H$

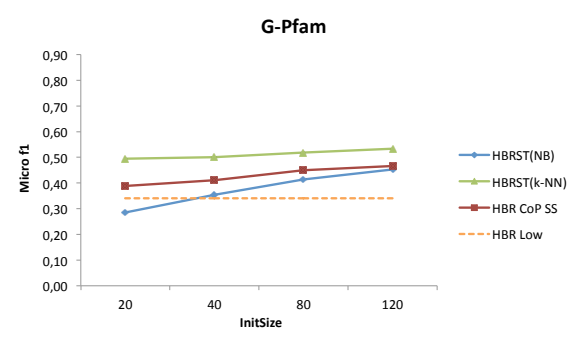

(g) Conjunto de dados G-Pfam

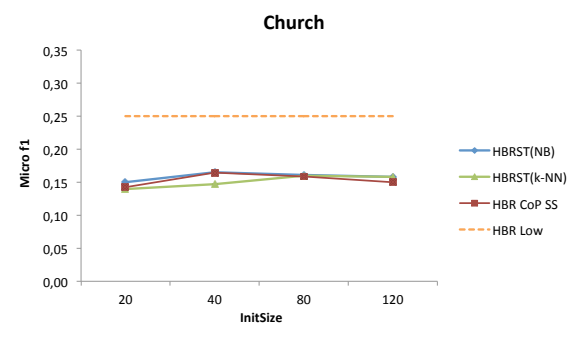

(b) Conjunto de dados Church

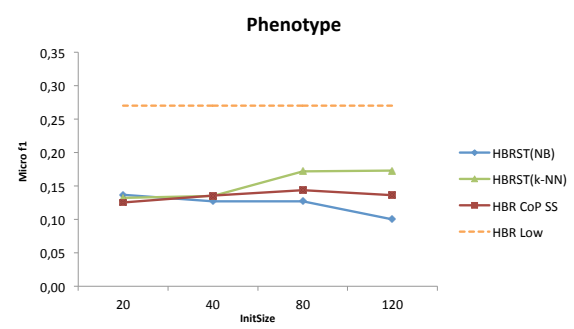

(d) Conjunto de dados Phenotype

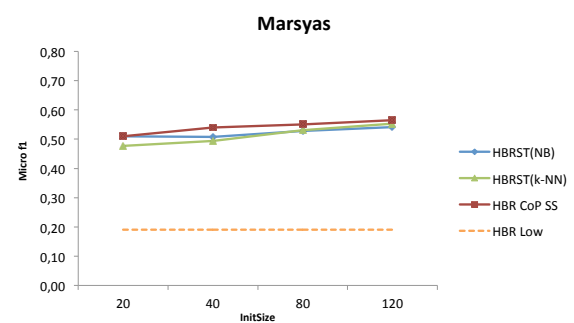

(f) Conjunto de dados Marsyas

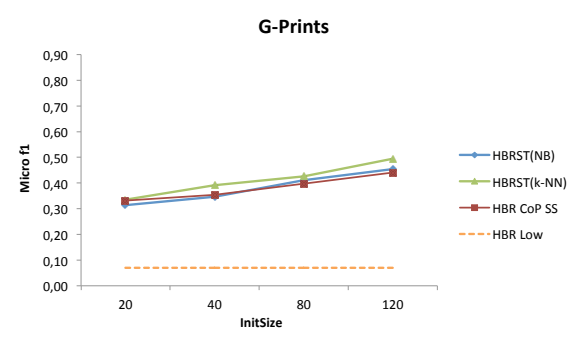

(h) Conjunto de dados G-Prints

Figura 6.22: Valores da medida $f_{1}^{\mu}$ para o Cenário 4 de classificação hierárquica.

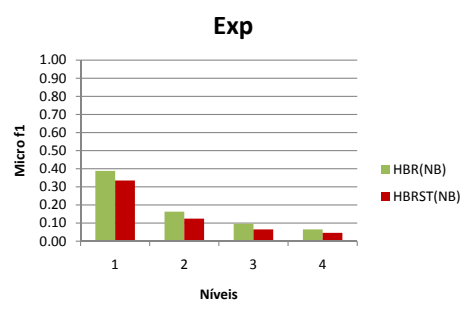

(a)

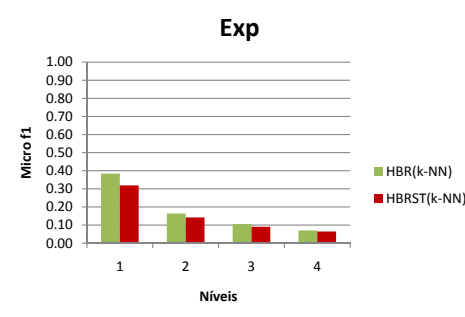

(b)

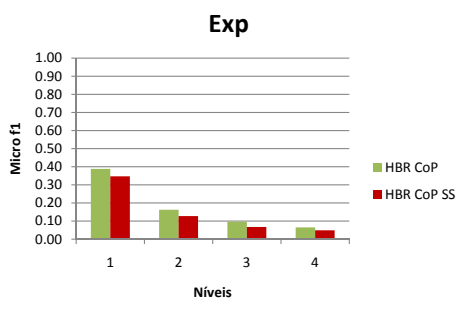

(c)

Figura 6.23: Comparação por nível da taxonomia Exp - InitSize 40. 


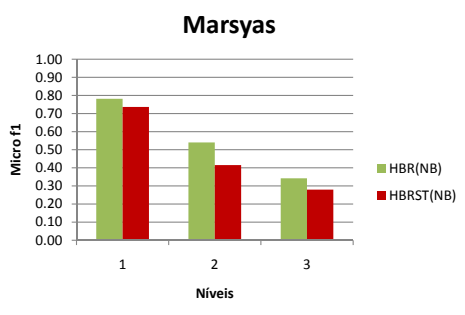

(a)

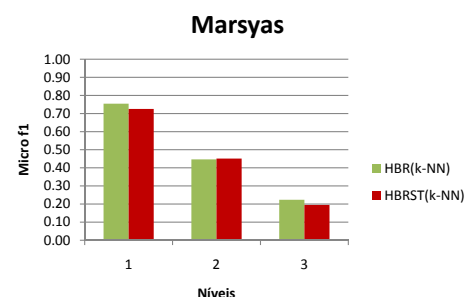

(b)

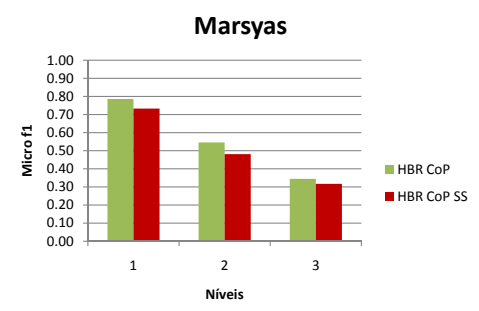

(c)

Figura 6.24: Comparação por nível da taxonomia Marsyas - InitSize 40.

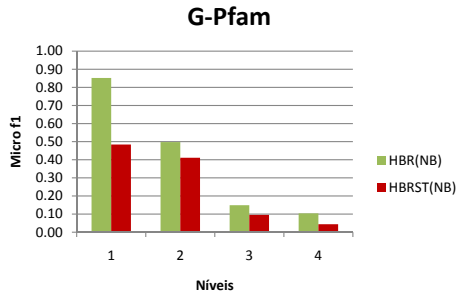

(a)

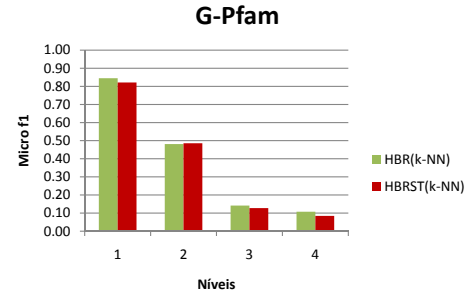

(b)

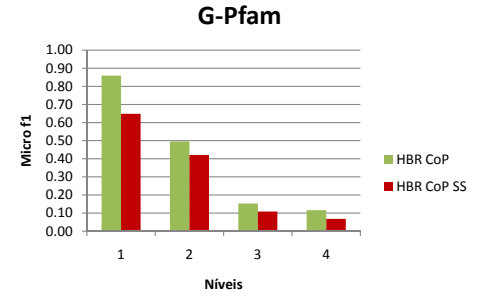

(c)

Figura 6.25: Comparação por nível da taxonomia G-Pfam - InitSize 40.

os conjuntos de dados de funções gênicas. Essa fato está diretamente relacionado à capacidade de classificação dos modelos iniciais construídos com poucos exemplos. Observe que mesmo nos casos para os quais todos os exemplos rotulados são utilizados para construir os classificadores, a performance global do classificador hierárquico é ruim para esses conjuntos de dados. Desse modo, com um número reduzido de exemplos de treinamento, a tarefa tornase ainda mais complexa. Em consequência disso, os pontos de contenção identificados pelos métodos de aprendizado ativo não são necessariamente bons exemplos para ajudar na construção de melhores classificadores.

Os resultados para os outros conjuntos de dados, apesar de melhores, não são ainda suficientemente bons, uma vez que os métodos supervisionados, que em geral são mais eficientes em termos de tempo computacional, apresentam resultados melhores que os métodos equivalentes semissupervisionados, mesmo utilizando poucos exemplos.

Na comparação entre os métodos semissupervisionados baseados em SELFTRAINING, $\operatorname{HBR}_{S T}(\mathrm{NB})$ e $\mathrm{HBR}_{S T}(k-\mathrm{NN})$, com os métodos de aprendizado ativo $\mathrm{HBR}_{C o P S S+A L}$ e $\mathrm{HBR}_{C o T e s t i n g}$, observa-se que na maioria dos casos os métodos SELF-TRAining são melhores ou equivalentes aos métodos de aprendizado ativo, com exceção para o conjunto de dados Marsyas. Esse observação vale também para a comparação entre o método $\mathrm{HBR}_{C o P S S}$ com os métodos de aprendizado ativo. Entretanto, nesse caso, o método $\mathrm{HBR}_{\text {CoTesting }}$ supera o método HBR $_{C o P S S}$ para os conjuntos de dados G-Pfam e G-Prints com valores de $f_{1}^{\mu}$ não significativamente maiores. 
Tabela 6.24: Valores de $f_{1}^{\mu}$ para o Cenário 5 de classificação hierárquica.

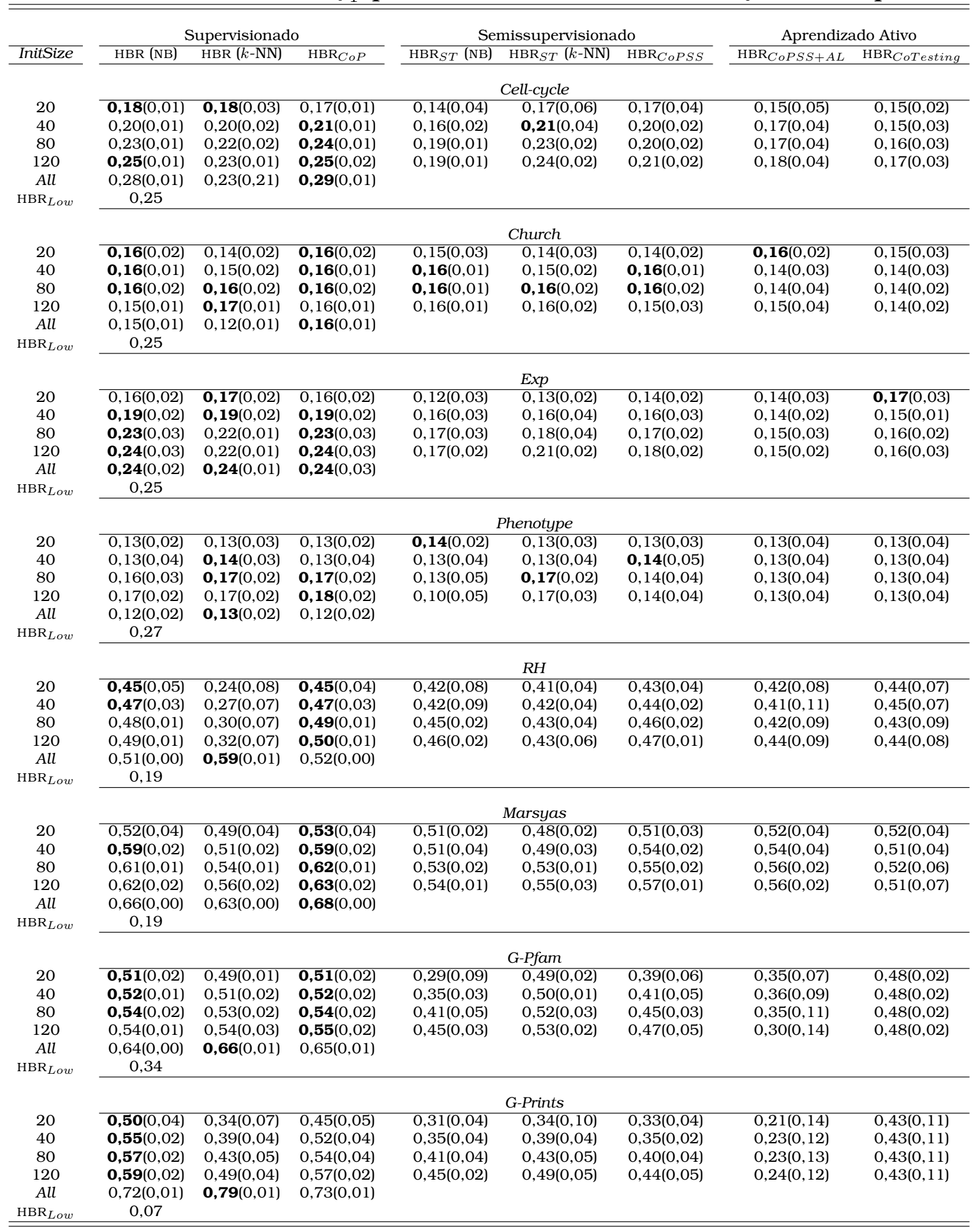

Para simplificar a análise e comparação da performance dos métodos de aprendizado ativo, $\mathrm{HBR}_{C o P S S+A L}$ e $\mathrm{HBR}_{C o T e s t i n g}$, bem como do método $\mathrm{HBR}_{C o P S S}$, na Figura 6.26 são apresentados graficamente seus respectivos valores de $f_{1}^{\mu}$ e cada variação de InitSize. Além disso, o valor dessa medida obtida pelo método baseline $\mathrm{HBR}_{\text {Low }}$ também é apresentado.

Com o objetivo de verificar o grau de influência do aprendizado ativo neste 


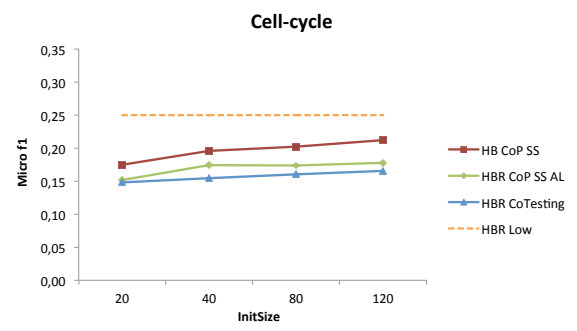

(a) Conjunto de dados Cell-cycle

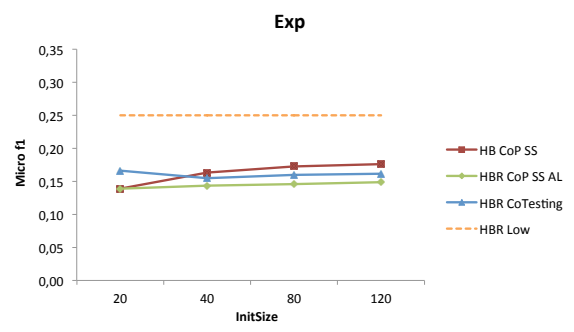

(c) Conjunto de dados Exp

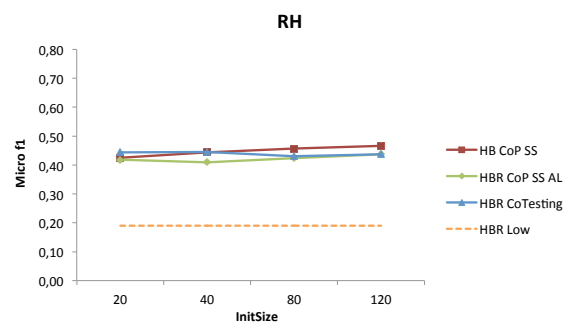

(e) Conjunto de dados $R H$

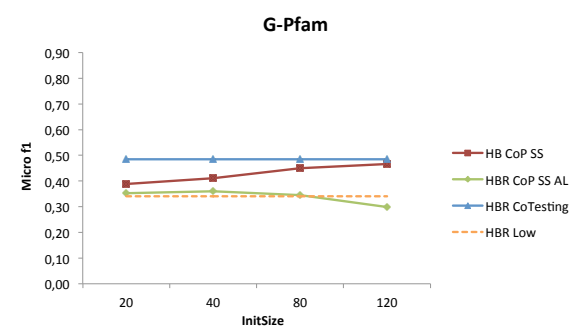

(g) Conjunto de dados G-Pfam

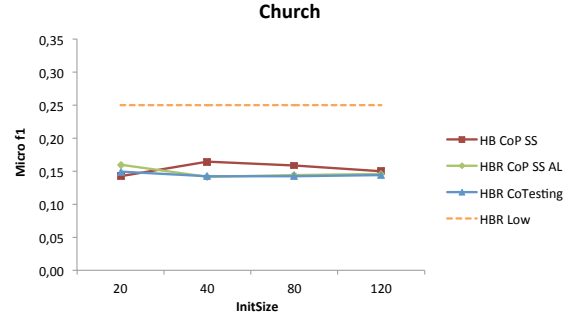

(b) Conjunto de dados Church

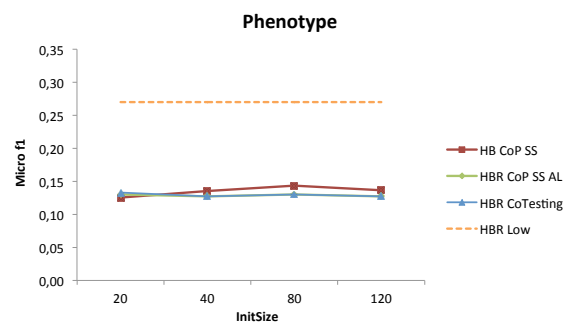

(d) Conjunto de dados Phenotype

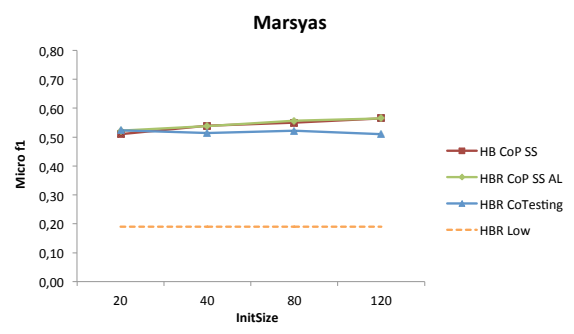

(f) Conjunto de dados Marsyas

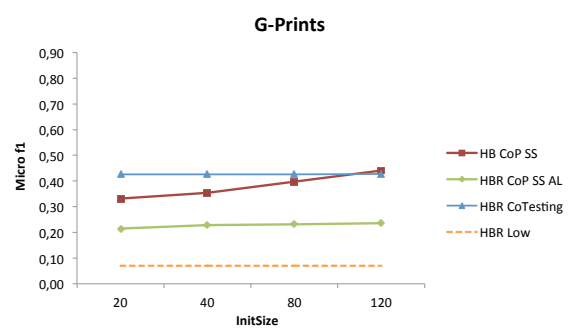

(h) Conjunto de dados G-Prints

Figura 6.26: Valores da medida $f_{1}^{\mu}$ para o Cenário 5 de classificação hierárquica. 
cenário, é apresentado na Tabela 6.25 o percentual de melhora ( $\Delta$ ) ou degradação $(\nabla)$ dos métodos "inativos" $\operatorname{HBR}_{S T}(\mathrm{NB}), \mathrm{HBR}_{S T}(k-\mathrm{NN})$ e $\mathrm{HBR}_{C o P S S}$, em relação de desempenho dos métodos ativos $\mathrm{HBR}_{C o P S S+A L}$ e $\mathrm{HBR}_{\text {CoTesting. Como }}$ pode ser observado nessa tabela, para a maioria dos conjuntos de dados os métodos com aprendizado ativo apresentaram resultados inferiores aos métodos "inativos", indicando que o processo de identificação dos pontos de contenção mais informativos não foi eficaz a ponto de contribuir para a melhora no desempenho dos classificadores nas iterações iniciais. Consequentemente, nas iterações seguintes houve a propagação dos erros de classificação e a inserção de exemplos erroneamente rotulados no conjunto de exemplos de treinamento, degradando ainda mais a performance dos classificadores finais.

Entre os dois métodos de aprendizado ativo para classificação hierárquica, o $\mathrm{HBR}_{\text {CoTesting }}$ superou o método $\mathrm{HBR}_{C o P S S+A L}$ em diversos experimentos. Essa informação está apresentada na Tabela 6.26. Uma vez que o número de exemplos rotulados utilizado para a construção dos classificadores locais é fixo, e que o número de consultas é variável, conclui-se que o modelo inicial, construído sem o auxílios do "oráculo, não foi capaz de identificar pontos de contenção que provessem informações realmente úteis para melhora dos classificadores. Assim, talvez se o classificador inicial for construído com um conjunto de exemplos de treinamento um pouco maior, o processo de identificação e rotulação dos pontos de contenção pode ser mais eficaz, resultando em classificadores também mais eficazes.

Os gráficos para comparação da performance do classificador hierárquico para cada nível da taxonomia de classes, considerando os conjuntos de dados Exp, Marsyas e G-Pfam e InitSize 40, são apresentados nas Figuras 6.27, 6.28 e 6.29, respectivamente.

Está claro que não existe diferença significativa entre os diferentes métodos comparados nas Figuras 6.27 e 6.28, relacionadas aos conjuntos de dados Exp e Marsyas, respectivamente. Contudo, na Figura 6.29, observa-se que os métodos $\mathrm{HBR}_{S T}(k-\mathrm{NN})$ e $\mathrm{HBR}_{\text {CoTesting }}$ sobressaem em relação aos demais no primeiro nível.

O motivo dessa diferença de desempenho dos métodos semissupervisionados coperspectiva está fortemente relacionado à baixa performance da perspectiva treinada com o algoritmo base NB. A degradação acentuada no desempenho do classificador $\mathrm{HBR}_{C o P S S}$ em relação ao $\mathrm{HBR}_{S T}(k-\mathrm{NN})$ é gerada pela propagação dos erros de classificação, que provavelmente ocorrem devido às diferenças entre os graus de confiança na classificação obtidos em cada perspectiva. Nesse caso, a perspectiva com NB está predizendo a classe errada com grau de confiança maior que a perspectiva $k$-NN está predizendo a classe correta, fazendo com que a sua predição equivocada prevaleça, pois o desacordo 
Tabela 6.25: Comparação dos métodos de aprendizado ativo com métodos semissupervisionados multirrótulo. Os símbolos $\Delta$ e $\nabla$ indicam, respectivamente, melhora e degradação do método "inativo" em relação ao método ativo.

\begin{tabular}{|c|c|c|c|c|c|c|}
\hline \multirow[b]{2}{*}{ InitSize } & \multicolumn{3}{|c|}{$\mathrm{HBR}_{C o P S S+A L}$} & \multicolumn{3}{|c|}{ HBR $_{\text {CoTesting }}$} \\
\hline & $\mathrm{HBR}_{S T}(\mathrm{NB})$ & $\mathrm{HBR}_{S T}(k-\mathrm{NN})$ & $\mathrm{HBR}_{C o P S S}$ & $\mathrm{HBR}_{S T}(\mathrm{NB})$ & $\mathrm{HBR}_{S T}(k-\mathrm{NN})$ & $\mathrm{HBR}_{C o P S S}$ \\
\hline & \multicolumn{6}{|c|}{ Cell-cycle } \\
\hline 20 & $\nabla 06 \%$ & $\Delta 10 \%$ & $\Delta 15 \%$ & $\nabla 04 \%$ & $\Delta 13 \%$ & \ $18 \%$ \\
\hline 40 & $\nabla 06 \%$ & \ $23 \%$ & $\Delta 13 \%$ & $\Delta 06 \%$ & \ $39 \%$ & \ $27 \%$ \\
\hline 80 & А $10 \%$ & $\Delta 35 \%$ & А $17 \%$ & А $19 \%$ & \ $46 \%$ & $\Delta 26 \%$ \\
\hline \multirow[t]{2}{*}{120} & $\Delta 07 \%$ & А $34 \%$ & А 19\% & А $14 \%$ & \ $44 \%$ & \ $28 \%$ \\
\hline & \multicolumn{6}{|c|}{ Church } \\
\hline 20 & $\nabla 07 \%$ & $\nabla 11 \%$ & $\nabla 09 \%$ & $\nabla 02 \%$ & $\nabla 06 \%$ & $\nabla 05 \%$ \\
\hline 40 & $\Delta 16 \%$ & А $04 \%$ & А $16 \%$ & А $16 \%$ & $\Delta 03 \%$ & А $16 \%$ \\
\hline 80 & $\Delta 11 \%$ & А $11 \%$ & А $10 \%$ & А $13 \%$ & $\Delta 12 \%$ & А $11 \%$ \\
\hline \multirow[t]{2}{*}{120} & $\Delta 08 \%$ & $\Delta 09 \%$ & $\Delta 03 \%$ & $\Delta 10 \%$ & $\Delta 10 \%$ & $\Delta 04 \%$ \\
\hline & \multicolumn{6}{|c|}{$\operatorname{Exp}$} \\
\hline 20 & $\nabla 11 \%$ & $\nabla 03 \%$ & - & $\nabla 25 \%$ & $\nabla 19 \%$ & $\nabla 16 \%$ \\
\hline 40 & $\Delta 09 \%$ & А $14 \%$ & А $14 \%$ & $\Delta 01 \%$ & $\Delta 06 \%$ & $\triangle 05 \%$ \\
\hline 80 & А $15 \%$ & \ $22 \%$ & А $18 \%$ & $\Delta 05 \%$ & \ $11 \%$ & $\Delta 08 \%$ \\
\hline \multirow[t]{2}{*}{120} & А $16 \%$ & А $39 \%$ & А $18 \%$ & $\Delta 07 \%$ & А $28 \%$ & ॥ 09\% \\
\hline & \multicolumn{6}{|c|}{ Phenotype } \\
\hline 20 & $\Delta 03 \%$ & $\nabla 01 \%$ & $\nabla 06 \%$ & $\Delta 03 \%$ & $\nabla 01 \%$ & $\nabla 06 \%$ \\
\hline 40 & - & $\Delta 06 \%$ & $\Delta 06 \%$ & - & $\Delta 06 \%$ & $\Delta 06 \%$ \\
\hline 80 & $\nabla 03 \%$ & А $32 \%$ & А $10 \%$ & $\nabla 03 \%$ & А $32 \%$ & А $10 \%$ \\
\hline \multirow[t]{2}{*}{120} & $\nabla 22 \%$ & $\Delta 36 \%$ & $\Delta 07 \%$ & $\nabla 22 \%$ & $\Delta 36 \%$ & $\Delta 07 \%$ \\
\hline & \multicolumn{6}{|c|}{$R H$} \\
\hline 20 & - & $\nabla 02 \%$ & $\Delta 02 \%$ & $\nabla 06 \%$ & $\nabla 08 \%$ & $\nabla 04 \%$ \\
\hline 40 & $\Delta 02 \%$ & $\triangle 02 \%$ & $08 \%$ & $\nabla 06 \%$ & $\nabla 06 \%$ & - \\
\hline 80 & $\Delta 07 \%$ & $\Delta 01 \%$ & $\Delta 08 \%$ & $\Delta 05 \%$ & $\nabla 01 \%$ & $\Delta 06 \%$ \\
\hline \multirow[t]{2}{*}{120} & $\Delta 05 \%$ & $\nabla 01 \%$ & $\Delta \quad 07 \%$ & $\Delta 05 \%$ & $\nabla 01 \%$ & $\Delta 07 \%$ \\
\hline & \multicolumn{6}{|c|}{ Marsyas } \\
\hline 20 & $\nabla 03 \%$ & $\nabla 09 \%$ & $\nabla 02 \%$ & $\nabla 03 \%$ & $\nabla 09 \%$ & $\nabla 03 \%$ \\
\hline 40 & $\nabla 06 \%$ & $\nabla 08 \%$ & - & $\nabla 01 \%$ & $\nabla 04 \%$ & $\Delta 05 \%$ \\
\hline 80 & $\nabla 05 \%$ & $\nabla 04 \%$ & $\nabla 01 \%$ & $\Delta 01 \%$ & $\Delta 02 \%$ & $\Delta 05 \%$ \\
\hline \multirow[t]{2}{*}{120} & $\nabla 04 \%$ & $\nabla 02 \%$ & & $\Delta 06 \%$ & $\Delta 08 \%$ & $\Delta 10 \%$ \\
\hline & \multicolumn{6}{|c|}{ G-Pfam } \\
\hline 20 & $\nabla 19 \%$ & $\Delta 40 \%$ & $\Delta 10 \%$ & $\nabla 41 \%$ & $\Delta 02 \%$ & $\nabla 20 \%$ \\
\hline 40 & $\nabla 02 \%$ & ॥ $39 \%$ & $\Delta 14 \%$ & $\nabla 27 \%$ & $\Delta 03 \%$ & $\nabla 15 \%$ \\
\hline 80 & А $20 \%$ & А $50 \%$ & А $30 \%$ & จ $14 \%$ & \ $07 \%$ & > 07\% \\
\hline \multirow[t]{2}{*}{120} & $\Delta 52 \%$ & $\Delta 79 \%$ & А $56 \%$ & $\nabla 07 \%$ & А $10 \%$ & $\nabla 04 \%$ \\
\hline & \multicolumn{6}{|c|}{ G-Prints } \\
\hline 20 & $\triangle 46 \%$ & $\Delta 56 \%$ & $\triangle 55 \%$ & $\nabla 26 \%$ & $\nabla 21 \%$ & $\nabla 22 \%$ \\
\hline 40 & \ $52 \%$ & $\Delta 72 \%$ & $\Delta 55 \%$ & $\nabla 19 \%$ & $\nabla 08 \%$ & จ $17 \%$ \\
\hline 80 & \ $78 \%$ & $85 \%$ & \ $72 \%$ & $\nabla 04 \%$ & - & $\nabla 07 \%$ \\
\hline 120 & А $92 \%$ & А $109 \%$ & $86 \%$ & А $06 \%$ & А $16 \%$ & А $03 \%$ \\
\hline
\end{tabular}

é resolvido a considerando o maior grau de confiança na classificação.

Quando apenas o aprendizado ativo é utilizado $\left(\mathrm{HBR}_{\text {CoTesting }}\right)$, a perspectiva treinada com o algoritmo base $k$-NN contribui para a identificação de pontos de contenção mais informativos e, consequentemente, melhora o desempenho do classificador final devido à classificação correta desses exemplos dada pelo “oráculo”. Essa observação é reforçada pelo resultado do método semissupervisionado em conjunto com aprendizado ativo, i.e., $\mathrm{HBR}_{C o P S S+A L}$, o qual resultou em um valor de $f_{1}^{\mu}$ um pouco melhor que o método $\mathrm{HBR}_{C o P S S}$. No entanto, mesmo com exemplos de treinamento mais informativos para a construção dos classificadores nas iterações iniciais, a inclusão de outros exemplos que 
Tabela 6.26: Comparação entre $\mathrm{HBR}_{C o P S S+A L}$ e HBR $\mathrm{HoTesting}_{\text {. }} \mathrm{O}$ símbolo $\boldsymbol{\Delta}$ indica que o método apresentou melhor resultado.

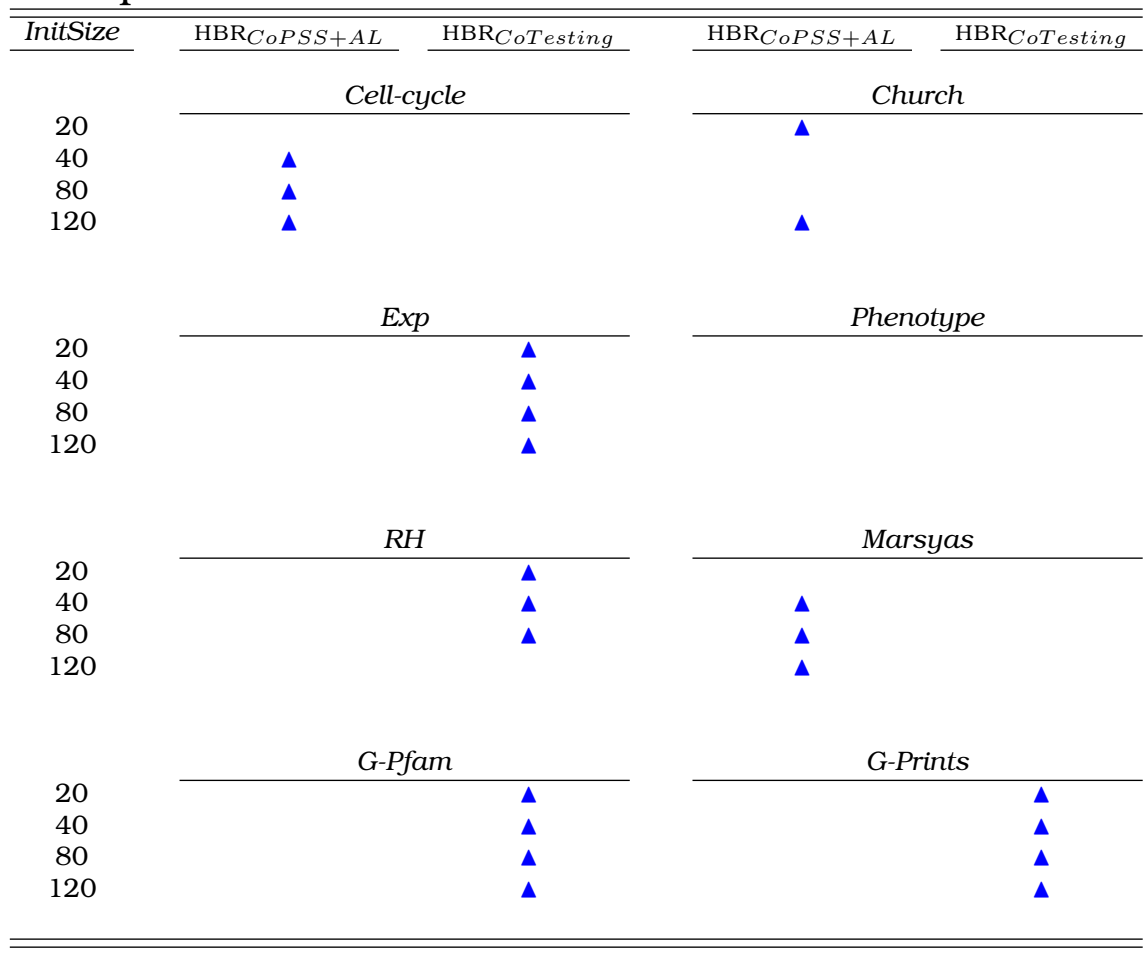

não são rotulados pelo "oráculo" nas iterações seguintes, degrada o desempenho do classificador final.

Essa diferença de performance não tão acentuada nos níveis mais profundos da hierarquia.

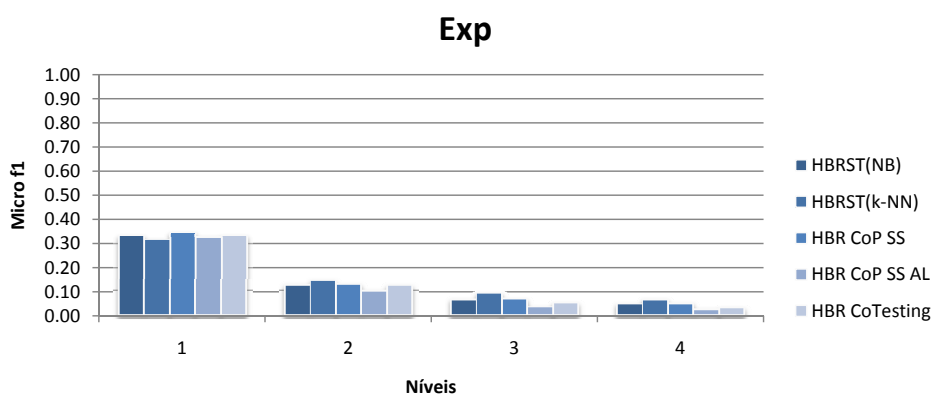

Figura 6.27: Comparação dos métodos semissupervisionados hierárquicos com e sem aprendizado ativo para Exp.

Em cenários de classificação complexos como este, no qual existem naturalmente diversos fatores capazes de degradar o modelo final de classificação, os métodos de aprendizado semissupervisionados devem ser utilizados com cautela, preferencialmente, construindo os classificadores locais a partir de algoritmos de aprendizado eficazes para a tarefa em questão. A escolha dos algoritmos de aprendizado depende da tarefa e dos dados disponíveis para treinamento. Além disso, é necessário utilizar estratégias que possam minimizar a propagação de erros através da hierarquia durante o processo de 


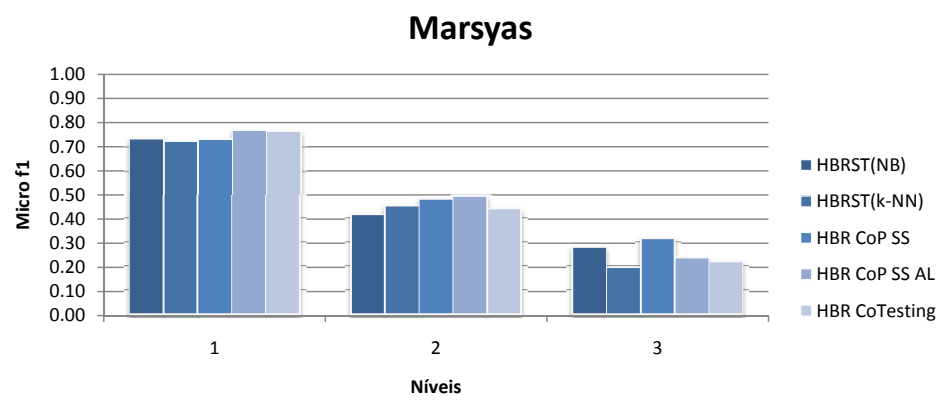

Figura 6.28: Comparação dos métodos semissupervisionados hierárquicos com e sem aprendizado ativo para Marsyas.

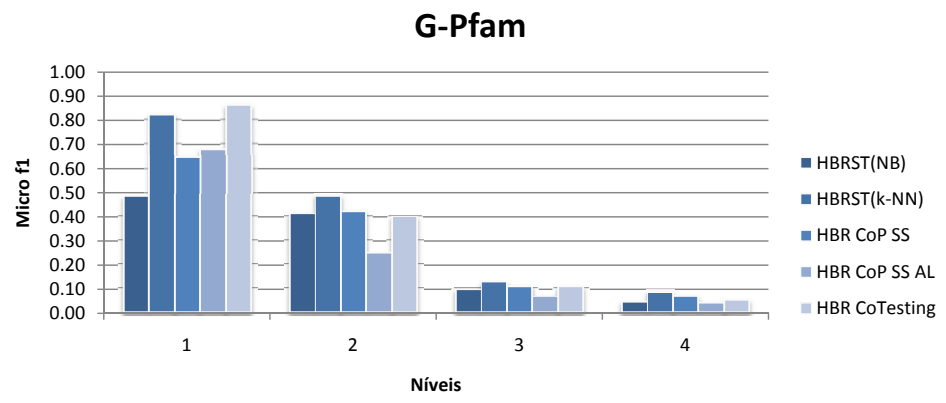

Figura 6.29: Comparação dos métodos semissupervisionados hierárquicos com e sem aprendizado ativo para G-Pfam.

aprendizado, como as estratégias implementadas nos algoritmos propostos na Seção 5.6 na página 94. Mesmo as estratégias mais simples, em alguns casos, podem contribuir significativamente para aumentar a qualidade do modelo gerado. A desvantagem de usar essas diferentes estratégias ou algoritmos de aprendizado mais robustos, é o aumento do custo computacional para a construção dos classificadores. Em (Metz et al., 2011b) estão sendo apresentados os resultados obtidos nos Cenários 3, 4 e 5 .

\subsection{Considerações finais}

Neste capítulo foram avaliados os algoritmos propostos. Quanto ao aprendizado supervisionado, ainda que o uso de duas perspectivas para a construção do classificador multirrótulo ou hierárquico possa auxiliar, dependendo do conjunto de dados, uma das perspectivas "domina" o processo de aprendizado, o que tanto pode melhorar quanto degradar a eficácia do classificador. Uma possível solução seria utilizar uma terceira perspectiva para dificultar a possibilidade de degradação do modelo.

Nas avaliações realizadas, foram utilizados $k$-NN e NB como algoritmos base em cada perspectiva a fim de realizar um estudo uniforme. Porém, em casos reais, dado um conjunto de exemplos, é importante procurar por algoritmos base que apresentem resultados ao menos melhores que o baseline fornecido 
pelo $\mathrm{BR}_{\text {Low }}$ (multirrótulo) e $\mathrm{HBR}_{\text {Low }}$ (hierárquico).

Quanto ao aprendizado semissupervisionado, é possível observar que o problema central desse tipo de aprendizado, presente também no aprendizado semissupervisionado monorrótulo, agrava-se consideravelmente nos casos de classificação mais complexa como multirrótulo e hierárquica.

Acreditamos que, para minimizar esse problema, é necessário utilizar o aprendizado ativo de uma maneira mais agressiva. Os algoritmos de aprendizado ativo propostos interrogam o "oráculo" no início do processo, caso sejam encontrados pontos de contenção. Porém, na primeira iteração desses algoritmos na qual não há um ponto de contenção, o aprendizado ativo é desativado. Entretanto, novos pontos de contenção poderiam aparecer e ser desambiguados pelo "oráculo" em iterações futuras.

Também nos experimentos realizados, no fim do processo de aprendizado semissupervisionado, todos os exemplos não rotulados são obrigatoriamente rotulados pelo algoritmo, o que pode degradar ainda mais o modelo. Considerando que um dos objetivos do aprendizado semissupervisionado é incrementar o número de exemplos rotulados para serem utilizados por algoritmos supervisionados, acreditamos que, se permitirmos ao algoritmo somente rotular exemplos "seguros", ainda que não todos, esse conjunto menor de exemplos rotulados, porém mais informativo, pode apresentar melhores resultados quando utilizado por algoritmos supervisionados. 


\section{CAPÍTULO 7 \\ Conclusões e direcionamentos para trabalhos futuros}

Este trabalho foi realizado com o objetivo geral de pesquisar e desenvolver novos métodos de aprendizado semissupervisionado para tarefas de classificação de exemplos multirrotulados, considerando os cenário de classificação multirrótulo plana e classificação hierárquica.

Como complemento a esse objetivo geral, foram elaborados alguns objetivos específicos relacionados às seguintes tarefas:

1. proposta a elaboração de baselines para avaliação de métodos de classificação multirrótulo e hierárquica;

2. projeto e implementação de métodos de aprendizado supervisionado e semissupervisionado, tanto para classificação multirrótulo quanto hierárquica;

3. aplicação do aprendizado ativo nos contextos de classificação multirrótulo e classificação hierárquica; e

4. projeto e implementação de ferramentas para a avaliação empírica dos métodos propostos.

Durante a execução deste projeto de doutorado, outros trabalhos altamente correlacionados a este foram desenvolvidos em colaboração com colegas do grupo de pesquisa, os quais contribuíram de maneira significativa para que os objetivos específicos deste projeto de doutorado fossem alcançados, e para 
que o conhecimento gerado dessas atividades fosse disseminado por meio de publicações científicas.

Os principais desafios enfrentados e as limitações a eles relacionadas, assim como as principais contribuições deste trabalho e os direcionamentos para trabalhos futuros, são apresentados a seguir.

\subsection{Dificuldades e limitações}

Algumas das dificuldades encontradas durante o desenvolvimento deste projeto são problemas inerentes às abordagens de aprendizado utilizadas: classificação multirrótulo, classificação hierárquica, aprendizado semissupervisionado mono e coperspectiva. Cada abordagem de aprendizado, por si, contém alguns fatores responsáveis pela degradação dos modelos de classificação gerados. Consequentemente, quando essas abordagens são utilizadas em conjunto, esses fatores são somados, o que torna a tarefa ainda mais complexa, pois mais de um tipo de degradação do modelo deve ser considerado.

Outras dificuldades estão relacionadas à disponibilidade de informação a respeito do uso dessas diferentes abordagens de aprendizado em conjunto. É importante mencionar que não é de nosso conhecimento a existência de trabalhos que tratem de tarefas de classificação complexas como essas em conjunto. Esse fato dificulta o desenvolvimento da pesquisa, uma vez que não existe a troca de informações com outros pesquisadores, seja por meio de publicações em periódicos ou comunicação pessoal em eventos científicos especializados.

A falta de conjuntos de dados para a avaliação dos métodos propostos também foi um desafio, pois em geral são poucos os conjuntos de dados disponiveis para essas tarefas, principalmente para a classificação hierárquica monorrótulo. Os poucos conjuntos de dados disponíveis são, em geral, de domínios altamente correlacionados, o que dificulta a avaliação generalizada dos métodos propostos e, consequentemente, limitou o escopo das avaliações experimentais apresentadas neste trabalho.

A avaliação dos resultados experimentais obtidos com métodos de classificação multirrótulo e classificação hierárquica também gerou dificuldades, pois diferentemente da classificação monorrótulo, para as tarefas de classificação multirrótulo e classificação hierárquica não existe um método ou conjunto de medidas de avaliação totalmente aceitos pela comunidade, o que dificulta a comparação com alguns resultados obtidos por outros pesquisadores. 


\subsection{Principais Contribuições}

A seguir são listadas as principais contribuições específicas deste trabalho.

1. Baselines para classificação: como mencionado anteriormente, diferentemente da classificação plana monorrótulo, os algoritmos desenvolvidos para as tarefas de classificação multirrótulo e/ou classificação hierárquica, são usualmente avaliados por meio de comparações com outros algoritmos desenvolvidos para a mesma tarefa. Com esse tipo de avaliação, é possivel identificar qual algoritmo apresenta o melhor resultado dentro de um escopo bem definido. Entretanto, somente esse tipo de análise comparativa não possibilita mensurar a real capacidade de aprendizado dos algoritmos. Para eliminar esse problema, propusemos neste trabalho dois métodos para estimativa de medidas de avaliação baseadas no multirrótulo majoritário, um para a tarefa de classificação multirrótulo plana e outro para a tarefa de classificação monorrótulo hierárquica, ambos utilizados como baseline para a avaliação experimental apresentada neste trabalho.

2. Métodos propostos: foram propostos diversos métodos para as tarefas de classificação multirrótulo e classificação hierárquica, tanto para aprendizado supervisionado como semissupervisionado utilizando diferentes abordagens. Esses métodos são sumarizados na Tabela 7.1.

Tabela 7.1: Métodos propostos

\begin{tabular}{|c|c|c|c|}
\hline Monoperspectiva & $\begin{array}{c}\text { Modo } \\
\text { Sup. } \\
\text { Semissup. }\end{array}$ & $\begin{array}{c}\text { Multirrótulo } \\
\mathrm{BR}_{S T} \\
\end{array}$ & $\begin{array}{c}\text { Hierárquico } \\
\mathrm{HMR}_{E x t}, \mathrm{HMR}_{E x t M \text { ulti }} \mathrm{e} \mathrm{HDR} \\
\mathrm{HBR}_{S T} \\
\end{array}$ \\
\hline Coperspectiva & $\begin{array}{c}\text { Sup. } \\
\text { Semissup. }\end{array}$ & $\begin{array}{c}\mathrm{BR}_{C o P} \\
\mathrm{BR}_{C o P S S}\end{array}$ & $\begin{array}{c}\mathrm{HBR}_{C o P} \\
\mathrm{HBR}_{C o P S S}\end{array}$ \\
\hline Aprend. Ativo & & $\begin{array}{c}\mathrm{BR}_{\text {CoPSS }}+A L \\
\mathrm{BR}_{\text {CoTesting }} \\
\end{array}$ & $\begin{array}{c}\mathrm{HBR}_{\text {CoPSS }}+A L \\
\mathrm{HBR}_{\text {CoTesting }} \\
\end{array}$ \\
\hline Baseline & & $\mathrm{BR}_{\text {Low }}$ & $\mathrm{HBR}_{\text {Low }}$ \\
\hline
\end{tabular}

3. HARPIA ${ }^{1}$, um framework para a avaliação experimental da classificação hierárquica: para as tarefas de classificação monorrótulo e multirrótulo planas, existem ao menos dois frameworks para avaliação experimental bem conhecidos pela comunidade, nos quais estão disponíveis uma grande gama de algoritmos e métodos de avaliação. Para a classificação hierárquica, por outro lado, não existia uma ferramenta semelhante. Nesse sentido, a integração no HARPIA de diferentes bibliotecas e frameworks desenvolvidos para as tarefas de classificação, conjuntamente

\footnotetext{
${ }^{1}$ http://sites.labic.icmc.usp.br/jeanmetz/harpia.html
} 
à implementação dos algoritmos supervisionados e semissupervisionados hierárquicos propostos neste trabalho, constituem uma das suas principais contribuições.

4. Avaliação do aprendizado semissupervisionado: neste trabalho foram apresentados resultados de um amplo estudo experimental de métodos de classificação semissupervisionada para problemas multirrótulo e hierárquicos considerando diversos cenários. A partir desses resultados, obtidos pelos algoritmos implementados na HARPIA e Mulan², foi possível avaliar os diferentes métodos e observar a performance dos métodos propostos.

Além das contribuições específicas, outras foram originadas nos trabalhos em colaboração:

1. O método para classificação plana multirrótulo supervisionada, BR+, capaz de identificar automaticamente as relações de dependência entre rótulos; e

2. O método UBC, utilizado como topline para avaliação de métodos para classificação multirrótulo baseados em stacking.

\subsection{Trabalhos Futuros}

Como observado a partir dos resultados experimentais, para a maioria dos cenários e conjuntos de dados, os métodos semissupervisionados para classificação multirrótulo e classificação hierárquica não foram semelhantes às suas respectivas versões supervisionadas. A partir da análise desses resultados, realizada com objetivo de entender os fatores que degradaram o processo de aprendizado por meio da abordagem semissupervisionada, foram identificadas algumas estratégias para melhorar a capacidade de aprendizado desses métodos.

Essas estratégias são listadas a seguir:

1. Utilizar algoritmos base mais eficazes: nas avaliações realizadas, devido à complexidade computacional dos métodos e do tamanho dos conjuntos de dados, além da necessidade de realizar avaliações utilizando um cenário comum para todos os conjuntos e dados com o objetivo de comparar os resultados, foram utilizados $k$-NN e NB como algoritmos de aprendizado base em cada perspectiva. Porém, em casos reais é importante selecionar o algoritmo base considerando as características dos dados,

\footnotetext{
${ }^{2}$ http://mulan. sourceforge.net/
} 
e que seja capaz de superar ao menos os resultados dos métodos baseline. Como trabalho futuro, pretendemos avaliar os métodos propostos utilizando algoritmos de aprendizado baseados em outros modelos, como SVM e árvores de decisão.

2. Limitar a quantidade de exemplos rotulados no processo de semissupervisão: nos experimentos realizados, todos os exemplos não rotulados foram obrigatoriamente rotulados pelo algoritmo durante o processo de semissupervisão. Essa característica pode ter contribuído para a degradação dos modelos. Considerando que um dos objetivos do aprendizado semissupervisionado é incrementar o número de exemplos rotulados para serem utilizados por algoritmos supervisionados, acreditamos que, se permitirmos ao algoritmo incrementar o conjunto de treinamento rotulando somente exemplos "seguros", os quais podem ser mais informativos, a tendência é que os modelos de classificação finais sejam mais "fortes".

3. Degradação dos modelos: o problema central do aprendizado semissupervisionado, ou seja, a degradação do modelo originada pela rotulação equivocada de exemplos no início do processo, foi observado nos resultados obtidos, tanto para a classificação multirrótulo quanto hierárquica. Esse problema, como mencionado anteriormente, ocorre também no contexto de classificação plana monorrótulo, mas agrava-se consideravelmente nos casos de classificação mais complexa como multirrótulo e hierárquica.

Acreditamos que, para minimizar esse problema, é necessário utilizar o aprendizado ativo de uma maneira mais agressiva. Os algoritmos de aprendizado ativo propostos, caso encontrem pontos de contenção, interrogam o "oráculo" apenas no início do processo de autorrotulação de exemplos. Porém, caso não sejam identificados pontos de contenção ou o limite de consultas tenha sido atingido, o aprendizado ativo é desativado e apenas o procedimento semissupervisionado continua nas próximas iterações. Entretanto, uma vez que os modelos de classificação em cada perspectiva são atualizados, novos pontos de contenção podem ser identificados, mas não podem ser desambiguados pelo "oráculo” nessas iterações. Por outro lado, se o aprendizado ativo for também utilizado nessas iterações, esses exemplos também poderiam ser rotulados pelo “oráculo". Obviamente, para manter a proposta factivel, deve-se controlar o número de consultas e mantê-lo dentro de um limiar razoável.

4. Uso de perspectivas: como foi observado nos resultados das avaliações experimentais, uma das perspectivas quase sempre "domina" o processo de aprendizado coperspectiva, o que tanto pode melhorar quanto degra- 
dar a eficácia do classificador. Para entender melhor esse comportamento é necessária uma análise mais detalhada do processo de aprendizado dos classificadores nas diferentes perspectivas em cada iteração, considerando, por exemplo, o percentual de exemplos classificados de maneira diferente pelos dois classificadores, assim como o grau de confiança dessas predições. Além disso, com o uso de apenas duas perspectivas a predição é sempre definida pela "perspectiva mais confiante", mesmo quando essa perspectiva está errada. Outra alternativa é utilizar um número ímpar de perspectivas, a partir dos quais a predição poderia ser determinada não apenas pelo grau de confiança dos classificadores, mas também utilizando uma estratégia de votação.

Essas estratégias serão desenvolvidas e avaliadas em trabalhos futuros. 


\section{Referências Bibliográficas}

Abe, N. \& Mamitsuka, H. (1998). Query learning strategies using boosting and bagging. Em ICML 1998: Proceedings of the Fifteenth International Conference on Machine Learning, páginas 1-9. Morgan Kaufmann Publishers Inc. Citado na página 70.

Abney, S. (2007). Semisupervised Learning for Computational Linguistics. Chapman \& Hall. Citado na página 62.

Alpaydin, E. (2010). Introduction to Machine Learning. MIT Press, 2nd edição. Citado na página 8.

Antonopoulos, I., Pikrakis, A., Theodoridis, S., Cornelis, O., Moelants, D., \& Leman, M. (2007). Music retrieval by rhythmic similarity applied on greek and african traditional music. Em ISMIR 2007: Proceedings of International Symposium/Conference on Music Information Retrieval, páginas 297300. Citado na página 136.

Balcan, M.-F., Blum, A., \& Yang, K. (2004). Co-Training and expansion: Towards bridging theory and practice. Em NIPS 2004: Proceedings of The Advances in Neural Information Processing Systems, páginas 89-96. Citado na página 66.

Barbedo, J. G. A. \& Lopes, A. (2007). Automatic genre classification of musical signals. EURASIP Journal on Applied Signal Processing, 2007:157-157. Citado na página 35.

Barutcuoglu, Z., Schapire, R. E., \& G.Troyanskaya, O. (2006). Hierarchical multi-label prediction of gene function. Bioinformatics, 22(7):830-836. Citado na página 37.

Basu, S., Banerjee, A., \& Mooney, R. (2002). Semi-supervised clustering by seeding. Em ICML 2002: Proceedings of The Nineteenth International Con- 
ference on Machine Learning, páginas 19-26. Morgan Kaufmann Publishers Inc. Citado na página 58.

Batista, G. E. A. P. A., Prati, R. C., \& Monard, M. C. (2004). A study of the behavior of several methods for balancing machine learning training data. SIGKDD Explorations Newsletter, 6:20-29. Citado na página 15.

Belkin, M. \& Niyogi, P. (2004). Semi-supervised learning on Riemannian manifolds. Machine Learning, 56(1-3):209-239. Citado na página 56.

Belkin, M., Niyogi, P., \& Sindhwani, V. (2006). Manifold regularization: A geometric framework for learning from labeled and unlabeled examples. Journal of Machine Learning Research, 7:2399-2434. Citado na página 57.

Blockeel, H., Bruynooghe, M., Dzeroski, S., Ramon, J., \& Struyf, J. (2002). Hierarchical multi-classification. Em MRDM 2002: Proceedings of the First SIGKDD Workshop on Multi-relational Data Mining, páginas 21-35. Citado nas páginas 35 and 49 .

Blum, A. \& Chawla, S. (2001). Learning from labeled and unlabeled data using graph mincuts. Em ICML 2001: Proceedings of The Eighteenth International Conference on Machine Learning, páginas 19-26. Morgan Kaufmann Publishers Inc. Citado na página 62.

Blum, A. \& Mitchell, T. (1998). Combining labeled and unlabeled data with Co-Training. Em COLT 1998: Proceedings of The eleventh annual conference on Computational learning theory, páginas 92-100. ACM Press. Citado nas páginas 57, 64, and 67.

Boutell, M. R., Luo, J., Shen, X., \& Brown, C. M. (2004). Learning multi-label scene classification. Pattern Recognition, 37:1757-1771. Citado nas páginas 14 and 112 .

Braga, I. A. (2010). Aprendizado semissupervisionado multidescrição em classificação de textos. Dissertação de Mestrado, ICMC-USP. Citado nas páginas $69,70,71,72$, and 114 .

Braga, I. A., Matsubara, E. T., \& Monard, M. C. (2009). Um estudo sobre a rotulação de exemplos no aprendizado semissupervisionado multivisão. Em ENIA 2009: Anais do XXIX Congresso da Sociedade Brasileira de Computação - Encontro Nacional de Inteligência Artificial, páginas 1059-1068. Citado na página 70.

Braga, I. A. \& Monard, M. C. (2010). Projeto e implementação do algoritmo semissupervisionado multidescrição CoAL (Co-training with Active Learning). Relatório técnico, ICMC-USP. Citado na página 67. 
Brinker, K. \& Hüllermeier, E. (2007). Case-based multilabel ranking. Em IJCAI 2007: Proceedings of the 20th International Conference on Artificial Intelligence, páginas 702-707. Citado na página 17.

Burred, J. J. \& Lerch, A. (2003). A hierarchical approach to automatic musical genre classification. Em DAFx 2003: Proceedings of The 6th International Conference on Digital Audio Effects, páginas 8-11. Citado na página 34.

Cai, L. \& Hofmann, T. (2007). Exploiting known taxonomies in learning overlapping concepts. Em IJCAI 2007: Proceedings of the 20th International Joint Conference on Artifical intelligence, páginas 714-719. Morgan Kaufmann Publishers Inc. Citado na página 36.

Cano, P., Gomez, E., Gouyon, F., Herrera, P., Koppenberger, M., Ong, B., Serra, X., Streich, S., \& Wack, N. (2006). Ismir 2004 audio description contest. Relatório técnico, Music Technology Group. Pompeu Fabra University. Citado na página 135.

Castelli, V. \& Cover, T. M. (1996). The relative value of labeled and unlabeled samples in pattern recognition with an unknown mixing parameter. IEEE Transactions on Information Theory, 42(6):2102-2117. Citado na página 61.

Ceci, M. \& Malerba, D. (2003). Hierarchical classification of HTML documents with WebClass II. Em ECIR 2003: Proceedings of the 25th European conference on IR research, páginas 57-72. Springer-Verlag. Citado nas páginas 39 and 150.

Chapelle, O. (2006). Introduction to Semi-supervised Learning, capítulo 1, páginas 1-12. Volume 1 de Chapelle et al. (2006). Citado nas páginas 59 and 63.

Chapelle, O., Schölkopf, B., \& Zien, A., editores (2006). Semi-Supervised Learning, volume 1. MIT Press. Citado nas páginas 57, 63, 177, 178, and 185.

Cherman, E. A., Metz, J., \& Monard, M. C. (2010a). Explorando dependência entre rótulos no classificador multirrótulo binary relevance. Em WCI 2010: Proceedings of III Workshop on Computational Intelligence in Joint Conference - SBIA/SBRN/JRI 2010, páginas 1-6. Publicado em CD-ROM. Citado nas páginas 78 and 79 .

Cherman, E. A., Metz, J., \& Monard, M. C. (2010b). A simple approach to incorporate label dependency in multi-label classification. Em MICAI 2010: Proceedings of 9th Mexican International Conference on Artificial Intelligence. Advances in Soft Computing: Part II, volume 6438 de Lecture Notes in Artificial 
Intelligence, páginas 33-43. Springer-Verlag. Citado nas páginas 21, 78, 79, and 80 .

Cherman, E. A., Metz, J., \& Monard, M. C. (2012). Incorporating label dependency into the binary relevance framework for multi-label classification. Expert Systems with Applications, 39(2):1647-1655. Citado na página 80.

Cherman, E. A., Monard, M. C., \& Metz, J. (2010c). Métodos multirrótulo independentes de algoritmo: um estudo de caso. Em CLEI 2010: Anais do XXXVI Coferência Latino-americana de Informática, páginas 1-14. Publicado em CD-ROM. Citado na página 77.

Cherman, E. A., Monard, M. C., \& Metz, J. (2011). Multi-label problem transformation methods: a case study. CLEI Electronic Journal, 14(1):1-10. paper 4. Citado nas páginas 78 and 114 .

Clare, A. (2003). Machine learning and data mining for yeast functional genomics. Tese de Doutorado, Departament of Computer Science, University of Wales. Citado na página 35.

Clare, A. \& King, R. D. (2001). Knowledge discovery in multi-label phenotype data. Em PKDD 2001: Proceedings of the 5th European Conference on Principles of Data Mining and Knowledge Discovery, páginas 42-53. SpringerVerlag. Citado nas páginas 16, 27, and 47.

Cohen, I., Cozman, F. G., Sebe, N., Cirelo, M. C., \& Huang, T. S. (2004). Semisupervised learning of classifiers: Theory, algorithms, and their application to human-computer interaction. IEEE Transactions on Pattern Analysis and Machine Intelligence, 26(12):1553-1567. Citado na página 62.

Costa, E. P., Lorena, A. C., Carvalho, \& Freitas, A. A. (2007). A review of performance evaluation measures for hierarchical classifiers. Em Evaluation Methods for Machine Learning II: papers from the 2007 AAAI Workshop, páginas 1-6. AAAI Press. Citado na página 48.

Cozman, F. \& Cohen, I. (2002). Unlabeled data can degrade classification performance of generative classifiers. Em FLAIRS 2002: Proceedings of The International Florida Artificial Intelligence Society Conference, páginas 327331. AAAI Press. Citado nas páginas 61 and 62.

Cozman, F. \& Cohen, I. (2006). Risks of Semi-Supervised Learning: How Unlabeled Data Can Degrade Performance of Generative Classifier, capítulo 4, páginas 57-72. Volume 1 de Chapelle et al. (2006), 1 edição. Citado na página 61. 
Crammer, K., Singer, Y., K, J., Hofmann, T., Poggio, T., \& Shawe-taylor, J. (2003). A family of additive online algorithms for category ranking. Journal of Machine Learning Research, 3:2003. Citado na página 17.

Dembczynski, K., Waegeman, W., Cheng, W., \& Hüllermeier, E. (2010). On label dependence in multi-label classification. Em MLD 2010: Proceedings of the second International Workshop on Learning from Multi-Label Data in International Conference of Machine Learning (ICML), páginas 5-12, Haifa Israel. Citado na página 81.

Demsar, J. (2006). Statistical comparisons of classifiers over multiple data sets. Journal of Machine Learning Research, 7:1-30. Citado nas páginas 148 and 149.

Dietterich, T. G. (1998). Approximate statistical tests for comparing supervised classification learning algorithms. Neural Computation, 10(7):1895-1923. Citado na página 143.

Eisner, R., Poulin, B., Szafron, D., Lu, P., \& Greiner, R. (2005). Improving protein function prediction using the hierarchical structure of the gene ontology. Em IEEE CIBCB 2005: Proceedings of Symposium on Computational Intelligence in Bioinformatics and Computational Biology, páginas 1-10. Citado nas páginas 39, 41, and 150 .

Elisseeff, A. \& Weston, J. (2001a). A kernel method for multi-labelled classification. Em Advances in Neural Information Processing Systems, páginas 681-687. MIT Press. Citado nas páginas 17 and 112.

Elisseeff, K. \& Weston, J. (2001b). Kernel methods for multi-labelled classification and categorical regression problems. Em Advances in Neural Information Processing Systems, páginas 681-687. MIT Press. Citado na página 17.

Fagni, T. \& Sebastiani, F. (2007). On the selection of negative examples for hierarchical text categorization. Em Proceedings of The 3rd Language Technology Conference, páginas 24-28. Citado nas páginas 39, 40, and 150.

Fillmore, D. (2004). Modern drug discovery. It's a GPCR world, 11:24-28. Citado na página 137.

Freitas, A. \& de Carvalho, A. C. (2007). A tutorial on hierarchical classification with applications in bioinformatics. Em Research and Trends in Data Mining Technologies and Applications, capítulo 7, páginas 175-208. IGI Global. Citado nas páginas 9, 27, 30, 33, 34, 37, 44, 45, 48, and 137. 
Freund, Y. \& Schapire, R. E. (1995). A decision-theoretic generalization of on-Line learning and an application to boosting. Journal of Computer and System Sciences, 55:119-139. Citado na página 16.

Ghani, R. (2002). Combining labeled and unlabeled data for multiclass text categorization. Em ICML 2002: Proceedings of The Nineteenth International Conference on Machine Learning, páginas 187-194. Morgan Kaufmann Publishers Inc. Citado na página 57.

Godbole, S. \& Sarawagi, S. (2004). Discriminative methods for multi-labeled classification. Em Advances in Knowledge Discovery and Data Mining, Lecture Notes in Computer Science, páginas 22-30. Citado na página 21.

Gouyon, F., Herrera, P., \& Cano, P. (2002). Pulse-dependent analyses of percussive music. Em ICASSP 2002: Proceedigns of 22nd IEEE International Conference on Acoustics, Speech, and Signal Processing, volume 4, páginas 1-6. Citado na página 136.

Greene, D. \& Cunningham, P. (2007). Constraint selection by committee: An ensemble approach to identifying informative constraints for semisupervised clustering. Em ECML 2007: Proceedings of the 18th European Conference on Machine Learning, páginas 140-151. Springer-Verlag. Citado na página 70 .

Greiner, R., Grove, A., \& Schuurmans, D. (1997). On learning hierarchical classifications. Em ResearchIndex; The NECI Scientifc Literature Digital Library (Online). Citado na página 42.

Gupta, S., Kim, J., Grauman, K., \& Mooney, R. J. (2008). Watch, listen \& learn: Co-training on captioned images and videos. Em ECML 2008: Proceedings of the 19th European Conference on Machine Learning, volume 5211 de Lecture Notes in Computer Science, páginas 457-472. Springer-Verlag. Citado na página 64.

Hall, M., Frank, E., Holmes, G., Pfahringer, B., Reutemann, P., \& Witten, I. H. (2009). The Weka data mining software: An update. SIGKDD Explorations, 11(1):10-18. Citado nas páginas 113 and 139.

Holden, N. \& Freitas, A. (2009). Hierarchical classification of protein function with ensembles of rules and particle swarm optimisation. Soft Computing Journal, 13(3):259-272. Citado na página 49.

Holden, N. \& Freitas, A. A. (2006). Hierarchical classification of g-proteincoupled receptors with a pso/aco algorithm. Em SIS 2006: Proceedings of 
IEEE Swarm Intelligence Symposium, páginas 77-84. IEEE Press. Citado na página 49.

Hosmer, David W., J. (1973). A comparison of iterative maximum likelihood estimates of the parameters of a mixture of two normal distributions under three different types of sample. Biometrics, 29(4):761-770. Citado na página 57.

Joachims, T. (1999). Transductive inference for text classification using support vector machines. Em ICML 1999: Proceedings of the 16th International Conference on Machine Learning, páginas 200-209. Citado na página 62.

John, G. H. \& Langley, P. (1995). Estimating Continuous Distributions in Bayesian Classifiers. Em UAI 1995: Proceedings of the Eleventh Annual Conference on Uncertainty in Artificial Intelligence, páginas 338-345. Citado na página 114.

Kiritchenko, S. \& Matwin, S. (2001). Email classification with co-training. Em CASCON 2001: Proceedings of the 2001 conference of the Centre for Advanced Studies on Collaborative research, página 8. IBM Press. Citado na página 64.

Kiritchenko, S., Matwin, S., \& Famili, A. F. (2005). Functional annotation of genes using hierarchical text categorization. Em Proceedings of The BioLINK SIG: Linking Literature, Information and Knowledge for Biology, páginas 1-4. Citado nas páginas 45, 47, 48, 51, and 53.

Kiritchenko, S., Matwin, S., Nock, R., \& Famili, A. (2006). Learning and evaluation in the presence of class hierarchies: Application to text categorization. Em Advances in Artificial Intelligence, volume 4013 de Lecture Notes in Computer Science, páginas 395-406. Springer-Verlag. Citado nas páginas 48 and 51.

Klein, D., Kamvar, S. D., \& Manning, C. D. (2002). From instance-level constraints to space-level constraints: Making the most of prior knowledge in data clustering. Em ICML 2002: Proceedings of The Nineteenth International Conference on Machine Learning, páginas 307-314. Morgan Kaufmann. Citado na página 58.

Koprinska, I., Poon, J., Clark, J., \& Chan, J. (2007). Learning to classify e-mail. Information Sciences, 177(10):2167-2187. Citado na página 64.

Labrou, Y. K. (1999). Yahoo as an ontology - using yahoo categories to describe documents. Em CIKM 1999: Proceedings of the 1999 ACM Conference on Information and Knowledge Management. Citado na página 47. 
Laguna, V. \& Lopes, A. A. (2009). Mult-view approach for semi-supervised scientific paper classification. Em WAAMD 2009: Anais do V Workshop em Algoritmos e Aplicações de Mineração de Dados, páginas 26-33. Citado na página 64.

Lewis, D. D. \& Gale, W. A. (1994). A sequential algorithm for training text classifiers. Em SIGIR 1994: Proceedings of the 17th annual international ACM SIGIR conference on Research and development in information retrieval, páginas 3-12. Springer-Verlag. Citado na página 70.

Li, T. \& Ogihara, M. (2003). Detecting emotion in music. Em ISMIR 2003: Proceedings of the International Symposium on Music Information Retrieval, páginas 239-240. Citado na página 14.

Li, T., Zhang, C., \& Zhu, S. (2006). Empirical studies on multi-label classification. Em ICTAI 2006: Proceedings of the 18th IEEE International Conference on Tools with Artificial Intelligence, páginas 86-92. Citado na página 14.

Lidy, T. \& Rauber, A. (2005). Evaluation of feature extractors and psychoacoustic transformations for music genre classification. Em ISMIR 2005: Proceedings of 6th International Conference on Music Information Retrieval, páginas 34-41. Citado na página 136.

Lippmann, R. (1989). Pattern classification using neural networks. IEEE Communications Magazine, 27:47-54. Citado na página 57.

Lipscomb, C. E. (2000). Medical subject headings (MeSH). Bulletin of the Medical Library Association, 88(3):265-266. Citado na página 27.

Lord, P. W., Stevens, R. D., Brass, A., \& Goble, C. A. (2003). Investigating semantic similarity measures across the gene ontology: the relationship between sequence and annotation. Bioinformatics, 19(10):1275-1283. Citado na página 49 .

Luo, X. \& Heywood, Z. A. N. (2005). Evaluation of two systems on multiclass multi-label document classification. Em ISMIS 2005: Proceedings of the 15th International Symposium on Methodologies for Intelligent Systems, páginas 161-169. Citado na página 17.

Matsubara, E. T. (2004). O algoritmo de aprendizado semi-supervisionado Co-Training e sua aplicação na rotulação de documentos. Dissertação de Mestrado, ICMC-USP. Citado na página 70.

Matsubara, E. T., Monard, M. C., \& Prati, R. C. (2006). On the class distribution labelling step sensitivity of Co-Training. Em IFIP 2006: Proceedings 
of The International Federation for Information Processing Congress, Artificial Intelligence in Theory and Practice, volume 217, páginas 199-208. Citado na página 67.

McLachlan, G. J. (1975). Iterative reclassification procedure for constructing asymptotically optimal rule of allocation in discriminant analysis. Journal of the American Statistical Association, 70(350):365-369. Citado na página 57.

McLachlana, G. J. \& Ganesalingama, S. (1982). Updating a discriminant function on the basis of unclassified data. Communications in Statistics - Simulation and Computation, 11:753-767. Citado na página 57.

Metz, J. \& Freitas, A. A. (2009). Extending hierarchical classification with semi-supervised learning. Em UKCI 2009: Proceedings of the UK Workshop on Computational Intelligence, páginas 1-6. Citado nas páginas 37, 50, 104, and 144.

Metz, J., Freitas, A. A., \& Monard, M. C. (2010). Um estudo sobre métodos de classificação hierárquica e medidas de avaliação. Relatório Técnico 364, ICMC - USP. Citado nas páginas 39, 48, and 149.

Metz, J., Freitas, A. A., Monard, M. C., \& Cherman, E. A. (2011a). A study on the selection of local training sets for hierarchical classification tasks. Em ENIA 2011: Anais do VIII Encontro Nacional de Inteligência Artificial, páginas 1-12. Publicado em CD-ROM. Citado nas páginas 39, 41, 48, 143, 149, and 150.

Metz, J., Monard, M. C., Cherman, E. A., \& Freitas, A. A. (2011b). Exploiting disagreement learning on hierarchical classification problems (a ser submetido). Knowledge and Information Systems, 1:1-17. Citado na página 166.

Mitchell, T. M. (1997). Machine Learning. McGraw-Hill. Citado na página 8.

Mladenić, D. \& Grobelnik, M. (1998). Feature selection for classification based on text hierarchy. Em CONALDO 1998: Text and the Web, Conference on Automated Learning and Discovery, páginas 1-6. Citado nas páginas 37 and 39 .

Muslea, I., Minton, S., \& Knoblock, C. A. (2000). Selective sampling with redundant views. Em AAAI/IAAI 2000: Proceedings of The 17th National Conference on Artificial Intelligence and 20th Conference on Innovative Applications of Artificial Intelligence, páginas 621-626. AAAI Press / The MIT Press. Citado na página 70. 
Muslea, I., Minton, S., \& Knoblock, C. A. (2006). Active learning with multiple views. Journal of Artificial Intelligence Research (JAIR), 27:203-233. Citado na página 70 .

Nigam, K., McCallum, A. K., Thrun, S., \& Mitchell, T. M. (2000). Text classification from labeled and unlabeled documents using EM. Machine Learning, 39(2/3):103-134. Citado na página 62.

O’Neill, T. J. (1978). Normal discrimination with unclassified observations. Journal of the American Statistical Association, 73:821-826. Citado na página 57.

Ozay, M. \& Vural, F. (2008). Performance analysis of stacked generalization classifiers. Em Proceedings of the 16th IEEE Conference on Signal Processing, Communication and Applications (SIU'2008), páginas 1-4. Citado na página 17.

Qi, G. J., Hua, X. S., Rui, Y., Tang, J., Mei, T., \& Zhang, H. J. (2007). Correlative multi-label video annotation. Em MULTIMEDIA 2007: Proceedings of the 15th International Conference on Multimedia, páginas 17-26. ACM. Citado na página 14.

Giu, X., Gao, W., \& Huang, X. (2009). Hierarchical multi-class text categorization with global margin maximization. Em ACL-IJCNLP 2009: Proceedings of the Joint conference of the 47th Annual Meeting of the Association for Computational Linguistics and the 4th International Joint Conference on Natural Language Processing of the Asian Federation of Natural Language Processing. Conference Short Papers, páginas 165-168. Association for Computational Linguistics. Citado na página 36.

Quinlan, J. R. (1993). C4.5 Programs for Machine Learning. Morgan Kaufmann Publishers. Citado na página 16.

Read, J., Pfahringer, B., \& Holmes, G. (2008). Multi-label classification using ensembles of pruned sets. Em ICDM 2008: Proceedigns of International Conference on Data Mining, páginas 995-1000. Citado nas páginas 112 and 113.

Read, J., Pfahringer, B., Holmes, G., \& Frank, E. (2009). Classifier chains for multi-label classification. Em ECML/PKDD 2009: Proceedings of the European Conference on Machine Learning and Knowledge Discovery in Databases: Part II, páginas 254-269. Citado na página 22.

Ruepp, A., Zollner, A., Maier, D., Albermann, K., Hani, J., Mokrejs, M., Tetko, I., Güldener, U., Mannhaupt, G., Münsterkötter, M., \& Mewes, H. W. (2004). 
The funcat, a functional annotation scheme for systematic classification of proteins from whole genomes. Nucleic Acids Research, 32(18):5539-5545. Citado na página 27.

Russell, S. J. \& Norvig, P. (2010). Artificial Intelligence: A Modern Approach. Prentice Hall, 3rd edição. Citado na página 10.

Sasaki, M. \& Kita, K. (1998). Rule-based text categorization using hierarchical categories. Em SMC 1998: Proceedings of the IEEE International Conference on Systems, Man, and Cybernetics, volume 3, páginas 2827-2830. Citado na página 47.

Schapire, R. E. \& Singer, Y. (2000). Boostexter: A boosting-based system for text categorization. Machine Learning, 39:135-168. Citado na página 16.

Schapire, R. E., Singer, Y., \& Singhal, A. (1998). Boosting and Rocchio applied to text filtering. Em SIGIR 1998: Proceedings of the 21st annual international ACM SIGIR conference on Research and development in information retrieval, páginas 215-223. ACM. Citado na página 40.

Secker, A., Davies, M., Freitas, A., Timmis, J., Mendao, M., \& Flower, D. (2007). An experimental comparison of classification algorithms for the hierarchical prediction of protein function. Expert Update, 9(3):17-22. Citado na página 37.

Secker, A., Davies, M. N., Freitas, A. A., Clark, E. B., Timmis, J., \& Flower, D. R. (2010). Hierarchical classification of g-protein coupled receptors with data driven selection of attributes and classifiers. International Journal of Data Mining and Bioinformatics, 4(2):191-210. Citado na página 37.

Seeger, M. (2006). A Taxonomy for Semi-Supervised Learning Methods, capítulo 2, páginas 15-31. Volume 1 de Chapelle et al. (2006), 1 edição. Citado na página 9.

Seung, H. S., Opper, M., \& Sompolinsky, H. (1992). Query by committee. Em COLT 1992: Proceedings of the fifth annual workshop on Computational learning theory, páginas 287-294. ACM. Citado na página 70.

Shahshahani, B. \& Landgrebe, D. (1994). The effect of unlabeled samples in reducing the small sample size problem and mitigating the hughes phenomenon. IEEE Transactions on Geoscience and Remote Sensing, 32(5):1087 -1095. Citado nas páginas 57 and 62.

Silla, C. N., Koerich, A. L., \& Kaestner, C. A. A. (2008). The latin music database. Em ISMIR 2008: Proceedings of 9th International Conference on Music Information Retrieval, páginas 451-456. Citado na página 135. 
Silla Jr, C. \& Freitas, A. (2011). A survey of hierarchical classification across different application domains. Data Mining and Knowledge Discovery, 1:142. Citado nas páginas $9,30,31,36$, and 37.

Silla Jr, C. N. \& Freitas, A. A. (2009a). A global-model naive bayes approach to the hierarchical prediction of protein functions. Em ICDM 2009: Proceedings of the 9th IEEE International Conference on Data Mining, páginas 992-997. Citado na página 137.

Silla Jr, C. N. \& Freitas, A. A. (2009b). Novel top-down approaches for hierarchical classification and their application to automatic music genre classification. Em SMC'09: Proceedings of the 2009 IEEE international conference on Systems, Man and Cybernetics, páginas 3499-3504. IEEE Press. Citado na página 135.

Singhal, A., Mitra, M., \& Buckley, C. (1997). Learning routing queries in a query zone. Em SIGIR 1997: Proceedings of the 20th Annual International ACM Special Interest Group on Information Retrieval Conference on Research and development in information retrieval, páginas 25-32. ACM. Citado na página 40.

Spyromitros, E., Tsoumakas, G., \& Vlahavas, I. (2008). An empirical study of lazy multilabel classification algorithms. Em Artificial Intelligence: Theories, Models and Applications, volume 5138 de Lecture Notes in Computer Science, páginas 401-406. Citado na página 17.

Struyf, J., Dzeroski, S., Blockeel, H., \& Clare, A. (2005). Hierarchical multiclassification with predictive clustering trees in functional genomics. Em EPIA 2005: Proceedings of 12th Portuguese Conference on Artificial Intelligence. Progress in Artificial Intelligence, volume 3808 de Lecture Notes in Computer Science, páginas 272-283. Springer-Verlag. Citado na página 47.

Sun, A., Lim, E., \& Ng, W. (2003a). Performance measurement framework for hierarchical text classification. Journal of the American Society for Information Science and Technology, 54:1014-1028. Citado nas páginas 33 and 42 .

Sun, A. \& Lim, E.-P. (2001). Hierarchical text classification and evaluation. Em ICDM 2001: Proceedings of the 2001 IEEE International Conference on Data Mining, páginas 521-528. IEEE Computer Society. Citado nas páginas 30, 37 , and 48 .

Sun, A., Lim, E.-P., \& Ng, W.-K. (2003b). Hierarchical text classification methods and their specification. Kluwer International Series In Engineering And Computer Science, 1(729):236-256. Citado na página 37. 
Sun, A., Lim, E.-P., Ng, W.-K., \& Srivastava, J. (2004). Blocking reduction strategies in hierarchical text classification. IEEE Transactions on Knowledge and Data Engineering, 16(10):1305-1308. Citado nas páginas 37, 94, and 95.

Thabtah, F. A., Cowling, P., \& Peng, Y. (2004). MMAC: A new multi-class, multi-label associative classification approach. Em ICMD 2004: Proceedings of Fourth IEEE International Conference on Data Mining, páginas 217-224. Citado na página 17.

Tikk, D., Biró, G., \& Yang, J. D. (2004). A hierarchical text categorization approach and its application to frt expansion. Australian Journal of Intelligent Information Processing Systems, 8(3):123-131. Citado na página 37.

Toutanova, K., Chen, F., Popat, K., \& Hofmann, T. (2001). Text classification in a hierarchical mixture model for small training sets. Em CIKM 2001: Proceedings of the Tenth International Conference on Information and Knowledge Management, páginas 105-113. ACM. Citado na página 47.

Trohidis, K., Tsoumakas, G., Kalliris, G., \& Vlahavas, I. (2008). Multilabel classification of music into emotions. Em ISMIR 2008: 9th International Conference on Music Information Retrieval, páginas 325-330. Citado nas páginas 14,17 , and 112 .

Tsoumakas, G. \& Katakis, I. (2007). Multi-Label Classification: An Overview. International Journal of Data Warehouse and Mining, 3(3):1-13. Citado nas páginas 15, 16, and 24 .

Tsoumakas, G., Katakis, I., \& Vlahavas, I. (2010). Mining multi-label data. Em Data Mining and Knowledge Discovery Handbook, páginas 667-685. Springer-Verlag. Citado nas páginas 7, 9, 14, 15, 17, 26, and 37.

Tzanetakis, G. \& Cook, P. (2002). Musical genre classification of audio signals. IEEE Transactions on Speech and Audio Processing, 10(5):293-302. Citado na página 136.

Ueda, N. \& Saito, K. (2003). Parametric mixture models for multi-labeled text. Em Advances in Neural Information Processing Systems 15, The MIT Press. Citado na página 14.

Vapnik, V. \& Vashist, A. (2009). A new learning paradigm: Learning using privileged information. Neural Networks, 22(5-6):544-557. Citado na página 65.

Vapnik, V. N. (1998). Statistical Learning Theory. Wiley-Interscience. Citado na página 62 . 
Vens, C., Struyf, J., Schietgat, L., Džeroski, S., \& Blockeel, H. (2008). Decision trees for hierarchical multi-label classification. Machine Learning, 73(2):185-214. Citado nas páginas 36 and 42.

Wagstaff, K., Cardie, C., Rogers, S., \& Schrödl, S. (2001). Constrained kmeans clustering with background knowledge. Em ICML 2001: Proceedings of The Eighteenth International Conference on Machine Learning, páginas 577-584. Morgan Kaufmann. Citado na página 58.

Wang, J., Shen, X., \& Pan, W. (2009). On large margin hierarchical classification with multiple paths. Journal of the American Statistical Association, 104(487):1213-1223. Citado na página 36.

Witten, I. H., Frank, E., Holmes, G., \& Hall, M. (2011). Data Mining: Practical machine learning tools and techniques, volume 1. Morgan Kaufmann Publishers Inc., 3rd edição. Citado nas páginas 141 and 149.

Wolpert, D. H. (1992). Stacked generalization. Neural Networks, 5:241-259. Citado na página 17.

Wu, F., Zhang, J., \& Honavar, V. (2005). Learning classifiers using hierarchically structured class taxonomies. Em Abstraction, Reformulation and Approximation, volume 3607 de Lecture Notes in Computer Science, páginas 313-320. Springer-Verlag. Citado na página 31.

Xiao, Z., Dellandrea, E., Dou, W., \& Chen, L. (2007). Automatic hierarchical classification of emotional speech. Em ISMW 2007: Ninth IEEE International Symposium on Multimedia Workshops, páginas 291-296. Citado na página 34.

Yeung, D.-Y., Chang, H., \& Dai, G. (2007). A scalable kernel-based algorithm for semi-supervised metric learning. Em IJCAI 2007: Proceedings of The 20th International Joint Conference on Artificial Intelligence, páginas 1138-1143. Citado na página 57.

Zhang, M.-L. (2006). Multilabel neural networks with applications to functional genomics and text categorization. IEEE Transactions on Knowledge and Data Engineering, 18(10):1338-1351. Senior Member-Zhou, Zhi-Hua. Citado nas páginas 14 and 17.

Zhang, M.-L. \& Zhou, Z.-H. (2005). A k-nearest neighbor based algorithm for multi-label classification. IEEE International Conference on Granular Computing, 2:718-721. Citado na página 17. 
Zhang, M.-1. \& Zhou, Z.-h. (2007). Multi-Label learning by instance differentiation. Em AAAI 2007: Proceedings of the Twenty-Second AAAI Conference on Artificial Intelligence, páginas 669-674. AAAI Press. Citado na página 14.

Zhang, Q. \& Sun, S. (2010). Multiple-view multiple-learner active learning. Pattern Recogn., 43:3113-3119. Citado na página 69.

Zhou, Z.-H. (2008). Semi-supervised learning by disagreement. Em IEEE GrC 2008: Proceedings of the IEEE International Conference on Granular Computing, páginas 93-93. Citado na página 64.

Zhou, Z.-H. \& Li, M. (2005). Tri-training: Exploiting unlabeled data using three classifiers. IEEE Transactions on Knowledge and Data Engineering, 17(11):1529-1541. Citado na página 68.

Zhou, Z.-H. \& Li, M. (2010). Semi-supervised learning by disagreement. Knowledge and Information Systems, 24:415-439. Citado nas páginas 1, 55, and 70 .

Zhu, X. (2008). Semi-supervised learning literature survey. Relatório Técnico 1530, Computer Sciences, University of Wisconsin-Madison. http://www . cs.wisc.edu/ jerryzhu/pub/ssl_survey.pdf. Citado na página 57.

Zhu, X., Ghahramani, Z., \& Lafferty, J. D. (2003). Semi-supervised learning using gaussian fields and harmonic functions. Em ICML 2003: Proceedings of The Twentieth International Conference on Machine Learning, páginas 912919. AAAI Press. Citado na página 55. 